UNIVERSIDADE DE SÃO PAULO

INSTITUTO DE GEOCIENCIAS

\title{
है \\ COMPORTAMENTO GEOQUÍMICO DE METAIS \\ PESADOS EM SEDIMENTOS ARGILOSOS DA \\ BACIA DE SÃO PAULO, SUZANO-SP
}

Andrea Amarante

Orientador: Prof. Dr. Joel Barbujiani Sígolo

DISSERTAÇÃO DE MESTRADO

Programa de Pós-Graduação em Geoquímica e Geotectônica

SÄO PAULO

1997 


\section{ERRATA}

1) No texto: substituir a denominação das Unidades

Para a Unidade 2:

Onde se lê araila de coloracão cinza-escura leia-se argilito de coloracão cinza-escura

Para a Unidade 3

Onde se lê silfe de coloracäo cinza-clara

leia-se silfito de coloracäo cinza clara

1I) Pág Xl, 3음orag., 4 a lin:

Onde se lê Cu, Zn, Mo e Mn

leiase $C u, Z n, P b$ e Mn

III) Pág. XIII, 3o parag, 3o lin:

Onde se lê Cu,Zn, Moe Mn

leiase $C u, Z n, p b$ ond $M n$

IV) Póg. 91, ifem 2 - 4o linha

Onde se lê $C U, Z n, M o$ e $M n$ leia-se $C U, Z n, P b$ e $M n$

V) Legendas das Figuras do Capítulo 8:

Pág.78

Onde se lê: Figura $43 / \ldots / T L-03$.

Leia-se: Figura $43(.) /$.$L -03. (eixo x: \% de$ argila; eixo y: conteúdo de $\mathrm{Pb}$ em $\mathrm{mg} / \mathrm{kg}$ )

Pág. 79

Onde se lê: Figura $44(\ldots)$ TL-O4.

Leia-se: Fiqura $44(\ldots)$ Th-04. leixo x:\% de argila; eixo y: conteúdo de Pb em $\mathrm{mg} / \mathrm{kg}$.

Onde se lê: Figura $45 / \ldots)$ TLO3.

Leia-se: Figura $45(\ldots)$ TL-03. (eixo x: \% de argila; eixo y: conteúdo de $\mathrm{Zn}$ em $\mathrm{mg} / \mathrm{kgl}$ 
Pág. 80

Onde se lê: Fiqura 46 (...) TL-OI.

Onde se lê: Figura 47 (...) TL-02.

Onde se lê: Figura $48(\ldots)$ TL-04.

Pág. 81

Onde se lê: Figura 49 (...) TL-02.

Onde se lê: Figura 50 (...) TL-02.

Onde se lê: Figura 57 (...) TL-Or.

Onde se lê: Figura $52, \ldots /$ II-O4.

Pág. 83

Onde se lê: Figura $53 / \ldots /$ TL-02.

Onde se lê: Figura 54 ....LTL-03.

Onde se lê: Figura 55 /... TL-O2.

Leia-se: Figura 53 (...) TL-02. leixo x: \% de matério orgânica; eixo y: conteúdo de $C$ em mg/kgl

Leia-se: Figura 54 (...) TL 03. (eixox:\% de matéria orgânica; eixo y: conteúdo de $C$ em ma/kg).

Leid-se: Figura 55 (...) TL-02. (eixo x: \% de matéria orgânica; eixo y: conteúdo de $\mathrm{N}$ em ma/kgl 
Pág. 84

Onde se lê: Figura 56 (...) TL-03.

Onde se lê: Figura 57 (...) TL-OT.

Leia-se: Figura 56 (...) TL-03. (eixo x: \% de argila; eixo y: conteúdo de Mn em mg/kg.

Leia-se: Figura 57 (...) TL-O7. /eixo X: conteúdo de Cu em mg/kg; eixo y: conteúdo de Zn em $\mathrm{ma} / \mathrm{kgl}$

\section{Pág. 85}

Onde se lê: Figura $58(\ldots) / T L-O T$.

Leia-se: Figura 58 (...) TL-O7. 1eixox: conteúdo de Cu em $\mathrm{mg} / \mathrm{kg}$; eixo y: conteúdo de $\mathrm{Pb}$ em $\mathrm{mg} / \mathrm{kg}$.

Onde se lê: Fiqura 59 (...) TL-Oz.

Leid-se: Figura 59 (...) Th-07. leixo $x$ : conteúdo de $\mathrm{Pb}$ em ma/kg; eixoy: conteúdo de zn em mg/kgl 


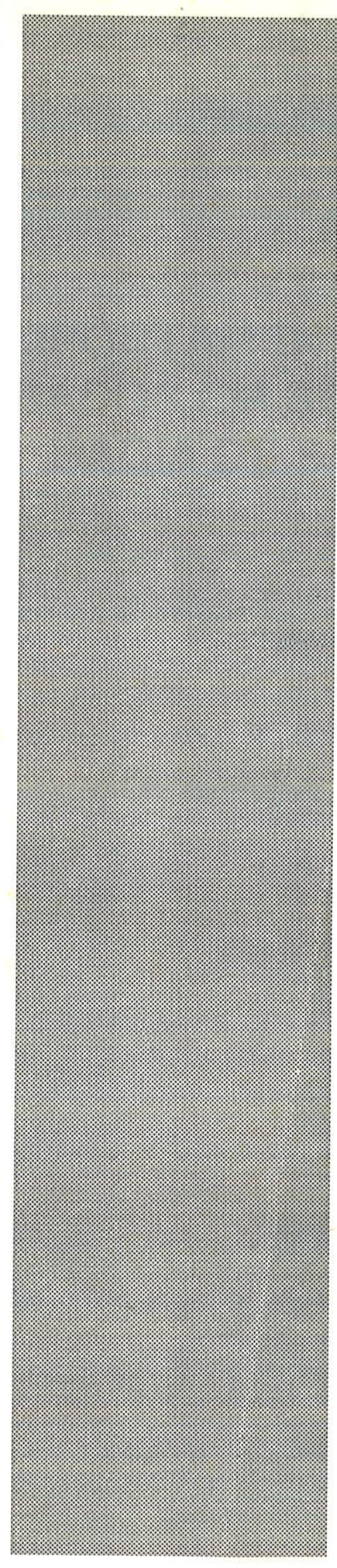

Dedico esta dissertação à minha família, em especial aos meus pais e ao Cassiano, que sempre acreditaram em mim 


\title{
UNIVERSIDADE DE SÃO PAULO INSTITUTO DE GEOCIÊNCIAS
}

\section{COMPORTAMENTO GEOQUÍMICO DE METAIS PESADOS EM SEDIMENTOS ARGILOSOS DA BACIA DE SÃO PAULO, SUZANO-SP}

\author{
ANDREA AMARANTE
}

Orientador: Prof. Dr. Joel Barbujiani Sígolo

DISSERTAÇÃO DE MESTRADO

COMISSÃO JULGADORA

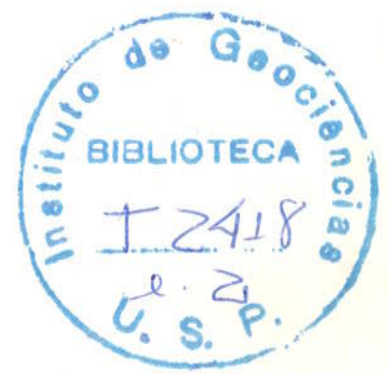

Nome

residente: Prof. Dr. Joel Barbujiani Sígolo xaminadores: Prof. Dr. José Roberto Campos Prof ${ }^{\mathrm{a}} \mathrm{Dr}^{\mathrm{a}}$. Sonia Maria Barros de Oliveira

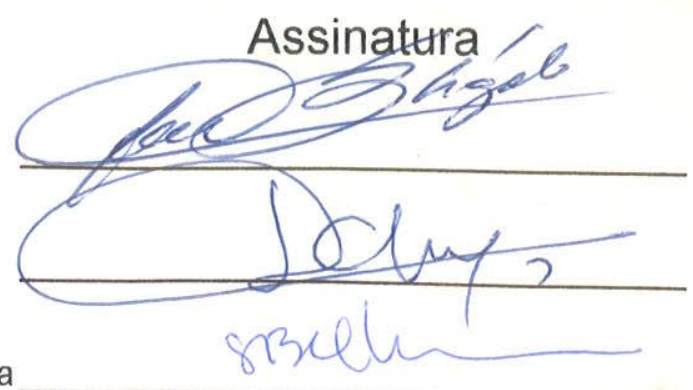

$$
\begin{gathered}
\text { SÃO PAULO } \\
1997
\end{gathered}
$$




\title{
UNIVERSIDADE DE SĀO PAULO INSTITUTO DE GEOCIENCIAS
}

\section{COMPORTAMENTO GEOQUÍMICO DE METAIS PESADOS EM SEDIMENTOS ARGILOSOS DA BACIA DE SĀO PAULO, SUZANO-SP}

\author{
Andrea Amarante
}

Orientador: Prof. Dr. Joel Barbujiani Sígolo

DISSERTAÇĀO DE MESTRADO

Programa de Pós-Graduação em Geoquímica e Geotectônica

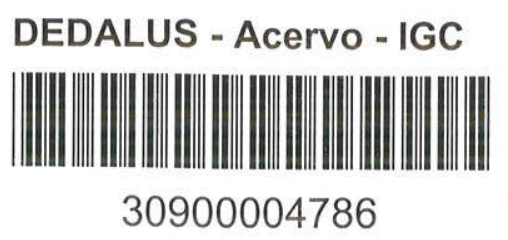

SÃO PAULO

1997 


\section{AGRADECIMENTOS}

Gostaria de expressar os meus agradecimentos:

Ao Prof. Dr. Joel Barbujiani Sigolo, que me orientov;

A CAPES, pelo financiamento de bolsa de estudo da mestranda;

A FAPESP, pelo financiamento do projeto através do Processo no 94/2142-4;

À Produquímica, que permitiu a execução do projeto, e forneceu todo o apoio logístico durante os trabalhos de campo;

Agradeço às pessoas que, de um modo ou de outro, me ajudaram durante este período de pesquisa:

Ao Samuel e d̀ Verônica, do DGG/USP, que deram todo o apoio durante as etapas de campo e de preparação das amostras;

À Cleide e Sueli, do Laboratório de Geoquímica do IG/USP; à Margarita, do Laboratório de Geoquímica do DPM/IG/UNESP e à Ivete, Draggo e Alves, do Laboratório de Análises Sedimentológicas do IG/SMA, pelas análises que foram tão valiosas para este trabalho;

Ao Hélder, do NUPEGEL/IAG/USP, pelas análises em MEV e DRX; e pela orientação durante o processamento dos dados;

Ao Flávio, do DRX, que acabei conhecendo apenas na etapa final deste trabalho, pelas aulas de Difratometria e pela orientação na interpretação dos resultados;

Aos amigos Antonio, Carla e Alix, da FEBASP, que me ajudaram a vencer este novo período da minha vida acadêmica;

Aos amigos Sandra, Samara, Francisco e Otávio, do IG/SMA, pela força e amizade durante o fechamento deste trabalho. 


\section{ÍNDICE}

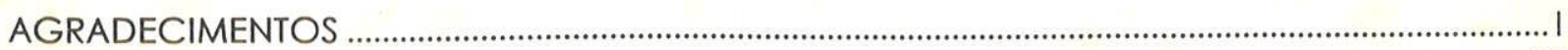

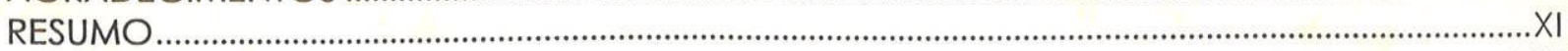

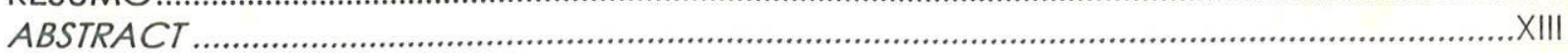

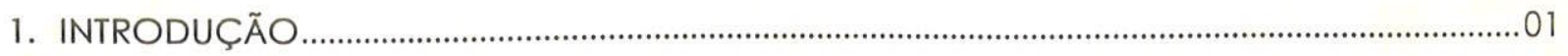

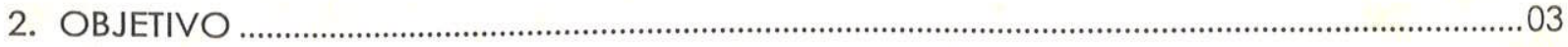

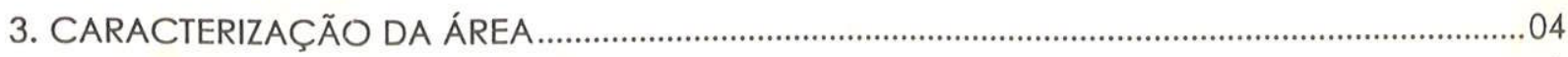

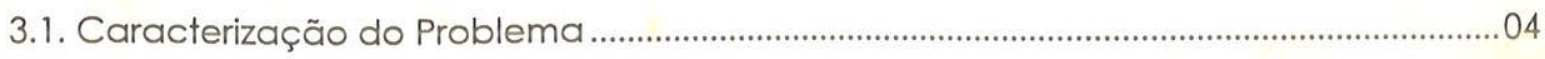

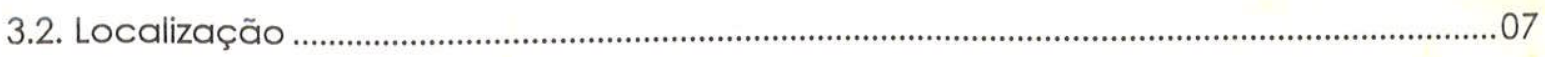

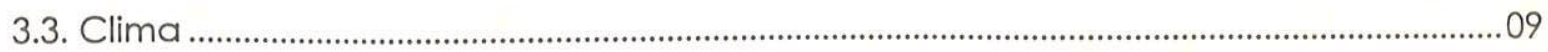

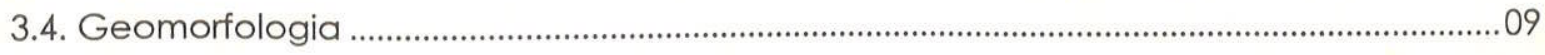

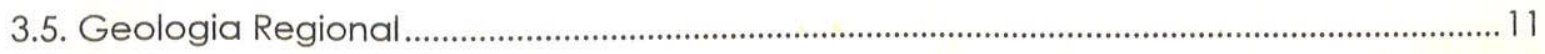

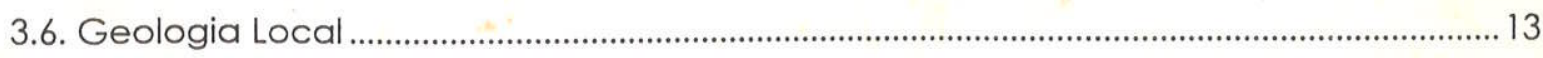

4. SÍNTESE SOBRE O CONHECIMENTO DOS METAIS PESADOS NO SOLO …………...................15

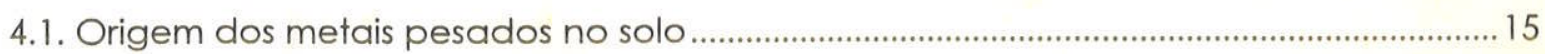

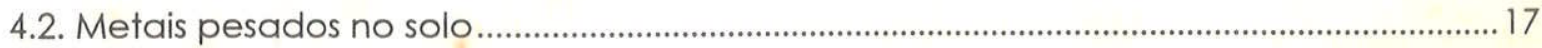

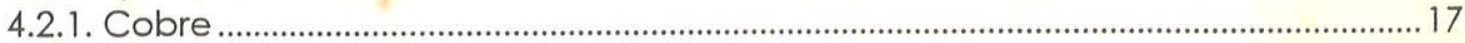

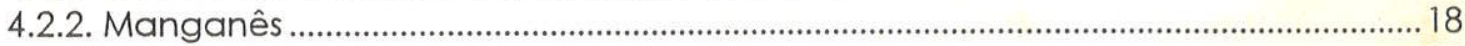

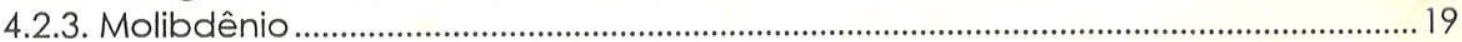

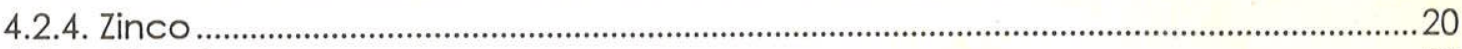

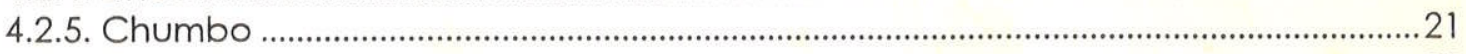

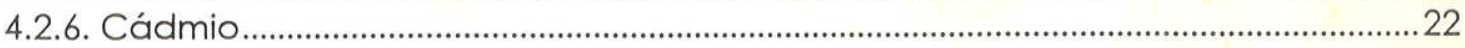

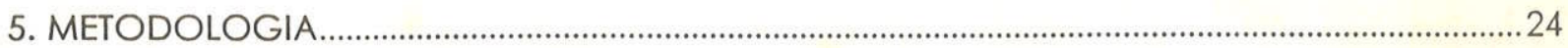

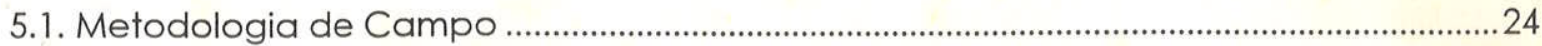

5.1.1. Seleção da seção a ser analisada e locação dos furos a trado.............................24

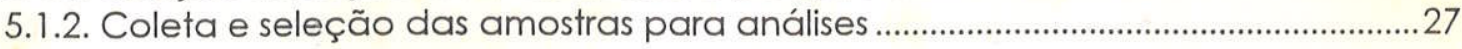

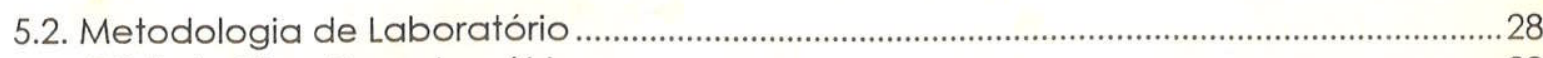

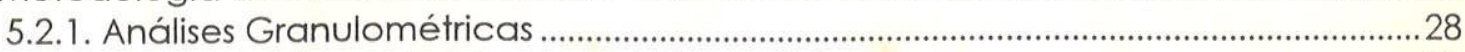

5.2.2. Dosagem do conteúdo de matéria orgânica ...............................................................29

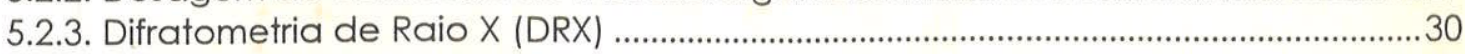

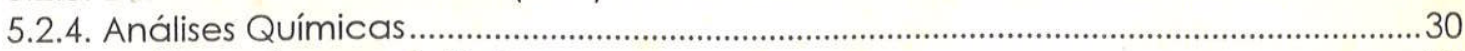

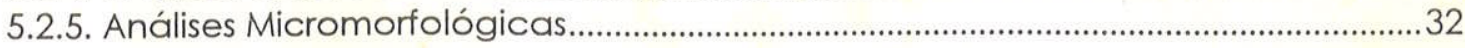

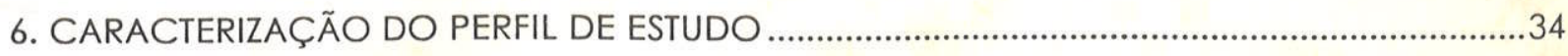

6.1. Unidade 1: Argila de coloração alaranjada (colúvio) ………………................................37

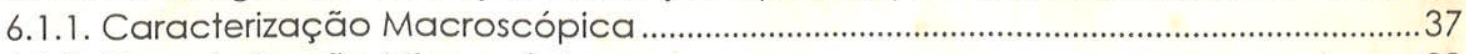

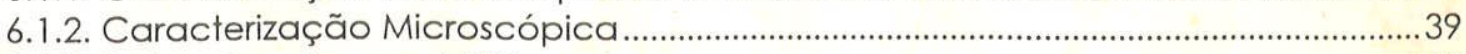

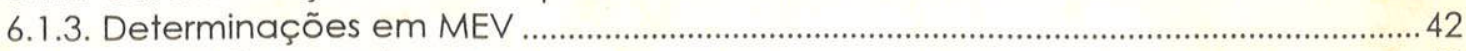

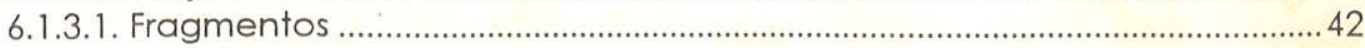

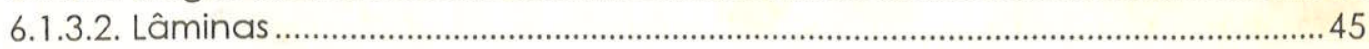


6.2. Unidade 2: Argila de coloração cinza-escura (sedimentos da Bacia de São Paulol.

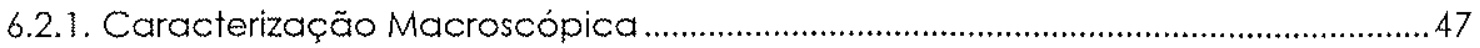

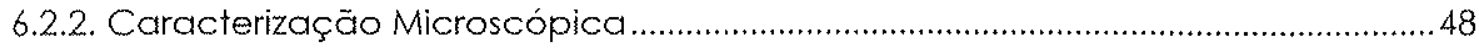

6.2.3. Determinações em DRX

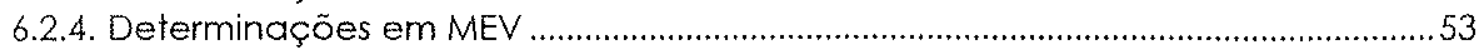

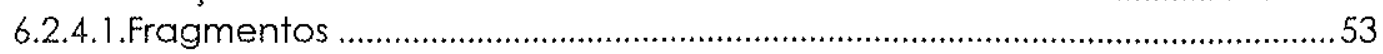

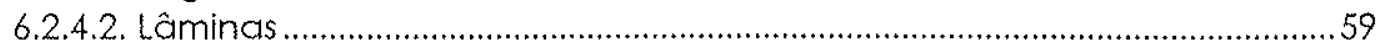

6.3. Unidade 3: Silte de coloração cinza-clara (sedimentos da Bacia de São Paulo) .......60

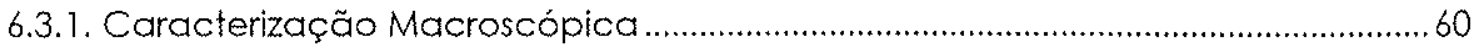

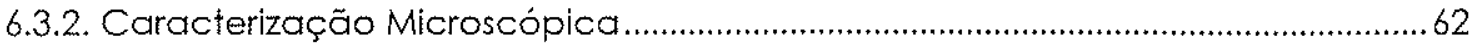

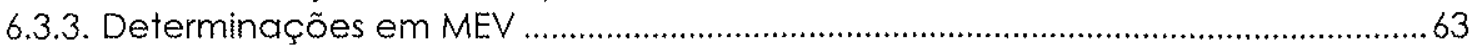

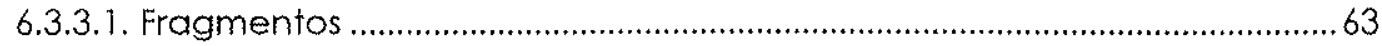

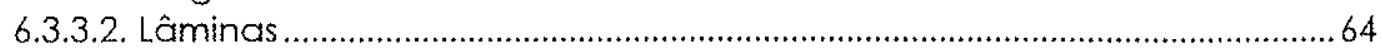

7. COMPORTAMENTO DOS METAIS PESADOS NA SEÇÃO DE ESTUDO …..............................65

7.1. Comportamento dos metais pesados nos furos localizados a jusante da lagoa de infiltração: TL-01, TL-02 e TL-03

7.2. Comportamento dos metais pesados nos furos localizados dentro da lagoa de infiltração: TL-04 e TL-05

7.3. Comportamento dos metais pesados nos furos localizados a montante da lagoa de infiltração: TL-06 e TL-07.

8. ASSOCIAÇÕES DO CONTEÚDO DE METAIS PESADOS COM A GRANULOMETRIA E TEOR DE MATÉRIA ORGÂNICA NA SEÇÃO DE ESTUDO

8.1. Associações do conteúdo de MP com a granulometria.................................................78

8.2. Associações do conteúdo de MP com o teor de matéria orgânica ..............................82

8.3. Correlações entre o comportamento de $\mathrm{CU}$. $\mathrm{Pb}$ e $\mathrm{Zn}$ no perfil .....................................84

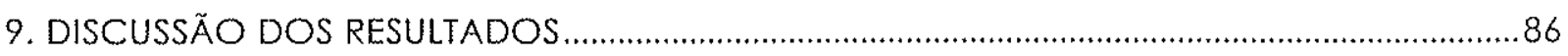

9.1. Comportamento dos MP na seção de estudo .............................................................86

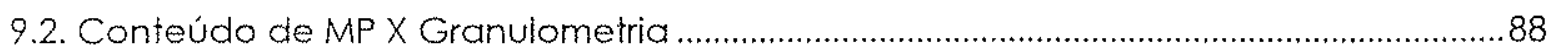

9.3. Conteúdo de MP X teor de matéria Orgânica ...................................................................89

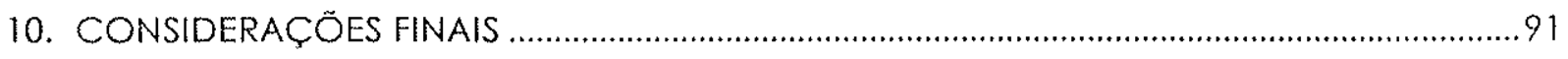

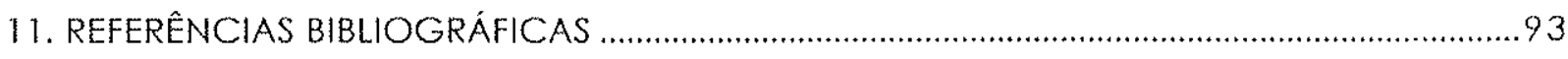

ANEXOS

Anexo 1: Análises Granulométricas Quantitativas para as amostras nos diferentes perfis

Anexo 2: Dosagem do conteúdo de matéria orgânica para as amostras nos diferentes perfis

Anexo 3: Análises Químicas por ICP-AES para as amostras nos diferentes perfis

Anexo 4: Descrição da seção estudada

Anexo 5: Comportamento dos metais ao longo da seção estudada-Parte l: Cu, Mn. Mo, Zn e Pb

Anexo 6: Comportamento dos metais ao longo da seção estudada-Parte ll: Cd 


\section{FOTOGRAFIAS}

Fotografia 01: Vista geral das instalações da indústria. .06

Fotografia 02: Vista da nascente do Córrego das Jaboticabeiras. Ao fundo, instalações da indústria.....

Fotografia 03: Aspecto de afloramento dos sedimentos da Bacia de São Paulo em terreno localizado a jusante da área da indústria. Material de aspecto siltoso, maciço, e coloração cinza-clara, correlacionado à Unidade 3 do perfil de estudo

Fotografia 04: Aspecto geral da lagoa de infiltração

Fotografia 05: Localização dos furos TL-01, TL-02 e TL-03. À direita do furo TL-01, poço de monitoramento de água da CETESB (PM-5). Ao fundo, estrada de servidão da indústria.. Fotografia tirada da barragem da lagoa para jusante.

Fotografia 06 : Unidades 1 (coloração alaranjada), 2 (coloração cinza-escura) e 3 (coloração cinza-clara), durante amostragem do perfil TL-03.

Fotografia 07: Aspecto do nivel de entulho do Furo Tl-06

\section{TABELAS}

Tabela 01: Composição química das tortas analisadas. .05

Tabela 02: Conteúdo em metais pesados das tortas analisadas

Tabela 03: Conteúdo em $\mathrm{Cd}$. Cu. $\mathrm{Mn}, \mathrm{Mo}, \mathrm{Pb}$ e $\mathrm{Zn}$ dos principais tipos de rochas ( $m g / \mathrm{kg})$. Exiraido de ALLOWAY (1995)

Tabela 04: Número total de amostras coletadas e encaminhadas para análise

Tabela 05: Teor de matéria orgânica, caracterização granulométrica e conteúdo de metais pesados no furo TL-01

Tabela 06: Teor de matéria orgânica, caracterização granulométrica e conteúdo de metais pesados no furo TL-O2

Tabela 07: Teor de matéria orgânica, caracterização granulométrica e conteúdo de metais pesados no furo TL-03

Tabela 08: Teor de matéria orgânica, caracterização granulométrica e conteúdo de metais pesados no furo TL-04

Tabela 09: Teor de matéria orgânica, caracterização granulométrica e conteúdo de metais pesados no furo Th-05

Tabela 10: Teor de matéria orgânica, caracterização granulométrica e conteúdo de metais pesados no furo TL-06

Tabela 11: Teor de matéria orgânica, caracterização granulométrica e conteúdo de metais pesados no furo $\mathrm{TL}_{\mathrm{L}}-07$ 


\section{FIGURAS}

Figura 01: Localizaçăo da área, vias de acesso e bacia hidrográfica simplificada

Figura 02: Geologia Regional, de acordo com CPRM, 1990

Figura 03: Área da indústria, com a localização da lagoa de infiltração e o perfil de estudo

Figura 04: Localizaçâo das tradagens TL-01 a TL-07 na seção de estudo, com as respectivas distâncias entre as mesmas.

Figura 05: Localizaçäo dos perfis dos poços $\mathrm{SO} 3$ e SO5, com os respectivos níveis amostrados

Figura 06: Organização espacial das unidades na seção de estudo

Figura 07: Diagrama de Classificação Texłural de Solos, segundo o Serviço de Conservação de Solos do Departamento de Agricultura dos Estados Unidos (extraido de Oliveira et al. 1992)

Figura 08: Distribuição das porcentagens de areia, argila e silte de amostras da Unidade 1 em diagrama triangular de classificação textural de solos, de acordo com CATI/SAA (1994)

Figura 9: Diagrama Espectral Químico (EDS) da imagem 1, com análise qualitativa apresentada em espectro.

Figura 10: Diagrama Espectral Químico (EDS) da imagem 2, com análise qualitativa apresentada em espectro.

Figura 11: Diagrama Espectral Químico (EDS) da imagem 3, com análise qualitativa apresentada em espectro.

Figura 12: Diagrama Espectral Químico (EDS) da imagem 4, com análise qualitativa apresentada em espectro.

Figura 13: Diagrama Espectral Químico (EDS) da imagem 5, com análise qualitativa apresentada em espectro.

Figura 14: Diagrama Espectral Químico (EDS) da imagem 6, com análise qualitativa apresentada em espectro.

Figura 15: Diagrama Espectra! Químico (EDS) da imagem 7, com análise qualitativa apresentada em espectro.

Figura 16: Diagrama Espectral Químico (EDS) da imagem 8, com análise qualitativa apresentada em espectro.

Figura 17: Diagrama Espectral Químico (EDS) da imagem 9, com análise qualiłativa apresentada em espectro.

Figura 18: Disłribuição das porcentagens de areia, argila e silte de amostras da Unidade 2 em diagrama triangular de classificação textural de solos, de acordo com CATI/SAA (1994) 
Figura 19: Resultado da análise por DRX da amostra do perfil TL-03, localizado a jusante da lagoa de infiltração.

Figura 20: Resultado da análise por DRX da amostra do perfil TL.05, localizado dentro da lagoa de infiltração.

Figura 21: Resultado da análise por DRX da amostra do perfil TL-06, localizado a montante da lagoa de infiltraçäo.

Figura 22: Diagrama Espectral Químico (EDS) da imagem 10, com análise qualitativa apresentada em espectro.

Figura 23: Diagrama Espectral Químico (EDS) da imagem 11, com análise qualitativa apresentada em espectro

Figura 24: Diagrama Espectral Químico (EDS) da imagem 12, com análise qualitativa apresentada em espectro.

Figura 25: Diagrama Espectral Químico (EDS) da imagem 13, com análise qualitativa apresentada em espectro.

Figura 26: Diagrama Espectral Químico (EDS) da imagem 14, com análise qualitativa apresentada em espectro.

Figura 27: Diagrama Espectral Químico (EDS) da imagem 15, com análise qualitativa apresentada em espectro.

Figura 28: Diagrama Espectral Químico (EDS) da imagem 16, com análise qualitativa apresentada em espectro.

Figura 29: Diagrama Espectral Químico (EDS) da imagem 17, com análise qualitativa apresentada em espectro.

Figura 30: Diagrama Espectral Químico (EDS) da imagem 18, com análise qualitativa apresentada em espectro.

Figura 31: Diagrama Espectral Químico (EDS) da imagem 19, com análise qualitativa apresentada em espectro.

Figura 32: Diagrama Espectral Químico (EDS) da imagem 20, com análise qualitativa apresentada em espectro.

Figura 33: Diagrama Espectral Químico (EDS) da imagem 21, com análise qualitativa apresentada em espectro

Figura 34: Diagrama Espectral Químico (EDS) da imagem 22, com análise qualitativa apresentada em espectro

Figura 35: Distribuição das porcentagens de areia, argila e silte de amostras da Unidade 3 em diagrama triangular de classificação textural de solos, de acordo com CATI/SAA (1994)

Figura 36: Diagrama Espectral Químico (EDS) da imagem 23, com análise qualitativa apresentada em espectro. 
Figura 37: Comportamento do Mn, Zn, Pb, Mo e Cu nos perfis TL-01 a TL-03, situados a jusante da lagoa de infiltração.

Figura 38: Comportamento do Ca nos perfis TL-01 a TL-03, situados a jusante da lagoa de infiltração.

Figura 39: Comportamento do Mn, Zn, Pb, Mo e Cu nos perfis TL-04 e TL-05, situados dentro da lagoa de infiltração.

Figura 40: Comportamento do Cd nos perfis TL-04 e TL-05, situados dentro da lagoa de infiltração

Figura 41: Comportamento do Mn, Zn, Pb, Mo e Cu nos perfis Tl-06 e Tl-07, situados a montante da lagoa de infiltração.

Figura 42: Comportamento do Cd nos perfis TL-06 e TL-07, situados a montante da lagoa de infiltração.

Figura 43: Gráfico de correlaçăo linear entre a porcentagem de argila e conteúdo de chumbo nas amostras do furo TL-03.

Figura 44: Gráfico de correlação linear entre a porcentagem de argila e conteúdo de chumbo nas amostras do furo TL-O4

Figura 45: Gráfico de correlação linear entre a porcentagem de argila e conteúdo de zinco nas amostras do furo TL-03

Figura 46: Gráfico de correlação linear entre a porcentagem de silte e conteúdo de cobre nas amostras do furo TL-01

Figura 47: Gráfico de correlação linear entre a porcentagem de silte e conteúdo de cobre nas amostras do furo Tt-O2......

Figura 48: Gráfico de correlação linear entre a porcentagem de silte e conteúdo de cobre nas amostras do furo TL-04.

Figura 49: Gráfico de correlação linear entre a porcentagem de silte e conteúdo de zinco nas amostras do furo TL-02

Figura 50: Gráfico de correlação linear entre a porcentagem de silte e conteúdo de molibdênio nas amostras do furo TL-02.

Figura 51 : Gráfico de correlação linear entre a porcentagem de areia e conteúdo de cobre nas amostras do furo TL-01

Figura 52 : Gráfico de correlação linear entre a porcentagem de areia e conteúdo de cobre nas amostras do furo TL-04

Figura 53 : Gráfico de correlação linear entre o teor de matéria orgânica e o conteúdo de cobre nas amostras do furo TL 02 .

Figura 54 : Gráfico de correlação linear entre o teor de matéria orgânica e o conteúdo de cobre nas amostras do furo TL-03.

Figura 55: Gráfico de correlação linear entre o teor de matéria orgânica e o conteúdo de manganês nas amostras do furo TL-02. 
Figura 56: Gráfico de correlação entre o teor de matéria orgânica e o conteúdo de manganês nas amostras do furo TL-03.

Figura 57: Gráfico de correlação linear entre o comportamento do Cu e Zn nos furos TL.-04 a TL-07

Figura 58: Gráfico de correlação linear entre o comportamento do $\mathrm{Cu}$ e $\mathrm{Pb}$ nos furos TL-04 a TL-07

Figura 59: Gráfico de correlação linear entre o comportamento do Pb e Zn nos furos TL-04 a TL-07

\section{QUADROS}

Quadro 01: Elementos traços de minerais comuns formadores de rochas (extraído de ALLOWAY, 19951

\section{FOTOMICROGRAFIAS}

Fotomicrografias 1 (luz natural) e 2 (luz polarizada): Aspecto da matriz da amostra SO3-03B, pertencente à Unidade 1. a) presença de quartzo com inclusões de rutilo (filetes); b) turmalina aparece como mineral acessório; c) grão de caulinita com material oxidado preenchendo as fraturas; d) matriz de coloração alaranjada, com microfissuras preenchidas por material quartzo-feldspático. Campo das fotos: $4,2 \mathrm{~mm}$ $\times 2,8 \mathrm{~mm}$ (objetiva 3.2; abertura 3,2:1).

Fotomicrografias 3 (luz natural) e 4 (luz polarizada): Aspecto da amostra SO3-03B. Cristal de mica (muscovita), com fraturas preenchidas por hidróxido de ferro (goethita). As fraturas dos grãos de quartzo também encontram-se preenchidas com este material. Campo das fotos: $2,7 \mathrm{~mm} \times 1,8 \mathrm{~mm}$ (objetiva 3,2; abertura $5: 1$ )

Fotomicrografias 5 (luz natural) e 6 (luz polarizada): Aspecto da amostra SO5-178. Nódulo de hidróxido de ferro (goethita) com vazios preenchidos por hidróxido de alumínio (gibsita), que se apresentam com coloração esbranquiçada com luz polarizada. Campo das fotos: $5,2 \mathrm{~mm} \times 3,7 \mathrm{~mm}$ (objetiva 1,6; abertura $5: 1$ ).

Fotomicrografia 7 (luz polarizada): Aspecto da amostra SO3-06B. Restos de matéria orgânica (raizes de planta) pseudomorfisada e mineralizada. Campo da foto: $5,2 \mathrm{~mm}$ $\times 3,7 \mathrm{~mm}$ (objetiva 1,6 ; abertura $5: 1$ )

Fotomicrografias 8 (luz natural) e 9 (luz polarizada): Aspecto do plasma da Amostra SO5-05A, de coloração marrom escura. Os grãos de quartzo encontram-se emersos no plasma, apresentando-se subarredondados. Alguns se apresentam com borda recoberta por material ferruginoso, e outros, com dissolução nas bordas. Campo das fotos: $4,2 \mathrm{~mm} \times 2,8 \mathrm{~mm}$ (objetiva 3,2; abertura 3,2:1)

Fotomicrografias 10 (luz natural) e 11 (luz polarizada): aspecto da amostra S05-05A. Caulinita em avançado grau de alteração, se incorporando ao plasma. Campo das fotos: 
Fotomicrografias 12 (luz natural) e 13 (luz polarizada): acumulação de material ferruginoso em nódulos na amostra SO3-02T. Campo das folos: $3.2 \mathrm{~mm} \times 2,1 \mathrm{~mm}$ (objetiva 3,2; abertura 4:11.

Fotomicrografia 14 (luz natural): Esqueletos de micas pseudomorfisadas por óxidos e hidróxidos de $\mathrm{Fe}$, comuns na matriz da amostra $\mathrm{SO} 5-02$, pertencente a esta unidade. Campo das fotos: $0,41 \mathrm{~mm} \times 0,28 \mathrm{~mm}$ (objetiva 20; abertura $5: 1$ ).

\section{IMAGENS}

Imagem 1: Morfologia de grão de solo da amostra SO5-16 em MEV: feição de dissolução de grãos de quartzo (aumento 1000X)

Imagem 2: Morfologia de grão de solo em MEV: aspecto da matriz da amostra SO514, de composição essencialmente caulinitica (aumento 750X)

Imagem 3: Morfologia de grão de solo em MEV: aspecto do material precipitado em uma das microcavidades da amostra sO5-13. Composição essencialmente caulinítica (aumento 500X)

Imagem 4: Morfologia de grão de solo da amostra SO5-16 em MEV: grão de carvão pseudomorfisado por Fe e Mn (aumento 100X).

Imagem 5: Detalhe da Imagem 4. Presença de nódulo de Fe e Ti em cavidade do grão de carvão. Aumento 500X

Imagem 6:Aspecto de nódulo de material ferruginoso (Fotomicrografias 5 e 6) em elétrons retrodifusos (aumento $35 \mathrm{X}$ ). O material ferruginoso está representado pelas porções mais claras.

Imagem 7: Delathe da parede do nódulo da Imagem 6, com fragmento de composto de Ce preso à sua estrutura

Imagem 8:Morfologia de grão de solo em MEV: KCl precipitado em microfissuras presentes na matriz da amostra SO3-06B. (Aumento 5000X)

Imagem 9: Morfologia de grão de solo em MEV: Cu associado a $\mathrm{Cl}$, precipitado em microfissuras presentes na matriz da amostra SO5-17B (Aumento 2000X)

Imagem 10: Morfologia de grão da amostra SO5-06 em MEV: grão de ilmenita (grão de formato losangular, no centro da fotol. Aumento $3500 \mathrm{X}$..

Imagem 11: Grão de composição metálica da amostra SO5-05 em MEV, com o emprego de elétrons retrodifusos: grão de zircão (grão de coloração mais clara). Aumento 2000X.

Imagem 12: Morfologia de grão de solo da amostra SO5-05 em MEV: aspecto da matriz. (Aumenio 1000X)

Imagem 13: Morfologia de grão de solo da amostra SO3-02 em MEV; sílica neoformada, na forma de bastonete (Aumento 2000X).

Imagem 14: Morfologia de grão de solo da amostra SO3-02 em MEV: neoformação de mineral de Cério (aumento 2000X) 
Imagem 15: Imagem em Split (luz natural/emprego de elétrons retrodifusos) de fragmento de composto de Zn (grão claro no centro da foto). Aumento $3500 \mathrm{X}$.

Imagem 16: Imagem em Solit (luz nałural/emprego de elétrons retrodifusos) de fragmento de composto de Zn preso a grão de argila (aumento 2000X) .

Imagem 17: Imagem em Split (luz natural / emprego de elétrons retrodifusos) de fragmento de composto de Cu associado à presença de cloretos (ponto claro no centro da foto esquerda - elétrons retrodifusos). Aumento $2000 \mathrm{X}$

Imagem 18: Imagem em split (luz natural / emprego de elétrons retrodifusos) de fragmento de composto de $\mathrm{Pb}$ de formato ovalado, que aparece em coloração mais clara no centro da foto (aumento 1500X)

Imagem 19: Morfologia de grão de solo em MEV; aspecto da matriz da amostra SO502. (Aumento 2000X)

Imagem 20: Morfologia de grão de solo da amostra SO5-07 em MEV: presença de ETR (Ce e La). Esfera no centro da imagem (Aumento 3500X)

Imagem 21: Grão de comportamento metálico da amostra SO5.07 em MEV com o emprego de elétrons retrodifusos: presença de ETR (Nd, Ce e La) associados à Prata. Aumento 1000X.....

Imagem 22: Composto de ETR ( $\mathrm{Nd}, \mathrm{Ce}$ e La) associado a $\mathrm{Mg}$ e Si, na matriz da amostra SO5-05B

Imagem 23: Morfologia de grão de solo da amostra SO5-02 em MEV: cristais de barita (Aumento 1500X). 


\section{RESUMO}

Esta dissertação estuda o comportamento geoquímico do $\mathrm{Cu}$, Pb, Zn, Mn, Mo e Cd contidos nos solos de uma área próxima à lagoa de infiltração de rejeitos de uma indústria de micronutrientes utilizados na agricultura, que está atualmente desativada. Uma seçāo perpendicular a esta lagoa foi construída com a locação de furos a jusante, no interior e a montante da lagoa, com o objetivo de estudar o comportamento dos metais nestas três situaçöes. A coleta de amostras foi executada de $25 \mathrm{em}$ $25 \mathrm{~cm}$. As amostras coletadas foram encaminhadas para as seguintes análises: granulométrica, conteúdo de matéria orgânica. Difratometria de Raio X (DRX), conteúdo total de Zn, Mn, Mo, Cu, Pb e Cd por ICP-AES e Microscopia Eletrônica de Varredura (MEV).

Basicamente, a seção de estudo pode ser dividida em quatro Unidades (litotipos): Unidade 1: argila de coloração alaranjada (colúvio), constituída de um latossolo; Unidade 2: argila de coloração cinza escura, rica em matéria orgânica, correspondente a sedimentos lacustres da Bacia de São Paulo; Unidade 3: silte de coloração cinza-clara, correspondente a sedimentos flúviomacustres da Bacia de São Paulo; Unidade 4: embasamento gnáissico (alterita) correspondente às rochas metamórficas pertencentes do Complexo Embu. Destas, apenas as três primeiras foram objeto de caracterização neste estudo.

O material infiltrado na lagoa atravessou as camadas situadas abaixo da mesma. tendo sido retido principalmente pela camada da argila cinza-escura (Unidade 2). Análises em MEV de amostras desta unidade identificaram a presença de metais $(\mathrm{Cu}, \mathrm{Zn}, \mathrm{Mo}$ e $\mathrm{Mn}$ ) presos à argilas, associados a sais neoformados e do Fe, e precipitados na matriz e no plasma.

$\mathrm{Cu}, \mathrm{Pb}$ e $\mathrm{Zn}$ possuem comportamento geoquímico semelhante nas áreas que sofreram intervenção antrópica (lagoa de infiltração e nivel de entulhol, apresentando altas concentrações nos niveis próximos à superfície, que diminuem com o aumento da profundidade. Nestes perfis, foram obtidas correlações acima de 0,85 para estes metais, sendo que para o Cu e Zn, esta correlação foi de 0,95.

Mn e Mo apresentam comportamento geoquímico semelhante ao longo do perfil, em relação aos diferentes litotipos, aumentando a sua concentração na Unidade 2. Há uma tendência de diminuição de suas concentrações quando o lençol freático é atingido.

Embora o Cd não apresente nenhuma correlação com granulometria, teor de matéria orgânica ou litotipos, ele possui um comportamento padrão em relação à profundidade, tendendo a diminuir a sua concentração até aproximadamente $2,00-2,50 \mathrm{~m}$ de profundidade, quando torna a aumentar até a profundidade de $3.50 \mathrm{~m}$, decaindo novamente. A partir desta profundidade, a concentração deste metal continua sofrendo aumento e decréscimo, até a base dos perfis. Para o perfil TL-05, a concentraçäo deste metal aumenta com a profundidade, decaindo quando a Unidade 3 (camada de silte cinzaclarol é atingida. Apenas no perfil TL-02, notou-se um comportamento 
deste metal semelhante do do $\mathrm{Zn}$, onde parece ocorrer um aumento e diminuição de concentração destes metais simultaneamente.

Existe uma correlação entre o comportamento dos metais pesados (MP) e as granulometrias finas do perfil. Ao contrário do citado em literatura, fol a fração silte, e não a argila, que apresentou as melhores correlaçōes com o conteúdo de metais pesados. A fração silte apresentou correlações de 0,70 para $\mathrm{Cu}, 0,64$ para $\mathrm{Zn}$ e 0,75 para $\mathrm{Mn}$, do passo que a argila teve suas maiores correlações obtidas para o $\mathrm{Pb} \in \mathrm{Zn}$. situando-se do redor de 0,55.

Ao analisar-se a seção como um todo, nota-se um desordenamento no comportamento geoquímico do $\mathrm{Mn}, \mathrm{Mo}, \mathrm{Cu}, \mathrm{Pb}$ e $\mathrm{Zn}$ nos perfis que estão sofrendo, diretamente, uma influência antrópica, ao passo que, nos perfis a jusante da lagoa, ocorre um ordenamento no comportamento destes metais. Nos perfis localizados a jusante da lagoa de infiltração, foram obtidas as melhores correlações entre os metais e as características intrínsecas do material (granulometria, teor de matéria orgânica e litotipos\}, do passo que nos demais perfis, foram obtidas as melhores correlações entre o comportamento dos metais, especialmente $\mathrm{Cu}, \mathrm{Pb}$ e $\mathrm{Zn}$. 


\begin{abstract}
The main purpose of this research is the study of the behaviour of $\mathrm{Cu}, \mathrm{Pb}, \mathrm{Zn}, \mathrm{Mn}, \mathrm{Mo}$ and $\mathrm{Cd}$ in soils near a desactivated infiltration lagoon inside a fertilizer industry. An upright profile was built crossing the lagoon, with auger drill holes made downstream, in the lagoon and upstream, in order to study the metal behaviour in these different situations. Different profile layers were sampled at every $25 \mathrm{~cm}$. The collected samples were analyzed for: granulometrical characterization, organic matter contents, $X$-ray Difractometry, total $\mathrm{Zn}$. Mn, Mo and $\mathrm{CU}$ by ICP-AES, and Electronic Scan Microscopy (ESM).
\end{abstract}

The profile was divided into four units: (1) orange argillaceous layer; (2) dark gray argillaceous layer (São Paulo Basin sediments); (3) gray siltic layer (São Paulo Basin sediments) and (4) weathered basement rock (Embu Complex). In this study on analysed Units 1, 2 and 3 only.

The infiltrated matter in the lagoon seeped the layers and was retained mainly in the dark gray argillaceous (Unit 2). ESM analysis of this unit samples identified the existence of metals (Cu. $\mathrm{Zn}$, Mo e Mn) on it, associated to neoformed salts and Fe, precipitated in the matrix and in the plasma.

$\mathrm{Cu}, \mathrm{Pb}$ and $\mathrm{Zn}$ show similar geochemical behaviour in areas influenced by anthropogenic activities (infiltration lagoon and waste level), with levels decreasing with depth, being higher next to the surface. In these profiles, there were found correlations around 0,85 for the behaviour of these metals; between $\mathrm{Cu}$ and $\mathrm{Zn}$, the correlation obtained was 0,95 .

Mn and Mo present similar geochemical behaviour through out the profile in relation to the different litotypes by increasing its concentration when Unit 2 is reached. There is a trend for decreasing its concentrations when the water table is reached.

Although the $\mathrm{Cd}$ does not show any correlation to granulometrical size, organic matter or litotypes, it has a standard behaviour in relation to the depth, decreasing its concentration until 2,50 meters. After that it increases until 3.50 meters, and decreases again. From this depth, this metal concentration varies increasing and decreasing until the bottom of the profile. In the profile TL-05, the Cd concentration increases with depth, decreasing when Unit 3 (gray siltic layer) is reached. For $\mathrm{TL} 02$ profile only it was observed a similar behaviour between $\mathrm{Cd}$ and $\mathrm{Zn}$, with simultaneous increasing and decreasing of concentration of both metals.

There is a correlation between heavy metals behaviour and fine granulometries of the proflle. Despite what is currently highlited in the literature, the best correlation with heavy metal was founded for silt fraction instead of the clay. For the silt fraction, it was obtained correlations of 0.70 for $\mathrm{Cu}, 0.64$ for $\mathrm{Zn}$ and 0.75 for $\mathrm{Mn}$; for the clay fraction, it was obtained correlations around 0,55 for $\mathrm{Pb}$ and $\mathrm{Zn}$. 
Analyzing the section as a whole on see a disorder in the metal geochemical behaviour of $\mathrm{Mn}, \mathrm{Mo}, \mathrm{Cu}, \mathrm{Pb}$ e $\mathrm{Zn}$ in the profiles under direct anthropogenic influence (into and upstream the lagoon). For the profiles downstream the lagoon, there is a trend for an order in the behaviour of these metals. The best correlations between heavy metals contents and the characteristics of the material (grain size, organic matter contents and litotypes) was found for the profiles dowstream the lagoon; in the other ones, it was obtained the best correlations between the behaviour of $\mathrm{Pb}$, Zn and $\mathrm{Cu}$. 


\section{INTRODUÇÃO}

A expressão "metal-pesado" é aplicada aos elementos com peso específico maior que $5 \mathrm{~g} / \mathrm{cm}^{3}$ ou número atômico maior que 20 . A expressão engloba metais, semi-metais e não-metais como o Selênio ( $\mathrm{Se}$ ). O termo também é utilizado para designar metais polventes do ar, água, solo, alimentos e forragens, como CU, Fe, $\mathrm{Mn}$, Mo, $\mathrm{Zn}, \mathrm{Co}, \mathrm{Ni}, \mathrm{V}, \mathrm{Al}, \mathrm{Ag}, \mathrm{Cd}, \mathrm{Cr}, \mathrm{Hg}$ e Pb. (AllowAY, 1990; MALAVOlTA, 1994; ALLOWAY, 1995).

Embora para estes elementos sejam empregados outros termos, como "elemento-traço" (AUBERT \& PINTA, 1977; KABATA-PENDIAS \& PENDIAS, 1984; MCBRIDE, 1994) oU "contaminante" (HAINES \& HARRIS, 1987), será adotada, neste trabalho, a denominação "metal pesado", termo mais empregado na maioria dos trabalhos que versa sobre este assunto.

A contaminação industrial do solo teve seus primeiros estudos na década de 70, nos quais eram apontadas concentrações anômalas de metais pesados em várias partes do mundo, especialmente em centros urbanos e industriais (ALLOWAY, 1990; ALLOWAY, 1995).

No Brasil, os primeiros estudos da concentração de metais pesados em solo datam também da década de 70. Tais estudos abordavam a concentração de metais pesados em diversos solos do País, e eram voltados para fins agronômicos, referentes à quantidade de micronutrientes presentes em diversos solos do Brasil (CATANI \& KÜPPER, 1946; CATANI \& GALO, 1951; VALADARES, 1975; VALADARES \& CATANI, 1975; BATAGLIA et al, 1976). Com a implantação do Programa Nacional do Meio Ambiente, em 1981, e no caso do Estado de São Paulo, com a criação da CETESB em 1973, inicio-se um rígido controle sobre a dispersão de metais e outros produtos tóxicos provenientes de indústrias e mineraçōes. Os estudos de concentrações de metais pesados em solos passaram a ser utilizados como medida de prevenção e controle dos efluentes lançados em solos e corpos d'água.

O esłudo de metais pesados em solo intensificou-se nas últimas décadas, como conseqüência dos avanços tecnológicos e do desenvolvimento de técnicas 
analíticas de detecção da concentração, bem como da necessidade de compreensão dos mecanismos de retenção dos metais no solo, a fim de fornecer respostas a medidas mitigadoras (KABATA-PENDIAS \& PENDIAS, 1984; ADRIANO, 1986; ALLOWAY, 1990; ALLOWAY, 1995).

Esies estudos têm se voltado principalmente para dois aspectos:

1. aspectos agronômicos, com identificação da contaminação do solo por metais pesados provenientes de seu emprego como micronutriente, e seu impacto na produção agrícola, bem como o estudo da acumulação destes metais nestes vegetais e seu grau de toxidez para o solo, as plantas, os animais e os seres humanos (TAN, 1993; MALAVOLTA, 1994; MCBRIDE, 1994; GÖSKET et al, 1996);

2. aspectos ambientais, com a identificação dos impactos relacionados ao estudo $e$ recuperação de solos contaminados por atividades industriais, de mineração e tratamento e disposição de resíduos (HAINES \& HARRIS, 1987; BARÈS, 1989; BENNET, 1989; LORING \& ASMUND, 1989; MANTEI \& COONROD, 1989; PROHIC \& JURACIC, 1989; ASSUNÇÃO, 1996; KARCZEWSKA, 1996; KELLY et al, 1996). Posteriormente, o conhecimento deste tipo de problema permitiu a indicação de áreas contaminadas e propostas específicas para remediação das mesmas (CASTELO BRANCO et al, 1996; COTTER-HOWELLS, 1996; KARCZEWSKA et al, 1996). 


\section{OBJETIVO}

O objetivo desta dissertação é diagnosticar, descrever e caracterizar os mecanismos de retenção de melais pesados por materiais naturais (argilas), através do estudo de um caso prático de contaminação por material disposto em lagoa de infiltração desativada.

A presente proposta de estudo visa assim, por meio do emprego de diferentes técnicas da geoquímica de superfície, caracterizar os materiais que retêm metais pesados na área, bem como estabelecer o comportamento geoquímico destes metais nos seios dos diferentes litotipos geológicos quando submetidos ao impacto polvidor pelos metais $\mathrm{Cu}, \mathrm{Mn}, \mathrm{Mo}, \mathrm{Zn}, \mathrm{Pb}$ e Cd.

Com base nos dados obtidos, identificar as prováveis correlações entre a composição mineralógica, as diferentes fraçōes granulométricas e o conteúdo de matéria orgânica com as concentrações anômalas destes diferentes metais pesados, em um horizonte específico de sedimento correlato à Bacia de São Paulo. 


\section{CARACTERIZAÇÃO DA ÁREA}

\subsection{Caracterização do Problema}

A indústria em foco produz insumos minerais que são utilizados na agricultura (micronutrientes à base de sais de Cu, $\mathrm{Zn}$ e $\mathrm{Mn}$ ), pecuária (suplementos para ração animal), além de produtos para tratamento de água e indústria química em geral .

A Fotografia 1 exibe vista geral da indústria, com a sua área de estocagem e beneficiamento.

O processo de beneficiamento caracteriza-se pela reciclagem de resíduos provenientes de outras indústrias, como compostos minerais, escória e cinzas de indústrias químicas e metalúrgicas.

No passado, os rejeitos provenientes do processo de beneficiamento eram dispostos aleatoriamente sobre o terreno da empresa, sem nenhum critério técnico. $O$ rejeito sólido chegou a ser utilizado para a construção de aterro que hoje comporta as instalações mais recentes. O rejeito líquido era disposto em lagoas de infiltração. que tinham como objetivo, como o próprio nome diz, promover a infiltração do material no solo.

Alualmente, as lagoas encontram-se desativadas, e não há registros exatos sobre a composição do material que era disposto nelas. Sabe-se que estudos de empresas de consultoria, contratadas pela empresa, constataram a existência de teores anômalos de Zinco $(700 \mathrm{mg} / \mathrm{kg}$ ) em camada de argila cinza-escura (orgânica) situada a jusante de uma das lagoas.

Estudos realizados na área da indústria (SÍGOLO \& MELLO JR., 1994; AMARANTE \& SIGGOLO, 1996; SÍGOLO \& AMARANTE, 1996; SÍGOLO \& AMARANTE, 1997) demonstraram a existência de uma contaminação do solo, subsolo e água subterrânea por metais pesados, especialmente $\mathrm{Cu}, \mathrm{Zn}$ e $\mathrm{Pb}$, próximos à área do aterro e à uma das lagoas de decantação desativadas. 
Na época dos trabahos de campo, não foi possivel obter junto à indústria a composição química original, seja do material disposto nas lagoas, seja do rejeito sólido que foi utilizado para a construção do aterro. Foram identificadas, porém, várias pithas de rejeitos provenientes do processo de beneficiamento atual da indústria (tortas), dispostas aleatoriamente em diferentes locais da indústria. Estes materiais foram amostrados e encaminhados para análise química, com o propósito de obter a composição química básica do material descartado pela indústria.

Foram analisadas três tortas que, para efeitos de diferenciação, foram denominadas torta branca, marrom e negra. Nas Tabelas 1 e 2 apresentadas abaixo é exibida a composição química destas tortas e seu conteúdo em metais pesados.

\begin{tabular}{|l|r|r|r|}
\hline \multirow{2}{*}{} & \multicolumn{3}{|c|}{ Composicāo (em \%) * } \\
\cline { 2 - 4 } & torta branca & torta marrom & torta negra \\
\hline $\mathrm{SiO}_{2}$ & 0,42 & 17,88 & 7,08 \\
\hline $\mathrm{Al}_{2} \mathrm{O}_{3}$ & 0,11 & 2,10 & 10,16 \\
\hline $\mathrm{Fe}_{2} \mathrm{O}_{3}$ & 0,36 & 10,41 & 5,83 \\
\hline $\mathrm{YiO}_{2}$ & $<0,01$ & 0,09 & 0,10 \\
\hline $\mathrm{CaO}$ & $<0,01$ & 0,27 & 0,10 \\
\hline $\mathrm{MgO}$ & 47,62 & 23,26 & 14,16 \\
\hline $\mathrm{Na} O$ & $<0,01$ & 0,01 & $<0,01$ \\
\hline $\mathrm{K}_{2} \mathrm{O}$ & $<0,01$ & 0,06 & 0,07 \\
\hline $\mathrm{MnO}$ & 0,15 & 2,82 & 10,66 \\
\hline $\mathrm{P}_{2} \mathrm{O} 5$ & $<0,01$ & 0,06 & 0,07 \\
\hline $\mathrm{LO}$ & 52,28 & 41,51 & 49,51 \\
\hline Total & 100,96 & 98,47 & 97,74 \\
\hline
\end{tabular}

"análises efeluadas pelo ACTLABS - Activalion Laboratories, Ontario, CANADÁ

Tabela 1: Composição química das tortas analisadas

\begin{tabular}{|c|c|c|c|}
\hline \multirow{2}{*}{$\begin{array}{c}\text { metais } \\
\text { presentes }\end{array}$} & \multicolumn{3}{|c|}{ Conteúdo (em mg/kg) } \\
\cline { 2 - 4 } & torta branca & torta marrom & torta negra \\
\hline $\mathrm{Cu}$ & 12,0 & 54,0 & 137,0 \\
\hline $\mathrm{Cr}$ & 342,0 & 25,0 & 1620,0 \\
\hline $\mathrm{Ca}$ & $<0,5$ & 0,8 & $<0,5$ \\
\hline $\mathrm{Mo}$ & $<5,0$ & $<5,0$ & 11,0 \\
\hline $\mathrm{Pb}$ & 16,0 & 54,0 & 81,0 \\
\hline $\mathrm{Zn}$ & 1016,0 & 3104,0 & 3171,0 \\
\hline $\mathrm{La}$ & 1,1 & 8,6 & 20,0 \\
\hline $\mathrm{Ce}$ & $<3,0$ & 16,0 & 23,0 \\
\hline $\mathrm{Co}$ & 4,0 & 39,0 & 48,0 \\
\hline $\mathrm{Ba}$ & 4,0 & 19,0 & 65,0 \\
\hline $\mathrm{Zr}$ & 20,0 & 43,0 & 18,0 \\
\hline $\mathrm{Ag}$ & $<4,0$ & 0,7 & 1,4 \\
\hline
\end{tabular}

Tabela 2: Conteúdo em metais pesados das tortas analisadas 


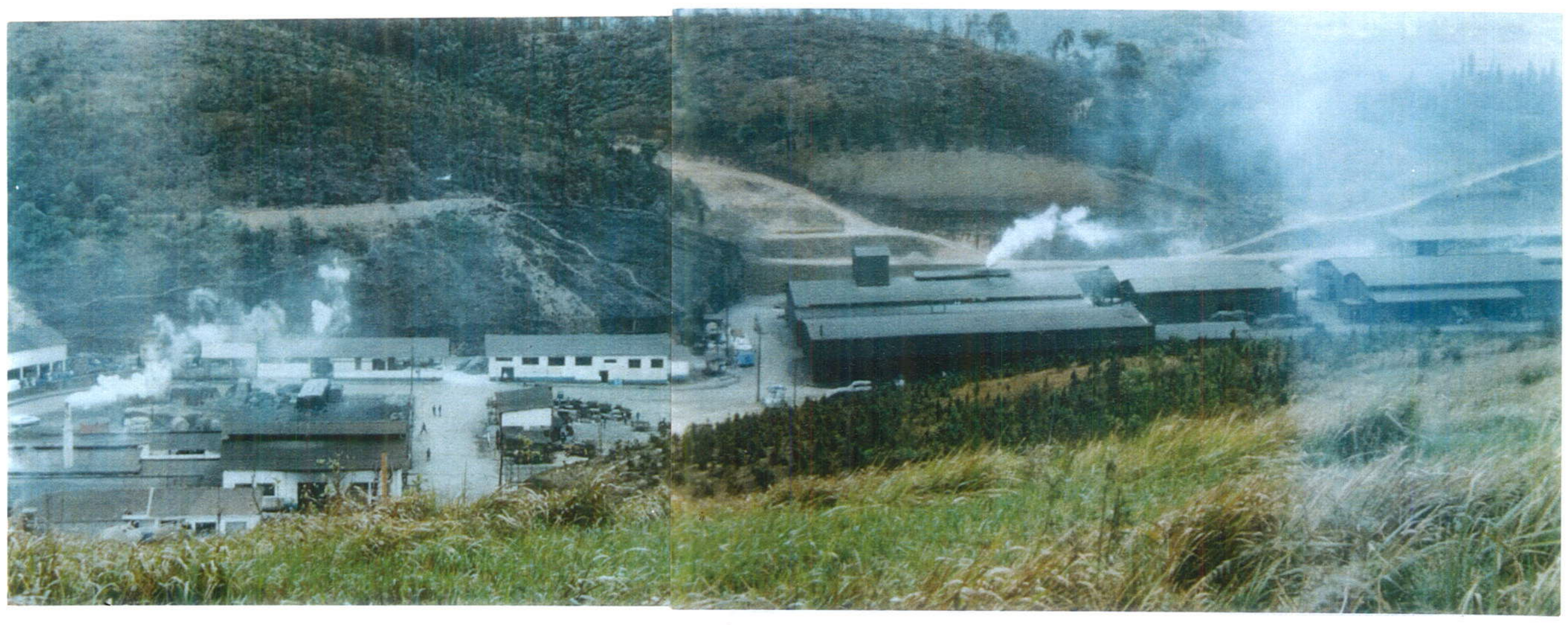

Fotografia 1: Vista geral das instalações da indústria. 
Através das análises, pode-se observar as expressivas concentrações de $\mathrm{Zn}$ e Cr, principalmente, além de Cu, Pbe MnO.

\subsection{Localização}

O município de Suzano localiza-se na Sub-Regiāo Leste da Regiäo

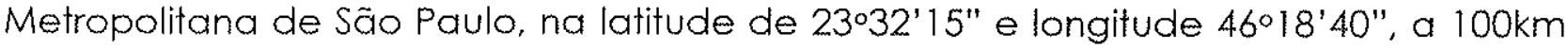
a leste da cidade de São Paulo.

A indústria em foco neste trabalho está localizada em um dos antigos pólos industriais do município, na sua porção sudeste.

O acesso à área é feito pela Rodovia Índio Tibiriçá (SP-31) até o Bairro de Paimeiras, na pista sentido Ribeirão Pires - Suzano, de onde se toma via secundária por $2 \mathrm{~km}$, até se atingir as instalações da indústria.

A Figura 1 ilustra a localização da área e as principais vias de acesso. 


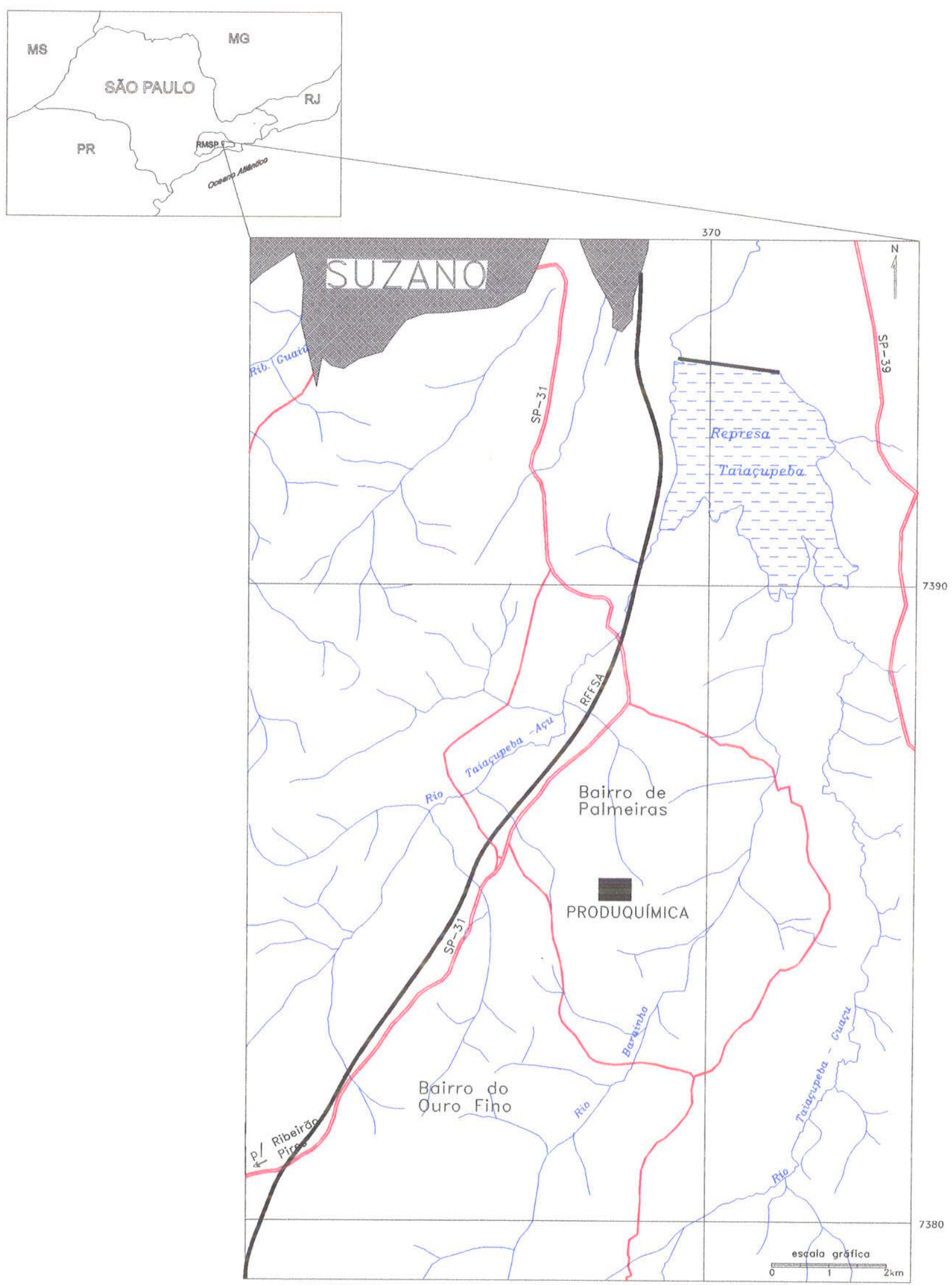

Figura 1: Localização da área, vias de acesso e bacia hidrográfica simplificada (adaptado de IGG, 1974) 


\subsection{Clima}

Em função de sua posição geográfica na porção sudeste do Planalto Atlântico, a região de Suzano sofre influência dos sistemas polar e tropical de massas de ar que se sucedem ao longo do ano, determinando em parte o tipo de clima da região.

De acordo com a classificação climática proposta por NIMER (1977), o clima da área classifica-se como Mesotérmico Brando, do tipo superúmido sem seca. Este é caracterizado por temperaturas amenas, com médias anuais em torno de $18^{\circ}$ a $19{ }^{\circ} \mathrm{C}$. No verão, a média do mês mais quente é inferior a $22^{\circ} \mathrm{C}$, com predomínio de temperaturas entre 18 e $20^{\circ} \mathrm{C}$; no inverno, as minimas registradas oscilam entre 6 e $8^{\circ} \mathrm{C}$.

A região apresenta altos índices de precipitação pluviométrica, atingindo valores acima de $1360 \mathrm{~mm}$. A estação chuvosa ocorre nos meses de dezembro a fevereiro, e o período de seca concentra-se no mês de junho. No período de seca, o indice pluviométrico chega a valores próximos a 30mm (PMS, 1991).

\subsection{Geomorfologia}

De acordo com a divisão geomorfológica do relevo paulisła (IPT/SICCT, 1981), a região encontra-se submetida aos domínios da Província Aflântica, na zona do Planalto Paulistano, subzona Morraria do Embu.

A zona geomorfológica do Planalto Paulistano é caracterizada pela dominância de formas de relevo suavizadas, em cotas altimétricas entre 715 e 900m, na maioria das vezes desenvolvidas sobre filitos, gnaisses, micaxistos e migmatitos. A subzona Morraria do Embu está essencialmente organizada em sistema de morrotes alongados paralelos, morrotes baixos e morros paralelos, normalmente com uma passagem gradual de um sistema para o outro.

O padrão de drenagem é do lipo em treliça, apresentando localmente característica subdendrítica, formando vales fechados a abertos e planícies interiores restritas. 
Na área da indústria, o relevo exibe forma de anfiteatro, formando um semicírculo cujo centro é a nascente do Córrego das Jaboticabeiras (Fotografia 2), afluente do Rio Taiaçupeba-Açu, que por sua vez é um importante afluente do Rio Tietê nesta região.

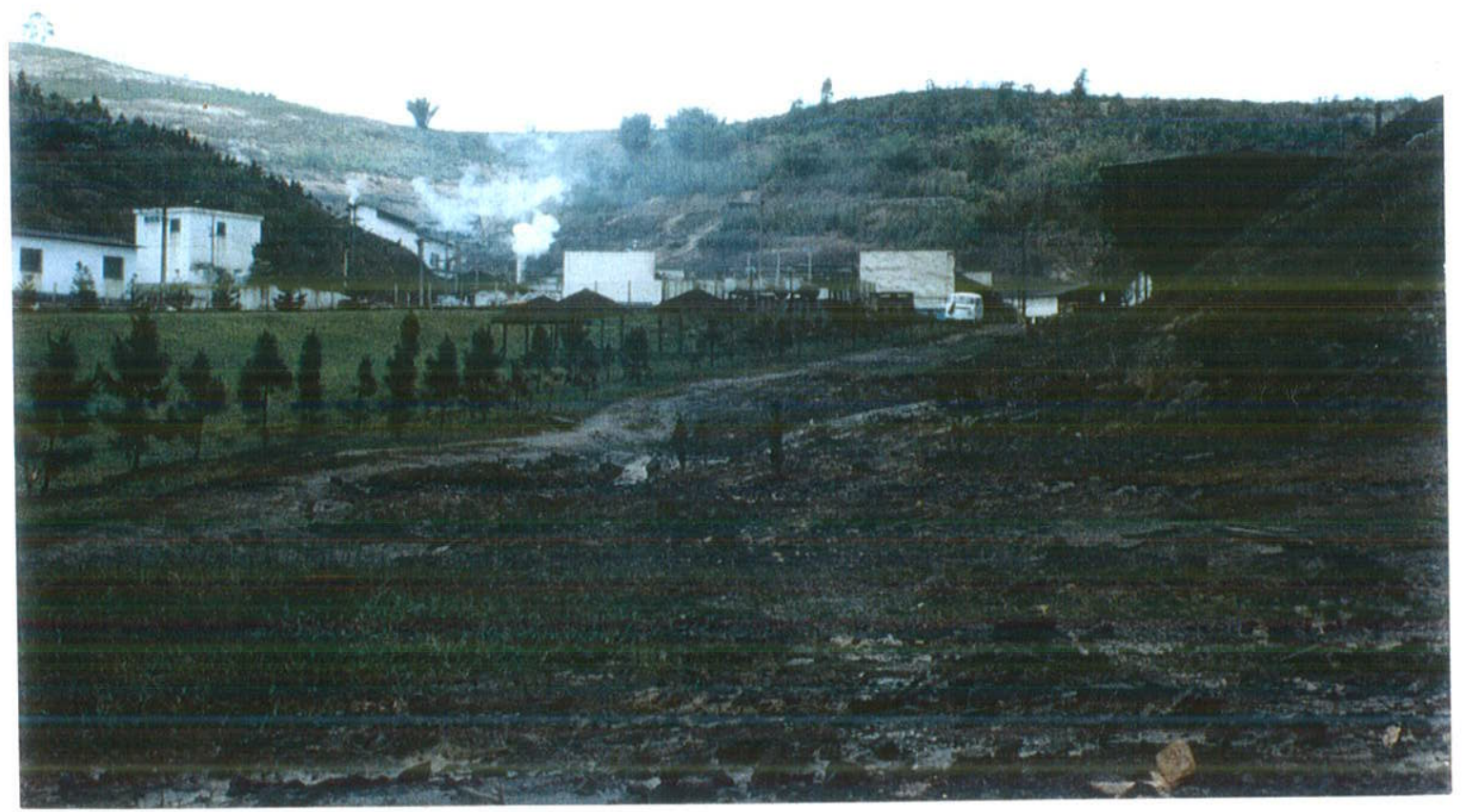

Fotografia 2: Vista da nascente do Córrego das Jaboticabeiras. Ao fundo, instalações da indústria. 


\subsection{Geologia Regional}

A geologia da área (CPRM, 1990) é caracierizada pela presença de rochas pertencentes ao Complexo Cristalino (Pré-Cambriano) com sedimentos da Bacia de São Pavlo e sedimentos Quaternários relacionados às várzeas dos rios atuais. A Figura 2 apresenta as principais unidades mapeadas na região.

O Embasamento Pré-Cambriano é representado por granitos sintectônicos e pós-tectônicos, migmatitos e gnaisses graníticos, mica-xistos e meta-arenitos, pertencentes ao Complexo Embu (CPRM, 1990). Caracterizam-se pela presença de sillimanita xistos feldspáticos, quartzitos finos e micáceos, rochas calciossilicatadas e metabásicas. Os terrenos formados por estas rochas são caracterizados por um desenvolvido manto de solo e por profundo grau de alteração de seus litotipos, sendo que nenhum de seus afloramentos apresenta rochas totalmente frescas.

Os sedimentos Terciários constituem-se de arenitos e pelitos com intercalação de conglomerados, correlatos à Bacia de São Paulo. Ocorrem nas paleovárzeas do Rio Tietê, tendo sido depositados em ambiente de sistema fluvial meandrante (RICCOMINI, 1989). As principais litologias encontradas são: arenitos finos, localmente conglomeráticos, com estratificações cruzadas acanaladas; siltitos e argilitos maciços, e siltitos finos, localmente conglomeráticos, com estratificação cruzada acanalada (MELO et al, 1986; MELO et al, 1987; CPRM, 1990).

Os sedimentos Quaternários estão associados aos aluviões delgados e relativamente extensos dispostos ao longo das várzeas atuais, e aos colúvios (MELO ef al, 1986; MELO et al, 1987; CPRM, 1990). 


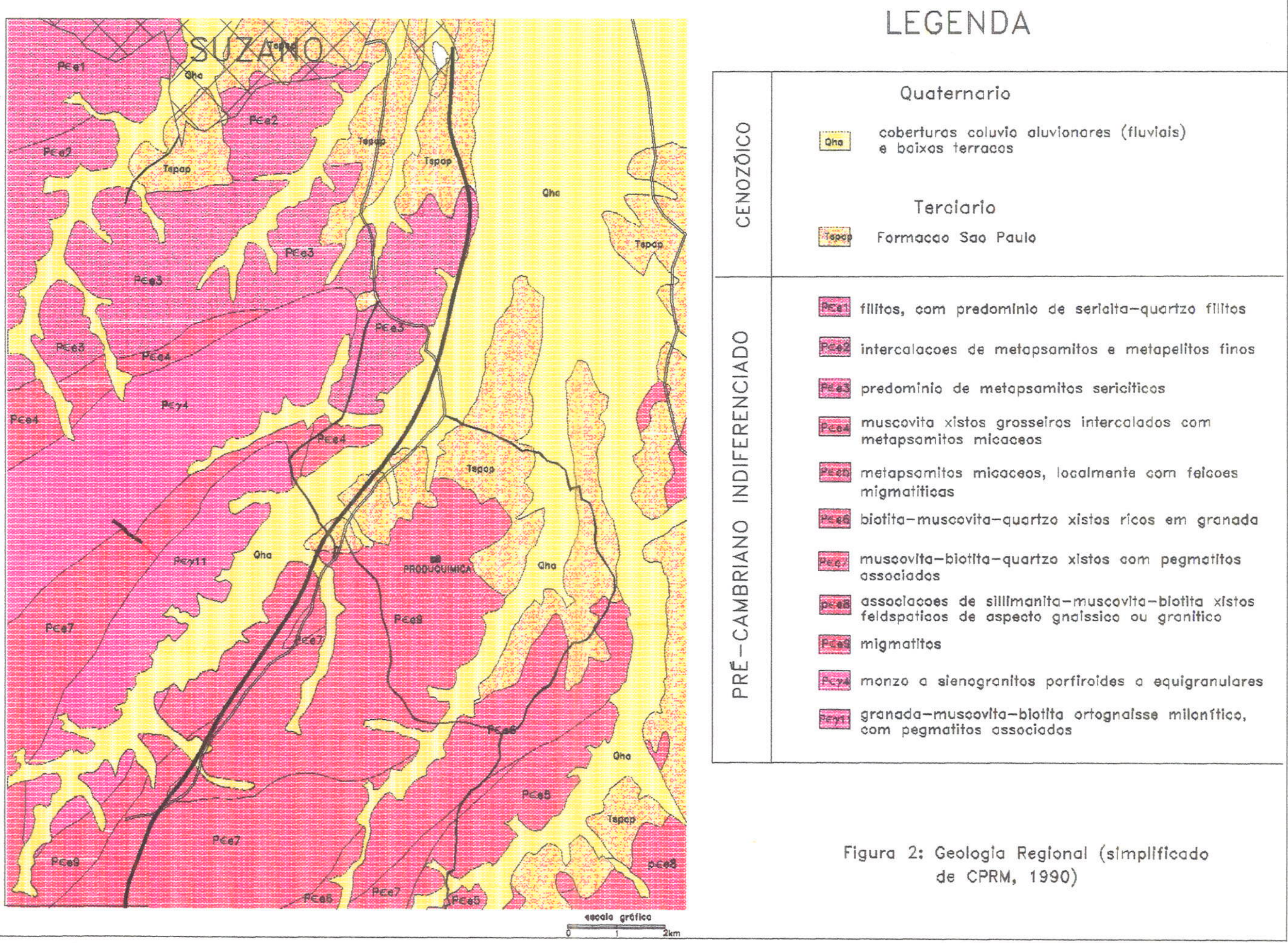




\subsection{Geologia Local}

A geologia local corresponde à área da lagoa de infiltração e seu entorno imediato. É constituída por três unidades distintas: colúvio, sedimentos da Bacia de São Paulo e embasamento (metamórficas do Complexo Embu intemperizadas).

O colúvio é caracterizado por material argilo-arenoso de coloração alaranjada, que apresenta-se composto essencialmente por grãos de quarłzo, e subordinadamente, micas (muscovita), sendo possível observar a presença de pequenos pontos milimétricos escuros (manganês?). Este colúvio é constituído em sua quase totalidade por latossolos areno argilosos.

Os sedimentos têm como representantes principais siltes de coloração cinzaclara, que afloram a jusante da lagoa, e no leito do Córrego das Jaboticabeiras. Caracterizam-se pela frequente presença de grãos de quartzo, bem menores que os observados no colúvio, e micas milimétricas de coloração clara (muscovita). Localmente, apresentam coloração cinza-escura - provavelmente devido à maior concentração de matéria orgânica em alguns níveis - como em um trecho do Córrego Jaboticabeiras localizado a jusante da indústria. Este material é utilizado pelas olarias existentes na região, na mistura para a fabricaçāo de tijolos (Fotografia 3), e provavelmente está correlacionado aos sedimentos da Bacia de São Paulo (argilitos e siltitos maciços) (CPRM, 1990).

O embasamento está representado por rochas metamórficas pertencentes ao Complexo Embu, e se apresenta com perfil de alteração bem desenvolvido (alteritas), não sendo observados afloramentos com resquícios de rocha sã. O material apresenta-se com coloração amarelo-alaranjada e iexłura areno-siltosa, sendo observados grãos de feldspatos caulinizados, e micas de coloração acinzentada (muscovitas) de dimensões milimétricas. 


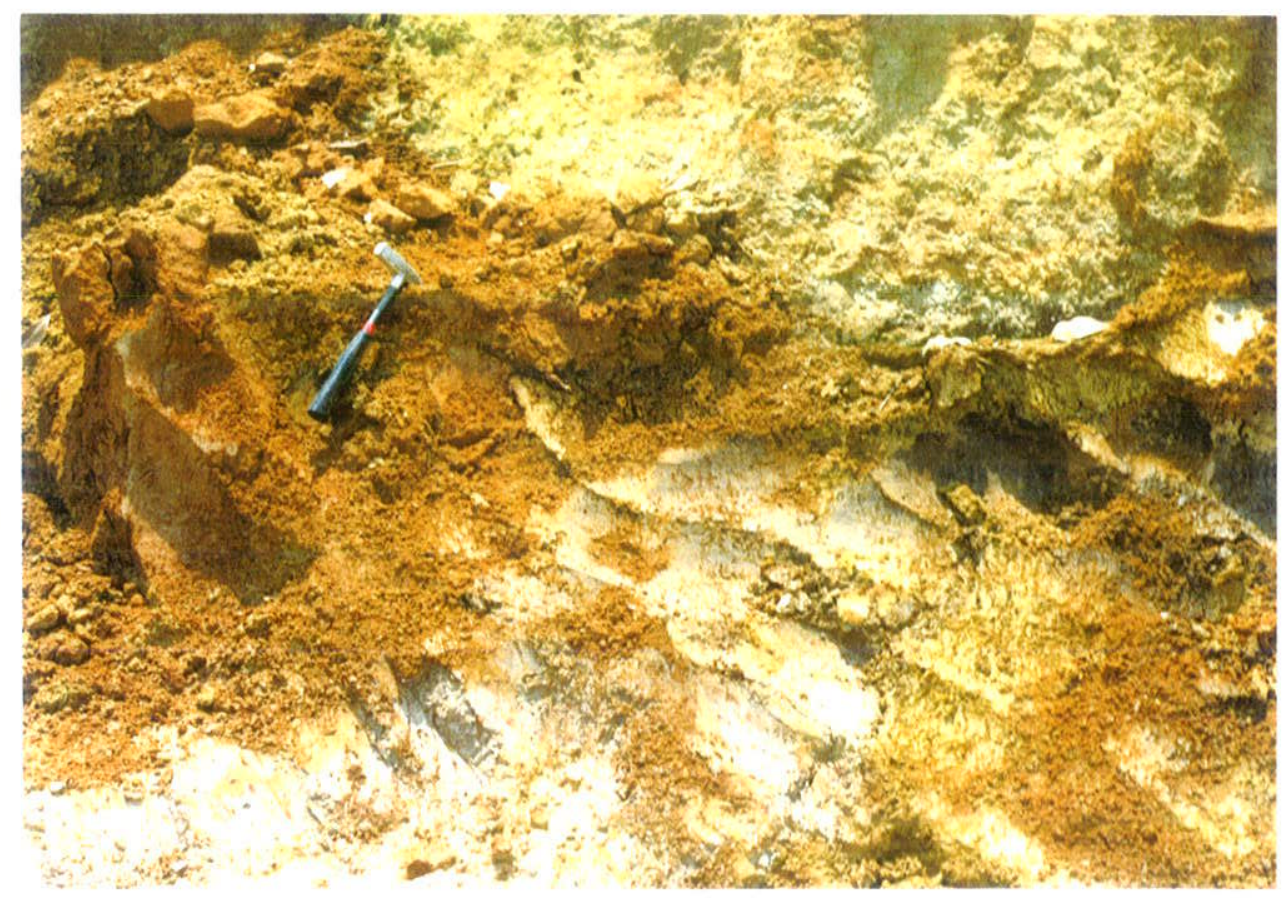

Fotografia 3: Aspecto de afloramento dos sedimentos da Bacia de São Paulo, em terreno localizado a jusante da área da indústria. Material siltoso, maciço, de coloração cinza-clara, correlacionado à Unidade 3 do perfil de estudo. 


\section{SÍNTESE SOBRE O CONHECIMENTO DOS METAIS PESADOS NO SOLO}

\subsection{Origem dos Metais Pesados no solo}

solo é composto por elementos que se encontram em três fases: sólida (orgânica e mineral), líquida e gasosa. As suas propriedades são resultantes dos equilibrios físicos e químicos entre estas três fases.

Os processos atuantes no intemperismo do material parental é que definem - conteúdo dos metais pesados (MP) no solo. Inicialmente, ele tende a ser semelhante ao da rocha de origem (Tabela 3), que por sua vezé conseqüência do conteúdo de MP nos minerais que constituem a rocha original (Quadro 1).

Com o passar do tempo, entretanto, a porcentagem destes elementos será diferente, devido à influência de reações e processos geoquímicos como dissolução, hidratação, hidrólise, oxidação, redução e carbonatação. São estes os principais responsáveis pelo processo de intemperismo químico da rocha e conseqüente formação do solo (KABATA-PENDIAS \& PENDIAS, 1984). Elementos traços podem vir a ser mobilizados por dissolução de minerais, e fixados por minerais secundários e neoformados, ou pela matéria orgânica, associada ou não a estes minerais. A competição existente entre alguns metais (CU e $\mathrm{Zn}$, por exemplo, de acordo com KUO \& BAKER, 1980) também pode vir a alterar a concentração dos mesmos ao longo do perfil do solo.

\begin{tabular}{|c|c|c|c|c|c|c|c|}
\hline \multirow{2}{*}{$\begin{array}{c}\text { metal } \\
\text { pesado }\end{array}$} & \multirow{2}{*}{$\begin{array}{l}\text { crosta } \\
\text { terrestre }\end{array}$} & \multicolumn{3}{|c|}{ rochas igneas } & \multicolumn{3}{|c|}{ rochas sedimentares } \\
\hline & & $\begin{array}{c}\text { Ultra- } \\
\text { máficas }\end{array}$ & $\begin{array}{l}\text { máficas } \\
\text { (basalios) }\end{array}$ & graníticas & calcários & arenitos & argilitos \\
\hline $\mathrm{Cd}$ & 0,1 & 0,12 & 0,13 & 0,09 & 0,028 & 0,05 & $0,22(<240)$ \\
\hline $\mathrm{Cu}$ & 50 & 42 & 90 & 13 & 5,5 & 30 & $39(<300)$ \\
\hline $\mathrm{Mn}$ & 950 & 1040 & 1500 & 400 & 620 & 460 & 850 \\
\hline Mo & 1,5 & 0,3 & 1 & 2 & 0,16 & 0,2 & $2.61<300 \mid$ \\
\hline $\mathrm{Pb}$ & 14 & 14 & 3 & 24 & 5.7 & 10 & $23(<400)$ \\
\hline $\mathrm{Zn}$ & 75 & 58 & 100 & 52 & 20 & 30 & $120(<1000)$ \\
\hline
\end{tabular}

Tabela 3: Conteúdo em $\mathrm{Cd}, \mathrm{Cu}, \mathrm{Mn}$, Mo, $\mathrm{Pb}$ e $\mathrm{Zn}$ dos principais tipos de rochas $(\mathrm{mg} / \mathrm{kg}$ ). Extraído de ALLOWAY (1995). 


\begin{tabular}{|c|c|c|}
\hline Mineral & Metais Pesados Constituintes & $\begin{array}{l}\text { Susceptibilidade ao } \\
\text { Intemperismo }\end{array}$ \\
\hline $\begin{array}{l}\text { Olivina } \\
\text { Hornblenda } \\
\text { Augita } \\
\text { Biotita } \\
\text { Apatita } \\
\text { Anortita } \\
\text { Andesina } \\
\text { Oligoclásio } \\
\text { Albita } \\
\text { Granada } \\
\text { Ortoclásio } \\
\text { Muscovita } \\
\text { Titanita } \\
\text { IImenita } \\
\text { Magnetita } \\
\text { Turmalina } \\
\text { Zircão } \\
\text { Quartzo }\end{array}$ & $\begin{array}{l}\text { Ni, Co, Mn, Li, Zn. Cu, Mo } \\
\text { Ni, Co, Mn, Sc, Li, V, Zn, Cu, Ga } \\
\text { Ni, Co, Mn, Sc, Li, V, Zn, Pb, Cu, Ga } \\
\text { Rb, Ba, Ni, Co, Sc, Li, Mn, V, Zn, Cu, } \\
\text { Ga } \\
\text { Terras Raras, Pb, Sr } \\
\text { Sr, Cu, Ga, Mn } \\
\text { Sr, Cu, Ga, Mn } \\
\text { Cu, Ga } \\
\text { Cu, Ga } \\
\text { Mn, Cr, Ga } \\
\text { Rb, Ba, Sr, Cu, Ga } \\
\text { F, Rb, Ba, Sr, Cu, Ga, V } \\
\text { Terras Raras, V, Sn } \\
\text { Co, Ni, Cr, V } \\
\text { Zn, Co, Ni, Cr, V } \\
\text { Li, F, Ga } \\
\text { Hf, V } \\
\text {-m.... }\end{array}$ & moderadamente estável \\
\hline
\end{tabular}

Quadro 1: Elementos traços de minerais comuns formadores de rochas fextraído de ALLOWAY, 1995).

Embora os metais pesados sejam componentes secundários da fase sólida dos solos, eles têm um papel importante na sua fertilidade, como por exemplo $\mathrm{Mn}$, Zn, B, Cu e Mo. Porém, o aumento da concentração de alguns MP por fatores antropogênicos pode fazer com que eles se tornem tóxicos para plantas e animais, especialmente no caso do $\mathrm{Hg}, \mathrm{Pb}, \mathrm{Cd}, \mathrm{Cu}$, Ni e Co (MCBRIDE, 1994).

Os metais pesados de origem antropogênica chegam ao solo provenientes de várias fontes (emissāo de gases, minerações, indústrias), e sua disseminação ou absorção depende das propriedades químicas e físicas do solo (KABATA.PENDIAS \& PENDIAS, 1984).

A persistência dos contaminantes no solo é maior que nos outros elementos da biosfera, e sua contaminação, especialmente por metais pesados, tende a ser virtualmente permanente. KABATA-PENDIAS \& PENDIAS (1984) citam alguns exemplos de meia vida de metais pesados no solo: $\mathrm{Zn}-70$ a 510 anos; $\mathrm{Cd}-13$ a 1100 anos; $\mathrm{Cu}-310$ a 1500 anos; $\mathrm{Pb}-740$ a 5900 anos. 


\subsection{Metais Pesados no Solo}

Neste ítem, serão apresentados resumidamente os aspectos geoquímicos referentes apenas do $\mathrm{Cu}, \mathrm{Mn}, \mathrm{Mo}, \mathrm{Zn}, \mathrm{Cd}$ e $\mathrm{Pb}$, que são os metais pesados estudados na presente dissertação.

\subsubsection{Cobre}

O cobre é encontrado praticamente em todas as rochas da crosta terrestre, sendo mais abundante em rochas máficas e intermediárias, e praticamente ausente em rochas carbonáticas (KABATA-PENDIAS \& PENDIAS, 1984). O seu teor médio para rochas eruptivas básicas é da ordem de 100 a $200 \mathrm{mg} / \mathrm{kg}$; para eruptivas ácidas, 10 a 20 mg/kg; para rochas metamórficas (xistos) e determinadas sedimentares (argilas e loess), 30 a $40 \mathrm{mg} / \mathrm{kg}$; e para areias, arenitos e calcários, de 3 a $15 \mathrm{mg} / \mathrm{kg}$.

Nos solos, o cobre ocorre precipitado com hidróxidos, carbonatos, fosfatos e silicatos, adsorvidos por argilas silicatadas, e formando complexos solúveis e insolúveis com a matéria orgânica do solo. (HAINES \& HARRIS, 1987). Ele é considerado um elemento muito versátil, apresentando grande habilidade para interagir quimicamente com minerais e compostos orgânicos do solo (KABATAPENDIAS \& PENDIAS, 1984; RAIJ el al, 1987; ALLOWAY, 1995).

O Cu aplicado ou depositado no solo tende a persistir no mesmo por ser fortemente fixado pela matéria orgânica e por óxidos de $\mathrm{Fe}, \mathrm{Al}, \mathrm{Mn}$ e pelos minerais de argila, sendo que esta intensidade diminui com o aumento do $\mathrm{pH}$. Em decorrência disto, é um dos menos móveis entre os metais pesados, fazendo com que geralmente seja encontrado próximo à superficie (MALAVOLTA, 1994; MCBRIDE, 1994), e apresente uma pequena variação na sua concentração ao longo do perfil (KABATA-PENDIAS \& PENDIAS, 1984).

De acordo com ADRIANO (1986), o cobre pode ocorrer no solo nas seguintes formas: (a) na solução do solo, tanto em forma iônica, $\mathrm{Cu}^{2+}$, quanto complexado; (b) adsorvido em locais normais de troca iônica; (c) adsorvido em locais de adsorção específicos; (d) ocluso em óxidos e hidróxidos do solo; (e) na matéria 
orgânica e em organismos vivos; e (f) na rede estrutural de minerais primários e secundários.

De acordo com este autor, observa-se uma correlação entre o conteúdo natural de cobre no solo e o seu material de origem: solos derivados de materiais de granulometria maior (areias e arenitos) ou de rochas ácidas contêm menor concentração de cobre do que os solos derivados de rochas sedimentares de granulometria mais fina (argilas) ou de rochas ígneas básicas. Alguns autores correlacionam a capacidade de retenção do cobre em solos com as partículas finas, especialmente argilas e siltes.

No caso da alta acumulação de Cu, observamse a sua precipitação na forma de hidróxido cúprico, óxidos ou hidróxidos carbonatados, em solos com pH abaixo de 6 (MCBRIDE, 1994).

Para os solos do Estado de São Paulo, VALADARES (1975) obteve os seguintes teores de Cu:

- solos derivados de rochas básicas (Terra Roxa Estruturada, Latossolo Roxo): 88 e $385 \mathrm{mg} / \mathrm{kg}$;

- solos derivados de materiais aluviais e coluviais (hidromórficos): 25 a 29 $\mathrm{mg} / \mathrm{kg}$;

- solos derivados de sedimentos modemos (Latossolo Vermelho Escuro, Vermelho Amarelo e Podzólico Vermelho Amarelol : 6 - $49 \mathrm{mg} / \mathrm{kg}$;

- solos derivados do arenito da Formação Bauru (podzolizados de Lins e Marília) : 3 a $7 \mathrm{mg} / \mathrm{kg}$;

- solos derivados de sedimentos modernos arenosos - 2 a $13 \mathrm{mg} / \mathrm{kg}$.

VALADARES (1975) aponta para uma correlação existente entre o teor de argila e o teor de cobre destes solos $(r=0,79)$. Embora tenha sido enfatizada a fixação do Cu por compostos orgânicos, neste trabalho o autor obteve uma correlação muito baixa $(r=0,17)$ entre o teor de cobre e o teor de matéria orgânica.

\subsubsection{Manganês}

Todas as rochas da crosta terrestre contêm manganês em concentraçōes geralmente mais altas que todos os outros metais pesados, exceto no caso do ferro (AUBERT \& PINTA 1977); o teor mais alto aparece nas rochas eruptivas ácidas (granitos, riolitos), metamórficas (xistos) e em algumas sedimentares (argilitos). A 
faixa de variação é de 200-1200 mg/kg, sendo que nos calcários o teor médio é de $400-600 \mathrm{mg} / \mathrm{kg}$, e nos arenitos entre 20 e $500 \mathrm{mg} / \mathrm{kg}$.

O manganês aparece no solo em três valências: (1) bivalente $\left(\mathrm{Mn}^{2+}\right)$, presente como cátion adsorvido ou na solução do solo; (2) trivalente $\left(\mathrm{Mn}^{3+}\right)$, como óxido altamente reativo: $\mathrm{MnO}_{3}$ e (3) tetravalente como $\mathrm{MnO}_{2}$. As três formas constituem um conjunto de equilíbrio dinâmico (CATANI \& GALLO, 1951). A ocorrência de $\mathrm{Mn}^{3+}$ e $\mathrm{Mn}^{4+}$ é favorecida pela elevação do $\mathrm{pH}$ em condições oxidantes (MALAVOLTA, 1994).

Para os solos do Estado de São Paulo, CATANI \& GALO (1951) obtiveram teores de $500 \mathrm{mg} / \mathrm{kg}$ para um solo derivado do arenito da Formação Bauru e 2000 $\mathrm{mg} / \mathrm{kg}$ para um solo do tipo Terra Roxa estruturada.

MALAVOLTA (1994) aponta as principais formas de ocorrência de manganês no solos: (a) na estrutura de minerais, geralmente óxidos, como a pirolusita $\left(\mathrm{MnO}_{2}\right)$; (b) complexados com matéria orgânica, solúveis ou insolúveis; (c) trocável, $\left(\mathrm{Mn}^{2+}\right.$ ) que está presente nos sítios de troca do complexo organo-mineral do solo; e (d) na solução do solo, na forma iônica $\left(\mathrm{Mn}^{2+}\right)$ ou complexado a compostos orgânicos.

MCBRIDE (1994) aponta que a mobilidade do Mn no solo não apresenta um parâmetro definido, visto que ele é extremamente sensível às condições do solo (acidez, umidade, atividade biológica, etc.), o que faz com que a sua solubilidade no solo oscile intensamente, e conseqüentemente, a sua concentração varie de deficiente à níveis considerados tóxicos.

\subsubsection{Molibdênio}

O molibdênio é encontrado em muitas rochas da crosta terrestre, geralmente em baixa concentração. Nas rochas ultrabásicas (dunito e peridotito), o nivel é baixo, de 0,2 a 0,4 $\mathrm{mg} / \mathrm{kg}$. Nas eruptivas básicas (basalto e gabro) chega a $1,4 \mathrm{mg} / \mathrm{kg}$, e nas eruptivas ácidas, como o granito, em $1,9 \mathrm{mg} / \mathrm{kg}$. Os níveis mais altos (2 mg/kg) são encontrados em rochas metamórficas (xistos) e sedimentares (argilitos). Arenitos e calcários possuem os teores mais baixos: 0,2-0,4 $\mathrm{mg} / \mathrm{kg}$ (AUBERT \& PINTA, 1977). MCBRIDE (1994) porém, aponta um teor médio mundial nos solos do redor de 1 a $3 \mathrm{mg} / \mathrm{kg}$ de Mo, sendo que nos EUA, este valor atinge $5,8 \mathrm{mg} / \mathrm{kg}$. 
Para os solos do Estado de São Paulo, BATAGLIA ef al (1976) encontraram os seguintes teores de Mo:

- solos derivados de rochas básicas (litossolo, terra roxa estruturada, latossolo roxo): 0,85 a 2,55 mg/kg;

- solos derivados de sedimentos modernos (latossolos vermelho-escuro e amarelo, podzólico vermelho amarelo): 0,79 a $3,73 \mathrm{mg} / \mathrm{kg}$;

" solos derivados do arenito da Formação Bauru: 0,31 a 0,47mg/kg.

De acordo com ADRIANO (1986), o conteúdo de Mo nos solos depende do material parental, grau de intemperismo e quantidade de matéria orgânica, sendo que o teor no solo tende a ser maior que o teor de seu material de origem.

No solo, o Molibdênio ocorre nas seguintes formas: (a) fixado dentro da estrutura cristalina de minerais primários e secundários; (b) adsorvido pelos materiais do solo como um ânion; (c) associado à matéria orgânica; (d) na forma trocável; (e) solúvel em água. Observa-se ainda, na literatura pertinente, que o molibdênio é fortemente fixado por óxidos de ferro e alumínio, e matéria orgânica.

\subsubsection{Zinco}

A maioria das rochas da crosta terrestre contém zinco em concentrações variáveis: básicas eruplivas (basalto, gabro): $70-130 \mathrm{mg} / \mathrm{kg}$, eruptivas ácidas (granito, riolito): $50-60 \mathrm{mg} / \mathrm{kg}$, metamórficas (xistos) e certas sedimentares (argilitos): $80 \mathrm{mg} / \mathrm{kg}$; argilas provenientes da desagregação do loess e argilas glaciais: 30-40 $\mathrm{mg} / \mathrm{kg}$. calcários e arenitos, 20 e $16 \mathrm{mg} / \mathrm{kg}$, respectivamente (MALAVOLTA, 1994).

Nos solos, o zinco pode ocorrer na forma de mineral primário ou como íon $\mathrm{Zn}^{2+}$ adsorvido às particulas muito finas. Ele precipita-se como hidróxido, fosfato, carbonato e silicato, podendo fazer parte dos materiais amorfos do solo. $\mathrm{O} \mathrm{zn}$ também pode ser adsorvido à matéria orgânica ou formar complexos com ela (RAlJ et al. 1987, ALLOWAY, 1995). O seu teor no solo é muito variável, refletindo a influência maior da rocha mãe, variando de fraços a $900 \mathrm{mg} / \mathrm{kg}$, com uma média entre 50 e $100 \mathrm{mg} / \mathrm{kg}$ (MALAVOLTA, 1994).

Para o Estado de São Paulo, VALADARES \& CATANI (1975) encontraram os seguintes teores de $\mathrm{Zn}$ :

- solos derivados de rochas básicas (latossolo - fase substrato basalto, terra roxa estruturada e latossolo roxol: 89 a $236 \mathrm{mg} / \mathrm{kg}$; 
- solos hidromórficos, provenientes de material aluvionar e coluvionar: 77 a $97 \mathrm{mg} / \mathrm{kg}$;

- solos derivados de sedimentos modernos (latossolos vermelho amarelo e escuro e podzólico vermelho amarelo): 26 a $94 \mathrm{mg} / \mathrm{kg}$;

- solos podzolizados (Lins e Marília): 16 a $26 \mathrm{mg} / \mathrm{kg}$;

- solos derivados de sedimentos modernos arenosos llatossolos vermelho amarelo e escuro e regossolo): 4 a $14 \mathrm{mg} / \mathrm{kg}$.

A repartição do $\mathrm{Zn}$ em várias formas é baseada nos modos pelos quais se comporta diante da extração por diferentes agentes químicos. O seu conteúdo lotal no solo pode ser dividido nas seguintes formas de ocorrência, de acordo com ADRIANO (1986): (a) lons $\mathrm{Zn}^{2+}$ livres, e/ou em complexos orgânicos na solução do solo; (b) Zn adsorvido e trocável na fração coloidal do solo, composta por partícula de argila, compostos húmicos e hidróxidos de $\mathrm{Fe}$ e $\mathrm{Al}$; e (c) minerais secundários e complexos insolúveis na fase sólida do solo.

MCBRIDE (1994) observa que em solos contaminados por altos valores de $\mathrm{Zn}$. ocorre uma tendência de precipitação de óxidos, hidróxidos e hidrocarbonetos de Zn, em pH abaixo de 6, estando a solubilidade do Zn limitada a pH maiores.

\subsubsection{Chumbo}

O Pb contido no solo é explicado pelo conteúdo natural da rocha mãe e por diversas fontes antropogênicas. MALAVOLTA (1994) aponta valores de Pb em diversas rochas da crosta terrestre: erupłivas básicas (basalto, gabro): $8 \mathrm{mg} / \mathrm{kg}$; eruptivas ácidas (granito, riolito) $20 \mathrm{mg} / \mathrm{kg}$; intermediárias (diorito, andesito), metamórficas (xistos) e certas sedimentares (argilitos) 15 a $20 \mathrm{mg} / \mathrm{kg}$; calcários e arenitos: $7-10 \mathrm{mg} / \mathrm{kg}$; litosfera: $16 \mathrm{mg} / \mathrm{kg}$.

As fontes antropogênicas de Pb estäo associadas à polventes colocados na atmosfera por emissão de veículos e minerações, fundições, esgoto, lodo derivado de esgoto, fertilizantes, etc (ALLOWAY, 1995).

Geraimente o chumbo se acumula nos primeiros centímetros do solo superficial, e o seu teor diminui à medida em que profundidade do perfil aumenta (ALLOWAY, 1995). MALAVOLTA (1994) observa que este tipo de distribuição é atribuída à acumulação pela matéria orgânica mediante reciclagem pelas plantas do $\mathrm{Pb}$ das camadas inferiores. O mesmo autor observa que, no caso do $\mathrm{Pb}$ 
antropogênico, ele apresenta o mesmo tipo de distribuição, podendo porém, atingir niveis mais profundos $(30-45 \mathrm{~cm})$.

A disponibilidade de $\mathrm{Pb}$ no solo é influenciada, de acordo com MALAVOLTA (1994) pelos seguintes fatores: textura do solo (solos mais argilosos tendem a fixar mais o chumbo); $\mathrm{pH}$ (a concentração de Chumbo no solo é inversamente proporcional ao pH) e matéria orgânica (o chumbo tende a ser fixado pela matéria orgânica do solo).

\subsubsection{Cádmio}

O Cádmio é um polvente potencialmente prejudicial do meio ambiente, visto que é um metal de rápida absorção pelo solo, com prazo longo de persistência e com acumulação de concentrações, provocando efeitos danosos em plantas e animais (MALAVOLTA, 1994).

De um modo geral, o Cd apresenta um comportamento geoquímico semelhante do $\mathrm{Zn}$, e o seu teor nestes minérios será diretamente proporcional do teor de $\mathrm{Zn}$ dos mesmos (THORNTON, 1996).

A concentração média de Ca na crosta terrestre é de $0,15 \mathrm{mg} / \mathrm{kg}$. Os teores médios encontrados nas rochas são: ígneas (andesito e diorito) - de 0,017 a 0,07 $\mathrm{mg} / \mathrm{kg}$; obsidiana e basalto - 0,22 a $0,25 \mathrm{mg} / \mathrm{kg}$; sedimentares: calcários 10,035 $\mathrm{mg} / \mathrm{kg})$, margas $(2,6 \mathrm{mg} / \mathrm{kg})$. Nas rochas metamórficas, os teores variam entre 0,11 nos eclogitos a $1 \mathrm{mg} / \mathrm{kg}$ nos xistos (MALAVOLTA, 1994).

A concentração de $\mathrm{Cd}$ em solos não contaminados por fontes antropogênicas é governada pelo teor na rocha de origem. O mesmo autor sugere que solos oriundos de rochas ígneas devem conter entre 0,1 e $0,3 \mathrm{mg} / \mathrm{kg}$ de $\mathrm{Cd}$, os oriundos de rochas metamórficas, entre 0,1 e $1 \mathrm{mg} / \mathrm{kg}$, e os de sedimentares, 11 $\mathrm{mg} / \mathrm{kg}$.

ADRIANO (1986) descreve de modo simplificado em quais formas o cádmio pode ser encontrado no solo: (a) trocável: adsorvido por atração eletrostática em sítios com carga negativa das argilas, matéria orgânica e óxidos hidratados; (b) redutivel; adsorvido ou coprecipitado com óxidos, hidróxidos de Fe, $\mathrm{Mn}$ e possivelmente de Al presentes no revestimento de minerais de argila ou partículas isoladas; (c) carbonato: precipitado como carbonato em solos com muito 
carbonato de cálcio livre, (d) bicarbonato, em reações alcalinas, possivelmente precipitado também como fosfato; (e) orgânico, complexado ou quelatizado, produtos de estabilidade e mobilidade variáveis; (f) fixado no interior da rede cristalina da argila, também chamada residual (g) sulfeto; muito insolúvel e estável, compostos de $\mathrm{Cd}$ e sulfetos que ocorrem em solos mal arejados como os arrozeiros inundados; (h) em solução: iônica ou complexada.

De acordo com MCBRIDE (1994), de um modo geral são considerados solos contaminados aqueles que possuem teores de Cd acima de $0,5 \mathrm{mg} / \mathrm{kg}$, sendo que as fontes de contaminação podem ser as seguintes: indústria (mineração e metalurgia), proximidade às auto-esirradas, aplicação de fertilizantes fosfatados com alto teor de Cd, ou tratamento por lodo de esgoto.

Para os solos tratados por lodo de esgoto, ADRIANO (1986) observou a seguinte distribuição porcentual das formas de $\mathrm{Cd}$, em relação ao total presente: solúvel em $\mathrm{H}_{2} \mathrm{O}<1 \%$; trocável - 21,3\%; preso à matéria orgânica - 45,4\%; preso a óxidos hidratados $-20,1 \%$, restante - residual. 


\section{METODOLOGIA}

\subsection{Metodologia de Campo}

Para delinear o comportamento geoquímico de retenção de metais pesados na área, associados a diferentes tipos de materiais naturais, elegeu-se um pequeno anfiteatro onde se localizava uma antiga lagoa da empresa. Isto ocorrev em virtude de estudos anteriores desenvolvidos por firmas de consultoria contratadas pela indústria, que identificaram teores anômalos de Zinco $(700 \mathrm{mg} / \mathrm{kg}$ ) nas camadas de argila cinza-escura siłuadas a jusante da barragem desta antiga lagoa.

A metodologia empregada para obtenção de amostras nesta unidade esłá descrita a seguir.

\subsubsection{Seleção da seção a ser analisada e locação dos furos à trado}

A seção escolhida para execução das tradagens inicia-se na estrada de servidão da indústria, sendo perpendicular a esta, e atravessa a lagoa de infiltração (Fotografia 4), seguindo para montante (Figura 3). Isto possibilitou a locação dos furos a jusante, dentro e a montante da lagoa de infiltração, com o objetivo de comparar o comportamento dos metais pesados no solo e subsolo, nestas três situaçōes.

Os furos receberam a denominação de TL-01 a TL-07, estando o primeiro localizado na parte inferior do perfil, próximo à estrada de servidão, e o último, na porção superior do perfil. Os furos TL-01, TL-02 e TL-03 estão localizados a jusante da lagoa (Fotografia 5), os furos TL-04 e TL-05, dentro da lagoa, e os furos TL-06 e TL-07, a montante da lagoa. Os furos foram locados de 10 em 10 metros de distância, sempre que possivel, sendo que em alguns locais esta distância situou-se entre 8 e 9 metros, obedecendo o perfil estabelecido anteriormente (Figura 4). 


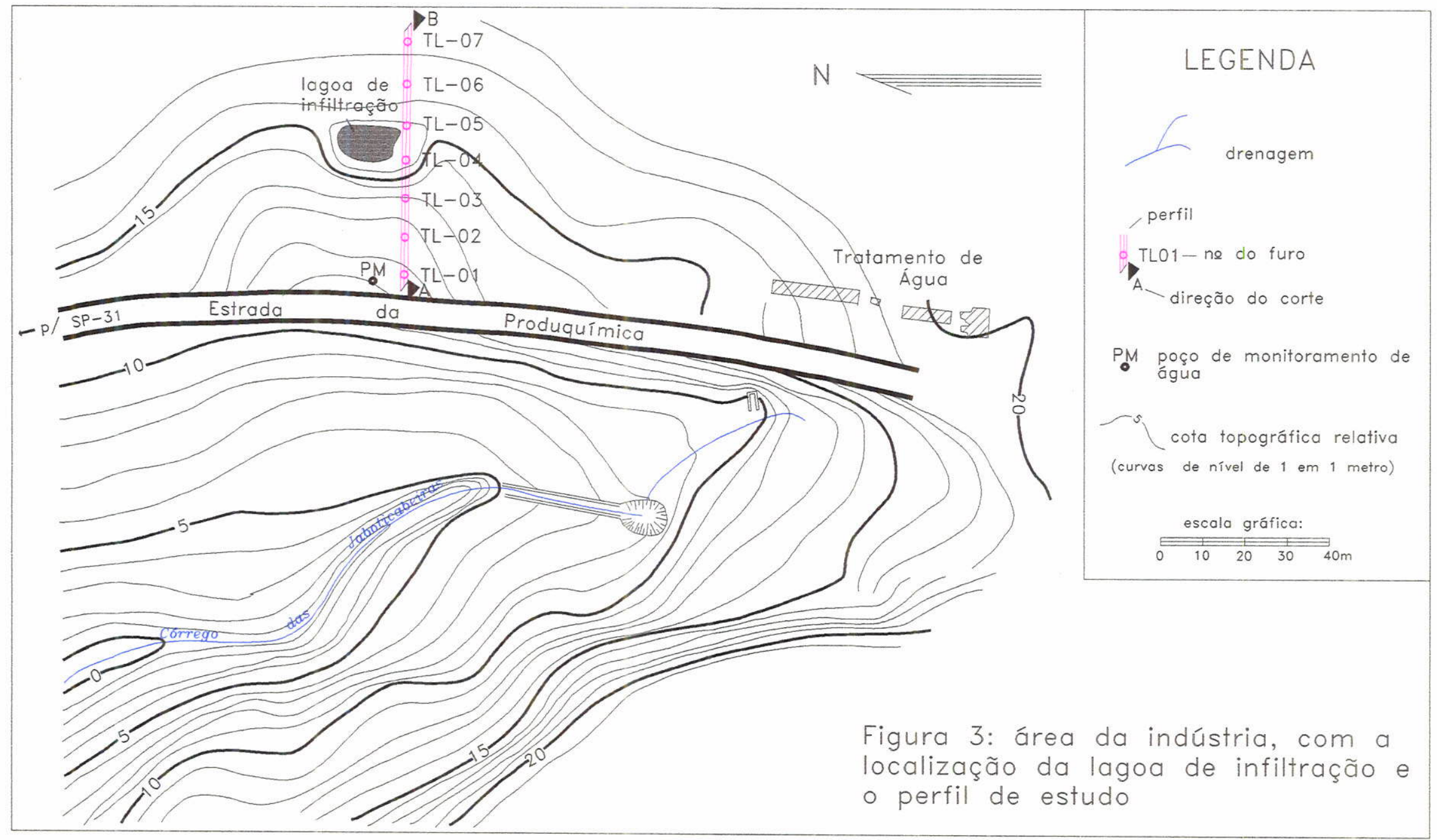




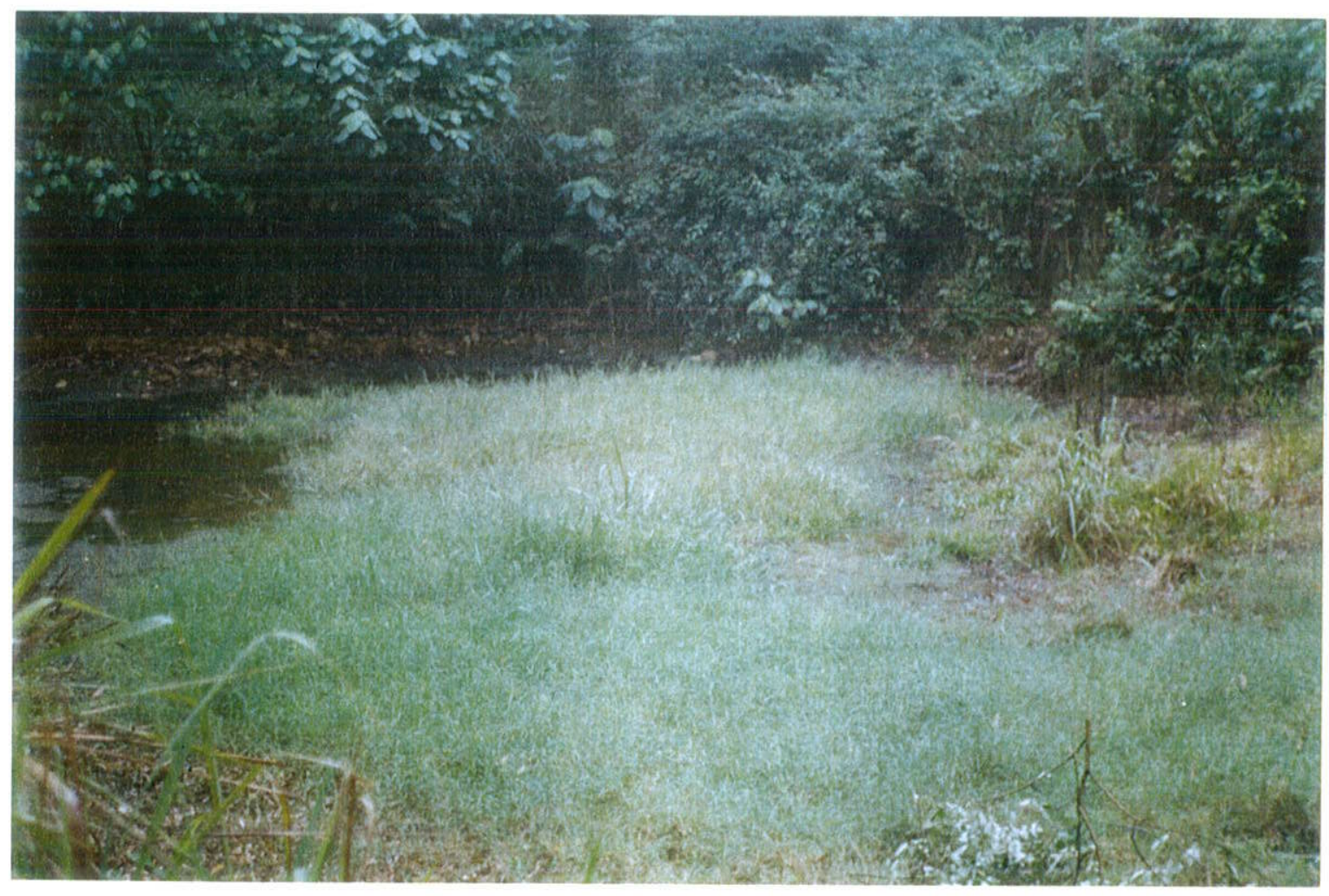

Fotografia 4: Aspecto geral da lagoa de infiltração.

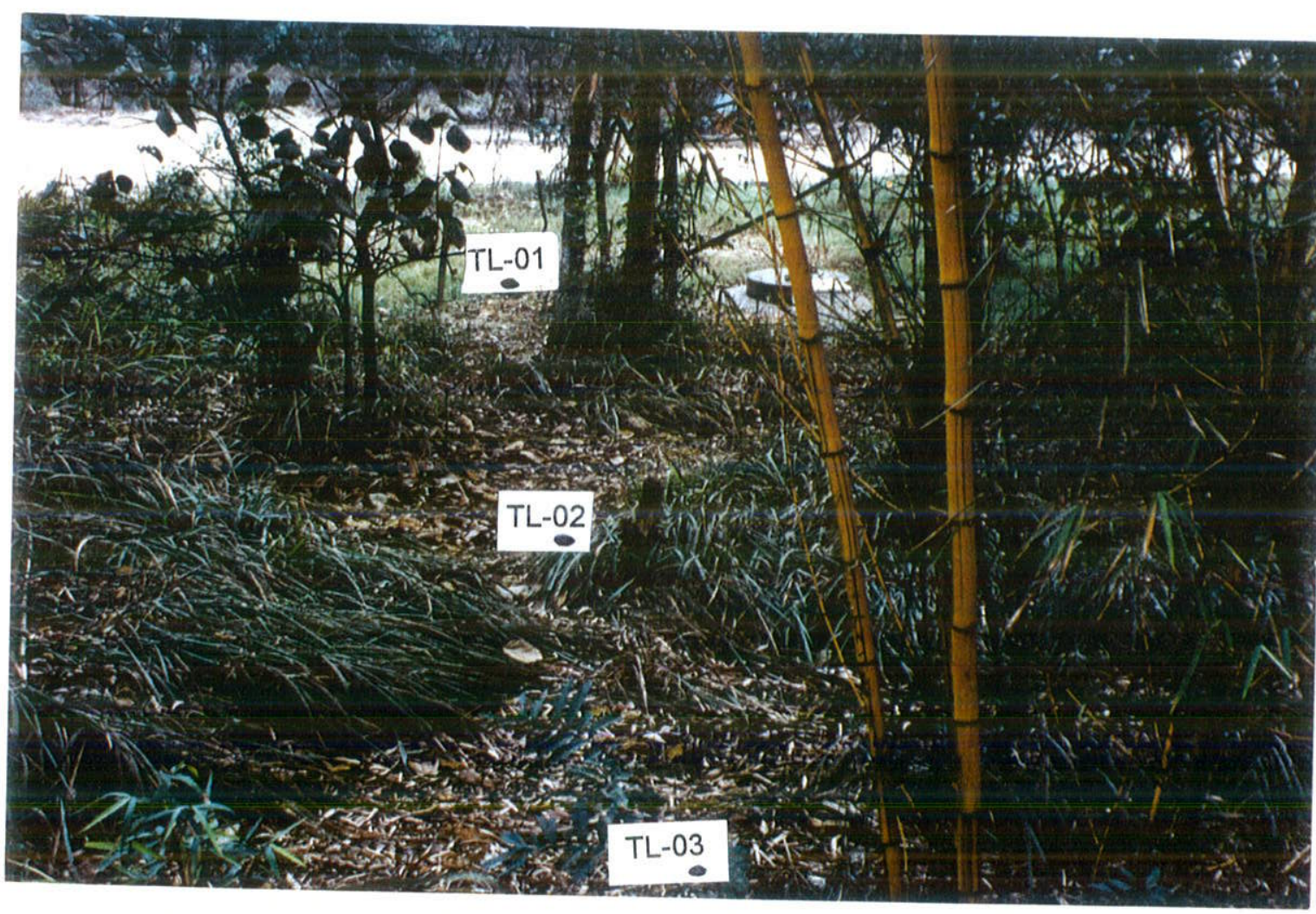

Fotografia 5: Localização dos furos TL-01, TL-02 e TL-03. À direita do furo TL-01, poço de monitoramento de água (PM). Ao fundo, estrada de servidão da indústria. Foto tirada da barragem da lagoa para jusante. 


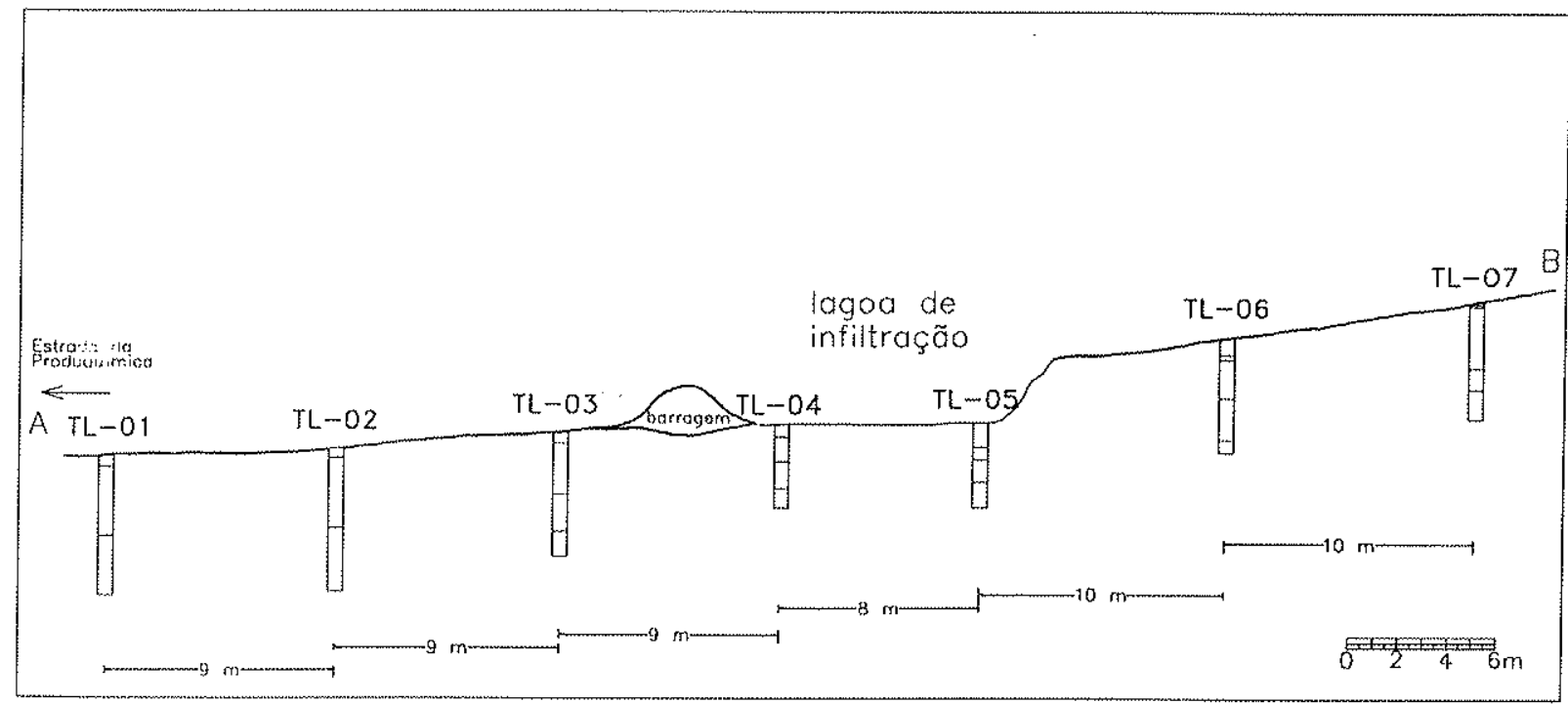

Figura 4: Localização das tradagens TL-01 a TL-07 na seção de estudo, com as respectivas distâncias entre as mesmas.

Cada furo locado tinha como propósito atravessar a camada de argila orgânica, identificada a jusante em afloramento ao longo da margem do Córrego das Jaboticabeiras e, se possível, atingir o nivel do lençol freático, para a obtenção de amostras que permitissem comparar o comportamento geoquímico dos metais pesados nas zonas saturada e não-saturada. Estes furos atingiram profundidade média de 4,5 metros, com o freático sendo atingido por volta dos 3,5 metros na época da tradagem, no mês de setembro (final da estação seca).

\subsubsection{Coleta e seleçâo das amostras para análises}

Os trabahthos de coleta de material visaram amostrar a toposseqüência na sua totalidade. Para isto, foram coletadas amostras de $0,25 \mathrm{em} 0,25 \mathrm{~m}$, sendo estas retiradas diretamente do trado (aproximadamente 350 gramas) e acondicionadas em sacos plásticos, que foram identificados com a seguinte nomenclatura: $n^{\circ}$ Furo trecho.

No Laboratório de Amostras do Departamento de Geologia Geral (DGG) do IG/USP, foi realizada a organização das amostras por furo e por profundidade. Com isto, obteve-se, para cada furo, uma visão geral dos seus níveis, bem como a clara identificação das amostras da camada de argila orgânica, o que possibilitou uma descrição mais detalhada das amostras. A partir destas informações, foi possivel 
elaborar um perfil com a localização das camadas de acordo com as profundidades obtidas na tradagem. Este desenho possibilitou a visualização das camadas na vertente, o que auxiliou na seleção das amostras que seriam encaminhadas para análise. No total, foram coletadas 139 amostras, que foram encaminhadas para análises granulométricas e químicas, de acordo com a Tabela 4, apresentada seguir.

\begin{tabular}{|c|c|c|c|c|c|c|c|c|c|c|}
\hline$n^{\circ}$ furo & $\begin{array}{c}n^{\circ} \text { de } \\
\text { amostras }\end{array}$ & $\begin{array}{c}\text { análise } \\
\text { granul } \\
\text { quant(1) }\end{array}$ & $\begin{array}{l}\text { ancilise } \\
\text { granul } \\
\text { quali (I) }\end{array}$ & $\begin{array}{c}\text { \% de mat. } \\
\text { org. } \\
\text { (5) }\end{array}$ & $\begin{array}{c}D R X \\
(2) \\
\end{array}$ & $\begin{array}{c}\text { análises } \\
\text { químicas } \\
\text { (4) }\end{array}$ & $\begin{array}{c}\text { MEV } \\
\text { (3) } \\
\text { gröos }\end{array}$ & $\begin{array}{l}\text { MEV } \\
\text { (3) } \\
\text { lôminas }\end{array}$ & $\begin{array}{l}\text { análise } \\
\text { micr. } \\
(2) .(4)\end{array}$ & TOTAL \\
\hline TL-01 & 18 & 10 & 10 & 09 & 03 & 09 & & & . & 59 \\
\hline TL-02 & 17 & 10 & 10 & 08 & 04 & 08 & & & - & 57 \\
\hline TL-03 & 22 & 15 & 15 & 09 & 11 & 09 & 08 & 04 & 10 & 99 \\
\hline TL-04 & 15 & 10 & 10 & 07 & 04 & 07 & & & - & 53 \\
\hline TL-05 & 16 & 11 & 11 & 09 & 07 & 09 & 17 & 04 & 21 & 97 \\
\hline TL-06 & 26 & 09 & 09 & 10 & 03 & 10 & & & - & 67 \\
\hline TL-07 & 25 & 07 & 07 & 07 & 02 & 07 & & & - & 55 \\
\hline TOTAL & 139 & 72 & 72 & $59+9(6)$ & 34 & $59+9(6)$ & 25 & 08 & 31 & 491 \\
\hline
\end{tabular}

11) Amostras encaminhadas para o Laboratório de Geoquímica-DGG/IG/USP

(2) Amostras encaminhadas para o NUPEGEL IAG/USP

(3) Amostras encaminhadas para o Laboratório de Geoquímica-DPM/IG/UNESP

(4) Amostras encaminhadas para o Laboratório de Análises Micromorfológicas - DGG/IG/USP

(5) Amostras encaminhadas ao Laboratório de Análises Sedimentológicas do IG/SMA

(6) amostras "dublês", para controle de qualidade das análises

Tabela 4: Número total de amostras coletadas e encaminhadas para análise

\subsection{Metodologia de Laboratório}

\subsubsection{Análises Granulométricas}

Para as análises granulométricas, foram selecionadas amostras localizadas ao longo do perfil, dando ênfase para três situações principais: (1) acima da camada de argila cinza-escura; (2) na camada de argila cinza-escura, e (3) abaixo da camada de argila cinza-escura.

As amostras foram secas à temperatura ambiente, desagregadas e tiveram suas frações maiores que $2 \mathrm{~mm}$ eliminadas por peneiramento, acondicionadas em sacos com cerca de 50 gramas de amostra, e posteriormente encaminhadas para o Laboratório de Geoquímica do Departamento de Geologia Geral - DGG/IG/USP. 
Foram determinadas, para cada amostra, as porcentagens de argila, silte fino, silte grosso, areia fina, areia grossa e leor de umidade.

O objetivo destas análises foi obter uma caracterização granulométrica destes horizontes, para futura correlação com suas características químicas e micromorfológicas, buscando obter informações quanto do seu potencial de retenção de metais pesados.

\subsubsection{Dosagem do conteúdo de matéria orgânica}

A dosagem do conteúdo de matéria orgânica foi realizada no Laboratório de Análises Sedimentológicas do Instituto Geológico, SMA. Foram analisadas 68 amostras, das quais 09 eram amostras "dublês", que serviram para determinar a eficácia do processo.

Dentre os métodos conhecidos para determinaçäo do conteúdo de matéria orgânica em solo (VERDADE, 1954; VERLENGIA \& GARGANTINI, 1968), foi empregada a metodologia proposta por NAVARRA et al (1980) que utiliza água oxigenada para ataque da matéria orgânica.

As amostras foram secas em estufa, a seguir, pesada $1 \mathrm{~g}$ de amostra, que foi colocada em um béquer e atacada com solução de água oxigenada a $10 \%$ (aproximadamente $80 \mathrm{ml}$ no total, adicionada aos poucos). A seguir, as amostras foram colocadas em chapa quente a aproximadamente $50-60^{\circ} \mathrm{C}$, onde foi se adicionando a mistura de água oxigenada até que houvesse o cessamento da reação da mesma com a matéria orgânica (evidenciada pela ausência de bolhas).

Devido ao fato do material ter sido moído a 200 mesh, o processo foi mais lento: as amostras mais claras demoraram de 1 a 2 dias para dissolverem a matéria orgânica; as mais escuras, de 4 a 5 dias para cessar a reação. Após a secagem da solução, a amostra foi colocada em estufa, e pesada novamente, obtendo-se a diferença do material retirado, e calculando-se a porcentagem do material perdido (matéria orgânica). 


\subsubsection{Difratometria de Raio X (DRX):}

Para estas análises, foram selecionadas amostras pertencentes à camada de argila cinza-escura.

As amostras foram secas em temperatura ambiente, moídas em moinho de ágata até obter-se granulometria inferior a 200 mesh (método do pó). Posteriormente, foram encaminhadas para o Núcleo de Pesquisa em Geoquímica e Geofísica da Litosfera - NUPEGEL do Instituto Astronômico e Geofísico - IAG da USP, onde foram analisadas.

No Laboratório de Difratometria de Raio X (DRX) do NUPEGEL, as 28 amostras foram preparadas para a análise. O material foi prensado em lâminas e submetido à análise por DRX, em um difratômetro TW3710 da marca Philips. Este equipamento encontra-se acoplado a um computador que possui o Software APD, através do qual foi realizado o tratamento preliminar de identificação dos principais minerais presentes, e a plotagem dos respectivos diagramas.

\subsubsection{Análises Químicas:}

Para as análises químicas, foram selecionadas amostras nos diferentes poços executados ao longo da toposseqüencia, sendo estas localizadas acima, dentro e abaixo da camada de argila orgânica. Foram selecionadas um total de 59 amostras, além de 09 para controle ("dublês").

As amostras foram secas à temperatura ambiente, moídas em moinho de ágata a granulometria inferior a 200 mesh, e acondicionadas em frasco com cerca de 15 gramas de amostras. Posteriormente, foram encaminhadas para o Departamento de Petrologia e Metalogenia do Instituto de Geociências da UNESP. em Rio Claro-SP, para análise dos metais CU, Zn, Pb, Cd, Mo e Mn por ICP-AES.

Fol utilizado o método de abertura total, com ácidos fortes a quente, com o objetivo de determinar o conteúdo total destes metais no solo. A metodologia empregada no Laboratório de Geoquímica do IG/UNESP para preparação das amostras para análise química pode ser descrita nas seguintes etapas: 
1. Pesagem de 0,25 gramas de amostra em balança de precisão (Marca METLER AJ100, com vidro "capela"- e precisão de 4 casas decimais), e acondicionamento das mesmas em cadinhos de teflon, previamente descontaminados (fervidos em ácido nítrico).

2. Atcique com ácido clorídrico (HCl) $1 \mathrm{M}(7$ a $10 \mathrm{ml}$ ), para acelerar a decomposição da matéria orgânica. Banho-maria até evaporação do $\mathrm{HCl}$.

3. Adição de ácido fluorídrico (HF) até decomposição total da amostra (pernoite: 12 horas).

4. Nas amostras onde, após esta etapa, verificou-se a presença de resíduo no fundo do cadinho, foi efetuada uma filtragem; a amostra filtrada foi posteriormente acondicionada em um balão volumétrico, sendo o volume restante (ałé $50 \mathrm{ml}$ ) preenchido com $\mathrm{HCl}$ 1,75M. As amostras que não apresentavam resíduo foram diretamente acondicionadas no balão volumétrico, sendo o volume restante 150 $\mathrm{ml}$ ), preenchido com $\mathrm{HCl}$ 1,75 M.

5. Secagem do resíduo do filtro, que foi posteriormente guardado.

6. Análise por Espectrometria de Emissão Atômica com Plasma Acoplado indutivamente (ICP..EAS).

As amostras 3J e 25J foram processadas duas vezes para verificar se o resíduo proveniente da filtragem ainda continha metal pesado ou não. Em um dos jogos, procedeu-se à metodologia normal. Nas amostras "dublês", foi elaborada a seguinte seqüência:

7. O resíduo do filtro foi acondicionado em cadinho com fundente, sendo posteriormente colocado em estufa até a fusão total do material. A seguir, foi adicionado ácido HF até a dissolução total da amostra, sendo esta solução adicionada do restante da amostra. A seguir, foi efefuada a análise por ICP-EAS.

8. Comparação com os resultados das análises das amostras $3 \mathrm{~J}$ e $25 \mathrm{~J}$ elaboradas pelo processo comum (etapas 1 a 6 ).

As amostras "dublês" foram analisadas pelo processo comum e pelo processo de fusão total, para verificar se o resíduo das amostras possuía uma concentração de metais pesados, ou somente matéria orgânica. 
Os resultados obtidos mostraram que o resíduo não continha metal pesado, visto que os erros de leitura se situavam dentro do limite de detecção do aparelho (0,5 - 1\%). Em decorrência do observado, as demais amostras foram processadas somente pela fusão parcial.

De acordo com observações dos técnicos deste laboratório (inf. verbal), quando o ataque químico é realizado em amostras de rocha, há a dissolução completa da amostra, sem resíduos. O resíduo só é encontrado em amostras de solos, e de determinados tipos, geralmente aqueles mais escuros e mais ricos em matéria orgânica. No caso das amostras deste trabalho, o que se observou é que houve uma relação entre a cor da amostra e a quantidade de resíduo: quanto mais escura a amostra, maior a quantidade de residuo no fundo do cadinho.

\subsubsection{Análises Micromorfológicas}

Para coleta do material indeformado, foram escavados um poço e um cachimbo, cujos locais foram escolhidos tomando-se por base os resultados obtidos nas análises químicas e na descrição macroscópica das tradagens iniciais execuladas. Foram utilizados os seguintes critérios:

a. Expressiva concentração de metais pesados; e

b. Presença da camada de argila cinza-escura acima do nivel do lençol freático

Com isto, foram selecionados dois pontos: (1) do lado do furo TL-03, situado abaixo da lagoa de decantação, atingindo a profundidade de 3 metros; (2) ao lado do furo TL-05, localizado dentro da lagoa, sendo que foi executado um poço de 1,80 metros e uma trincheira de 2,10 metros, acima do poço e em continuidade ao seu perfil (cachimbo), totalizando 3,90 metros de perfil vertical (Figura 5).

Para a coleta do material indeformado, utilizaram-se de saboneteiras ("caixa dura") e uma espátula. A coleta foi realizada da base para o topo da parede do poço, para evitar contaminação do material. A saboneteira foi fixada no solo, e suas laterais foram escavadas, sendo o conteúdo da saboneteira retirado intacto e orientado (topo-base), o que possibilitou a preservação de suas características texturais e estruturais. 


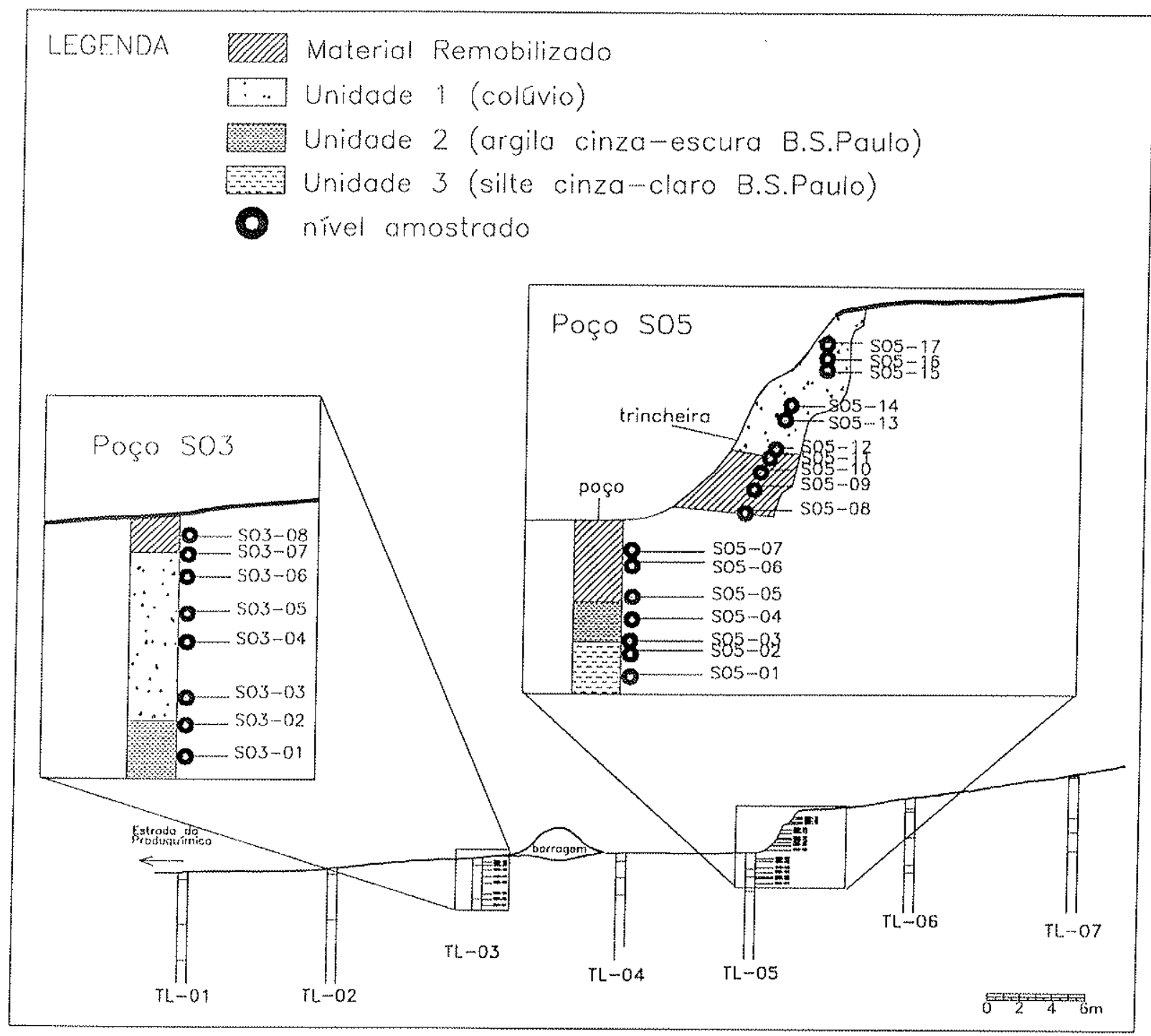

Figura 5: Localização dos perfis dos poços $\mathrm{SO} 3$ e $\mathrm{SO}$, com os respectivos níveis amostrados.

Posteriormente, foi efetuada uma seleção de grãos deste material em lupa microscópica, para serem analisados por Microscópio Eletrônico de Varredura (MEV), no NUPEGEL / IAG. Os materiais amostrados nas saboneteiras foram impregnados no Laboratório de impregnação de Amostras do DGG/IG/USP, e encaminhados para a confecção de lâminas delgadas na Seção de Laminaçāo do IG/USP. As lâminas não foram recobertas com lamínulas, para possibilitar a posterior análise em MEV. 


\section{CARACTERIZAÇÃO DO PERFIL DE ESTUDO}

Nos Anexos 1, 2 e 3 são apresentados, respectivamente, os resullados das análises granulométricas, conteúdo de matéria orgânica e análises químicas por ICPAES dos diferentes perfis da seção de estudo. No Anexo 4 encontra-se a descrição macroscópica dos níveis dos 7 perfis, realizada no local da amostragem, e, posteriormente, no Laboratório de Preparação de Amostras do DGG/IG/USP.

A Figura 6 exibe a disposição espacial das unidades na seção de estudo, de acordo com os dados obtidos através dos perfis das sondagens e dos poços elaborados na mesma. A seção pode ser dividida em quatro unidades, sendo que destas, apenas as três primeiras serão objeto de detalhamento nesta dissertação:

- Unidade 1: argila de coloração alaranjada, correspondente ao material coluvionar;

- Unidade 2: argila de coloração cinza escura, correspondente aos sedimentos da Bacia de São Paulo;

- Unidade 3: silte de coloração cinza-clara, correspondente aos sedimentos da Bacia de São Paulo;

- Unidade 4: embasamento gnáissico (alterita), correspondente às rochas metamórficas pertencentes ao Complexo Embu.

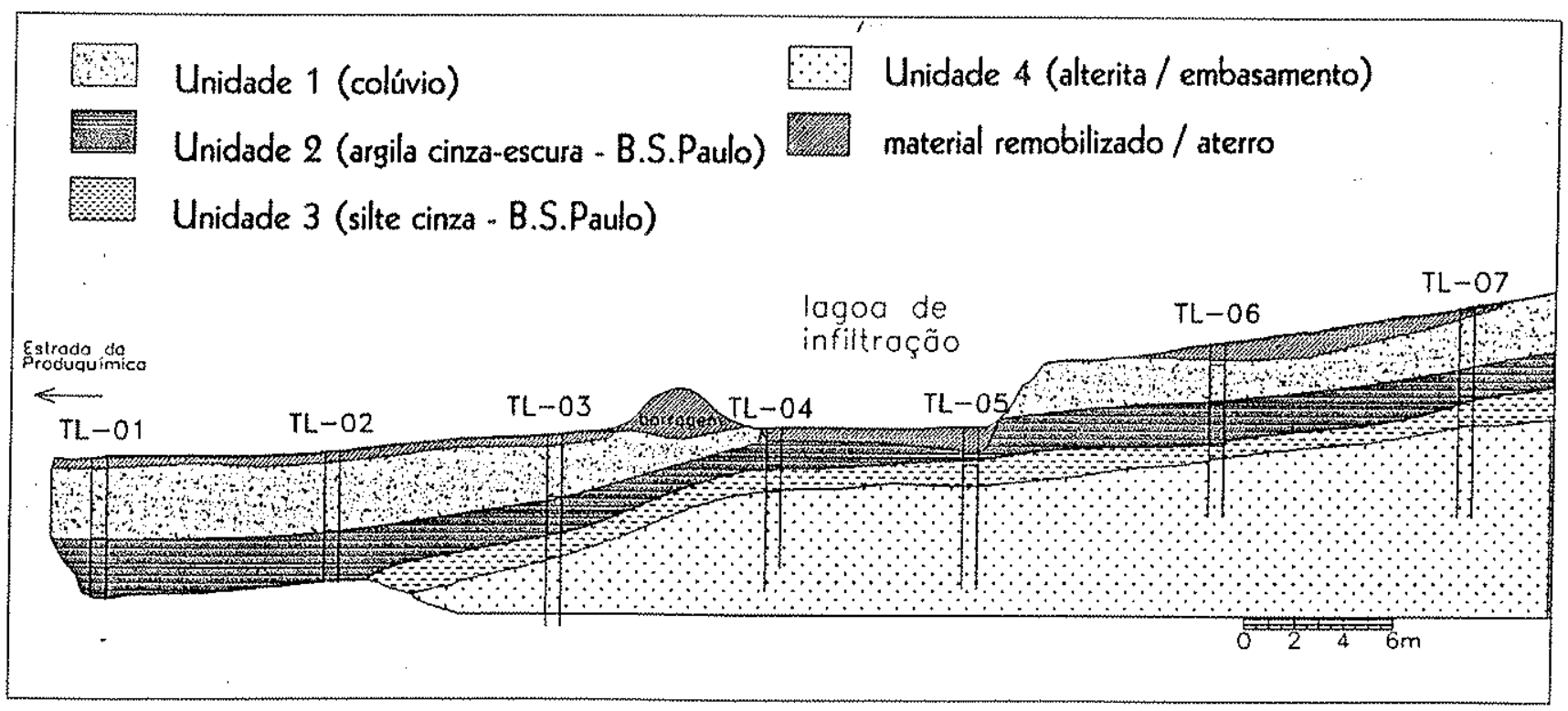

Figura 6: Organização espacial das unidades na seção de estudo. 
As três unidades descritas podem ser visualizadas na Fotografia 6, em uma seqüência de material retirado através do trado manual. O primeiro plano é dado pela base e o plano de fundo, pelo topo da seqüência.

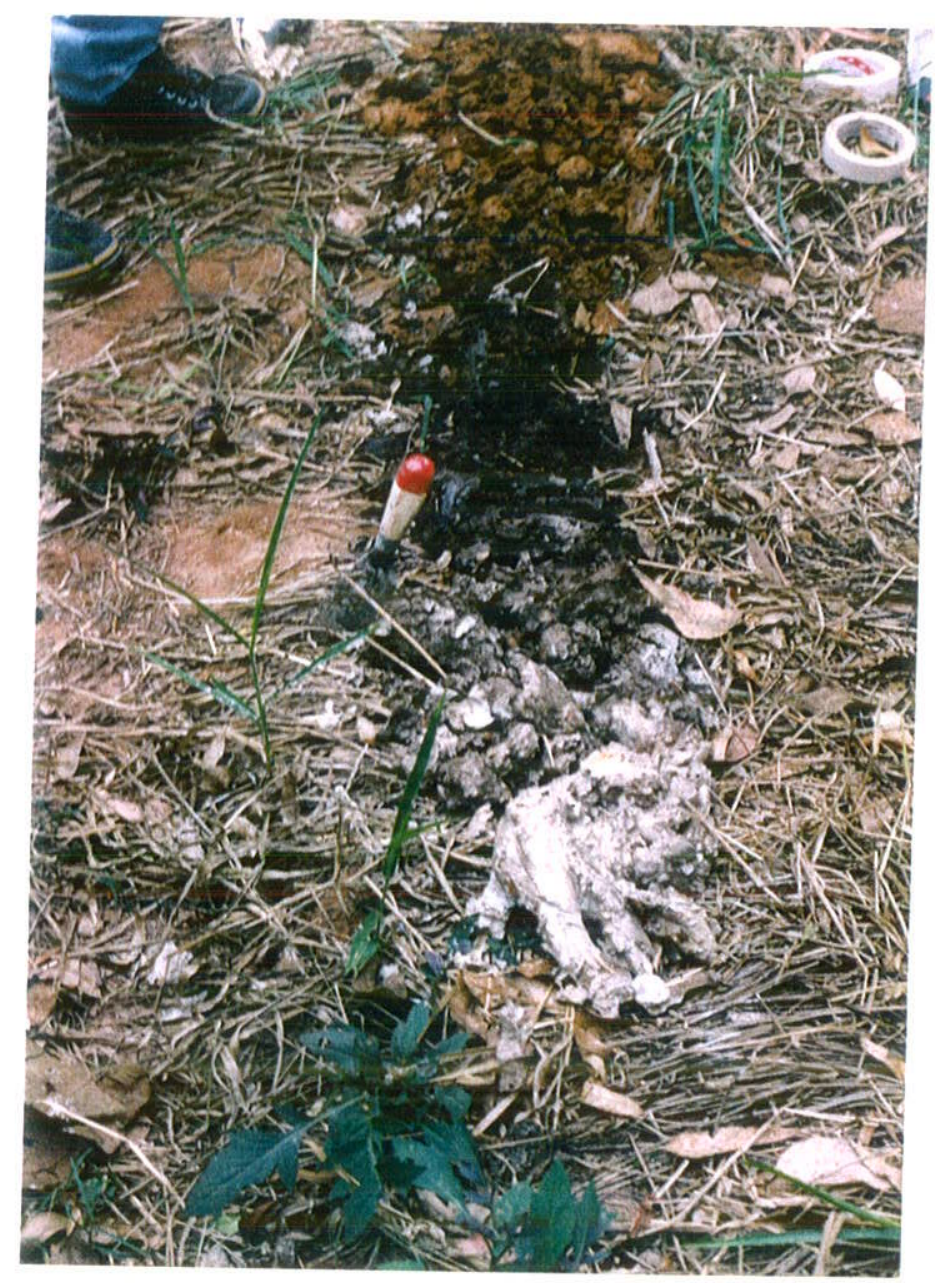

Fotografia 6: Unidades 1 (coloração alaranjada), 2 (coloração cinza-escura) e 3 (coloração cinza-clara), durante amostragem do perfil TL-03.

Para a classificação textural dos solos, utilizou-se o Diagrama proposto pelo serviço de Conservação de Solos do departamento de Agricultura dos Estados Unidos (Figura 7), que é amplamente utilizado para classificação de solos no Brasil (OLIVEIRA et al, 1992; CATI/SAA, 1994).

De acordo com esta classificação, as classes texturais do solo encontram-se divididas em três grandes grupos: areias, francos e argilas, sendo que dentro de cada grupo, existem subdivisões de classes específicas, totalizando 12 subclasses. As descrições destes grupos, apresentadas a seguir, foram compiladas de BRADY (1989). 


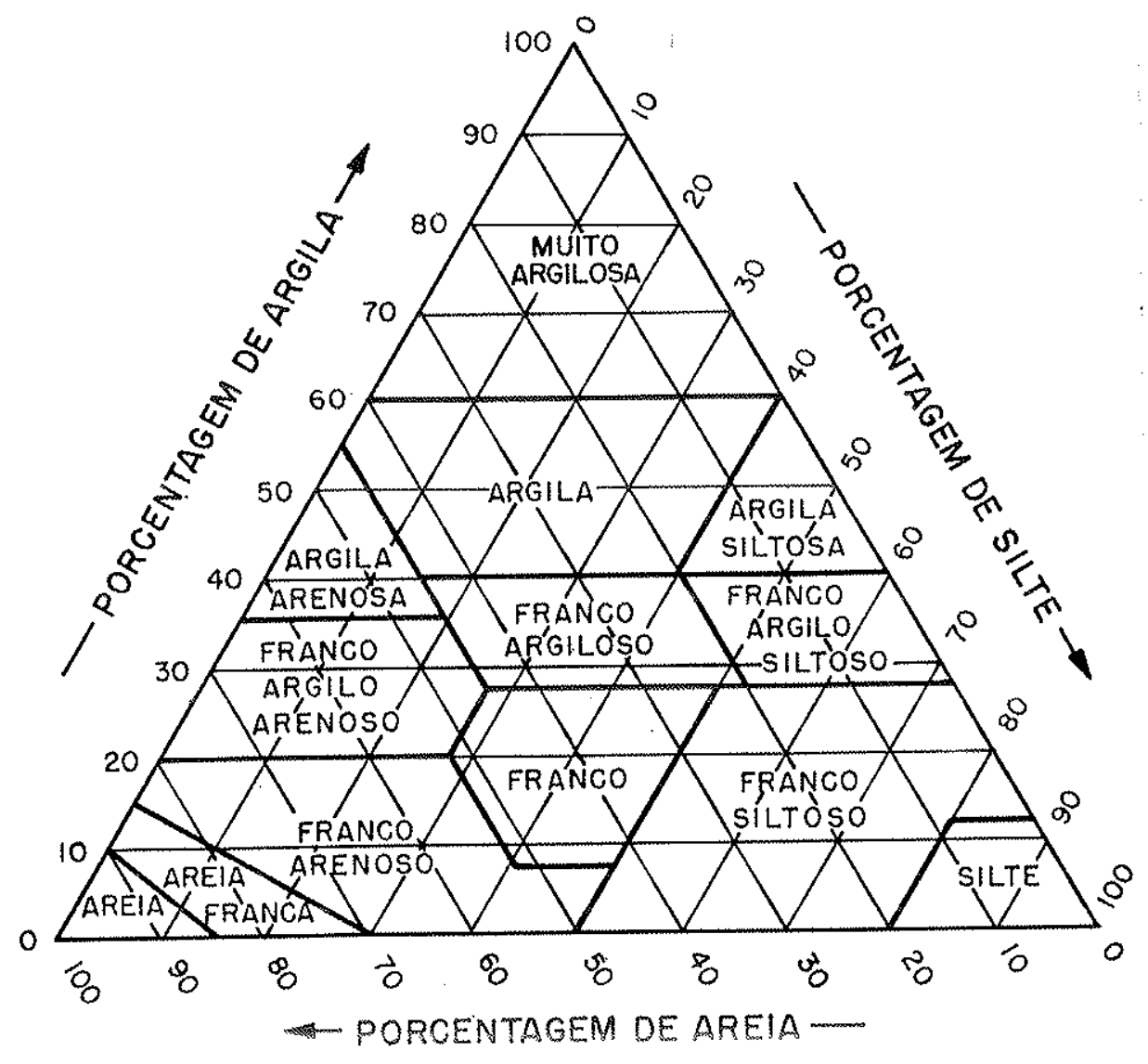

Figura 7: Diagrama de Classificação Textural de Solos segundo o Serviço de Conservação de Solos do Departamento de Agricultura dos Estados Unidos (extraido de OLIVEIRA et al, 1992).

\section{GRUPO DAS AREIAS}

Consideram pertencentes ao grupo das areias solos cujas frações granulométricas de areia totalizem $70 \%$ e as frações granulométricas de argila $15 \%$ ou menos do peso do material. Possui duas classes texturais específicas: areia e areia franca.

\section{GRUPO DAS ARGILAS}

Para ser designado como argila, um solo deverá conter pelo menos $35 \%$ da fração granulométrica de argila. Nestes tipos de solos, as características da fração 
granulométrica de argila são eminentemente dominantes e as classes designam-se como argila, argila arenosa e argila siltosa e multo argilosa.

\section{GRUPO DOS FRANCOS}

Embora mais complexo, pode-se definir um solo franco ideal como uma mistura de partículas de areia, silte e argila. De acordo com a predominância de uma ou outra granulometria, este solo poderá ser subdividido em franco, franco-arenoso, franco-siltoso, franco-argilo-siltoso, franco-argilo-arenoso e franco-argiloso.

Considera-se silte o solo com porcentagem de silte acima de $80 \%$, com menos de $12 \%$ de argila. De acordo com o autor, ele não é considerado com um grupo isolado.

Para a descrição macroscópica dos niveis, foram utilizadas descriçōes efefuadas durante a amostragem em campo e posterior descrição no laboratório.

Para a identificação microscópica das unidades, foram confeccionadas seções delgadas das amostras coletadas nos poços, previamente endurecidas para este fim.

Alguns grãos provenientes destas amostras também foram selecionados para a análise em MEV, com o objetivo de verificar a sua morfologia, bem como de identificar alguns metais pesados através do processo de varredura com elétrons retrodifusos.

Ém uma segunda etapa de análises por MEV, as seções delgadas foram analisadas em pontos pré-determinados, com o objetivo de se obter informações a respeito da composição da matriz e grãos, bem como identificar a presença de MP e a sua relação com microestruturas presentes na amostra.

\subsection{Unidade 1: Argila de coloração alaranjada (colúvio)}

\subsubsection{Caracterização Macroscópica}

Esta unidade corresponde à camada superior de sedimento do perfil de estudo. Caracteriza-se por um material argiloso, muito plástico, de coloração 
alaranjada, atingindo até 2,5 metros de profundidade no perfil, com exceção dos furos bealizados dentro da lagoa (TL-04 e TL-05), onde encontra-se praticamente ausente, devido à escavação de material para construção da lagoa. Nos furos TL-0l e TL-02, principalmente, nota-se um aumento da porcentagem de quartzo em direção à base da camada. Torna-se escurecido em direção à base, apresentando um contato gradual com a camada inferior. Observações realizadas nas paredes dos poços escavados no local permitem a visualização do seu acamamento paralelo ao declive do terreno (aproximadamente $8^{\circ}$ ). Esta unidade está relacionada ao material coluvionar que aflora na área.

Na Figura 8 encontra-se apresentada a distribuição das porcentagens de areia, argila e silte dos seus diversos niveis, de acordo com as análises granulométricas obtidas ao longo do perfil. De acordo com os resultados obtidos no Diagrama de Classificação Textural de Solos (CATI/SAA, 1994), esta Unidade pode ser classificada como de textura argilosa a franco-argilo-arenosa.

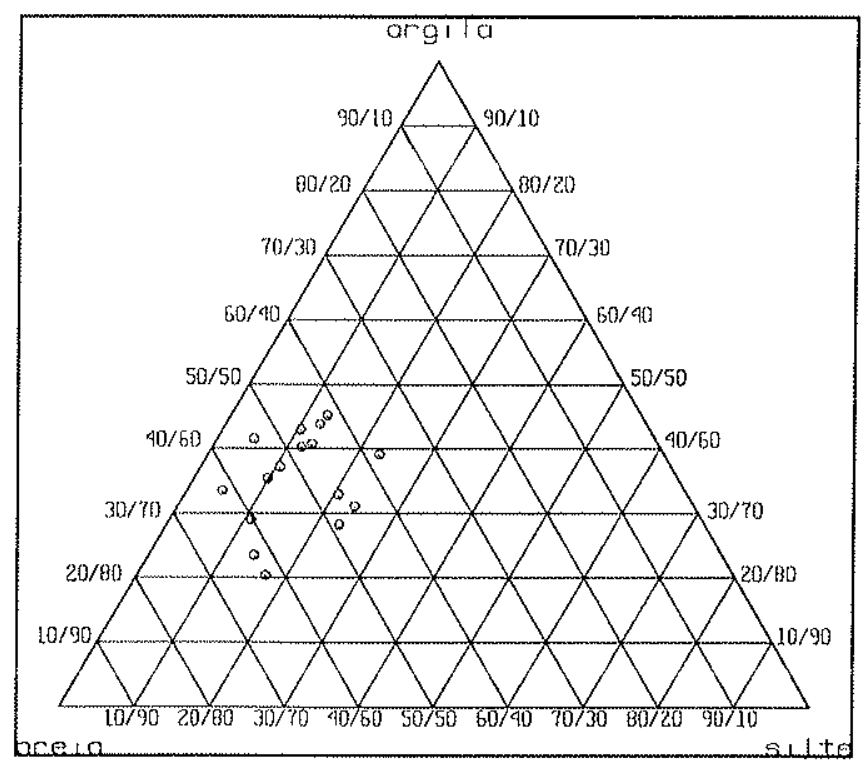

Figura 8 : Distribuição das porcentagens de areia, argila e silte de amostras da Unidade $1 \mathrm{em}$ diagrama triangular de classificação textural de solos, de acordo com CATI/SAA (1994).

Com relação ao conteúdo de matéria orgânica nesta unidade, foram detectados valores de 1 a $4 \%$. Um único valor anômalo de $5 \%$ foi determinado no furo TL-01, na profundidade de 0,75 a $1,00 \mathrm{~m}$. 


\subsubsection{Caracterização Microscópica}

Descrições de lâminas peirográficas pertencentes a esta unidade permitem a identificação de minerais primários constituintes representados predominantemente por quartzo, sendo observados, secundariamente, turmalina e muscovita.

O quartzo se apresenta, em sua maioria, com extinção ondulante (quartzo metamórfico), sendo que alguns se encontram com inclusões de rutilo (filetes). Alguns grãos apresentam-se fraturados, sendo que estas fraturas estão preenchidas por hidróxido de $\mathrm{Fe}$, como pode ser observado nas Fotomicrografias 1 e 2 da amostra SO3-03B.

Os minerais secundários são representados por material prateado (provável caulinita), produto da alteração das micas (muscovitas). Na maioria das vezes elas se encontram com suas clivagens preenchidas por hidróxido de $\mathrm{Fe}$ (goethita), como pode ser observado nas Fotomicrografias 3 e 4 da amostra SO3-03B.

O plasma presente constitui-se de diferentes argilominerais (com predomínio de caulinita) e hidróxidos de ferro e manganês (goethita e amorfos), que apresentam coloração marrom-alaranjada com luz natural, e com luz polarizada, coloração marrom escuro a preto com vários pontos de birrefringência alta (argilominerais) . Neste plasma, é possivel observar a formação de nódulos goethíticos, com vazios preenchidos por hidróxido de Al (gibbsita), que se apresentam com coloração esbranquiçada em luz polarizada, como pode ser observado nas Fotomicrografias 5 e 6 da amostra SO5-17B.

Nesta unidade, também é possivel observar restos de matéria orgânica pseudomorfisada e mineralizada, como exibido pela Fotomicrografia 7 da amostra SO3-06B. 
(1)

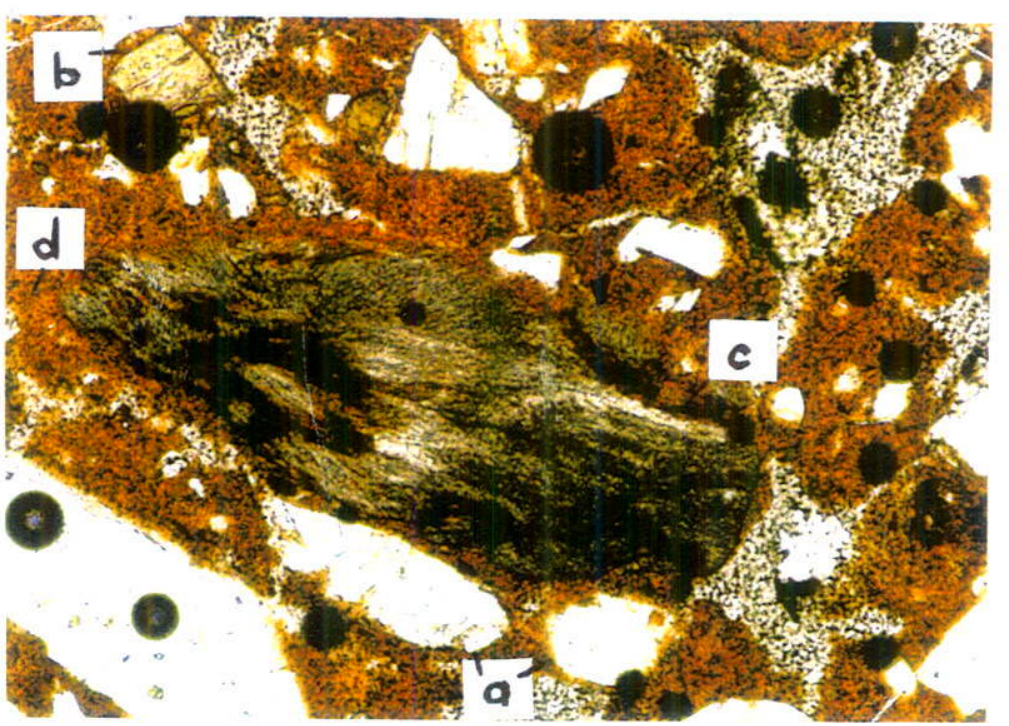

$(2)$

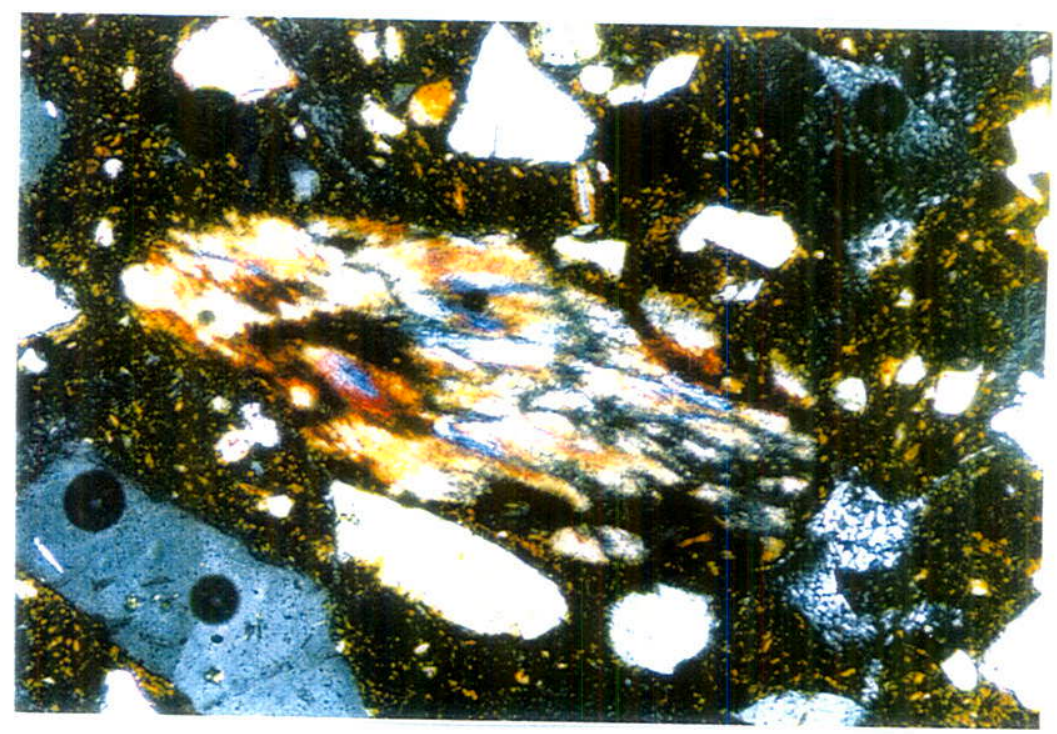

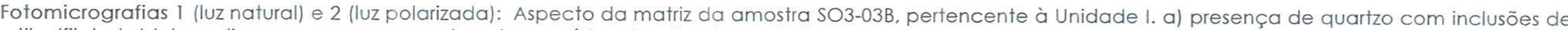

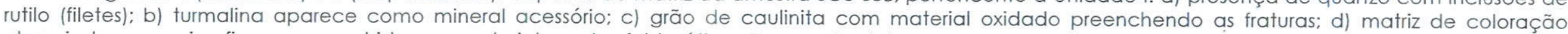
alaranjada, com microfissuras preenchidas por material quartzo-feldspático. Campo das fotos: 4:2 mm X 2,8 mm (objetiva 3.2; abertura 3,2:1).

(3)

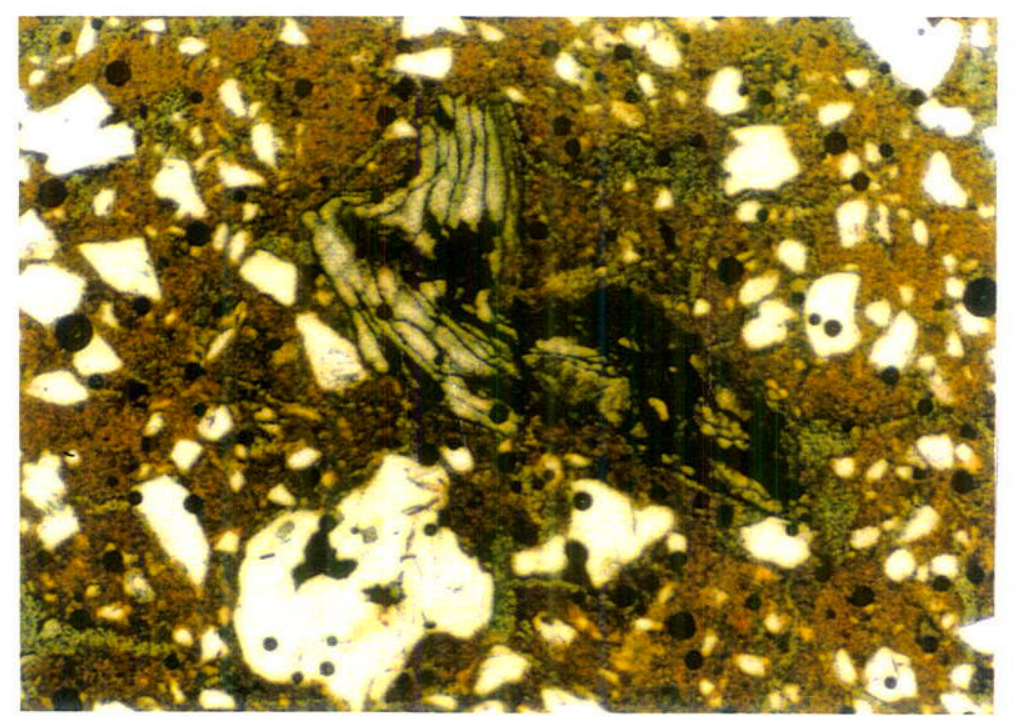

(4)

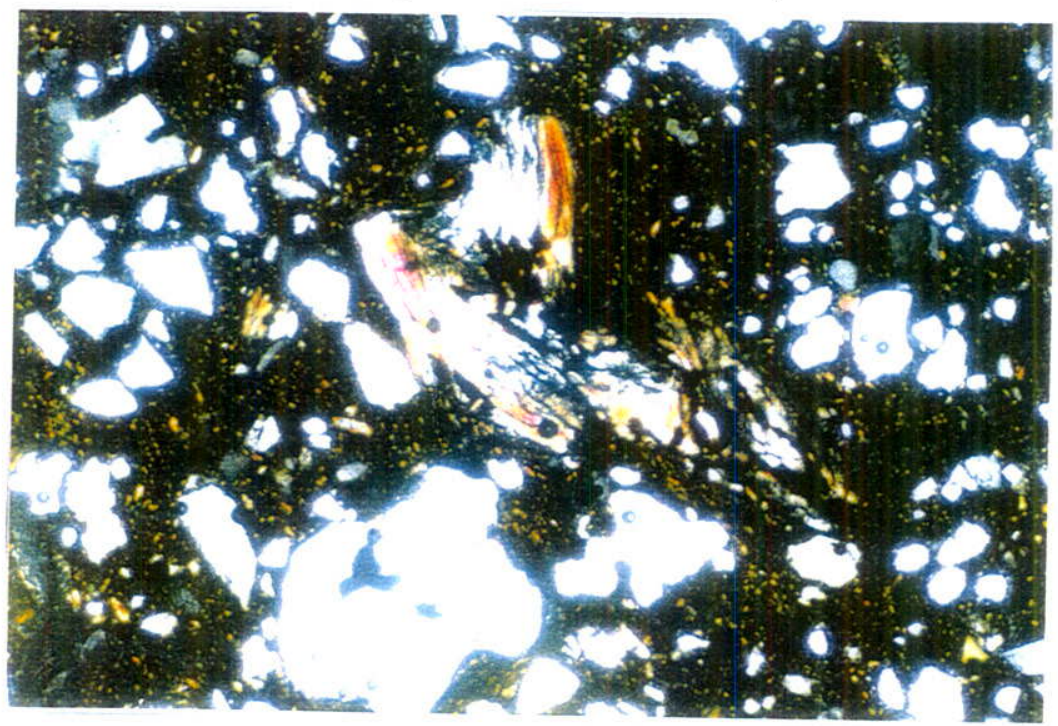

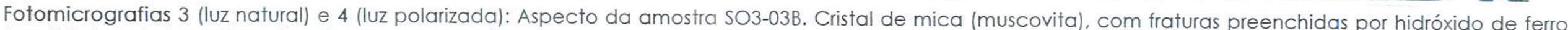

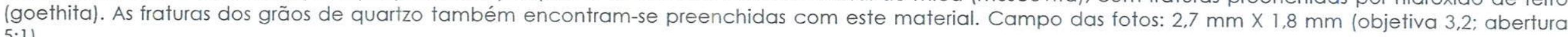
$5: 1)$. 
(5)

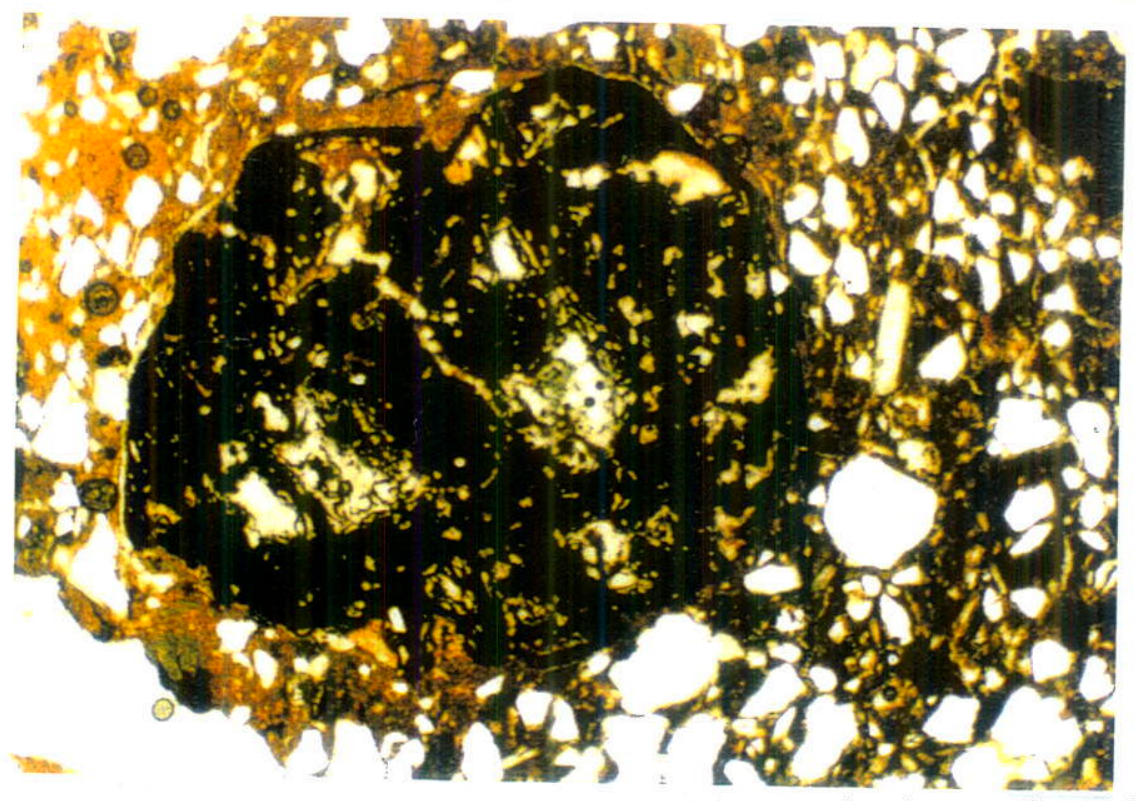

(6)

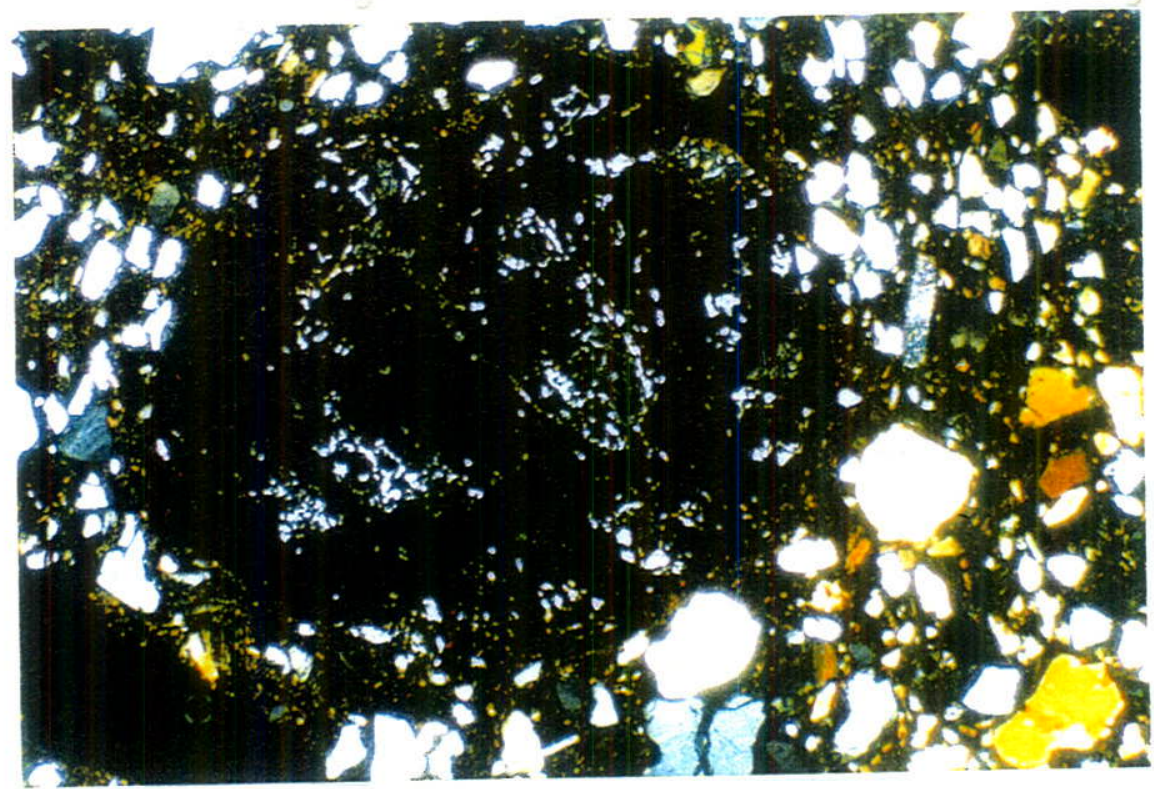

Eotomicrografias 5 (luz natural) e 6 (luz polarizada): Aspecto da amostra SO5-17B. Nódulo de hidróxido de ferro (goethita) com vazios preenchidos por hidróxido de alumínio (gibbsita), que se apresentam com coloração esbranquiçada com luz polarizada. Campo das fotos: 5,2mm $\times 3,7 \mathrm{~mm}$ (objetiva 1,6; abertura 5:1).

(7)

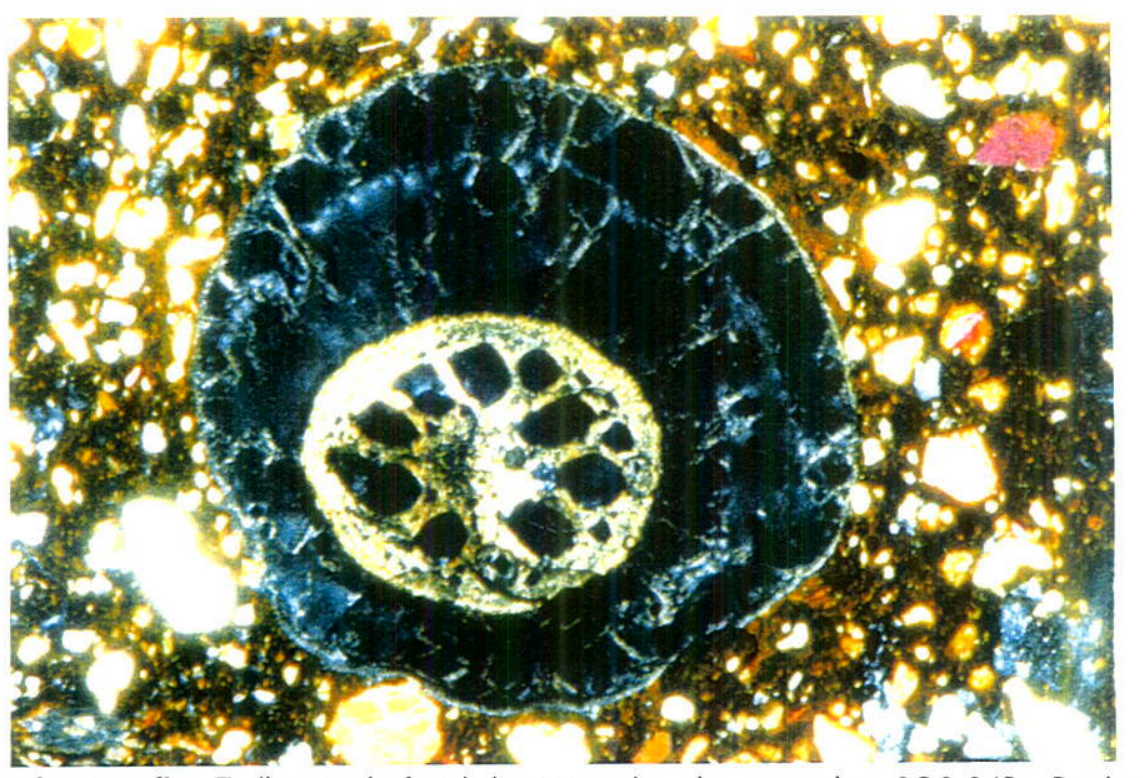

Fotomicrografia 7 (luz polarizada): Aspecto da amostra SO3-06B. Restos de matéria orgânica (raízes de planta) pseudomorfisada e mineralizada. Campo do foto: $5,2 \mathrm{~mm} \times 3,7 \mathrm{~mm}$ (objetiva 1,6; abertura 5:1) 


\subsubsection{Deierminações em MEV}

\section{1 .3 .1 . Fragmentos}

Nesta etapa, foram submetidos à análise por MEV fragmentos do material coletado dos poços $\mathrm{SO} 3$ e $\mathrm{SO} 5$, de dimensöes entre 4 e $8 \mathrm{~mm}$.

O material clástico encontra-se representado pelo quartzo, que é encontrado freqüentemente por toda a amostra. Alguns grãos se encontram recobertos por material rico em Al e Fe. Em alguns casos, é possível observar feições de dissolução nas suas paredes (Imagem 1, Figura 9).
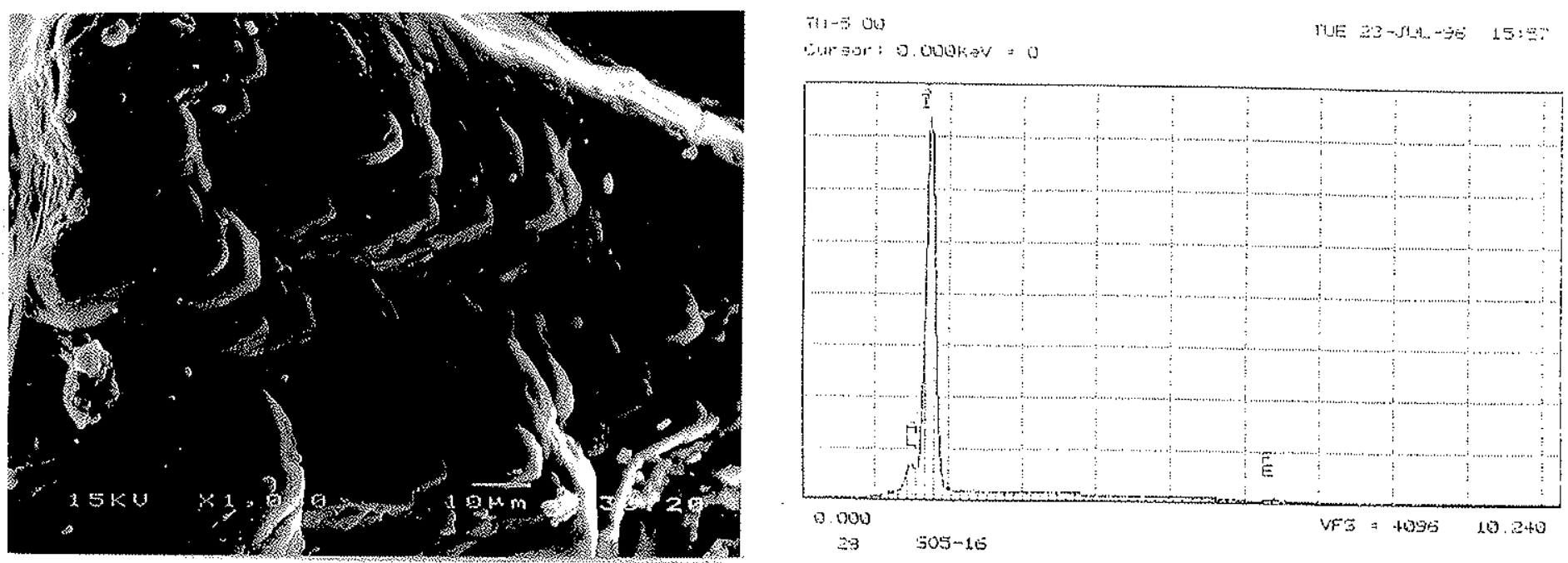

Imagem 1: Morfologia de grão de solo da amostra Figura 9: Diagrama Espectral Químico (EDS) da imagem SO5-16 em MEV: feição de dissolução de gräos de 1 , com análise qualitativa apresentada em espectro.. quartzo (aumento $1000 \mathrm{X}$ ).

A matriz é composta essencialmente por Fe, Al e Si, sendo que em alguns locais encontra-se associada com $K$ e Ti. Algumas vezes, apresenta aspecto pseudobotrioidal (Imagem 2, Figura 10).

Nesta unidade, ocorrem microcavidades nas quais se observa a presença de material reprecipitado (caulinita, às vezes goethita, etc.), como no exemplo da amostra SO5-13, onde observa-se a precipitação de caulinita em uma de suas microcavidades (Imagem 3, Figura 11). 

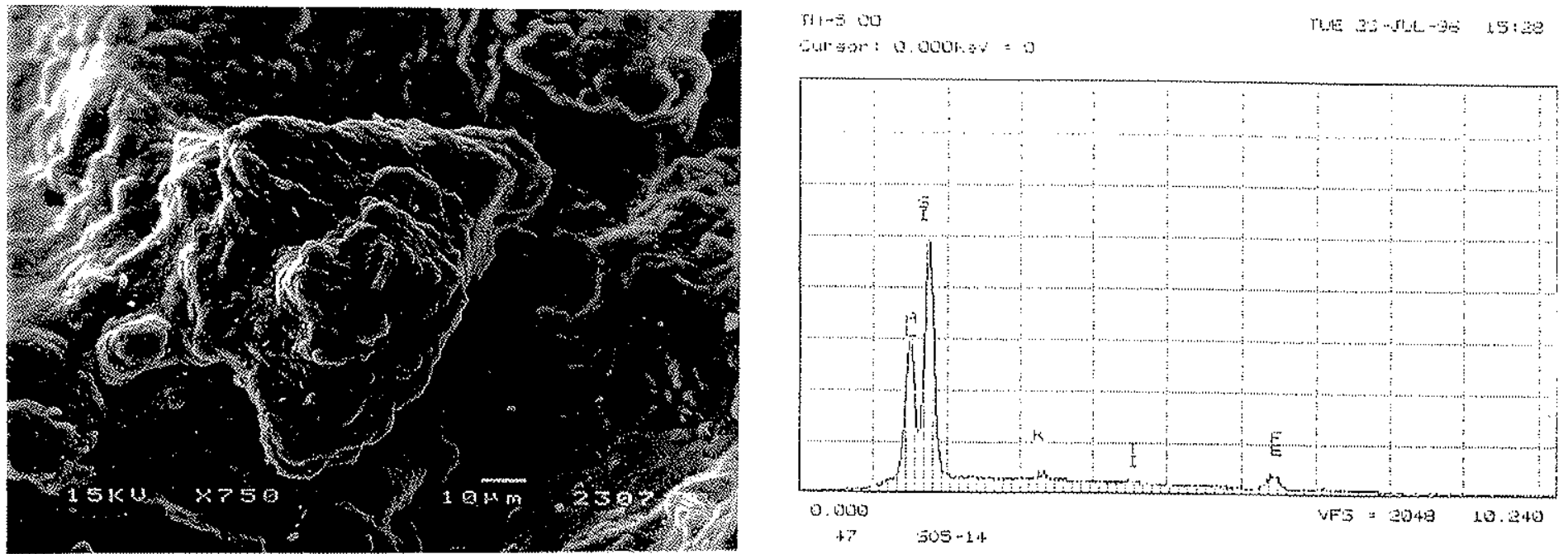

Imagem 2: Morfologia de grão de solo em MEV: Figura 10: Diagrama Espectral Quírnico (EDS)EDS da aspecto da matriz da amostra SO5-14, de imagem 2, com análise qualitativa apresentada em composição essencialmente caulinítica faumento espectro.

$750 \times)$.
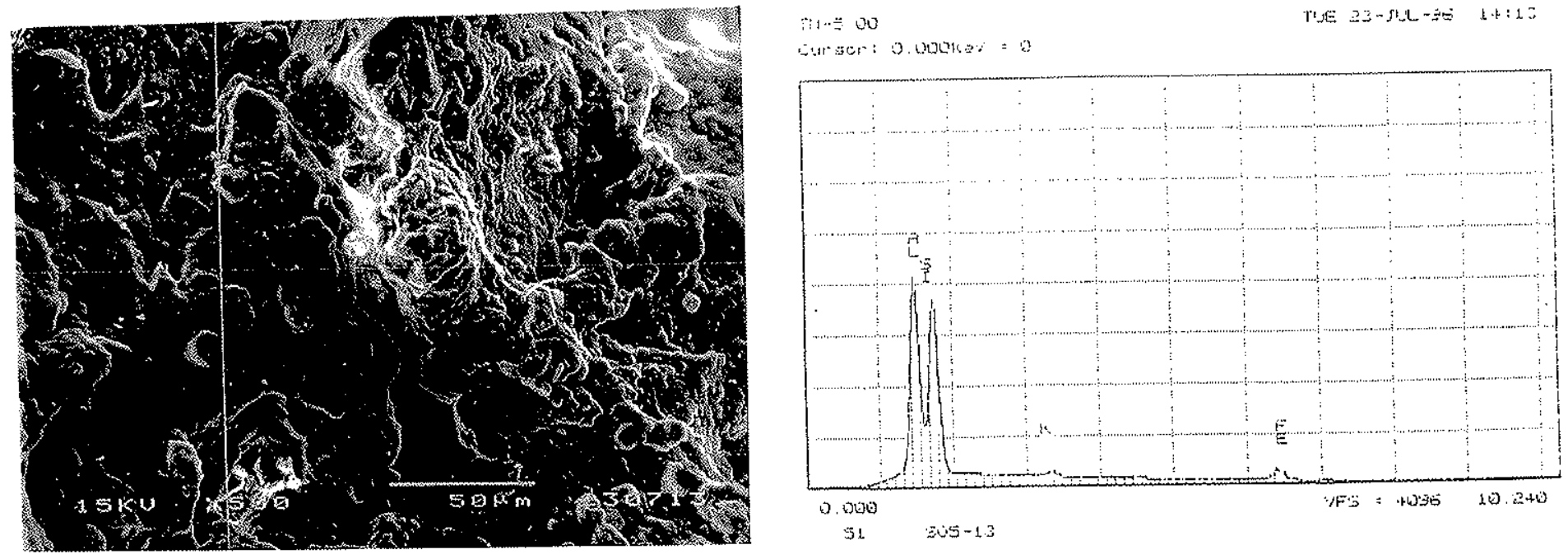

Imagem 3: Morfologia de grão de solo em MEV: Figura 11: Diagrama Espectral Químico (EDS) da imagern aspecto do material precipitado em uma das microcavidades da amostra so5-13. Composição essencialmente caulinítica (aumento 500X). 
Em alguns locais, é possível observar a pseudomorfose de fragmentos de carvão por hidróxidos e óxidos de Fe e Mn, como no exemplo da amostra SO5-16 (Imagem 4, Figura 12). Alguns nódulos de Fe e Ti são observados associados à este tipo de material (Imagem 5, Figura 13).

Com exceção do manganês, que pode fazer parte da composição natural do solo, visto que está sempre associado à matriz e raramente aos grãos de minerais, não foi observada a presença de nenhum outro metal pesado nos grãos desta unidade.
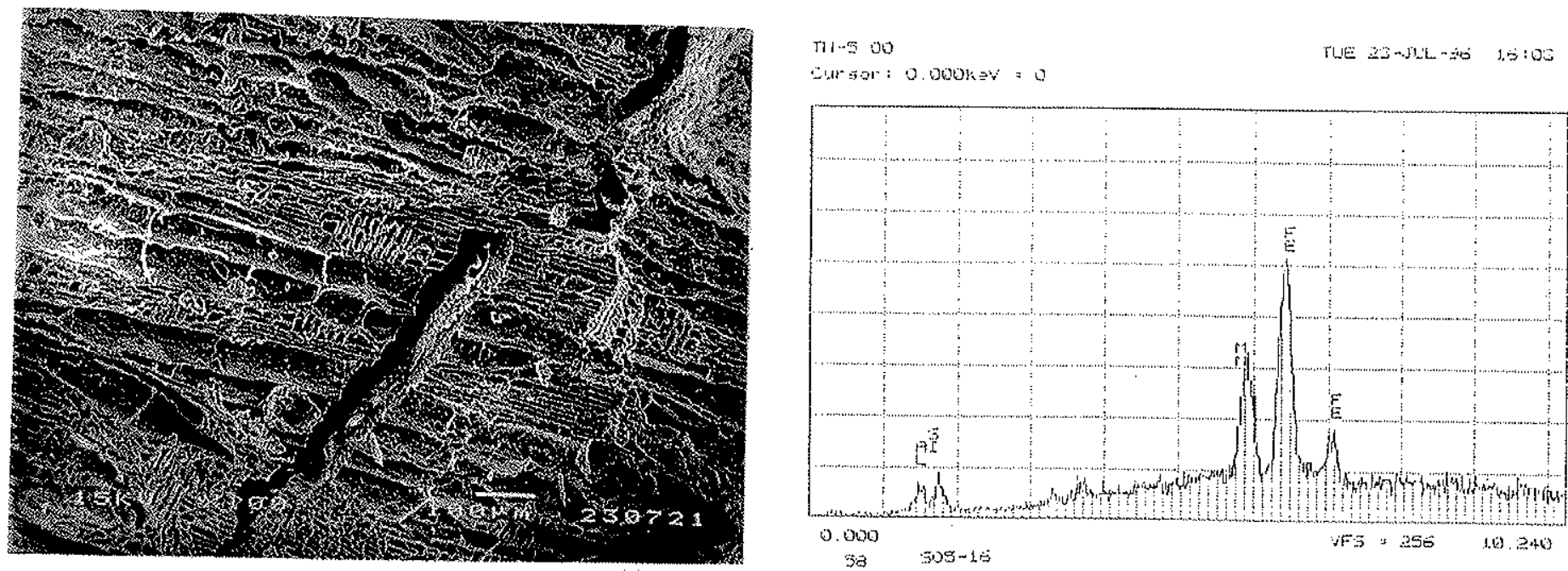

Imagem 4: Morfologia de grão de solo da amostra Figura 12: Diagrama Espectral Químico (EDS) da imagem SO5-16 em MEV: grão de carvão psevdomorfisado 4, com análise qualitativa apresentada em espectro. por Fe e Mn (aumento 100X).
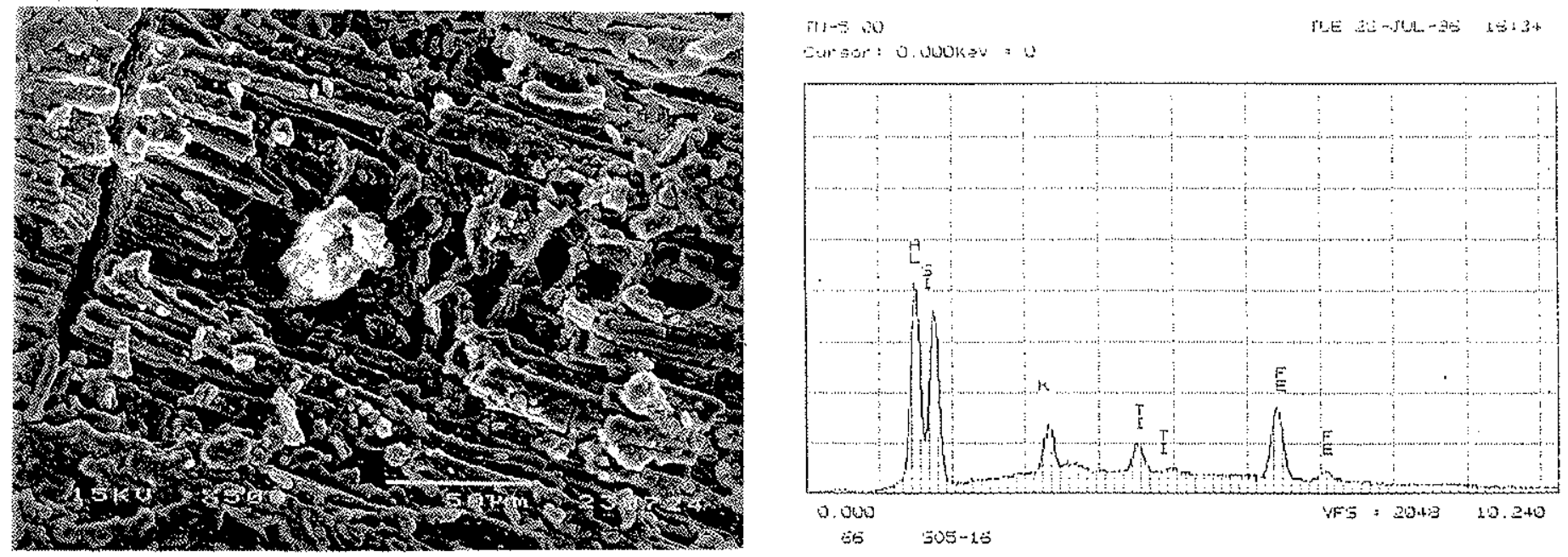

Imagem 5: Detalhe da Imagem 4. Presença de Figura 13: Diagrama Espectral Químico (EDS) da imagem nódulo de $\mathrm{Fe}$ e $\mathrm{Ti}$ em cavidade do grão de carvão. 5, com análise qualitativa apresentada em espectro. Aumento 500X. 


\subsubsection{Lâminas}

Análises em MEV de läminas pertencentes à esta Unidade identificaram uma grande presença de compostos de Fe, geralmente associados à matriz, na forma de pequenos fragmentos.

Em algumas partes da matriz, este Fe se concentra, formando nódulos de material ferruginoso, onde secundariamente estão associados Si, Al e Ti llmagem 6 , Figura 14). Dentro de alguns nódulos foi detectada a presença de gibbsita.
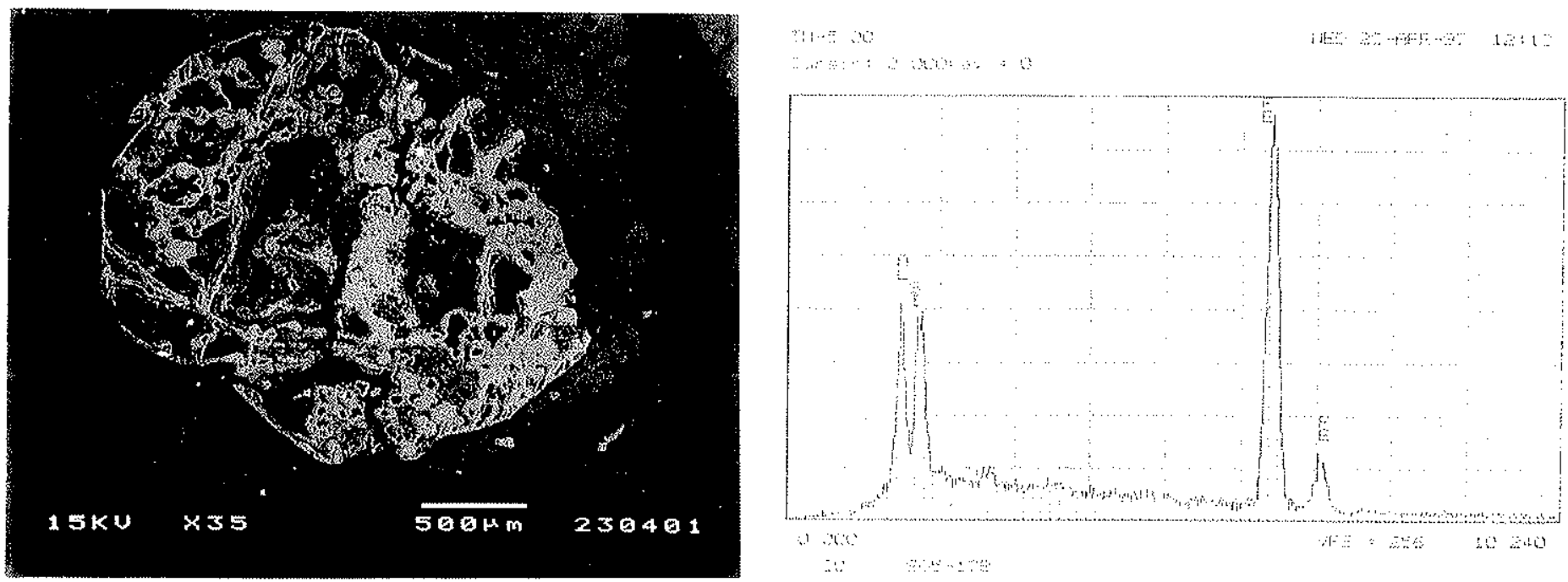

Imagem 6: Aspecto de nódulo de material figura 14: Biagrama Espectral Quimico (EDS)EDS da ferruginoso (Fotomicrografias 5 e 6 ), em elétrons imagem 6 , com análise qualitativa apresentada em retrodifusos (Aumento 35X). O material ferruginoso espectro. está representado pelas porçöes mais claras.

Na amostra 503-06, estes nódulos encontram-se com fosfatos precipitados no seu interior, sendo que em alguns pontos, os fosfatos estão associados a ETR e Ag. Na amostra SO5-17B, detectou-se a presença de fragmento de composto de Ce preso à parede do nódulo (Imagem 7. Figura 15). 

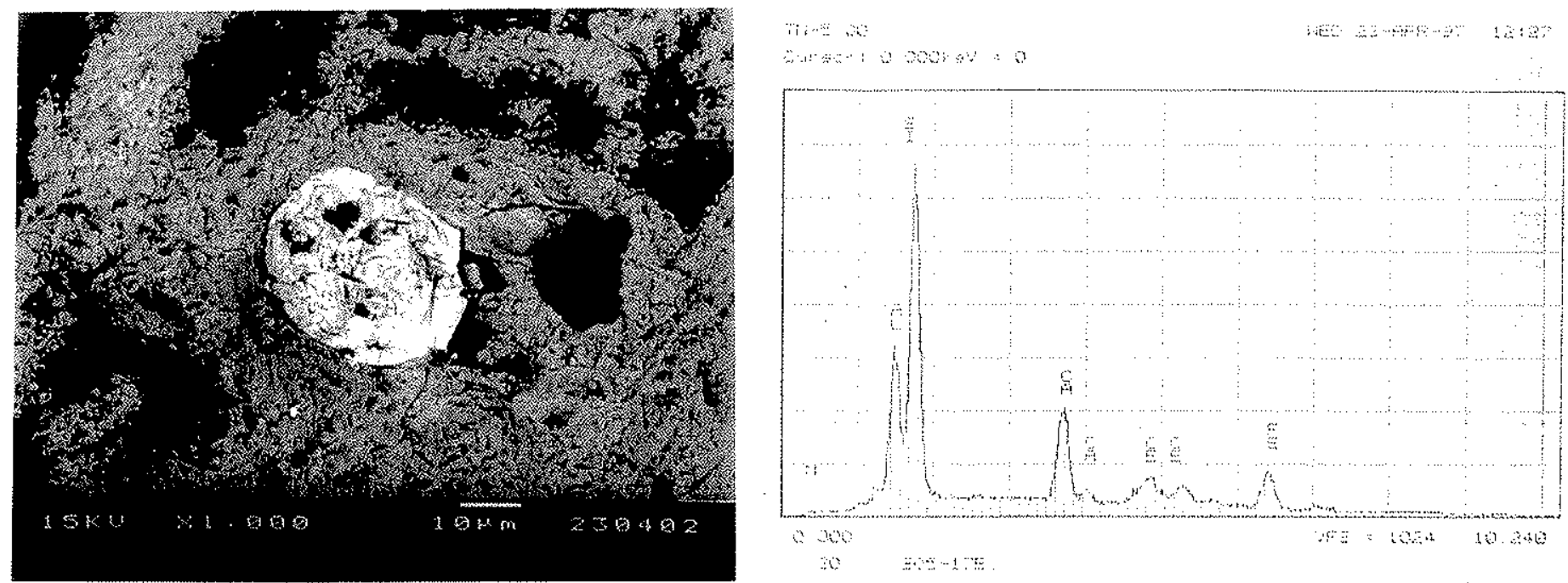

Imagem 7: Detathe da parede do nódulo da|Figura 15: Diagrama Espectral Químico (EDS) da imagem Imagem 6, com fragmento de composto de Ce 7. com análise qualitativa apresentada em espectro. preso à sua estrutura (Aumento $1000 \mathrm{X}$ ).

Também foi observada a precipitação de sais em microfissuras da matriz, geralmente sob a forma de cloretos, associados principalmente a $\mathrm{K}$ (Imagem 8 , Figura 16) e Na, e secundariamente, do Cu (Imagem 9, Figura 17).
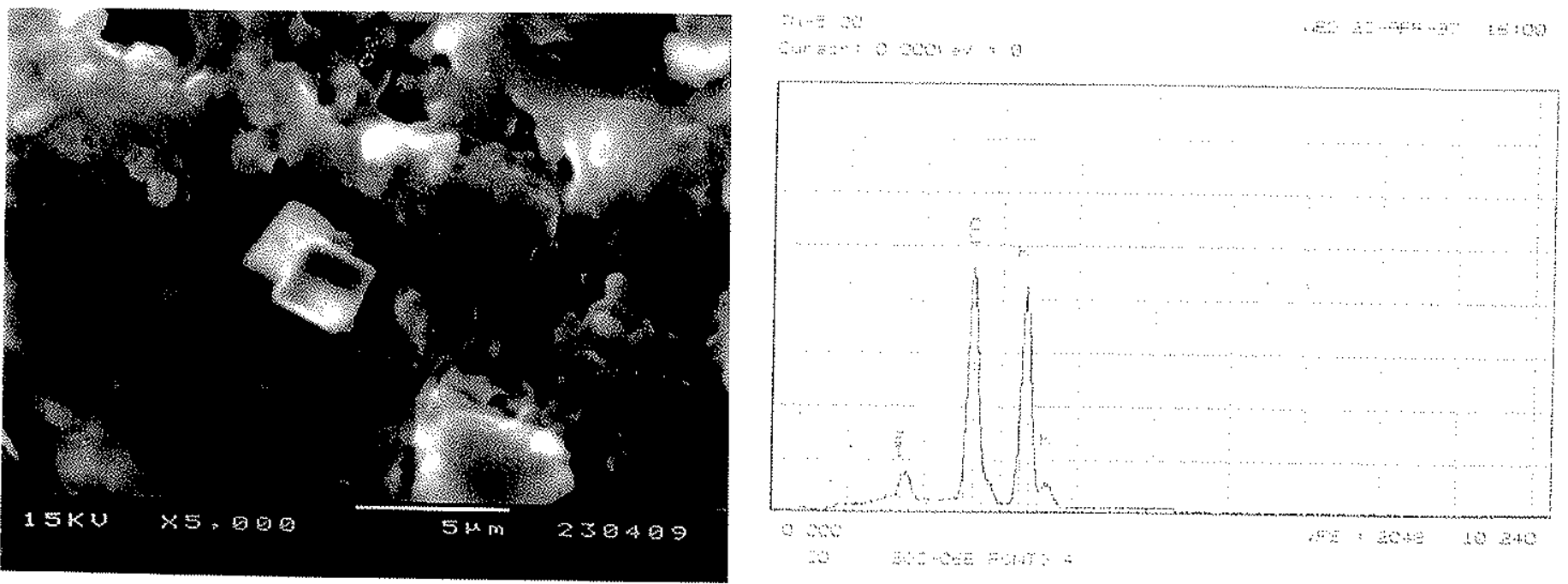

Imagem 8: Morfologia de gräo de solo em MEV: Figura 16: Diagrama Especiral Químico (EDS) da imagem cristais de $\mathrm{KCl}$ precipitados em microfissuras 8 , com análise qualitativa apresentada em espectro. presentes na matriz da amostra SO3-06B. (Aumento $5000 \times$ 

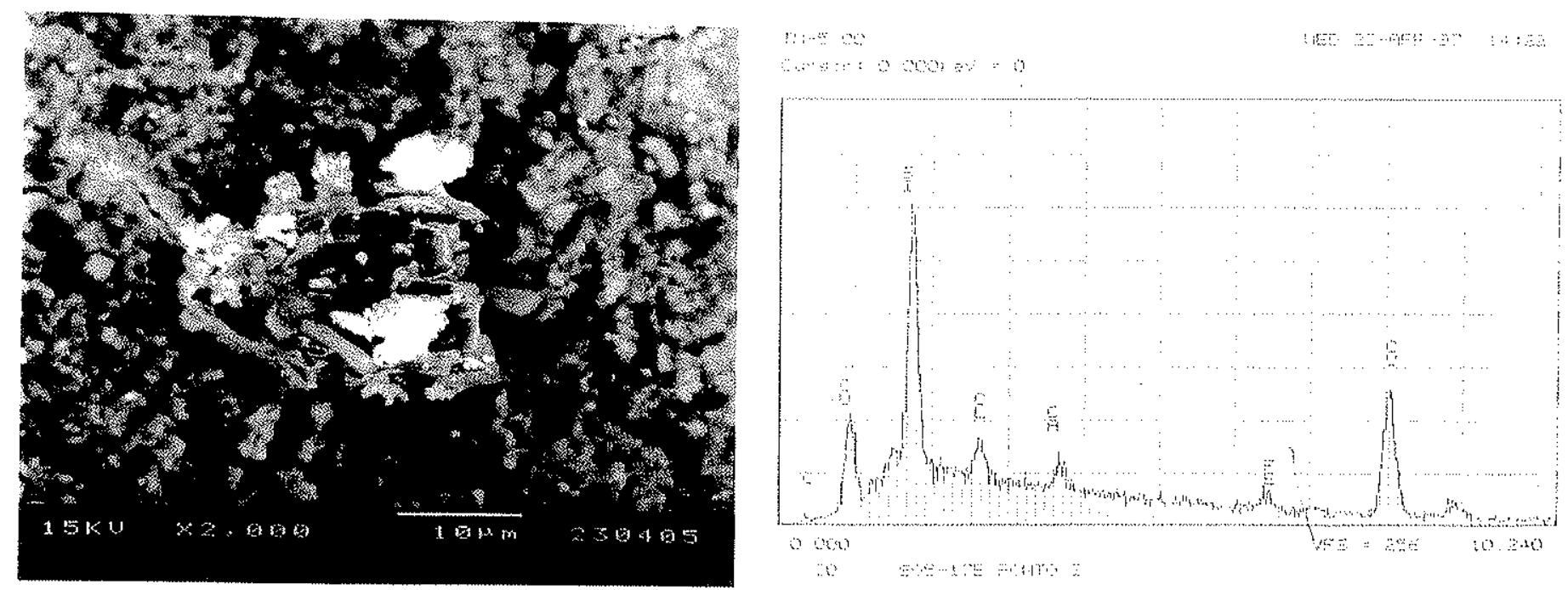

Imagem 9: Morfologia de gräo de solo em MEV: C associado a $\mathrm{Cl}$ precipitado em microfissuras presentes na matriz da amostra SO5-17B. (Aumento 2000X).

Figura 17: Diagrama Espectral Químico (EDS) da imagem 9. com análise qualltativa apresentada em espectio.

\subsection{Unidade 2: Argila de coloração cinza-escura (sedimentos da Bacia de São Paulo)}

\subsubsection{Caracterização Macroscópica}

Esía unidade é soloposta à Unidade 1. Apresenta espessura média entre 2 a 2,5 metros nos furos TL-01 e TL-02, diminuindo em direção ao topo do perfil, chegando de 0,80 a I metro nos furos TL-06 e Th-07. Constitui-se de argilas de coloração cinza escura. Nos furos onde foi possivel observar a sua base, (TL-03, TL-04, TL-05, TL-06 e TL.07), nota-se uma acentuada diminuição da quantidade de argila em direção à base, e a coloração tende do cinza-claro. O contato com a camada inferior é gradual. Provavelmente este material relaciona-se aos sedimentos pertencentes à Bacia de São Paulo que afloram nas proximidades da área de estudo, em particular, aos sistemas lacustres que são comumente descritos neste tipo de formação (MELO et al, 1986; RICCOMINI, 1989; TAKIYA, 1991)

Na Figura 18 é apresentada a distribuição das porcentagens de areia, argila e silte dos seus diversos niveis, de acordo com as análises granulométricas obtidas ao longo dos perfis nesta unidade. 


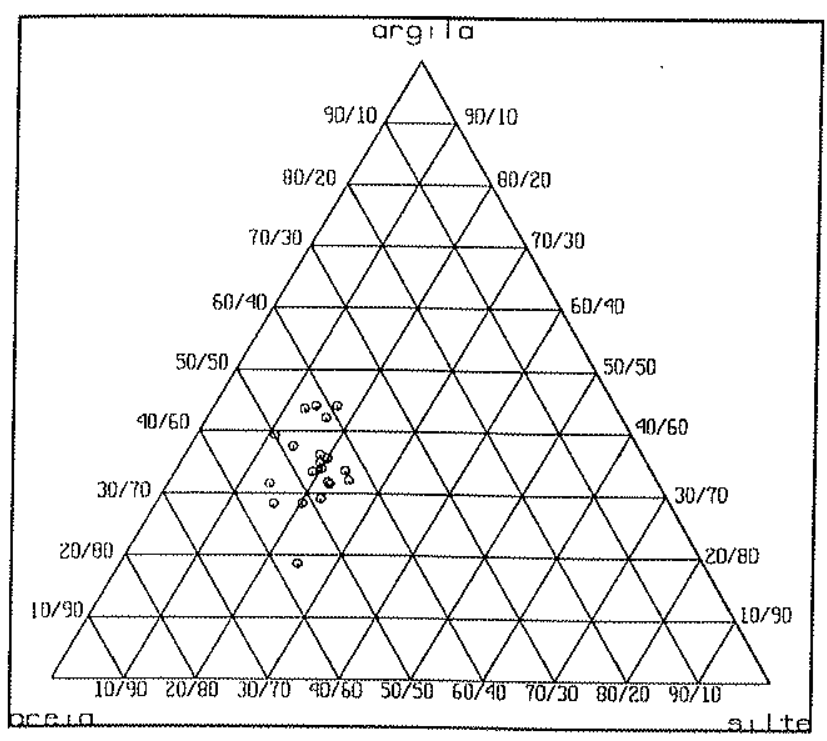

Figura 18: Distribuição das porcentagens de areia, argila e silte de amostras da Unidade 2 em diagrama triangular de classificação textural de solos, de acordo com CATI/SAA (1994).

Com os resultados obtidos no Diagrama de Classificação Textural dos Solos (SAA/CATI, 1994), podemos classificar esta Unidade como de textura argilosa a argilofranco- arenosa. O que se pode observar em relação à Unidade anterior (Unidade 1), é que houve uma maior uniformidade na distribuição dos diferentes dados ao longo do Diagrama, e há uma tendência à migração para o campo das argilas.

Nesta Unidade, foram obtidos os maiores teores de matéria orgânica das três unidades analisadas, situando-se entre 4 a $7 \%$ para os furos TL-01 a TL-03 e 4 a $5 \%$ nos demais furos, com exceção do furo 5 , onde não forom encontrados valores maiores que $2 \%$.

\subsubsection{Caracterização Microscópica}

As amostras pertencentes a esta unidade caracterizam se essencialmente pela presença de minerais primários semelhantes aos descritos para a Unidade I: o quartzo é o constituinte predominante, e como acessórios ocorrem muscovita e turmalinas.

Os grãos de quartzo encontram-se emersos no plasma, sendo que alguns se apresentam subarredondados, com bordas de dissolução ou sendo recobertos por hidróxido de ferro. As Fotomicrografias 8 e 9 exemplificam as características principais desta unidade, com relação aos minerais primários. 
Os minerais secundários são representados pelo material proveniente da alteração das micas (muscovita => caulinita), de coloração cinza-prateada e alta birrefringência em luz polarizada. Alguns pontos da lâmina exibem a miscigenação deste material em avançado grau de alteração com o fundo matricial (plasma) (Fotomicrografias 10 e 11).

O plasma apresenta-se compacto e fino em comparação com o plasma da Unidade I. Apresenta coloração escura, e em alguns pontos, nota-se a acumulação do material ferruginoso em nódulos (Fotomicrografias 12 e 13). São observadas poucas cavidades, e algumas fissuras onde ocorre percolação de hidróxido de ferro.

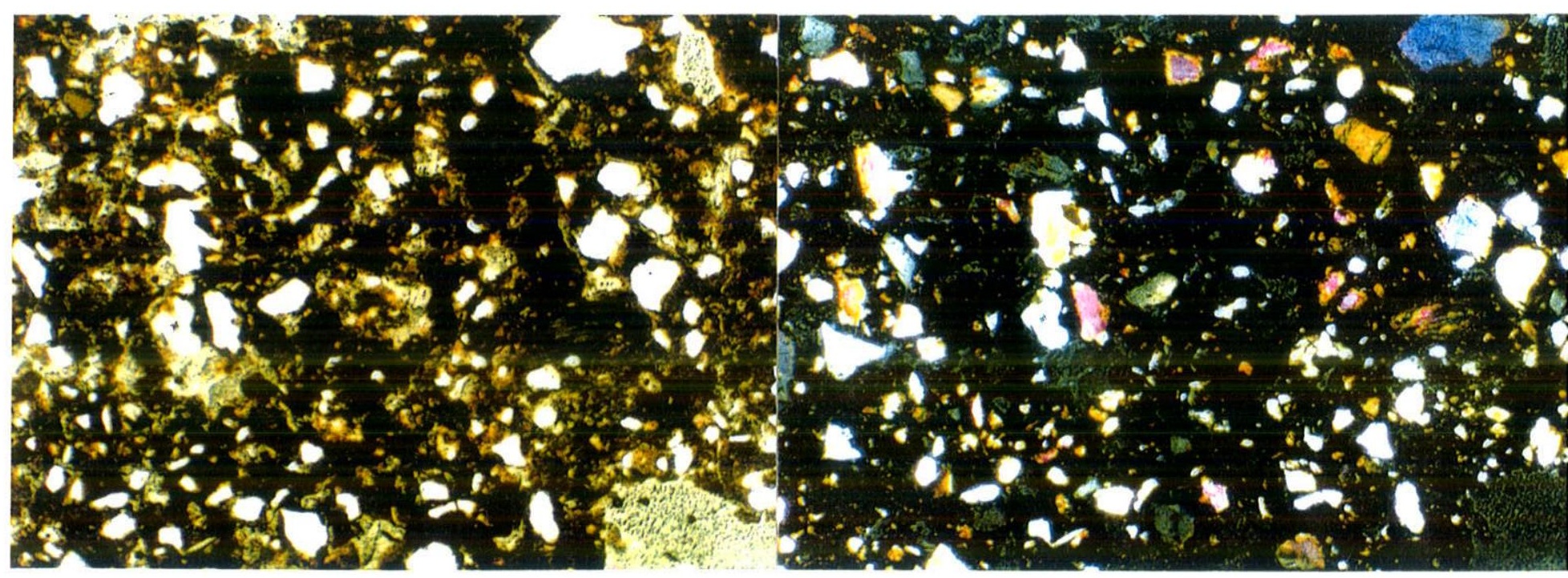

Fotomicrografias 8 (luz natural) e 9 (luz polarizada): Aspecto do plasma da Amostra SO5-05A, de coloração marrom escura. Os grãos de quartzo encontram-se emersos no plasma, apresentando-se subarredondados. Alguns se apresentam com borda recoberta por material ferruginoso, e outros, com dissolução nas bordas. Campo das fotos: $4,2 \mathrm{~mm} \times 2,8 \mathrm{~mm}$ (objetiva 3,2; abertura 3,2:1) 
(10)

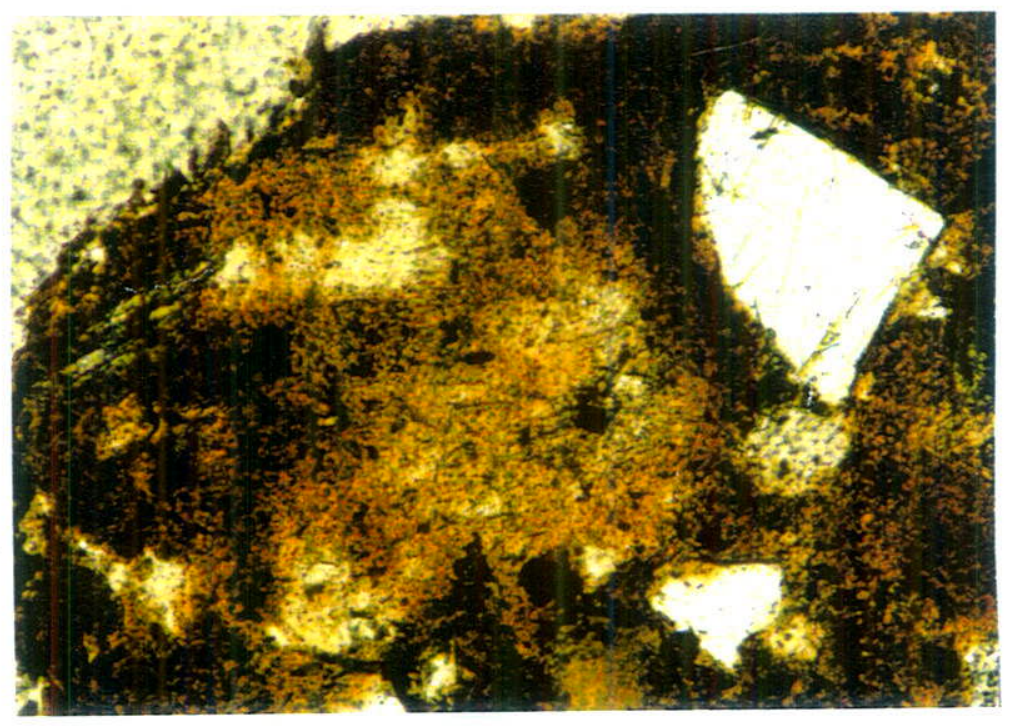

(11)

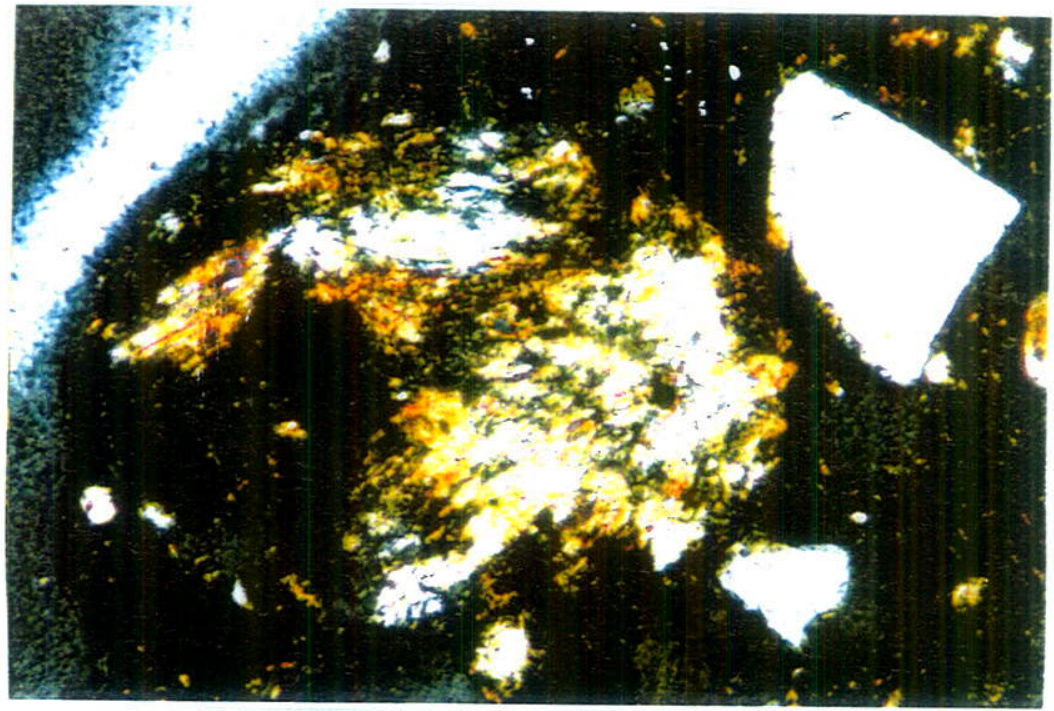

Fotomicrografias 10 (luz natural) e 11 (luz polarizada): aspecto da amostra SO5-05A. Caulinita em avançado grau de alteração, se incorporando ao plasma. Campo das fotos: $0,65 \mathrm{~mm} \times 0,45 \mathrm{~mm}$ (objetiva 20 , abertura $3,2: 1$ )

(12)

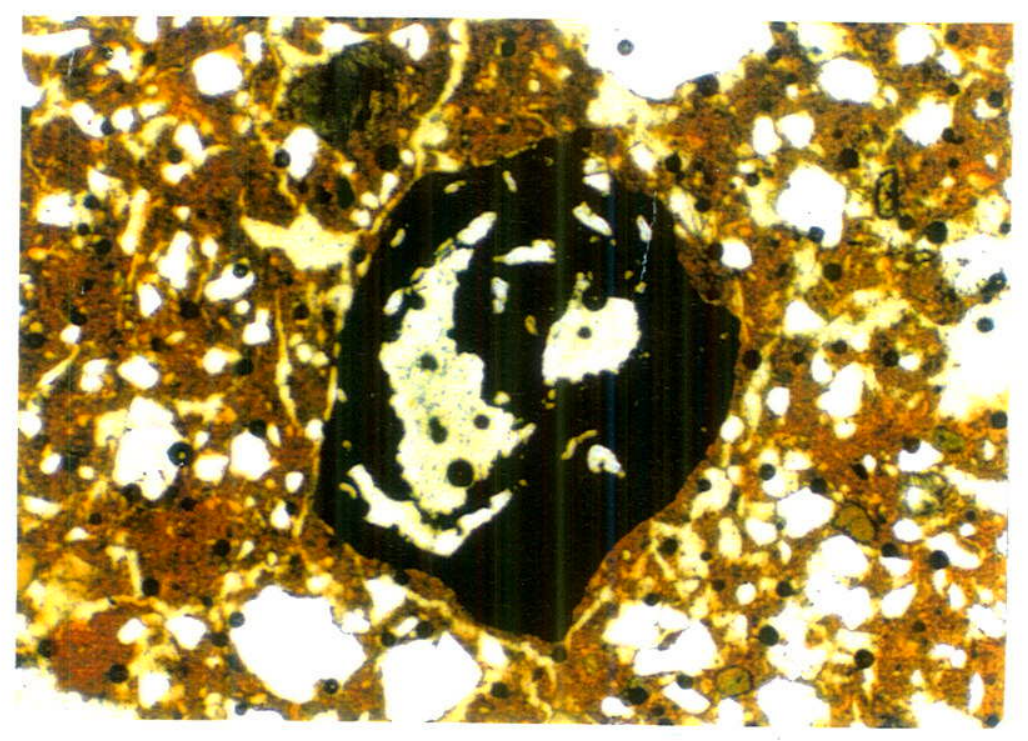

(13)

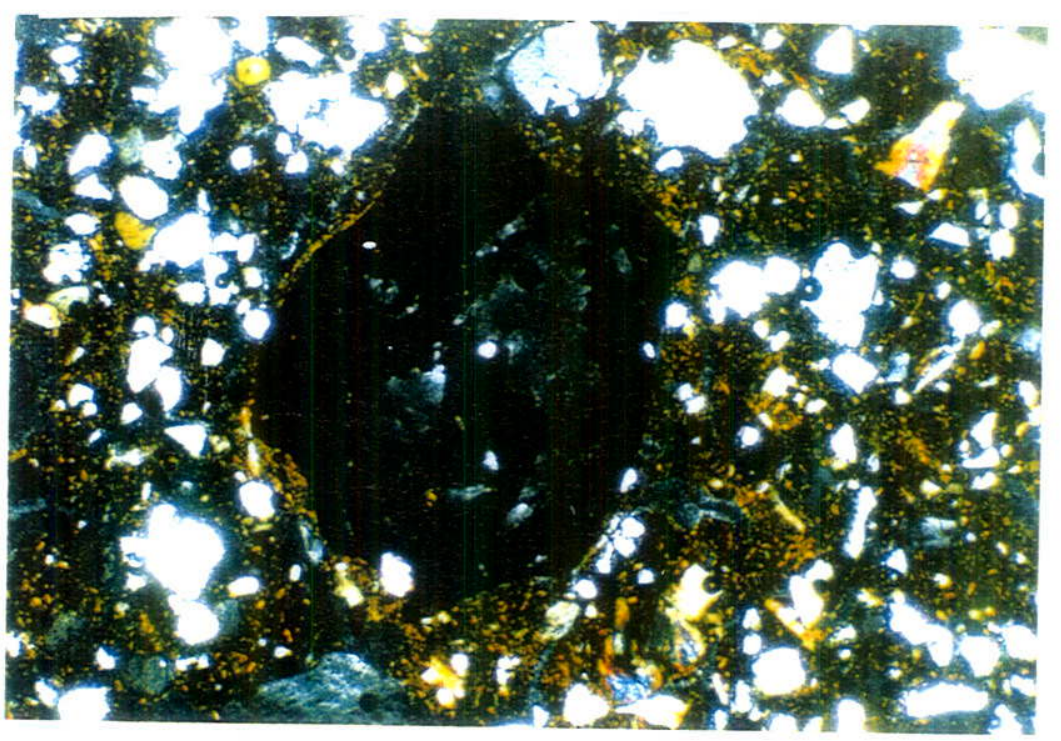

Fotomicrografias 12 (luz natural) e 13 (luz polarizada): acumulação de material ferruginoso em nódulos na amostra SO3-02T. Campo das fotos: 3.2mm $\times 2.1 \mathrm{~mm}$ (objetiva 3,2; abertura 4:1). 


\subsubsection{Determinações em DRX}

Somente as amostras pertencentes a esta unidade foram submetidas à análise por DRX. Para cada perfil, foram selecionadas no mínimo três amostras: uma na parte superior, outra no meio e outra na parte inferior da camada.

Os resultados obtidos para as diferentes amostras são semelhantes ao longo de toda a seção de estudo. Através dos espectros, foi possível a identificação de quartzo, muscovita e argila do grupo da caulinita.

As Figuras 19, 20 e 21 exibem os resultados obtidos, respectivamente, para os furos TL-03 (localizado a jusante da lagoa), TL-05 (localizado dentro da lagoa) e TL-06 (localizado a montante da lagoa de infiltração).

De um modo geral, não se observaram variações muito significativas nestes espectros ao longo da seção de estudo. O que se nota é uma variação na intensidade dos picos das amostras com maior porcentagem de areia para as amostras com menor porcentagem de areia, onde o pico mais intenso do Quartzo aparecia mais ou menos diferenciado em relação aos demais.

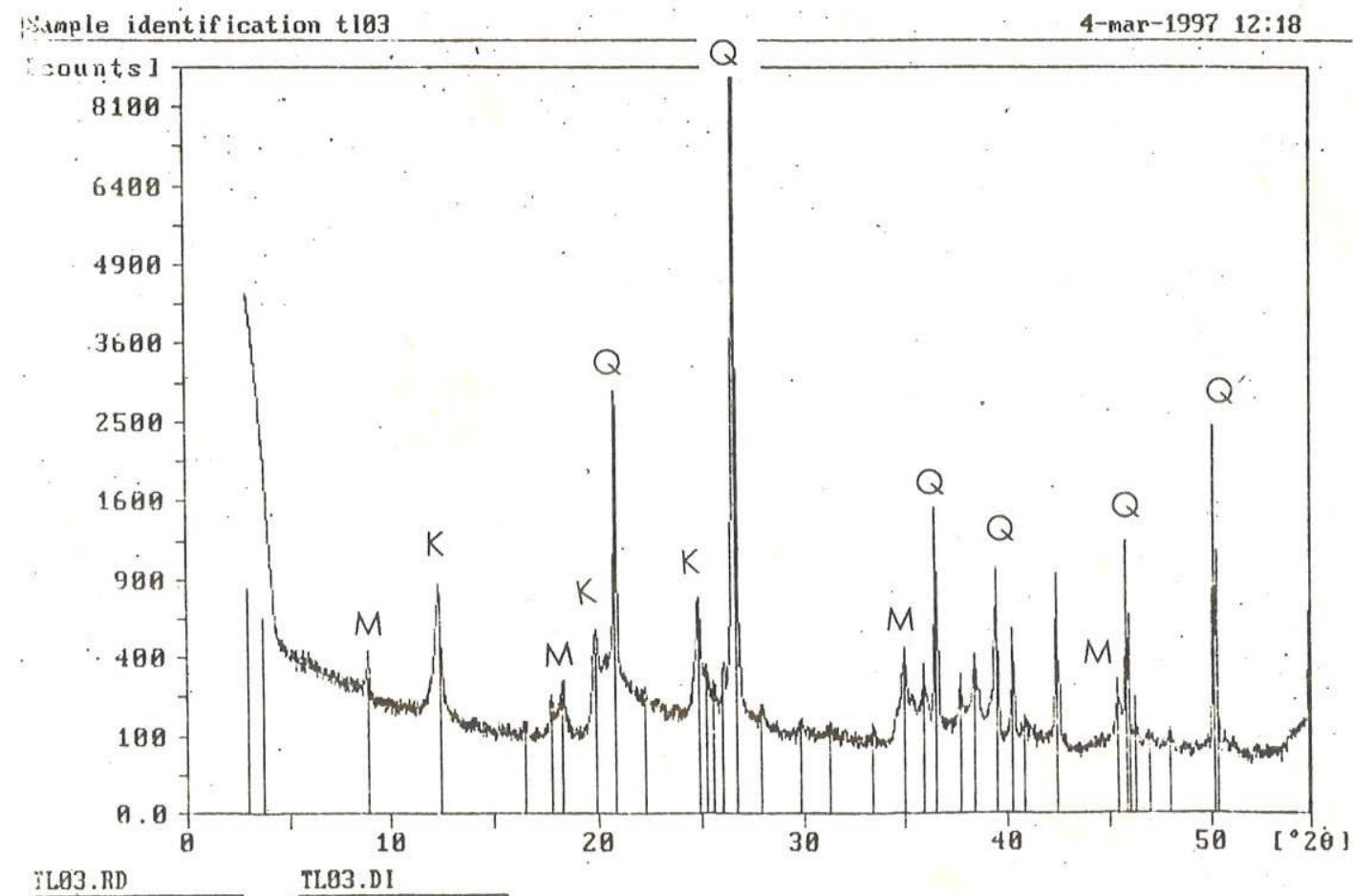

Q: quartzo; K: caulinita: M: muscovita.

Figura 19: Resultado da análise por DRX da amostra do perfil TL-03, localizado a jusante da lagoa de infiltração. 


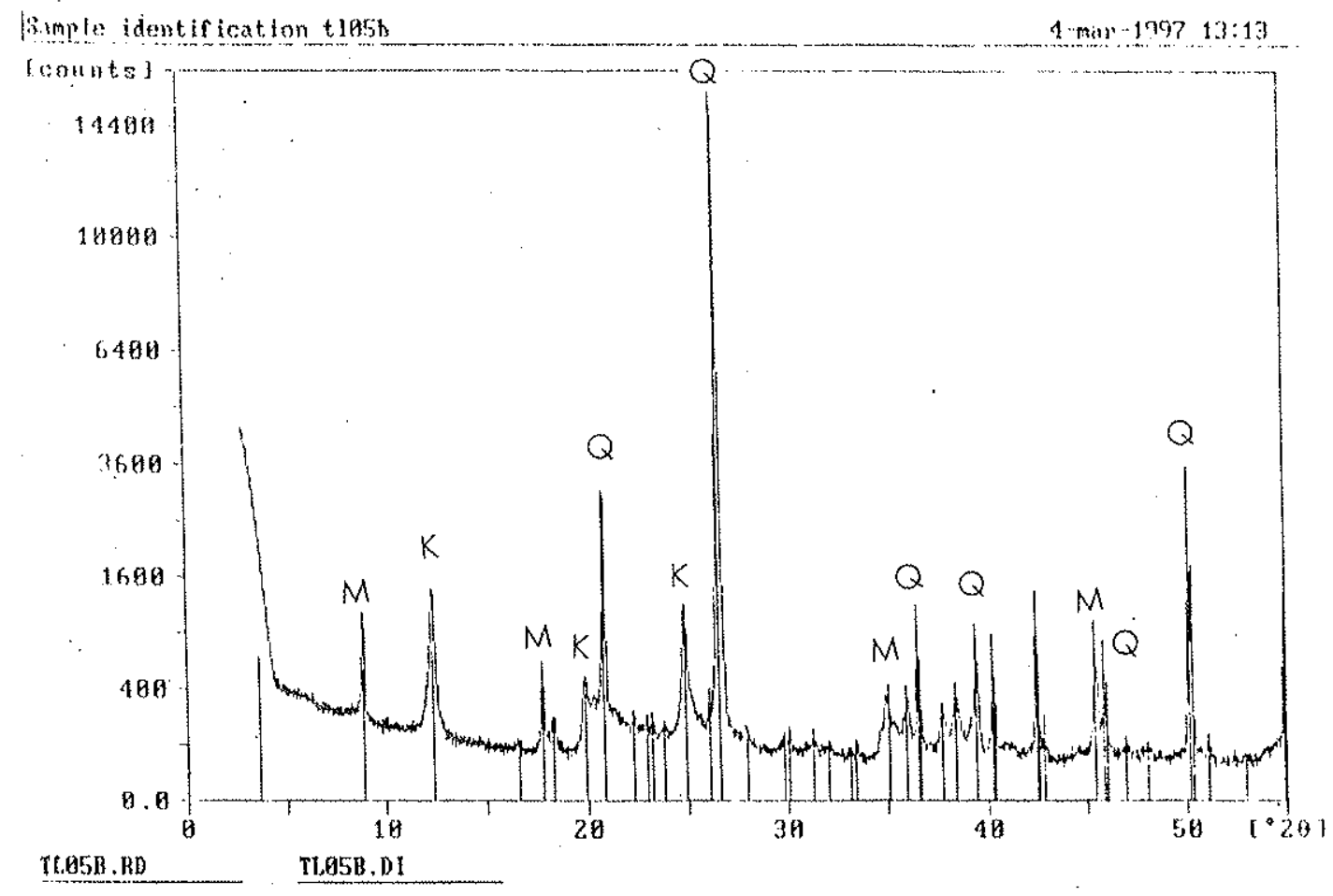

Q: quartzo; K: caulinita; $M:$ muscovita.

Figura 20: Resultado da análise por DRX da amostra do perfil TL-05, localizado dentro da lagoa de infiltração.

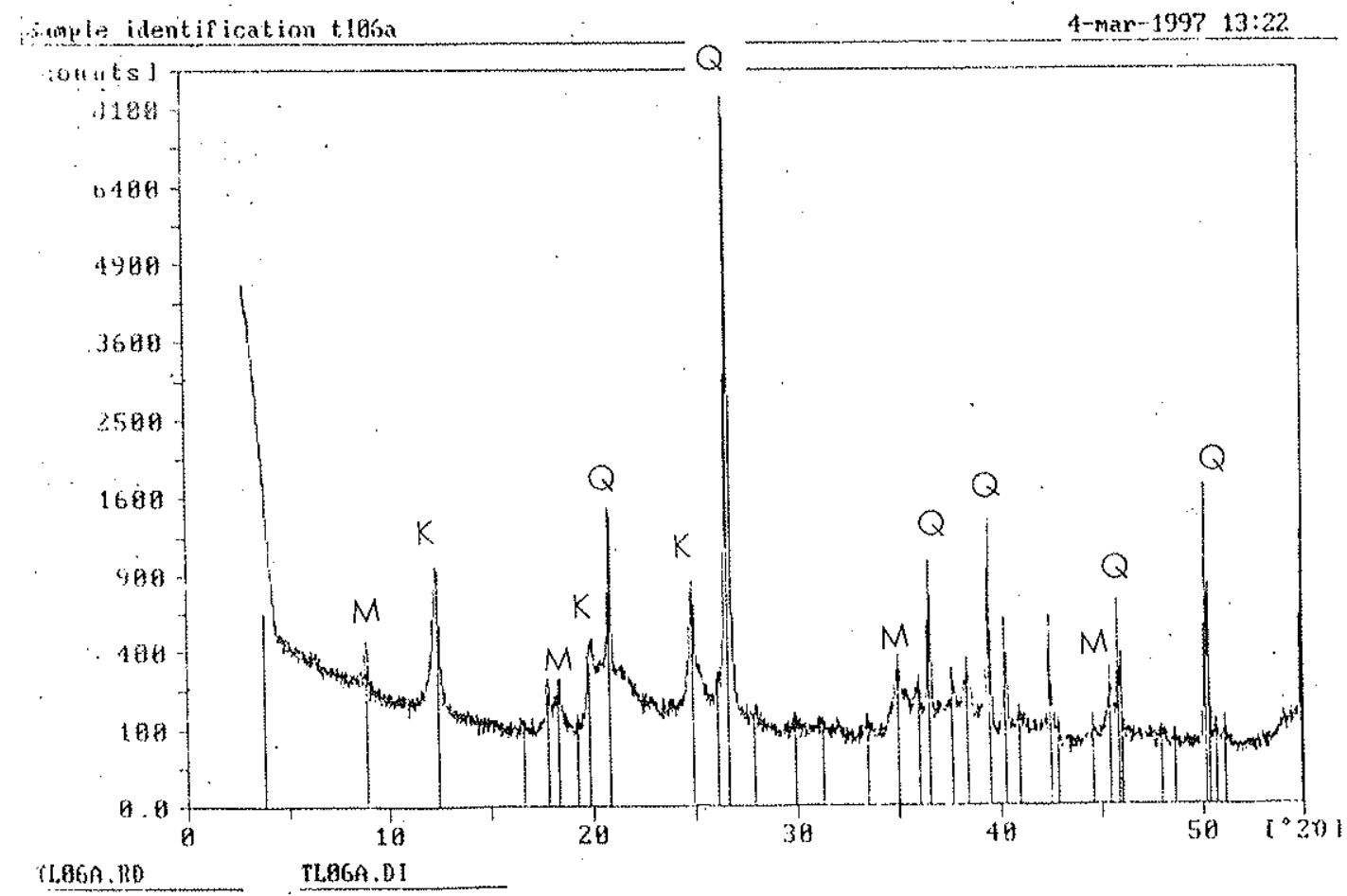

Q: quartzo; K: caulinita; M: muscovita.

Figura 21: Resultado da análise por DRX da amostra do perfil TL-06, localizado a montante da lagoa de infiltração. 


\subsubsection{Determinações em MEV}

\subsubsection{Fragmentos}

Os fragmentos desta unidade analisados em MEV, de dimensões entre 4 e $8 \mathrm{~mm}$, provém de amostras coletadas nos poços $\$ 03$ e $\$ 05$. Em função dos inúmeros dados obtidos, dividiu-se os resultados em: minerais primários, matriz, minerais neoformados e metais pesados.

\section{a) minerais primários:}

Os minerais primários são representados essencialmente por quartzo, sendo identificados os acessórios ilmenita (Imagem 10. Figura 22) e zircão (Imagem 11. Figura 23).
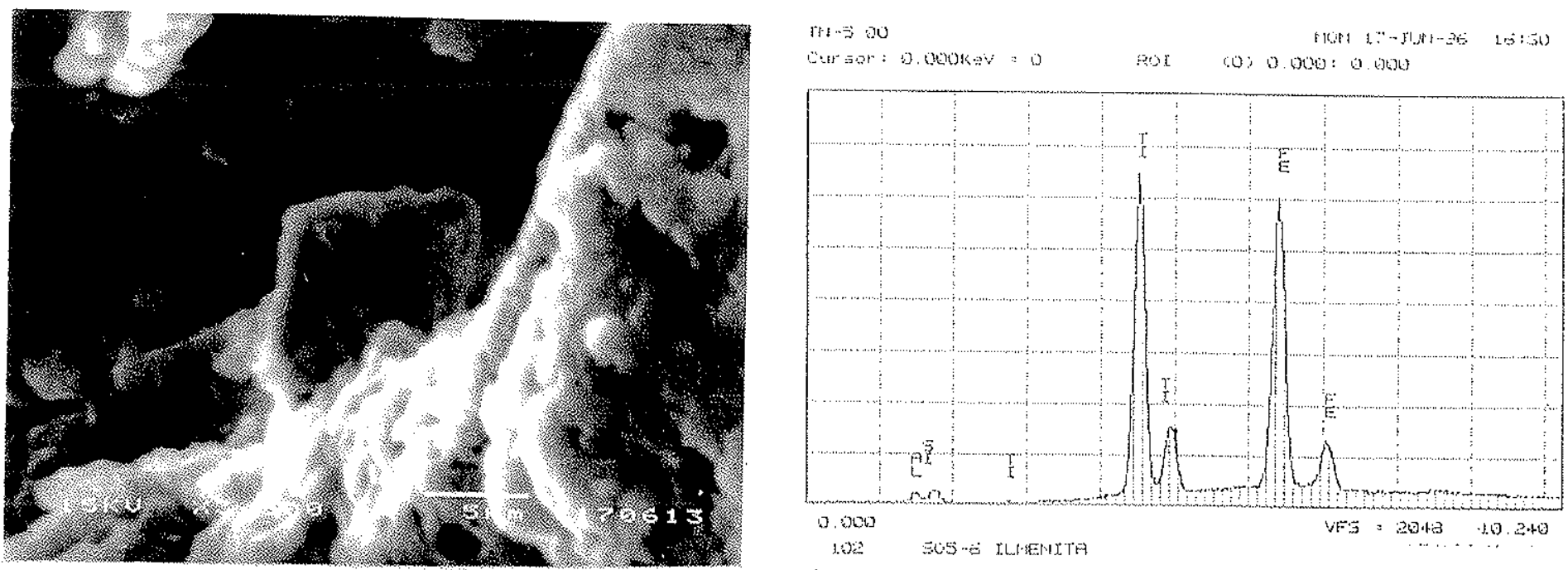

Imagem 10: Morfologia de gräo da amostra SO5-06 em MEV: grão de ilmenita (grão de formato

Figura 22: Diagrama Espectral Químico (EDS) da imagem 10. com análise qualitativa apresentada em espectro. losangular, no centro da fotol. Aumento $3500 \mathrm{x}$. 

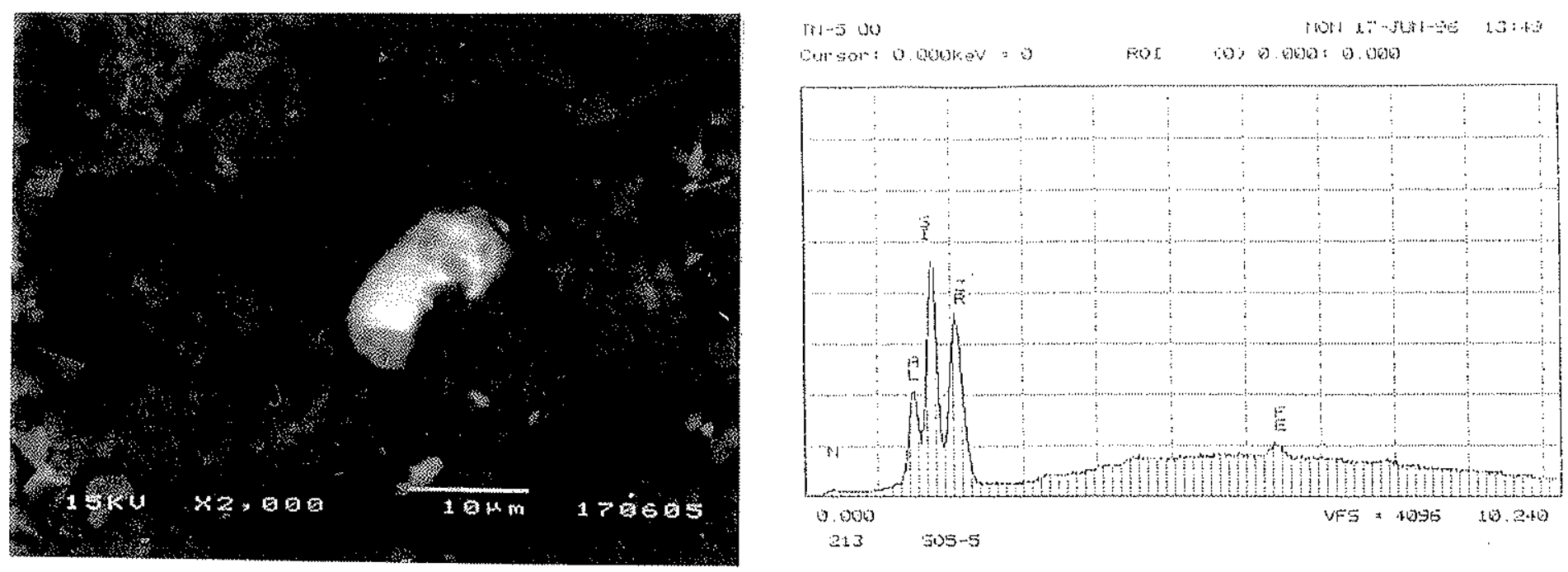

Imagem 11: Grão de composição metálica da|Figura 23: Diagrama Espectral Químico (EDS) da imagem amostra SO5-05 em MEV, com o emprego de elétrons retrodifusos: grão de zircão (grão de coloração mais clara). Aumento 2000X.

11. com análise qualitativa apresentada em espectro.

\section{b/matriz}

A matriz é composta de $\mathrm{Al}, \mathrm{Si}, \mathrm{K}, \mathrm{Tl}$ e $\mathrm{Fe}$. Alguns destes elementos são encontrados como nódulos ao longo desta. Em algumas amostras, observa-se a presença do Mn associado à matriz desta composição (Imagem 12, Figura 24).
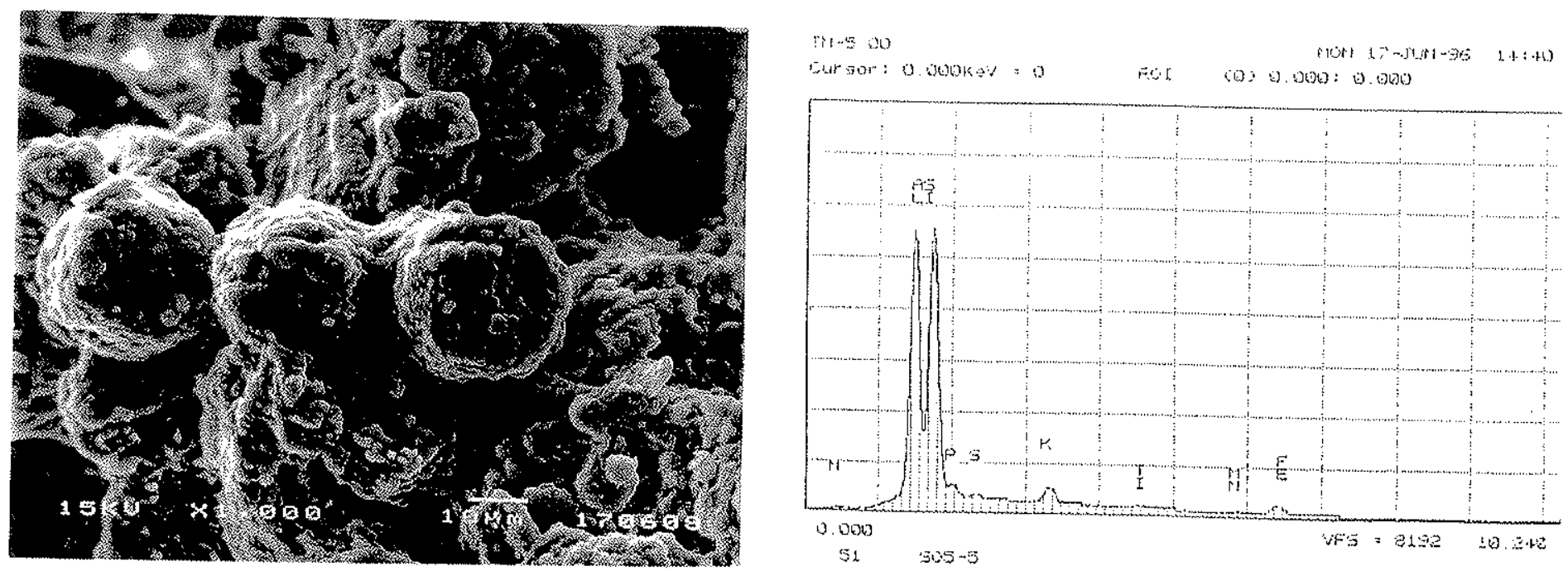

Imagem 12: Morfologia de grão de solo da amostra figura 24: Diagrama Espectral Químico (EDS) da imagem SO5-05 em MEV: aspecto da matriz. (Aumento 1000X). 12, com análise qualitativa apresentada em espectro. 


\section{c) minerais neoformados}

Ao longo desta unidade, foi possivel a identificaçäo de alguns minerais neoformados. A sílica proveniente da dissolução dos grãos de quartzo reprecipitou, originando um material secundário, na forma de placas de sílica, ou de bastonetes (imagem 13, Figura 25).
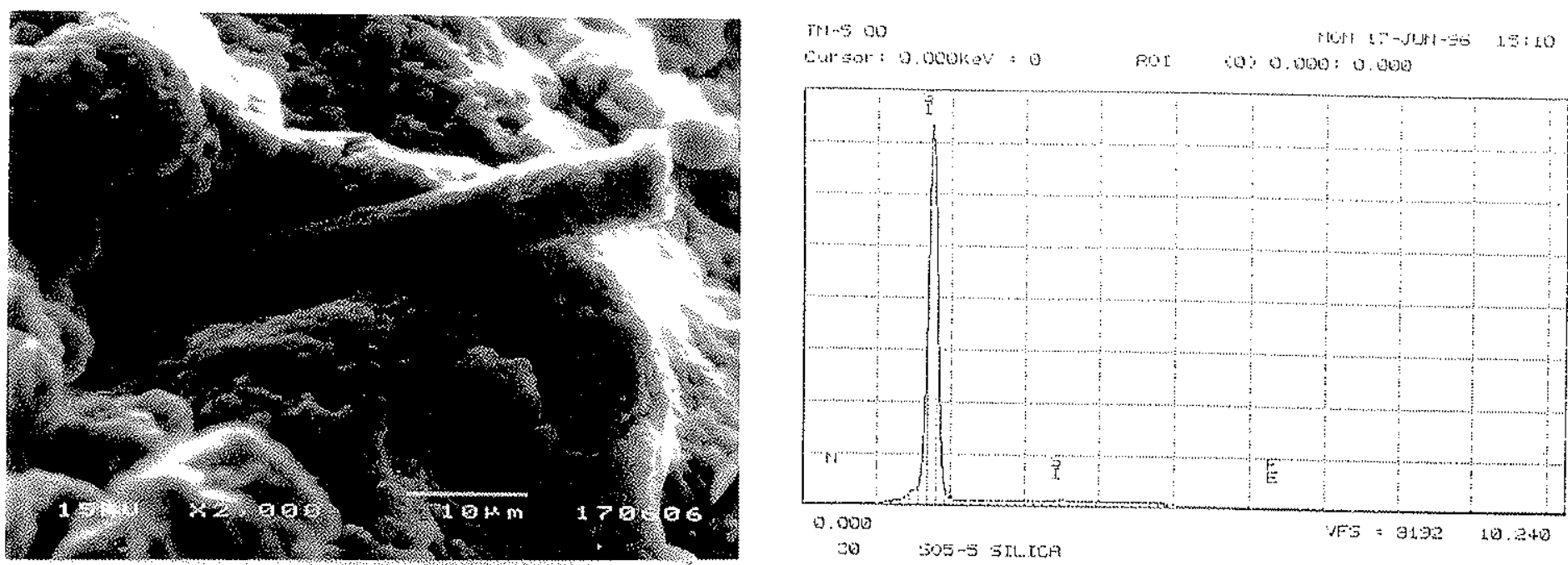

Imagem 13: Morfologia de grão de solo da amostra Figura 25: Diagrama Espectral Químico (EDS) da imagem SO5 05 em MEV: sílica neoformada, na forma de 13, com análise qualitativa apresentada em espectro. bastonete (Aumento 2000X).

A grande presença de Elementos Terras Raras, especialmente cério, possibilitou a neoformação de minerais (Imagem 14, Figura 26).
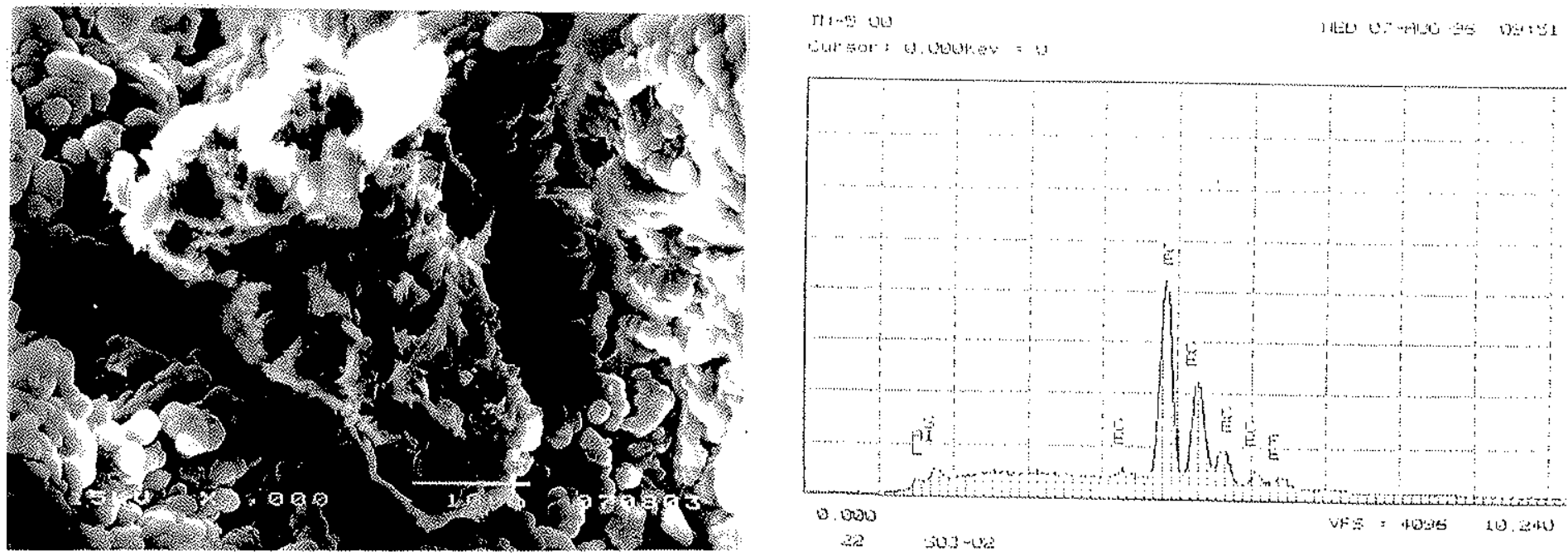

Imagem 14: Morfologia de grão de solo da amostra|Figura 26: Diagrama Espectral Quimico (EDS) da imagem SO3.02 em MEV: neoformaçäo de mineral de Cério 14, com análise qualitativa apresentada em espectro. (aumento 2000X). 


\section{d) metais pesados}

Nesta unidade foi delectada uma maior presença de melais pesados, principalmente nas amostras do poço SO3 (SO3-02) e nas amostras localizadas no poço dentro da lagoa, no perfil SO5 (SO5-04, SO5-05, SO5-06 e SO5-07).

O Zinco representa o metal mais abundante nestas amostras, estando quase sempre associado d̀ presença de Fe (Imagem 15 e Figura 27; Imagem 16 e Figura 28).

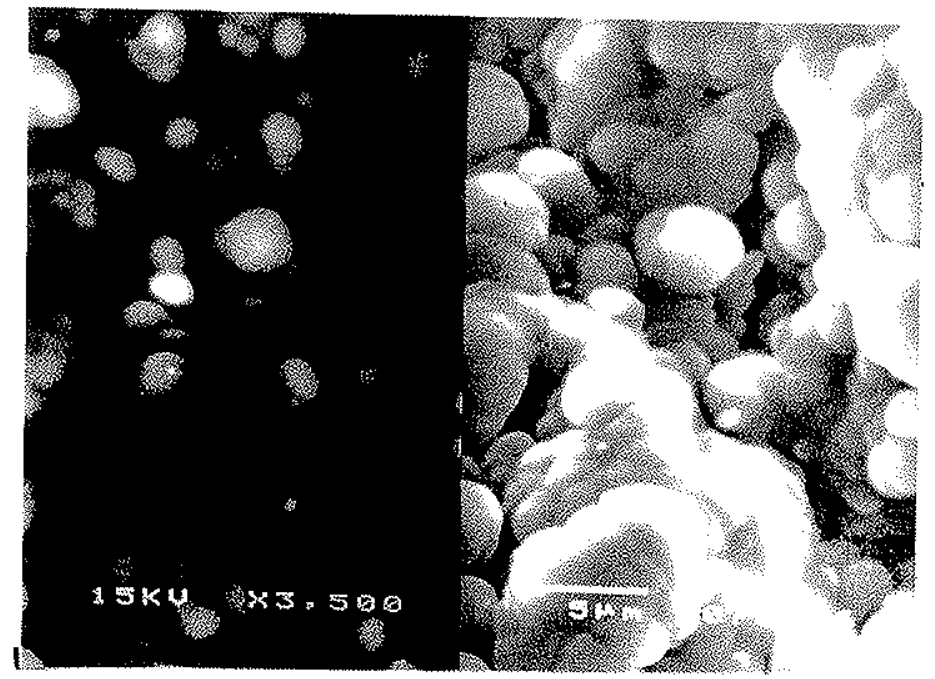

rins wo

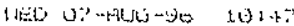

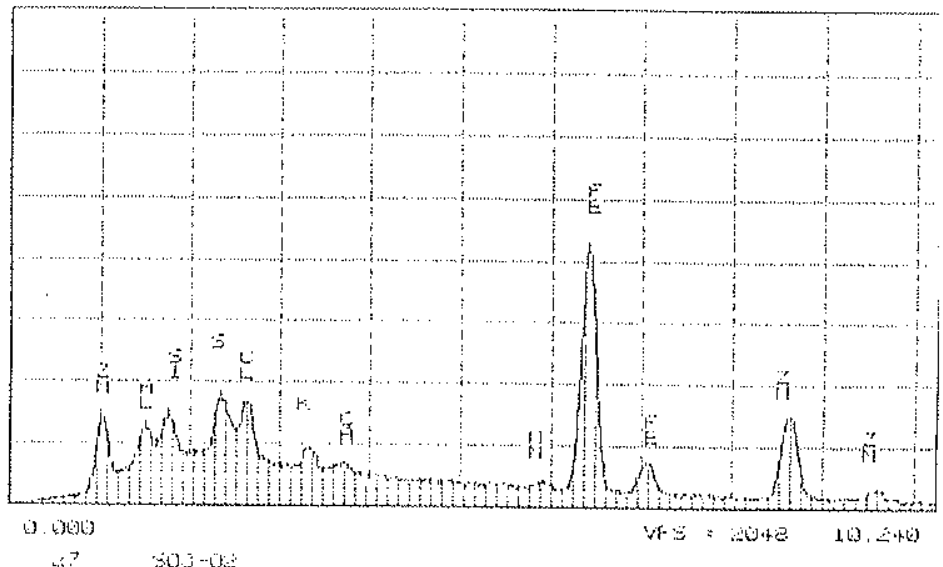

Imagem 15: Imagem em Split femprego de eléfrons /Figura 27: Diagrama Espectral Químico (EDS) da imagem retrodifusos/ luz. natural) de fragmento de composto $15, \mathrm{com}$ análise qualitativa apresentada em espectro. de $\mathrm{Zn}$ (grão claro no centro da foto). Aumento $3500 \mathrm{x}$.
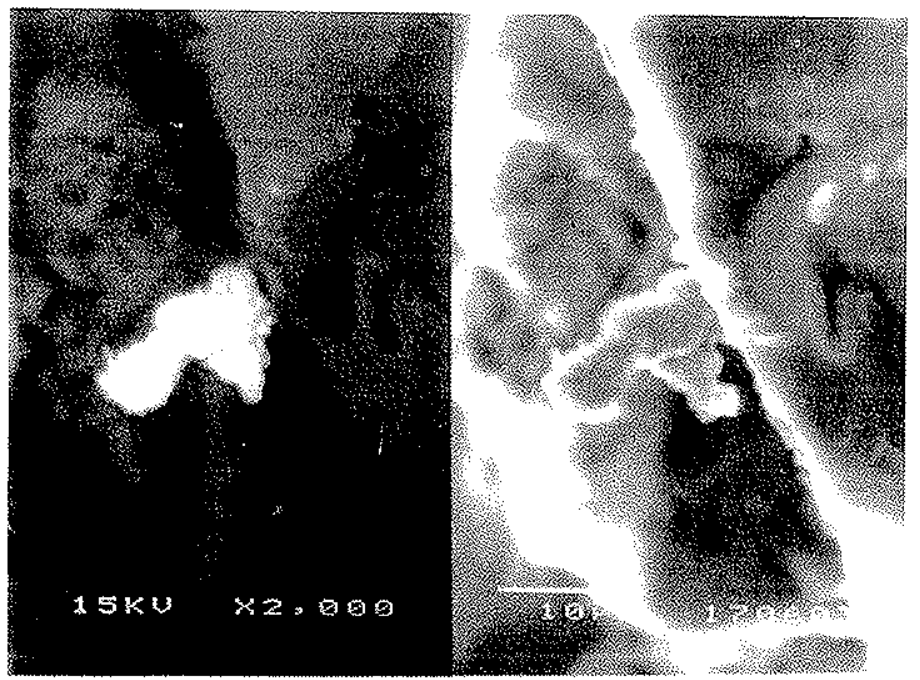

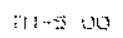

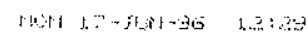

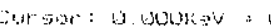

Fot

(0) $6.000: 0.060$

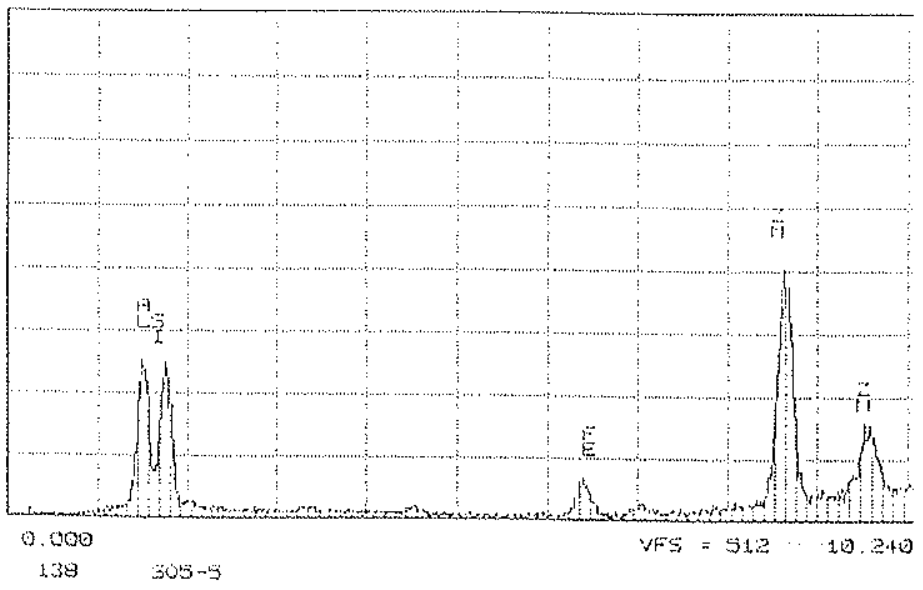

Imagem 16: Imagem em Split lemprego de elétrons figura 28: Diagrama Espectral Químico (EDS) da imagem retrodifusos/ luz natural) de fragmento de composto 16, com análise qualltativa apresentada em espectro. de Zn preso a gräo de argila (aumento $2000 \mathrm{X}$ ). 


\title{
O cobre aparece associado ao ferro (hidróxidos vários), e aos sais
} neoformados, como cloretos, por exemplo (imagem 17, Figura 29).
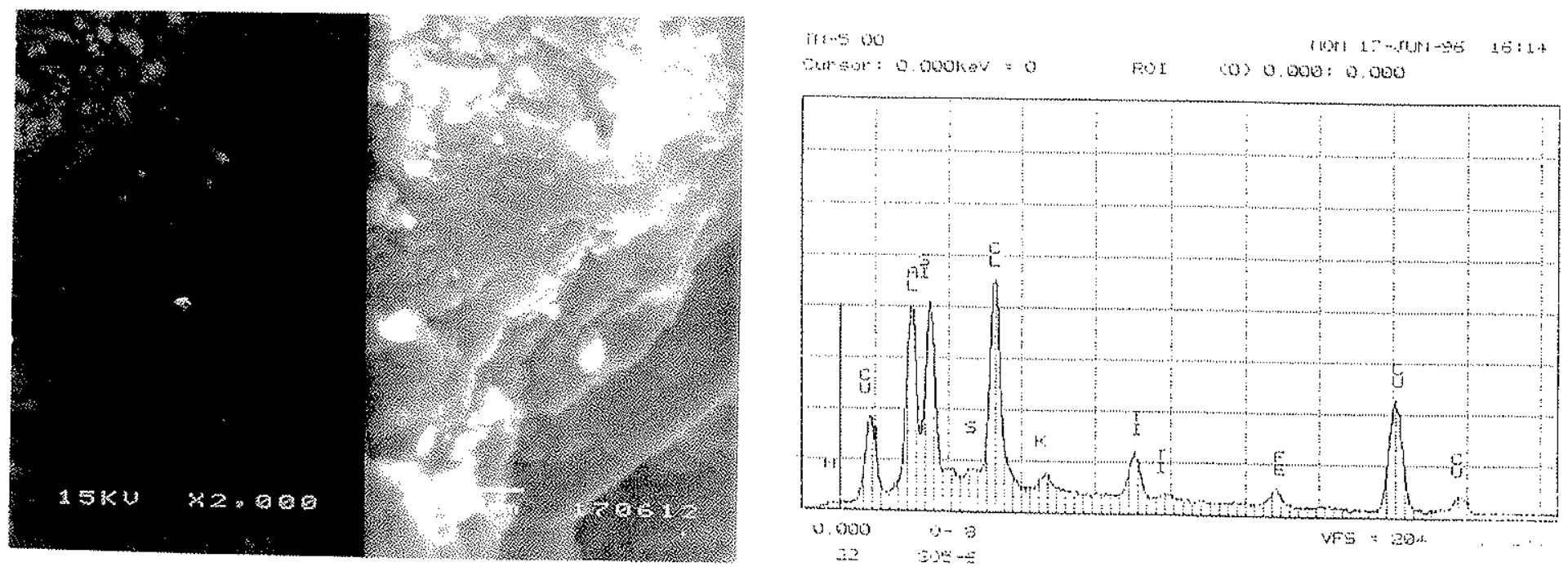

Imagem 17: Imagem em Split (emprego de elétrons|Figura 29: Diagrama Fspectral Químico (EDS) da imagem retrodifusos/ luz natural) de fragmento de composto de Cu associado à presença de cloretos (ponto claro no centro da foto esquerda - elétrons retrodifusos). Aumento 2000X.

\author{
17. com análise qualitativa apresentada em espectro.
}

O chumbo encontra-se disseminado na forma de compostos granulares de formato ovalado do longo das amostras desta unidade, sendo facilmente identificado no MEV através da utilização de elétrons retrodifusos, devido ao seu britho extremamente forte (Imagem 18. Figura 30 ).
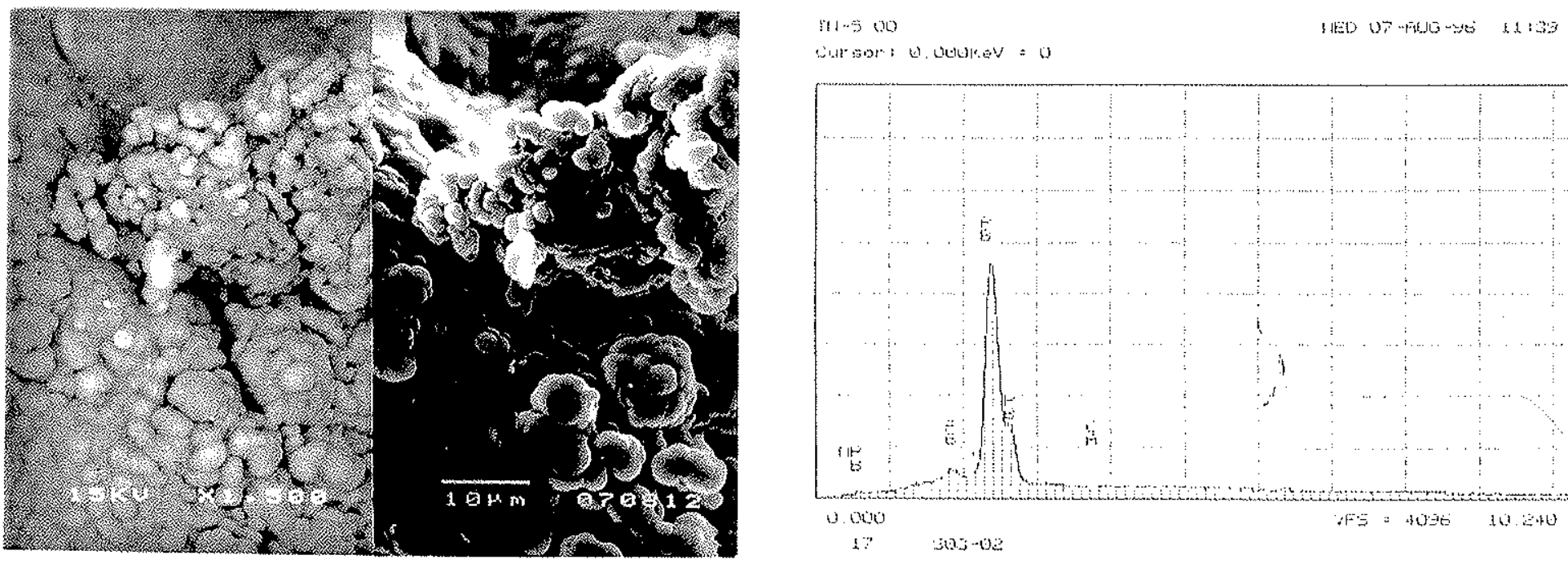

Imagem 18: Imagem em Split (emprego de elétrons figura 30: Diagrama Espectral Químico (EDS) da imagem retrodifusos/ luz natural) de fragmento de composto de $\mathrm{Pb}$ de formato ovalado, que aparece em coloração mais clara no centro da foto laumento $1500 \times)$. 
Como observado na Unidade 1, o manganês se encontra associado do material reprecipitado, geralmente com a presença de fe e Ti llmagem 19, Figura 31). Os Elementos Terras Raras (ETR), embora não abordados neste estudo, também são comumente detectados ao longo desta unidade (nas amostras SO3-02, SO5-05 e S05-07), estando representados principalmente pelo Cério e Lantânio (Imagem 20, Figura 32). Em muitos casos, os ETR são encontrados em associação com a Prata (Imagem 21, Figura 33).

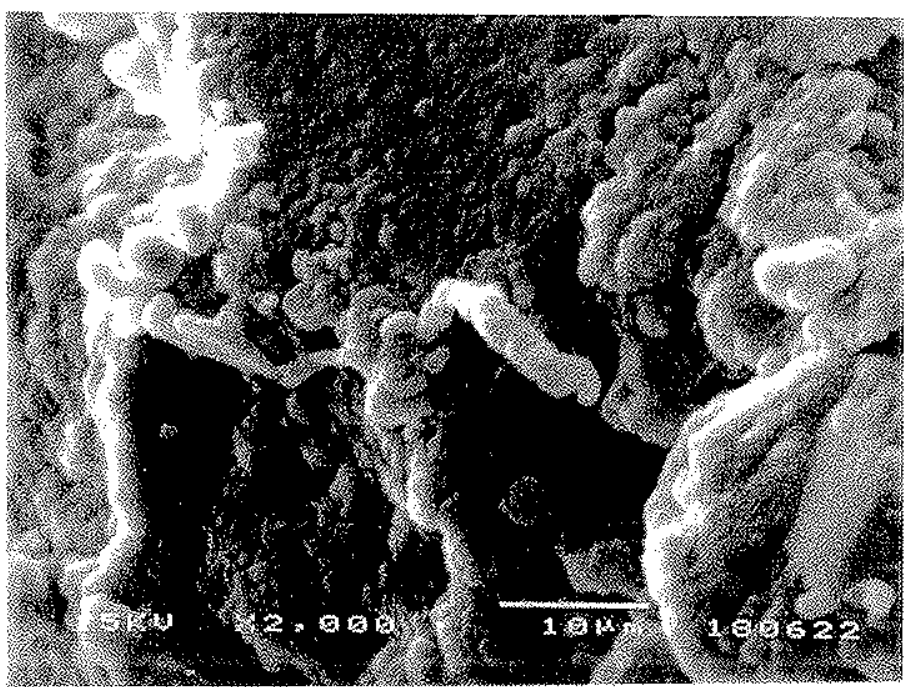

Imagem 19: Morfologia de gräo de solo em MEV: aspecto da matriz da amostra 505-02 (Aumento $2000 \times)$.

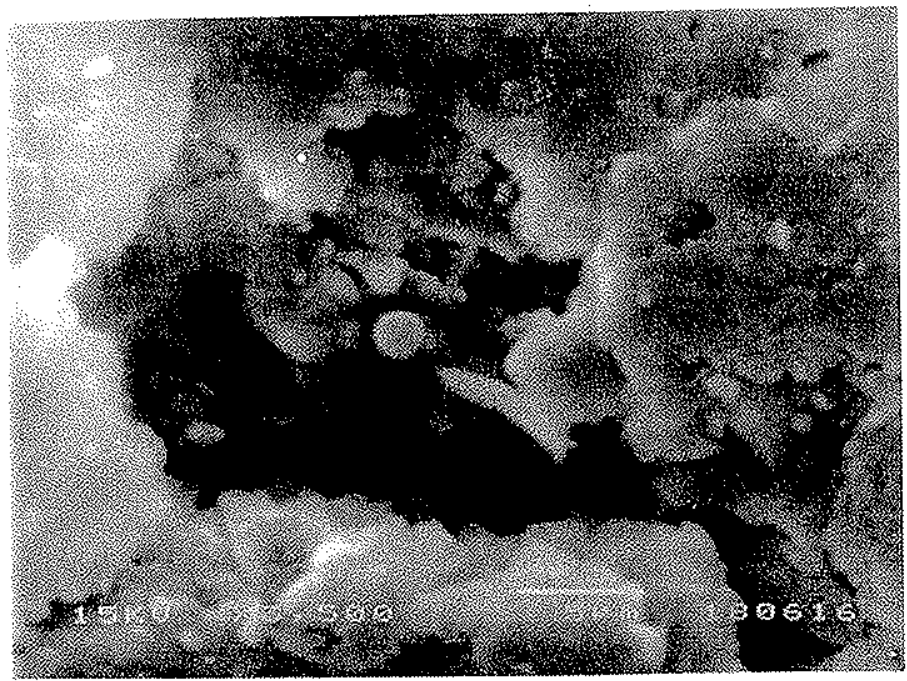

Imagem 20: Morfologia de grão de solo da amostra SO5.07 em MEV: presença de ETR (Ce e La). Esfera no centro da imagem (Aumento 3500X). a.s.

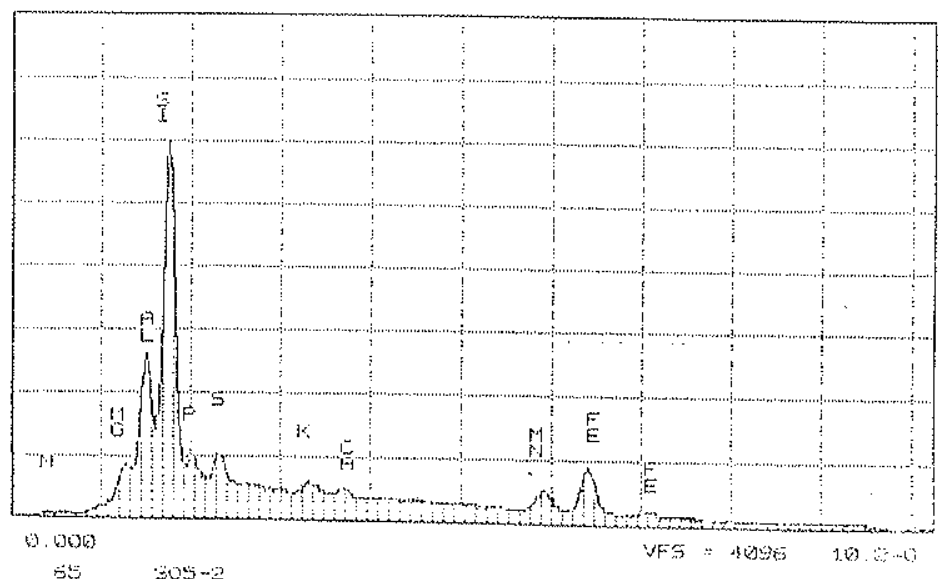

Figura 31: Diagrama Espectral Químico (EDS) da imagem 19, com análise qualitativa apresentada em espectro.

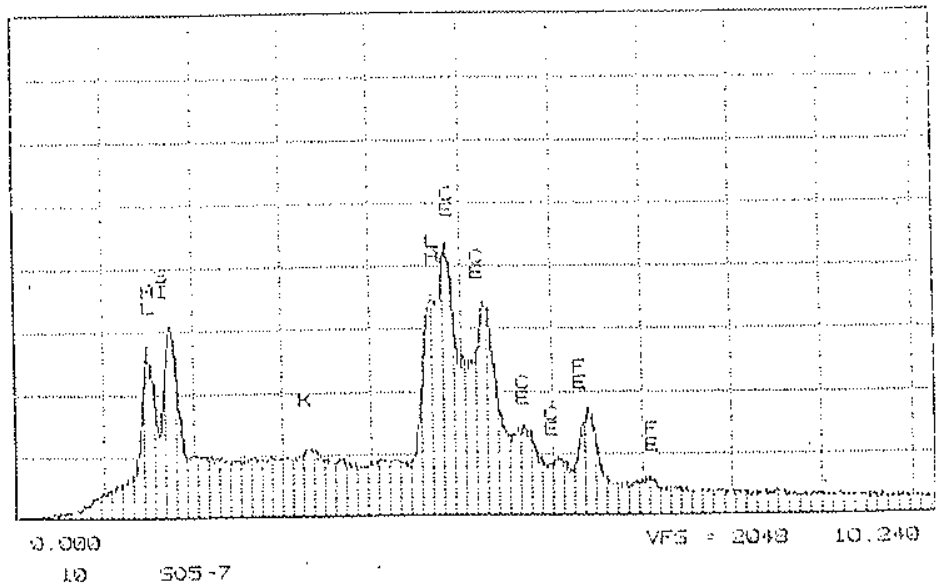

Figura 32: Diagrama Espectral Químico (EDS) da imagem 20, com análise qualitativa apresentada em espectro 

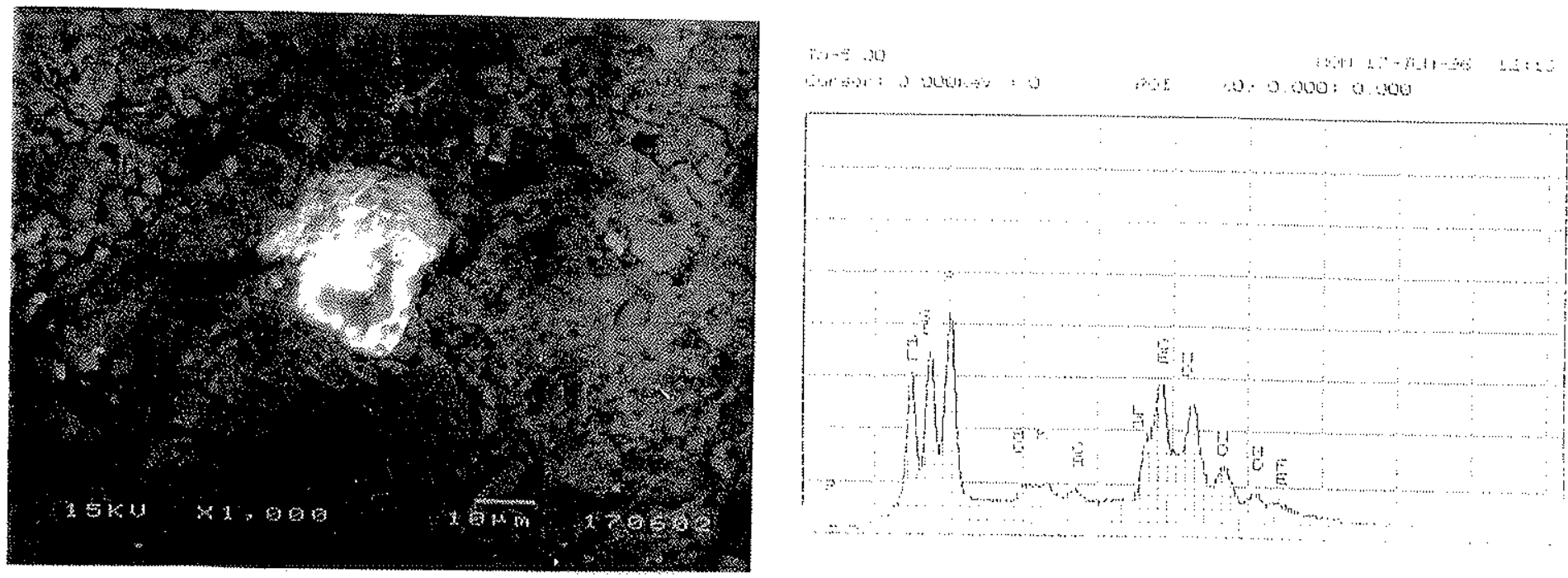

Imagem 21: Fragmento de comportamento Figura 33: Diagrama Espectral Químico (EDS) da imagem metálico da amostra $505-07 \mathrm{em} \mathrm{MEV}$ com 0 21, com análise qualitativa apresentada em espectro. emprego de elétrons retrodifusos: presenca de ETR (Nd, Ce e La) associados à Prata. Aumento $1000 \mathrm{x}$.

\subsubsection{Lâminas}

A análise em MEV de seções delgadas pertencentes a esta Unidade identificaram uma grande presença de sais (especialmente cloretos de $\mathrm{K}$ e $\mathrm{Na}$ ), precipitados ao longo das microfissuras presentes na matriz.

Foram identificados, ao longo da amostra, vários fragmentos de Fe e $\mathrm{Ti}$ disseminados, localizados principalmente ao longo da matriz. Também na matriz, foram identificados vários fragmentos de compostos associados a MP, como fosfatos de Ag e ETR; Cu associado a ETR; Ni associado a ETR; compostos de W, Sr e Co; e compostos de ETR (Imagem 22, Figura 34). 

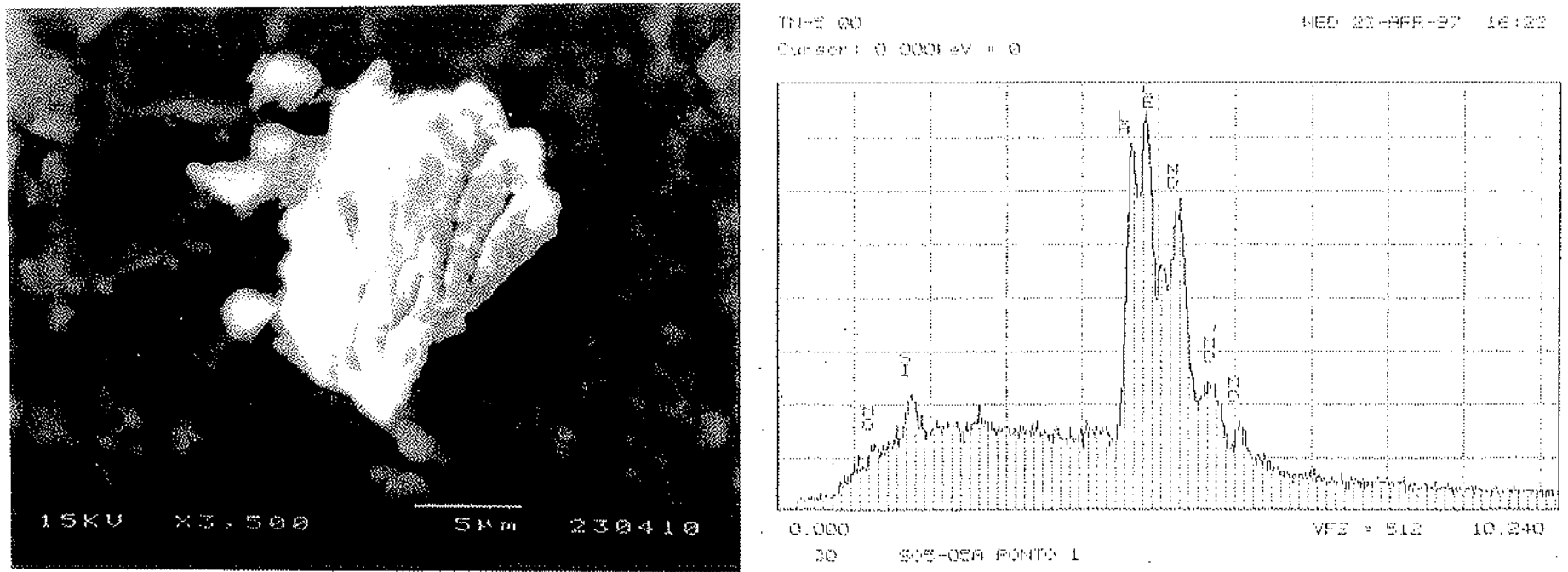

Imagem 22: Composto de ETR (Nd, Ce e La) Figura 34: Diagrama Espectral Químico (EDS) da imagem associado a $\mathrm{Mg}$ e Si, na matriz da amostra SO5-05 (Aumento $3500 \mathrm{X}$ )

22, com análise qualitativa apresentada em espectro.

\subsection{Unidade 3: Silte de coloração cinza-clara (sedimentos da Bacia de São Paulo)}

\subsubsection{Caracterização Macroscópica}

Esta unidade está localizada abaixo da camada de argila cinza-escura (Unidade 2), e acima do embasamento (alterita). Provavelmente, relaciona-se dos sedimentos da Bacia de São Paulo, que afloram a jusante do Córrego das Jaboticabeiras (Folografia 3), e que são utilizados em olarias para confecção da mistura para tijolos.

Caracteriza-se por um material de coloração cinza-clara, com textura siltosa, onde observa-se a presença de gräos de quarizo milimétricos que aumentam em quantidade em direção à sua base. O contato com o nível inferior (embasamento / alterita) é gradual.

Na Figura 35 é apresentada a distribuição das porcentagens de areia, argila e silte dos seus diversos níveis, de acordo com as análises granulométricas obtidas do longo do perfil. 


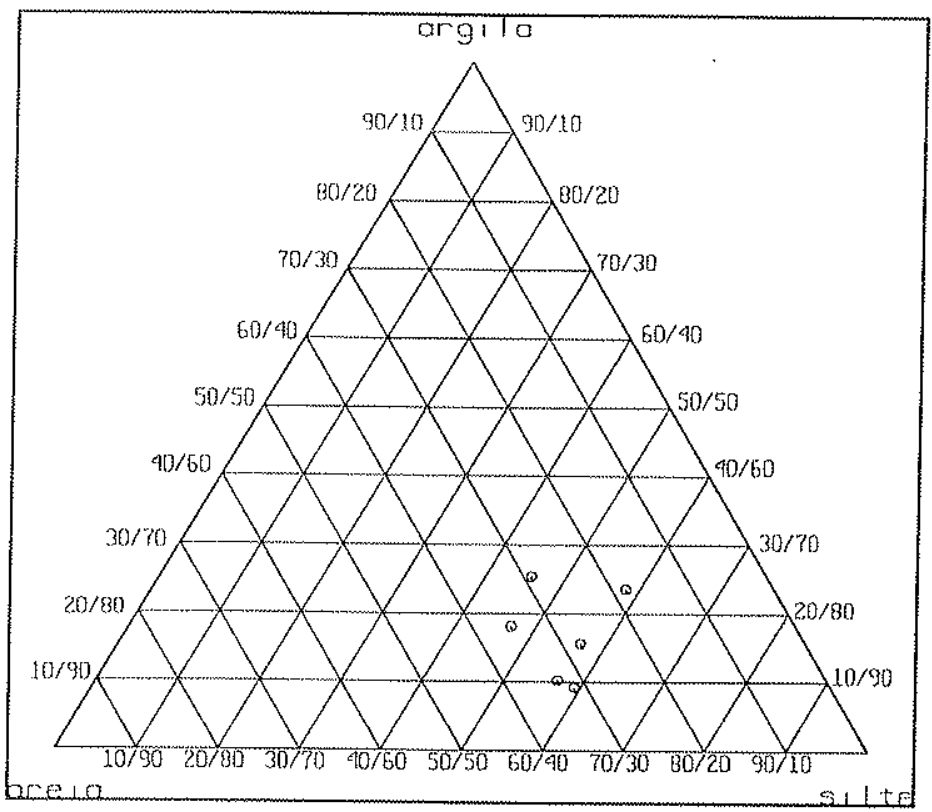

Figura 35: Distribuição da porcentagens de areia, argila e silte de amostras da Unidade 3 em diagrama triangular de classificação textural de solos, de acordo com CATI/SAA (1994).

De acordo com os resultados obtidos no Diagrama de Classificação Textural de Solos (CATI/SAA, 1994), podemos classificar a Unidade 3 como de textura franco a franco-siltosa. Com relaçäo aos niveis superiores (unidades 2 e 1), observa-se um maior aumento da porcentagem de silte, o que faz com que o material tenda para o campo dos francos / franco-siltosos.

Os valores do conteúdo de matéria orgânica para este nivel chegaram no máximo a $2 \%$. 


\subsubsection{Caracterização Microscópica}

Na lâmina S05-02, pertencente a esta unidade, pode-se observar a presença do material primário (clástico), representado por quartzos, turmalinas e alguns poucos minerais opacos $(<1 \%)$. Os grãos de quartzo são em sua maioria angulosos, e de dimensões variadas. Alguns apresentam-se com inclusões de rutilo, e a grande maioria possui extinção ondulante. Alguns grãos de quartzo encontram-se recobertos por um material muito fino, argiloso.

Com relação aos minerais secundários, há uma grande quantidade de minerais de coloração cinza prateada em luz natural, e com uma birrefringência alta em luz polarizada, muito comum ao longo das amostras de todas as unidades deste perfil (caulinitas), provindas da alteração da muscovita.

O plasma é de cor marrom clara, com porções mais escuras devido à maior concentração de óxidos de ferro e matéria orgânica. Em alguns pontos, observa-se a presença de esqueletos de micas pseudomorfisadas por óxidos e hidróxidos de Fe (Fotomicrografia 14).

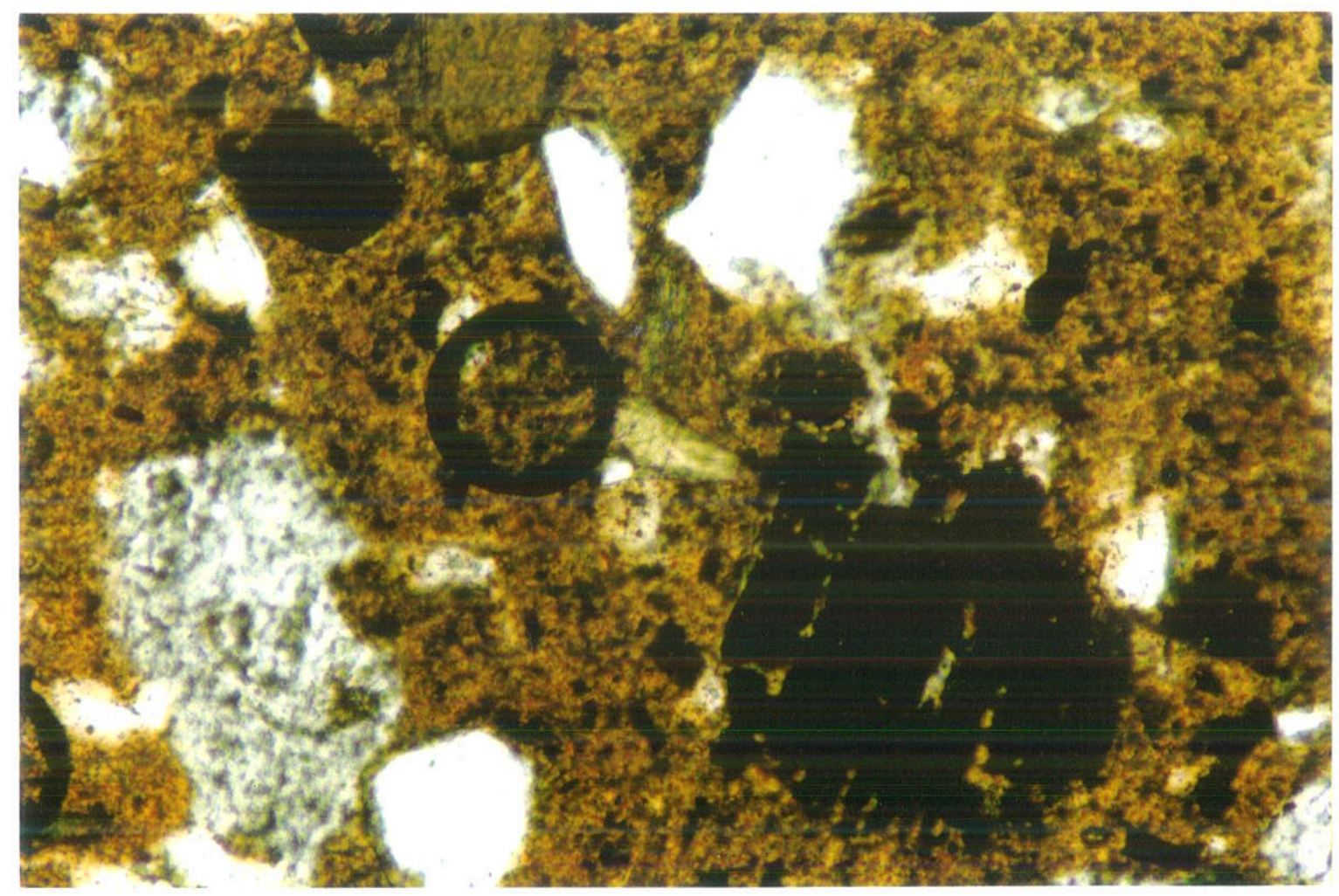

Fotomicrografia 14 (luz natural): Esqueletos de micas pseudomorfisadas por óxidos e hidróxidos de Fe, comuns na matriz da amostra SO5-02, pertencente a esta unidade. Campo das fotos: $0,41 \mathrm{~mm} X$ $0,28 \mathrm{~mm}$ (objetiva 20; abertura 5:1). 


\subsubsection{Determinaçōes em MEV}

\subsubsection{Fragmentos}

Os fragmentos das amostras SO5-01 e SO5-02, pertencentes a esta unidade, não exibiram conteúdos claros de $\mathrm{Zn}$, Cu e Pb. Foi apenas detectada a presença de manganês, geralmente associado à matriz ou ao material reprecipitado.

O quartzo continua sendo abundante, e apenas identificou-se a presença de cristais de barita (Imagem 23, figura 36), que não haviam sido identificados nos níveis anteriores. Estes cristais, geralmente bem formados, ocorrem em microfissuras do material, e podem ser explicados, de acordo com RICCOMINI et al (1988) como de provável origem hidrotermal.
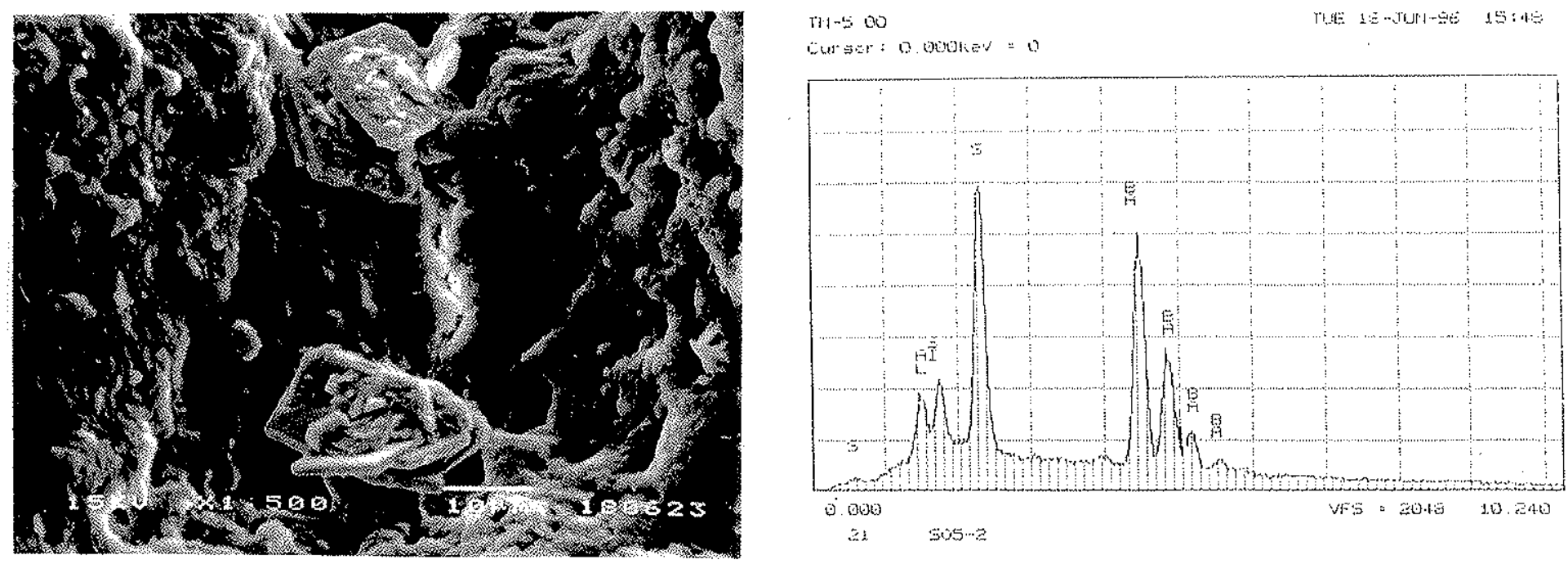

Imagem 23: Morfologia de gräo de solo da amostra Figura 36: Diagrama Espectral Quírnico (EDS) da SO5-02 em MEV: cristais de barita em imagem 23, com análise qualitativa apresentada em microcavidades (no centro superior e inferior da espectro.

imagem). Aumento $1500 x$. 


\subsubsection{Lâminas}

Análises em MEV de amostra do poço SO5 - único que atingiu esta Unidade identificaram uma matriz de composição essencialmente caulinítica (Si, Al, Ka, Ca e $\mathrm{Fel}$, onde observa se novamente a presença de $\mathrm{Cl}$.

Na matriz, foram encontrados muitos grãos de zircão disseminados, além de fragmentos de compostos de fosfato, associados a ETR (Nd, Ce e La) e à Ag. Também foram identificados compostos de Cu com Cl e Zn; Cu e Cr associados ao Fe; além de Sn, que não haviam sido delectados nos fragmentos analisados anteriormente.

A barita, que foi identificada nos fragmentos analisados em MEV, como cristais bem formados, ocorre na lâmina SO-05 na forma de fragmentos disseminados na matriz, estando associada à presença de Si e Al, em menor quantidade. 


\section{COMPORTAMENTO DOS METAIS PESADOS NA SEÇÃO DE ESTUDO}

De um modo geral, observa-se que há uma relação entre o padrão de comportamento dos MP e os litotipos presentes na seção de estudo - aqui representados pelas três Unidades descritas anteriormente: 1) colúvio; 2) argila cinza escura (B.S.Paulo) e 3) silte cinza-claro(B.S.Paulo). A seção pode ser dividida em três situações: a jusante, dentro e a montante da lagoa de infiltração.

O Anexo 5 apresenta a distribuição de $\mathrm{Cu}, \mathrm{Mn}, \mathrm{Mo}, \mathrm{Pb}$ e $\mathrm{Zn}$, e o Anexo 6, a distribuição de Cd na seção de estudo.

\subsection{Comportamento dos metais pesados nos furos localizados a jusante da lagoa de infiltração: TL-01, TL-02 e TL-03.}

As Tabelas 05, 06 e 07 apresentam os resultados analíticos para os metais Mo, $\mathrm{Mn}, \mathrm{Zn}, \mathrm{Cd}, \mathrm{Pb}$ e $\mathrm{Cu}$, bem como a caracterização granulométrica das unidades nos perfis TL-01 a TL-03. As Figuras 37 e 38 contemplam a distribuição comparada destes metais nos respectivos perfis de sondagem.

\begin{tabular}{|c|c|c|c|c|c|c|c|c|c|c|}
\hline \multirow[t]{2}{*}{$\begin{array}{l}\text { Profundidade } \\
(\mathrm{m}) \text { / Unidade }\end{array}$} & \multirow[t]{2}{*}{$\%$ mo } & \multicolumn{3}{|c|}{$\begin{array}{l}\text { Caracterização } \\
\text { Granulométrica } 1 \%\end{array}$} & \multicolumn{6}{|c|}{ Conteudo em metais pesados $(\mathrm{mg} / \mathrm{kg})$} \\
\hline & & argila & silte: & areia & Cu & $\mathrm{Pb}$ & $\ln$ & $\mathrm{Mn}$ & $\mathrm{Mo}$ & $\mathrm{Cd}$ \\
\hline $0.75-1,0011\}$ & 5 & 43.0 & 10.4 & 46.6 & 128.6 & 3.0 & 297.4 & 618.0 & 59.8 & 2.0 \\
\hline 1752.00111 & 3 & 33.5 & 4.7 & 61.8 & 135.0 & 16.0 & 219.9 & 601.0 & 60.8 & 2.0 \\
\hline $2.50-2.75111$ & 2 & 23.5 & 14.0 & 62.5 & 262.2 & 17.0 & 291.3 & 602.0 & 55.6 & 0.6 \\
\hline $3.00-3.25(1)$ & 1 & 28.2 & 23.1 & 48.7 & 417.8 & 29.0 & 205.6 & 794.0 & 77.6 & 3.3 \\
\hline $3.25-3.50(1)$ & 1 & 42.2 & 16.4 & 41.4 & 517.1 & 12.0 & 233.3 & 827.0 & 429.5 & 2.8 \\
\hline $3.50-3.7 .5(2)$ & 5 & 34.6 & 19.2 & 45.5 & 809.7 & 18.0 & 249.3 & 1249.0 & 423.1 & 0.0 \\
\hline $3.75-4.00(2)$ & 7 & 32.1 & 24.8 & 43.1 & 841.4 & 21.0 & 230.5 & 1340.0 & 409.2 & 2.2 \\
\hline $4.00-4.25\{2\}$ & 4 & 33.6 & 23.5 & 42.9 & 792.8 & 11.0 & 231.4 & 1276.0 & 372.9 & 1.4 \\
\hline
\end{tabular}

(1) Unidade /(colúvio); \{2) Unidade 2 (argila cinza-escura 8.S.Paulo) .

Tabela 05: Teor de matéria orgânica, caracterização granulométrica e conteúdo de metais pesados no furo TL-01. 


\begin{tabular}{|c|c|c|c|c|c|c|c|c|c|c|}
\hline \multirow[t]{2}{*}{$\begin{array}{l}\text { Profundidade } \\
\text { (m) } / \text { unidade }\end{array}$} & \multirow[t]{2}{*}{$8 \mathrm{mo}$} & \multicolumn{3}{|c|}{$\begin{array}{l}\text { Caracterização } \\
\text { Sranulométrica }(\%)\end{array}$} & \multicolumn{6}{|c|}{ Conteúdo em metais pesados $(\mathrm{mg} / \mathrm{kg})$} \\
\hline & & argila & silte & areia & 80 & $\mathrm{~Pb}$ & $\mathrm{Zn}$ & Mn & $\mathrm{Mo}$ & Cd \\
\hline $0.75,0011$ & 1 & 45.2 & 12.9 & 41.9 & 126.2 & 12.0 & 127.4 & 339.0 & 72.1 & 3.3 \\
\hline 150,17501 & 2 & 41.5 & 4.9 & 53.6 & 65.2 & 30 & 117.9 & 540.0 & 73.0 & 2.8 \\
\hline $2.00-22511$ & 2 & 29.0 & 10.8 & 60.2 & 48.6 & 0.0 & 135.9 & 303.0 & 53.8 & 0.0 \\
\hline $2.50-2.750$ & 2 & 40.2 & 11.9 & 47.9 & 151.8 & 2.6 & 208.8 & 421.0 & 68.7 & 2.2 \\
\hline $3.0003 .25(2)$ & 5 & n.d. & n.d. & n.d. & 391.7 & 10.0 & 187.2 & 597.0 & 403.3 & 1.4 \\
\hline $3,50-3,75(2)$ & 6 & 28.3 & 16.3 & 55.4 & 704.8 & 26.0 & 206.6 & 950.0 & 404.6 & 1.6 \\
\hline $3 / 754,00121$ & 5 & 29.1 & 22.4 & 48.5 & 672.0 & 25.0 & 207.0 & 907.0 & 396.6 & 1.6 \\
\hline $4.00-4.25(2)$ & 5 & 31.5 & 22.5 & 46.0 & 567.9 & 47.0 & 234.0 & 700.0 & 483.9 & 4.2 \\
\hline
\end{tabular}

(1) Unidade 1(colúvio): (2) Unidade 2 (argila cinzanescura B.S.Paulo): n.d.:não determinado.

Tabela 06: Teor de matéria orgânica, caracterização granulométrica e conteúdo de metais pesados no furo TL-02.

\begin{tabular}{|c|c|c|c|c|c|c|c|c|c|c|}
\hline \multirow{2}{*}{$\begin{array}{l}\text { Profundidade } \\
\text { (m) }\end{array}$} & \multirow[t]{2}{*}{ \%mo } & \multicolumn{3}{|c|}{$\begin{array}{l}\text { Caracterizacão } \\
\text { Granulometrica }(\%)\end{array}$} & \multicolumn{6}{|c|}{ Conteúdo em metais pesados $(\mathrm{mg} / \mathrm{kg})$} \\
\hline & & argila & silte & areia & $\mathrm{OU}$ & $\mathrm{Pb}$ & $\mathrm{Zn}$ & $\mathrm{Mn}$ & Mo & $\mathrm{Cd}$ \\
\hline $0.75 \% 1: 00111$ & n.d. & 39.1 & 23.0 & 37.9 & 151.8 & 13.0 & 208.8 & 421.0 & 68.7 & 3.4 \\
\hline $150-1,75^{\prime 11}$ & 2 & 37.2 & 10.5 & 52.3 & 115.3 & 30 & 191.1 & 186.0 & 68.6 & 2.8 \\
\hline $2.00-2.25(1)$ & 2 & n.d. & n.d. & n.d. & 129.3 & 25 & 287.9 & 168.0 & 72.1 & 2.6 \\
\hline $2.25-2.50(1)$ & 3 & 40.8 & 13.0 & 46.2 & 136.2 & 11 & 261.5 & 191.0 & 350.8 & 0.4 \\
\hline $2,75-3,00(2)$ & 4 & 43.7 & 12.7 & 43.6 & 303.7 & 32 & 157.2 & 554.0 & 398.0 & 1.2 \\
\hline $3.00-3.25(2)$ & 5 & 36.2 & 18.7 & 45.1 & 615.4 & 24 & 169.3 & 825.0 & 397.0 & 1.0 \\
\hline $3.50-3.75(2)$ & 5 & 33.5 & 19.0 & 47.5 & 802.3 & 9 & 203.5 & 1039.0 & 52.3 & 0.0 \\
\hline $3754: 00^{(2)}$ & 4 & 34.0 & 20.0 & 46.0 & 496.0 & 18 & 163.2 & 628.0 & 361.1 & 0.6 \\
\hline $4775-5.00^{(3)}$ & 2 & 18.3 & 23.5 & 58.2 & 134.7 & 0 & 81.1 & 148.0 & 318.6 & 0.0 \\
\hline
\end{tabular}

(1) Unidade ('colúvio); (2) Unidade 2 (argila cinza-escura B.S.Paulo); (3) Unidade 3 (sille cinza-claro B.S.Paulo); n.d.: năo determinado.

Tabela 07: Teor de matéria orgânica, caracterização granulométrica e conteúdo de metais pesados no furo TL-03.

Os furos localizados a jusante da lagoa de infiltração apresentam como característica principal o fato de não estarem alterados por escavações ou qualquer outro tipo de intervenção antrópica.

De um modo geral, observa-se uma tendência do aumento da concentração com a profundidade. Para o $\mathrm{Cu}$ e $\mathrm{Mn}$, há um aumento de suas concentrações, à medida que a camada de argila cinza-escura (Unidade 2 ) é atingida, sendo que estas concentrações tendem a diminuir logo abaixo do lençol freático. 


\section{LEGENDA}

Unidade 1 (colúvio)

Unidade 2 (argila cinza-escura - B.S.Pau O)

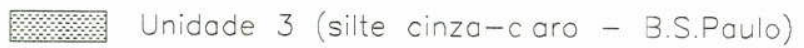

$\because$ Unidade 4 (alterita / embasamento)

पायाया material remobilizado / aterro

nivel de entulho

? nível d'águo
Metais Pesados

$$
\begin{aligned}
& \mathrm{Mn}- \\
& \mathrm{Zn}- \\
& \mathrm{Pb}- \\
& \mathrm{Mo}- \\
& \mathrm{Cu}-
\end{aligned}
$$

logoa ce infiltração

A

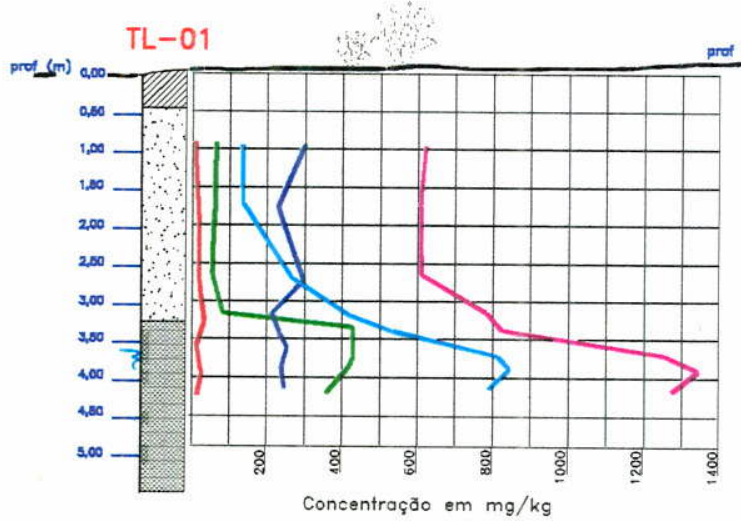

$T L-02$

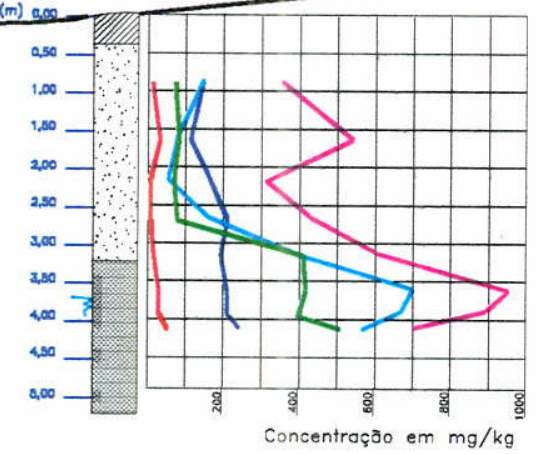

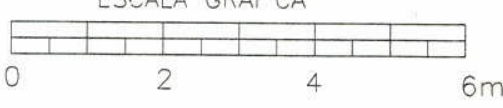

Figura 37: Comportamento do $\mathrm{Mn}, \mathrm{Zn}, \mathrm{Pb}, \mathrm{Mo}$ e $\mathrm{Cu}$ nos perfis $\mathrm{TL}-01$ a $\mathrm{T} L-03$, situados à jusante da lagoa de infiltração 


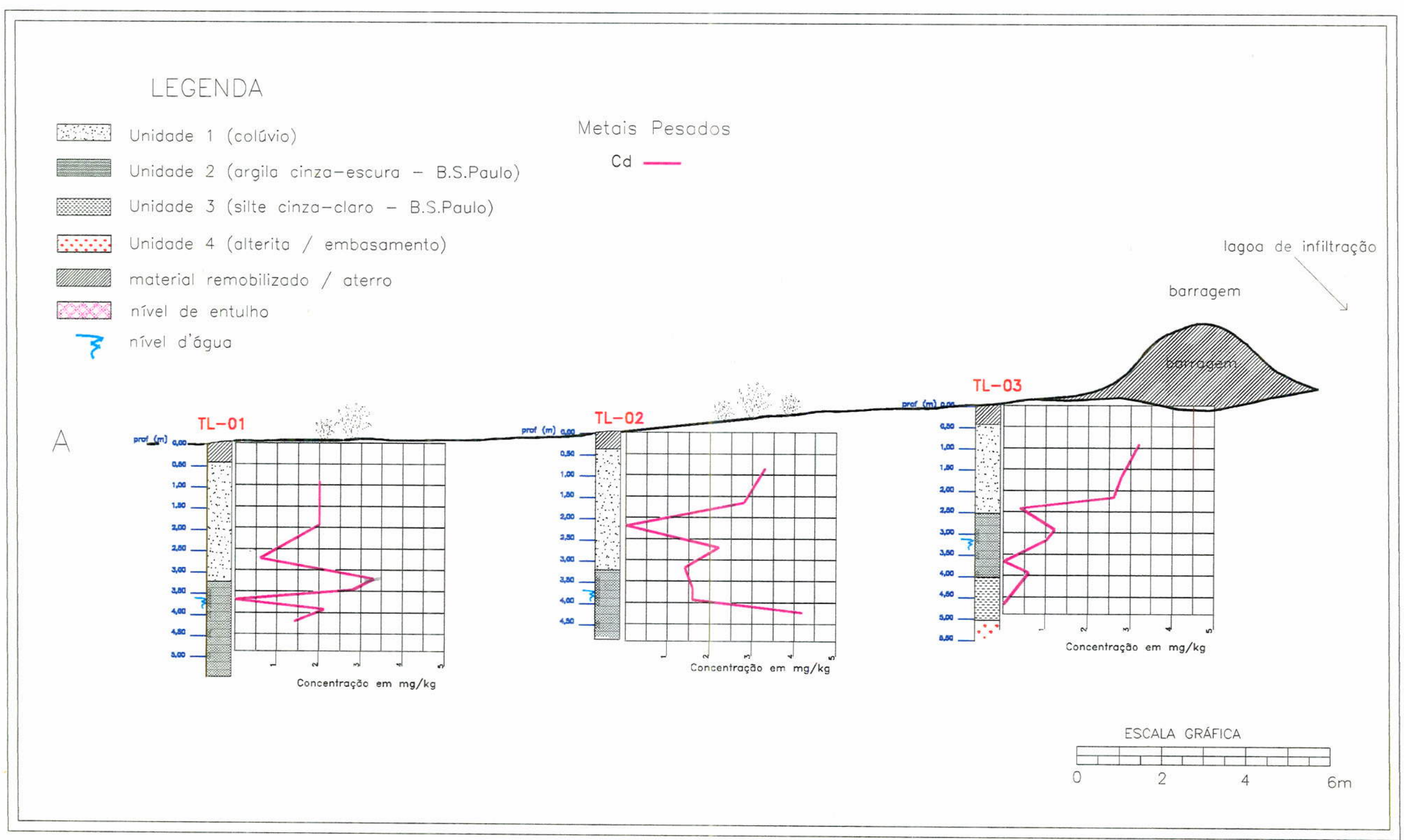

Figura 38: Comportamento do Cd nos perfis $T L-01$ a $T L-03$, situados a jusante da lagoa de infiltracão 
O Mo apresenta o mesmo comportamento, porém, nos perfis TL-02 e TL-03 há uma tendência de diminuição de sua concentração logo abaixo do nível do lençol freático. No perfil TL-03, que é o único deste trecho que atingiu a unidade 3 (silte cinza-claro), estes três metais têm suas concentrações diminuídas nesta Unidade, como pode ser observado na Figura 37.

O Zn sofre um pequeno aumento da concentração na base da Unidade 1 (colúvio), onde atingiu valores de 287 a $291 \mathrm{mg} / \mathrm{kg}$, sendo que esta concentração diminui ao se atingir a camada inferior.

O comportamento do $\mathrm{Pb}$ em relação aos diferentes litotipos nos perfis não apresenta um padrão uniforme, sendo obtidos valores de 0 a $47 \mathrm{mg} / \mathrm{kg}$.

Os teores de Cd oscilam entre 0 e $4 \mathrm{mg} / \mathrm{kg}$. Embora não tenha sido identificado um comportamento padrão com relação aos diferentes litotipos, observa-se um certo comportamento padrão do mesmo ao longo do perfil, em função da profundidade, principalmente nos primeiros $3,5 \mathrm{~m}$. Para os furos TL-01 a TL-03, o Cd apresenta uma queda na sua concentração na profundidade de 2,0 a 2,5 metros; esta concentração aumenta até 3,5 metros, decaindo novamente, e aumentando logo em seguida (Figura 38).

\subsection{Comportamento dos metais pesados nos furos localizados dentro da lagoa de infiltração: TL-04 e TL-05}

A Tabelas 08 e 09 apresentam os resultados analíticos para os metais $\mathrm{Mo}, \mathrm{Mn}$, $\mathrm{Zn}, \mathrm{Cd}, \mathrm{Pb}$ e $\mathrm{Cu}$, bem como a caracterização granulométrica das unidades nos perfis TL-04 e TL-05. As Figuras 39 e 40 exibem a distribuição comparada destes metais nos respectivos furos de sondagem.

\begin{tabular}{|c|c|c|c|c|c|c|c|c|c|c|}
\hline \multirow{2}{*}{$\begin{array}{l}\text { Profundidade } \\
\text { (m) }\end{array}$} & \multirow[t]{2}{*}{$\%$ mo } & \multicolumn{3}{|c|}{$\begin{array}{l}\text { Caracterização } \\
\text { Granulométrica }(\%)\end{array}$} & \multicolumn{6}{|c|}{$\begin{array}{l}\text { Conteúdo em metais pesados } \\
\qquad(\mathrm{mg} / \mathrm{kg})\end{array}$} \\
\hline & & argila & silte & areia & $\mathrm{Cu}$ & $\mathrm{Pb}$ & $2 n$ & $\mathrm{Mn}$ & Mo & $\mathrm{Cd}$ \\
\hline $0,250,50$ & 8 & 20,4 & 17,1 & 62,5 & 438 & 16 & 1075 & 27 & 512 & 0,0 \\
\hline $0,50-0,6011)$ & 4 & n.d. & n.d. & n.d. & 857 & 47 & 1136 & 333 & 544 & 2,0 \\
\hline $0,75,1,00(1)$ & n.d. & 35,6 & 20,0 & 44,4 & 861 & 76 & 1120 & 347 & 496 & 0,2 \\
\hline $1,00-1,2511$ & 4. & 31,8 & 22,0 & 46,2 & 945 & 129 & 721 & 423 & 369 & 0,6 \\
\hline $125-1,5011\}$ & 4 & 28,4 & 20,2 & 51,4 & 501 & 75 & 247 & 488 & 315 & 0,0 \\
\hline $1,50.1,7512\}$ & 4 & 33,2 & 10,2 & 56,6 & 193 & 87 & 138 & 490 & 405 & 1,0 \\
\hline $2,00-2,25 \mid 2\}$ & n.d. & 27,7 & 15.6 & 56,7 & 199 & 67 & 101 & 321 & 64 & 0,2 \\
\hline
\end{tabular}

(1) Unidade 1 (colúvio): (2) Unidade 2 (argila cinza-escura B.S.Paulo): n.d.: não determinado.

Tabela 08: Teor de matéria orgânica, caracterização granulométrica e conteúdo de metais pesados no furo $\mathrm{TL}-04$. 


\begin{tabular}{|c|c|c|c|c|c|c|c|c|c|c|}
\hline \multirow{2}{*}{$\begin{array}{l}\text { Profundicade } \\
\text { (m) }\end{array}$} & \multirow[t]{2}{*}{$\% \mathrm{mo}$} & \multicolumn{3}{|c|}{$\begin{array}{l}\text { Caracterização } \\
\text { Granulometrica }(\%)\end{array}$} & \multicolumn{6}{|c|}{ Confeudo em metais pesados $(\mathrm{mg} / \mathrm{kg})$} \\
\hline & & argila & silfe. & areia & $\mathrm{Cu}$ & $\mathrm{Pb}$ & $2 \mathrm{Ln}$ & $\mathrm{Mn}$ & Mo & $\mathrm{Cd}$ \\
\hline $0,25 \div 0,50$ & n.d. & 19,9 & 17.7 & 62,4 & 934 & 27 & 1104 & 570 & 387 & 0,0 \\
\hline 0,50075 & 2 & 25,8 & 16,3 & 57,9 & 377 & 34 & 280 & 352 & 65 & 0,6 \\
\hline $075.1,00$ & 2 & 25,7 & 17,7 & 56,6 & 231 & 29 & 134 & 352 & 371 & 0,6 \\
\hline $1,00 \cdot 1.2514$ & 1 & 39,3 & 10,8 & 49,9 & 214 & 20 & 143 & 491 & 394 & 0,8 \\
\hline $1,25 \ldots 1,50(1)$ & 1 & 41.5 & 13,2 & 45,3 & 119 & 24 & 73 & 622 & 417 & 1,2 \\
\hline $1,50-1,75(2)$ & 1 & 31.6 & 14,0 & 54,4 & 91 & 35 & 96 & 494 & 421 & 2.2 \\
\hline $1 / 75-2,00^{(2)}$ & 2 & 37,6 & 14,2 & 48,2 & 73 & 39 & 95 & 560 & 71 & 2,4 \\
\hline $2,00-2,25 \mid 21$ & 1 & 44,1 & 17,0 & 38,9 & 144 & 48 & 95 & 106 & 71 & 4,2 \\
\hline $2,50-2,75 \mid 3\}$ & n.d. & 31,6 & 9,2 & 59,2 & 73 & 38 & 125 & 72 & 72 & 2,6 \\
\hline
\end{tabular}

(1) Unidade 1(colúvio): (2) Unidade 2 (argila cinza-escura B.S.Paulo): (3) Unidade 3 (silte cinza-claro B.S.Paulo); n.d.: não determinado.

Tabela 09: Teor de matéria orgânica, caracterização granulométrica e conteúdo de metais pesados no furo TL-05.

Os perfis TL-04 e TL-05, localizados dentro da lagoa de infiltração, não possuem a parte superior do perfil de solo, devido a cortes e remobilização de material para construção da lagoa e "manipulações" de fundo da mesma (inclusão de cal, remoção com trator, etc).

No perfil TL-04, nota-se um aumento da concentração de $\mathrm{Mn}, \mathrm{Mo}, \mathrm{Cu}$ e $\mathrm{Zn}$, quando a camada de argila cinza-escura (Unidade 2) é atingida, sendo que para o Cu e $\mathrm{Zn}$, a concentração diminui ao se atingir a camada inferior (Unidade 3). Para o Mn e Mo, a concentração diminui quando o lençol freático é atingido.

O $\mathrm{Pb}$ tende a aumentar a sua concentração na camada de argila cinzaescura (Unidade 2) no furo $\mathrm{TL}-04$, sendo que esta concentração diminui assim que a unidade inferior é atingida. Para o perfil TL-05, ele não apresenta um comportamento definido, mas há uma tendência do aumento de sua concentração com a profundidade (Figura 39).

O Ca não apresenta padrões de comportamento comuns nos perfis TL-04 e TL05. No perfil TL-04, a sua concentração oscila, com comportamento semelhante do observado nos furos TL-01 a TL-03. No perfil TL-05, a concentração de Cd tende a aumentar com a profundidade, diminuindo apenas quando a camada de silte cinzaclaro (Unidade 3) é atingida (Figura 40). 


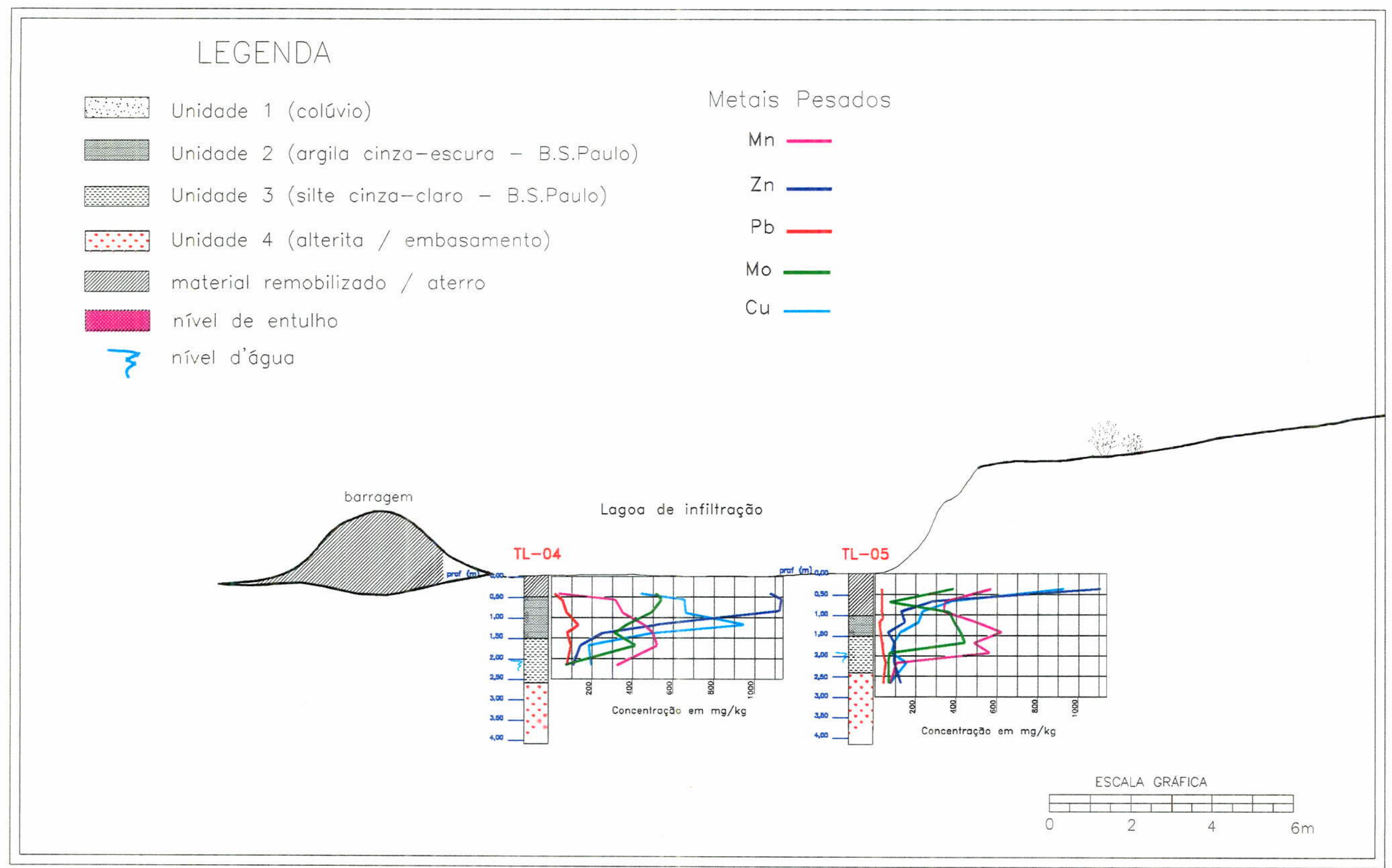

Figura 39: Comportamento do $\mathrm{Mn}, \mathrm{Zn}$, Pb, Mo e Cu nos perfis $T L-04$ e TL-05, situados dentro da lagoa de infiltração 


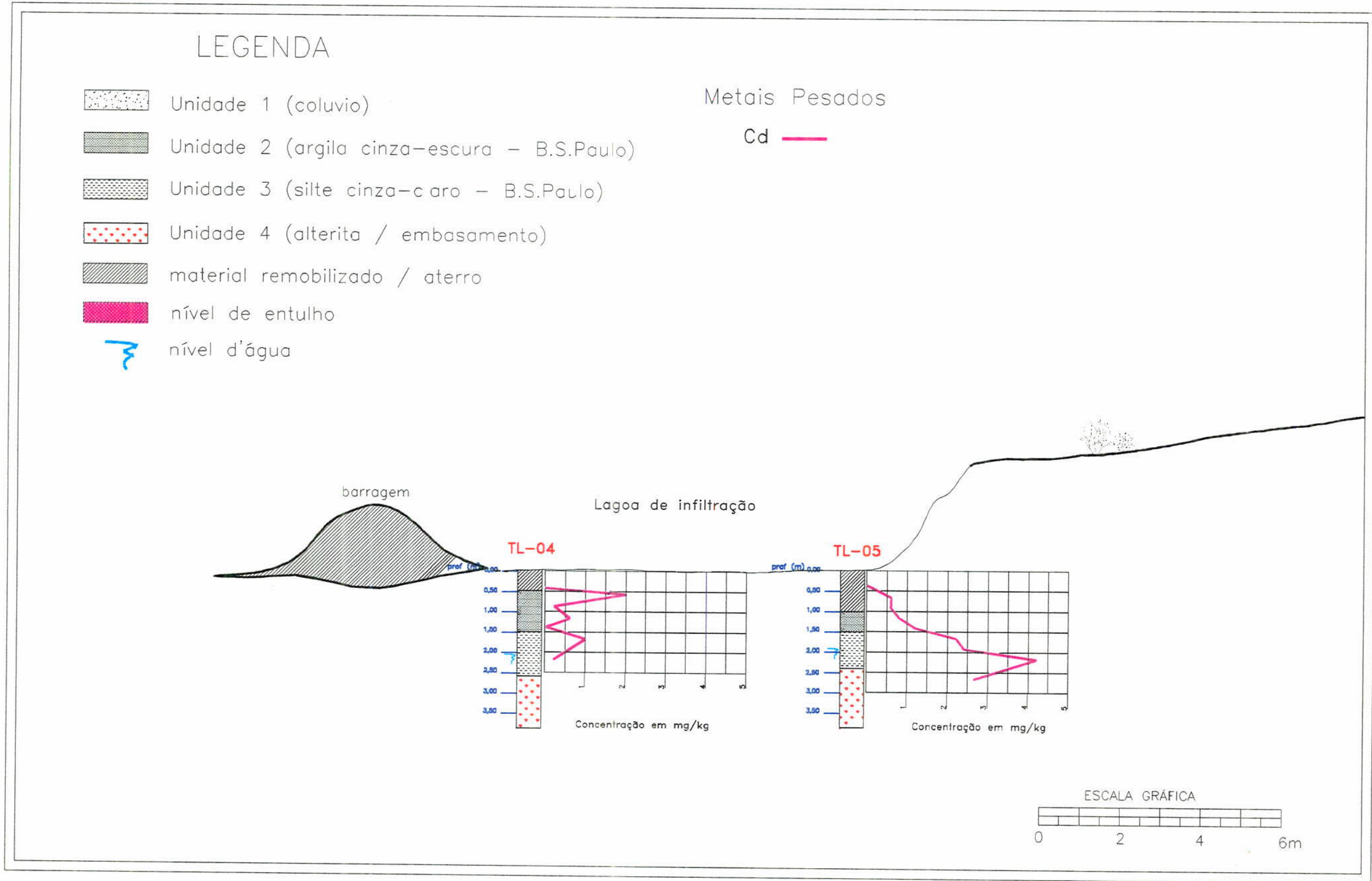

Figura 40: Comportamento do Cd nos perfis $T L-04$ e $T L-05$, situados dentro da lagoa de infiltração 
7.3. Comportamento dos metais pesados nos furos localizados a montante da lagoa de infiltração: TL-06 e TL-07

Quando o perfil de estudo foi idealizado, pretendia-se comparar o comportamento dos metais pesados no solo com e sem a influência da lagoa de infiltração. Os furos TL-06 e TL-07 seriam utilizados para se determinar os valores de background dos metais pesados nas diferentes unidades de estudo.

Porém, ao serem efetuadas as tradagens, detectou-se a existência de um nível de entulho, de aproximadamente $30 \mathrm{~cm}$ de espessura, na profundidade 0,50 a 0,80m, que foi atingido por estes dois furos. Este nível caracteriza-se por um material escuro e úmido, de maior porosidade, onde se observa a presença de resíduos da indústria, como fios, plásticos, restos de embalagens, etc. (Fotografia 07). Neste nível também foi identificado o maior valor de matéria orgânica para as amostras analisadas: 10\%.

Análises químicas de amostras pertencentes a este nível exibem um material com alta concentração de Cu (entre 3339 e 3375 mg/kg), Zn (entre 7174 e 8807 $\mathrm{mg} / \mathrm{kg}$ ), $\mathrm{Mn}$ (entre 6837 e $6545 \mathrm{mg} / \mathrm{kg}$ ) e Pb (entre 191 e $521 \mathrm{mg} / \mathrm{kg}$ ).

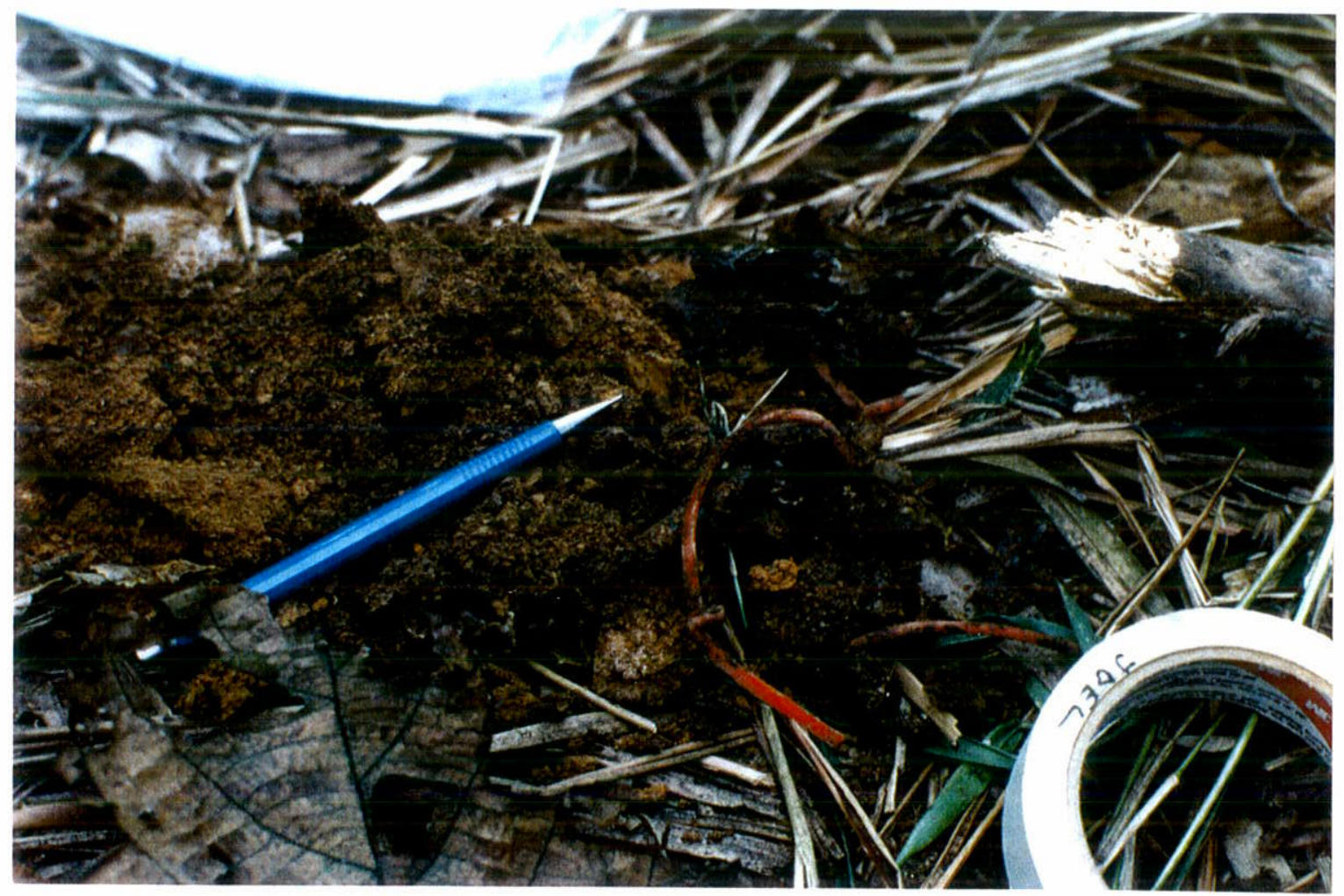

Fotografia 07: Aspecto do material presente em nível de entulho no furo TL-06. 
As Tabelas 10 e 11 apresentam os resultados analíticos para os metais e as Figuras 41 e 42 a distribuição comparada para Mo, Mn, $\mathrm{Zn}, \mathrm{Cd}, \mathrm{Pb}$ e $\mathrm{Cu}$ nos perfis de sondagem TL-06 e TL-07.

\begin{tabular}{|c|c|c|c|c|c|c|c|c|c|c|}
\hline \multirow{2}{*}{ Profundidade } & \multirow[t]{2}{*}{$\%$ mo } & \multicolumn{3}{|c|}{$\begin{array}{l}\text { Caracterizaçã } \\
\text { Granulométrica }(\%)\end{array}$} & \multicolumn{6}{|c|}{$\begin{array}{l}\text { Conteúdo em metais pesados } \\
\text { (mg/kg) }\end{array}$} \\
\hline & & argila & silte & arela & $\mathrm{Cu}$ & $\mathrm{Pb}$ & $\mathrm{Zn}$ & $\mathrm{Mn}$ & $\mathrm{Mo}$ & $\mathrm{Cd}$ \\
\hline $0,650,80$ & 8 & 29,2 & 7.1 & 63,7 & 3375 & 521 & 8807 & 2891 & 280 & 1,0 \\
\hline $0,751,00$ & 10 & 7.7 & 34,8 & 57,5 & 1190 & 155 & 3260 & 6545 & 28 & 0,0 \\
\hline 150,17511 & 4 & 32,9 & 20,6 & 46,5 & 197 & 69 & 658 & 780 & 49 & 0,2 \\
\hline $2,252,5011$ & 2 & 31,1 & 23,7 & 45,2 & 58 & 50 & 200 & 809 & 423 & 3,0 \\
\hline $2,50-2,75121$ & 2 & 18,6 & 24,6 & 56,8 & 48 & 33 & 70 & 1040 & 389 & 1,4 \\
\hline $2,75-3,00\{2\}$ & 3 & 18,0 & 34,0 & 48,0 & 88 & 21 & 54 & 1195 & 358 & 0,4 \\
\hline $3,25-3,50(2)$ & 4 & 34,3 & 22,2 & 43,5 & 74 & 28 & 76 & 1152 & 399 & 1,8 \\
\hline $3,50-3,75 \mid 2\}$ & 5 & 32,2 & 17,2 & 50,6 & 75 & 24 & 107 & 1304 & 172 & 1,0 \\
\hline $4,00-4,25,3$ & 2 & 36,7 & 13,2 & 50,1 & 62 & 46 & 121 & 956 & 77 & 3,8 \\
\hline $4,50-4,75(3)$ & 7 & 35,1 & 18,1 & 46,8 & 57 & 27 & 98 & 727 & 68 & 1,4 \\
\hline
\end{tabular}

(1) Unidade 1(colúvio): (2) Unidade 2 largila cinza-escura B.S.Paulo): (3) Unidade 3 (silte cinza-claro B.S.Paulo).

Tabela 10: Teor de matéria orgânica, caracterização granulométrica e conteúdo de metais pesados no furo TL-06.

\begin{tabular}{|c|c|c|c|c|c|c|c|c|c|c|}
\hline \multirow{2}{*}{$\begin{array}{l}\text { Profundidade } \\
\text { (m) }\end{array}$} & \multirow[t]{2}{*}{$\%$ mo } & \multicolumn{3}{|c|}{$\begin{array}{l}\text { Caracterizaçäo } \\
\text { Granulométrica }(\%)\end{array}$} & \multicolumn{6}{|c|}{$\begin{array}{l}\text { Conteúdo em metais pesados } \\
(\mathrm{mg} / \mathrm{kg})\end{array}$} \\
\hline & & argila & silte & areia & $\mathrm{Cu}$ & $\mathrm{Pb}$ & $\mathrm{Zn}$ & $\mathrm{Mn}$ & Mo & $\mathrm{Cd}$ \\
\hline $0,25-0,50$ & 4 & 22,0 & 17,7 & 60,3 & 3339 & 191 & 7174 & 6237 & 52 & 0,6 \\
\hline $1,00-1,2511$ & 6 & 43,8 & 12,6 & 43,6 & 59 & 22 & 94 & 234 & 70 & 2,8 \\
\hline $2,25-2,50\{1]$ & 4 & 35,4 & 9,8 & 54,8 & 71 & 16 & 77 & 219 & 65 & 1.2 \\
\hline $2,75-3,00^{(2)}$ & 5 & 40,3 & 12,4 & 47,3 & 58 & 29 & 78 & 348 & 61 & 1.8 \\
\hline $3,00-3,25\lfloor 2\rfloor$ & 4 & 36,6 & 19,0 & 44,4 & 85 & 37 & 57 & 354 & 408 & 1,4 \\
\hline $3,25-3,50^{(2)}$ & 2 & 24,9 & 29.8 & 45,3 & 69 & 30 & 64 & 412 & 187 & 2.2 \\
\hline $3,50-3,75(3)$ & 2 & 29.0 & 25,4 & 45,6 & 94 & 19 & 62 & 585 & 298 & 1,8 \\
\hline
\end{tabular}

(1) Unidade I/colúvio); (2) Unidade 2 (argila cinza-escura 8.S.Paulo); (3) Unidade 3 (silte cinza-claro B.S.Paulo);

Tabela 11: Teor de matéria orgânica, caracterização granulométrica e conteúdo de metais pesados no furo TL-07.

O $\mathrm{Cu}, \mathrm{Pb}$ e $\mathrm{Zn}$, que se encontram em altos teores no nível de entulho, diminuem a sua concentração com o aumento da profundidade, sendo que para o Cu, a concentração nas Unidades 1 e 2 deste trecho da seção atinge valores muito abaixo dos encontrados para este metal nas mesmas Unidades nos furos TL-01 a TL-03.

O Mn, presente em altos teores no nivel de entulho, diminui a sua concentração com a profundidade, porém, esta concentração volta a aumentar quando a camada de argila cinza-escura é atingida. Ao se atingir o lençol freático, a sua concentração diminui. 
Como pode se notar na Figura 41 , com exceção do $\mathrm{Mn}$, todos os outros metais decrescem em conteúdo com a profundidade (próximo de $1,5 \mathrm{~m}$ ), estabilizando as suas concentrações na base ou pouco abaixo do nivel de entulho.

Deste ponto em diante, Mo e Mn adquirem comportamento similar da concentração com a profundidade, ao passo que os outros metais mantêm-se estáveis até a base do perfil. Ao se atingir o lençol freático, Mo e Mn apresentam acentuada diminuição de suas concentrações.

O Mo, que não apresentou concentrações elevadas no nivel de entulho, tende a aumentar a sua concentração ao ser atingido o nivel de argila cinza-escura, sendo que esta concentração tende a diminuir quando a Unidade 3 é atingida.

Nestes perfis, o Cd apresenta um padrão de comportamento semelhante aos identificados nos furos TL-01 a TL-03, porém, no perfil TL-06, a sua maior concentração detectada foi na profundidade de $4,25 \mathrm{~m}$, na altura do lençol freático. 


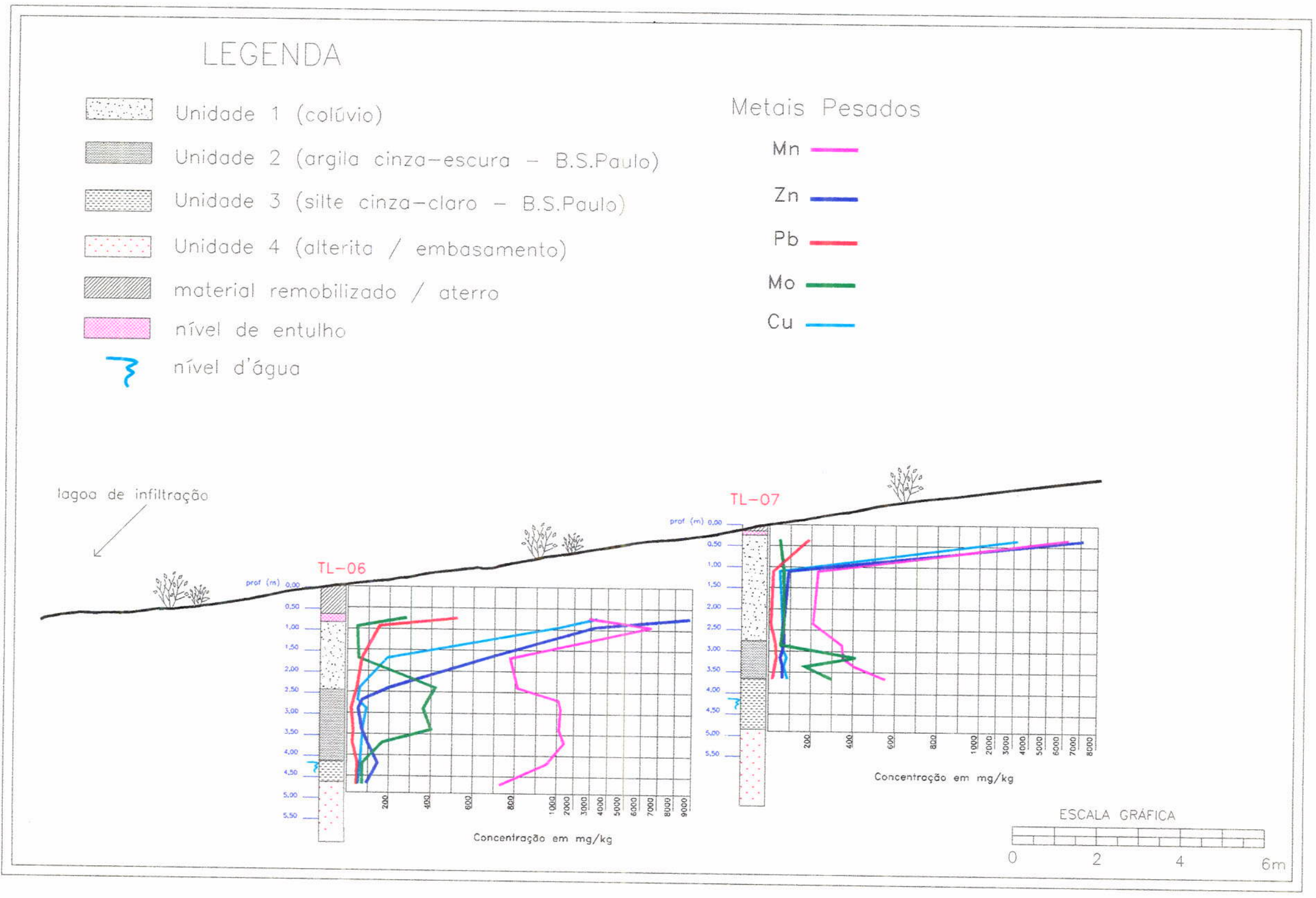

Figura 41: Comportamento do $\mathrm{Mn}, \mathrm{Zn}, \mathrm{Pb}, \mathrm{Mo}$ e $\mathrm{Cu}$ nos perfis TL-06 e $T L-07$, situados a montante da lagoa de infiltração 


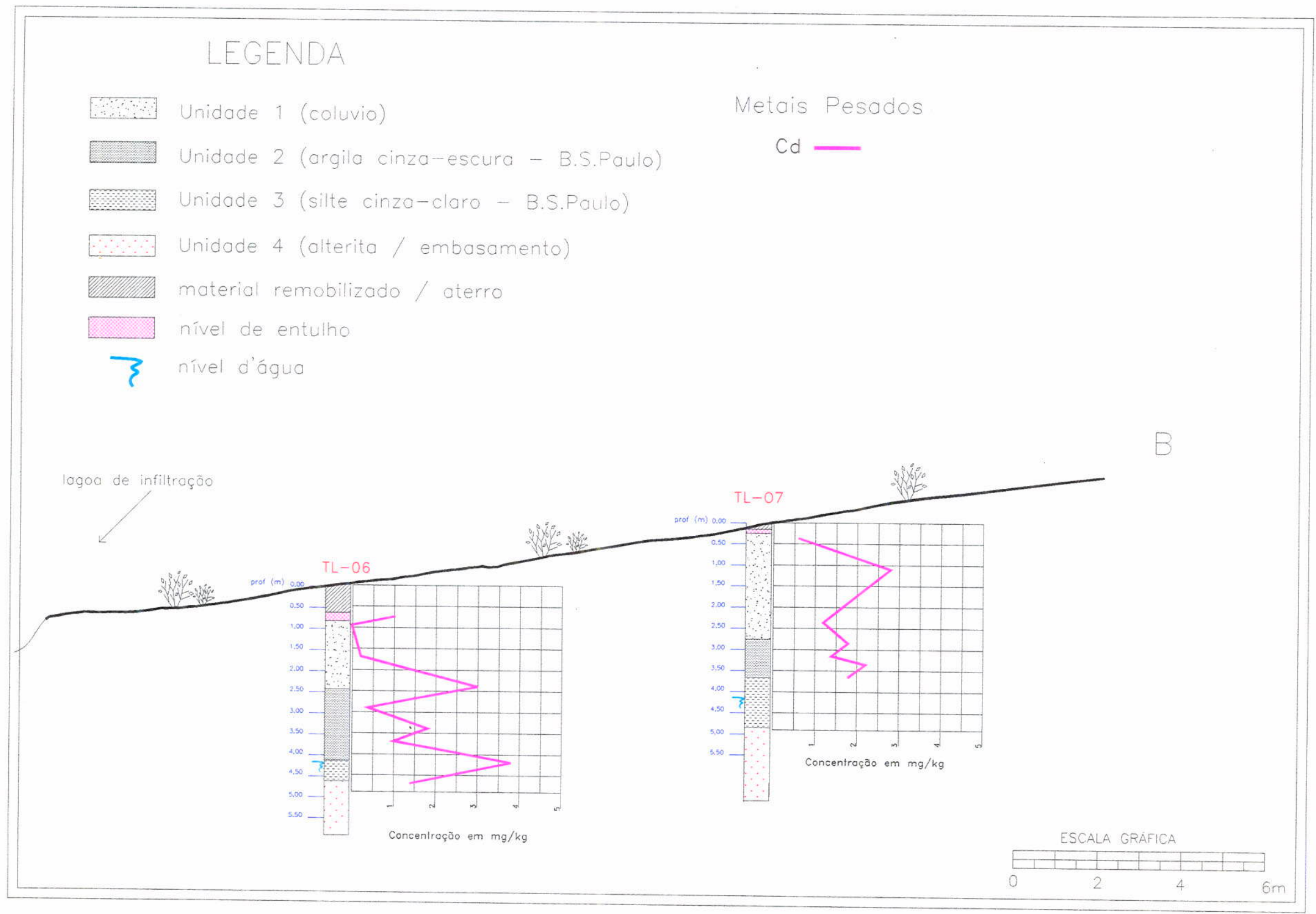

Figura 42: Comportamento do Cd nos perfis $T L-06$ e $T L-07$, situados a montante da lagoa de infiltração 


\section{ASSOCIAÇÕES DOS METAIS PESADOS COM A GRANULOMETRIA E TEOR DE MATÉRIA ORGÂNICA NA SEÇÃO DE ESTUDO}

Os dados obtidos através de análises químicas e granulométricas de amostras das diferentes unidades presentes no perfil, possibilitaram a identificação de correlações existentes entre o comportamento dos metais pesados $e$ as características granulométricas e de conteúdo de matéria orgânica no perfil.

Para a elaboração dos gráficos de correlação, utilizou-se o soffware Excel 5.0 for Windows. Os dados foram plotados 2 a 2 em um gráfico do tipo $X Y$, de onde foi possivel obter-se o valor da correlação linear entre estes dois dados (identificada nos gráficos como $\mathrm{R}^{2}$ ), bem como a reta de correlação linear e sua equação. Para uma correlação de $100 \%$, o valor de $R^{2}$ é igual a 1.

\subsection{Associações do conteúdo de MP com a granulometria}

Alguns furos exibem forte correlação entre a porcentagem de silte, argila ou areia, e o comportamento dos metais pesados no perfil. No caso do Mn, não foi possivel observar nenhuma correlação expressiva entre o seu conteúdo no perfil e a granulometria dos sedimentos.

\section{a) associacões com o conteúdo de araila}

Não foi observada uma boa correlação entre o conteúdo de argila e o teor de metais pesados ao longo de todo o perfil. As correlações mais altas observadas referem-se ao $\mathrm{Pb}$ e $\mathrm{Zn}$, encontrando-se, no primeiro caso, os valores de 0,46 (TL-03) e 0,56 (T́L-04) (Figuras 43 e 44), e para o segundo metal 0,53 (TL-03) (Figura 45).

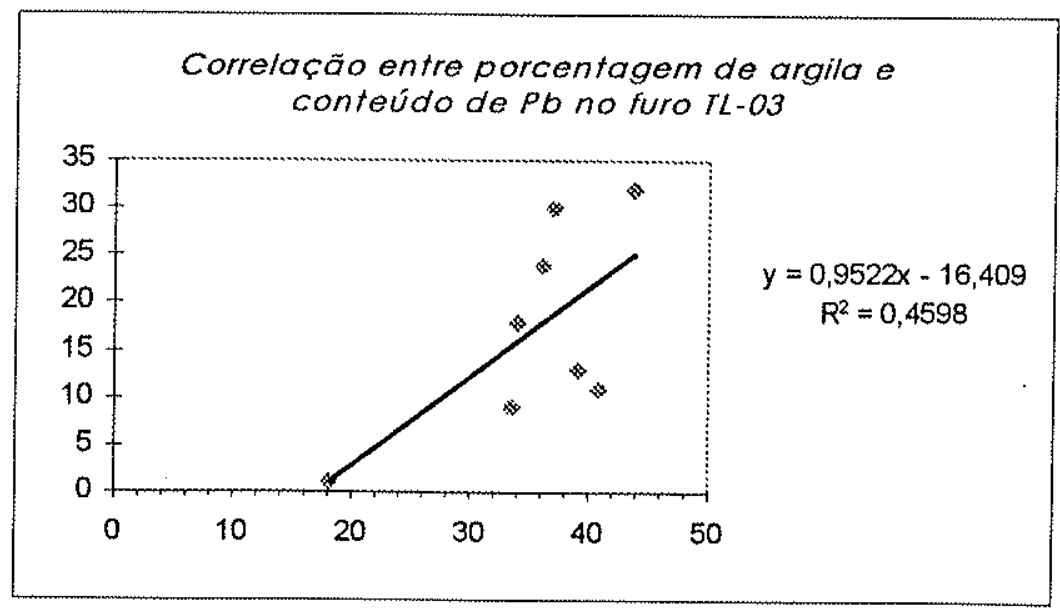

Figura 43 : Gráfico de correlação linear entre a porcentagem de argila e conteúdo de chumbo nas amostras do furo TL-03. 


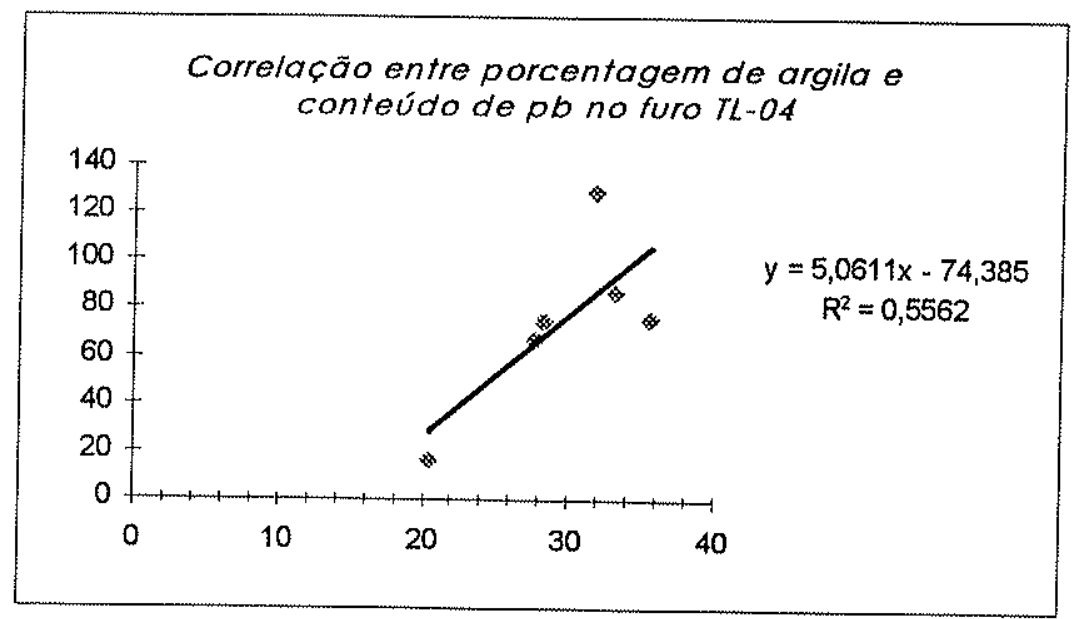

Figura 44 : Gráfico de correlação linear entre a porcentagem de argila e conteúdo de chumbo nas amostras do furo TL-04.

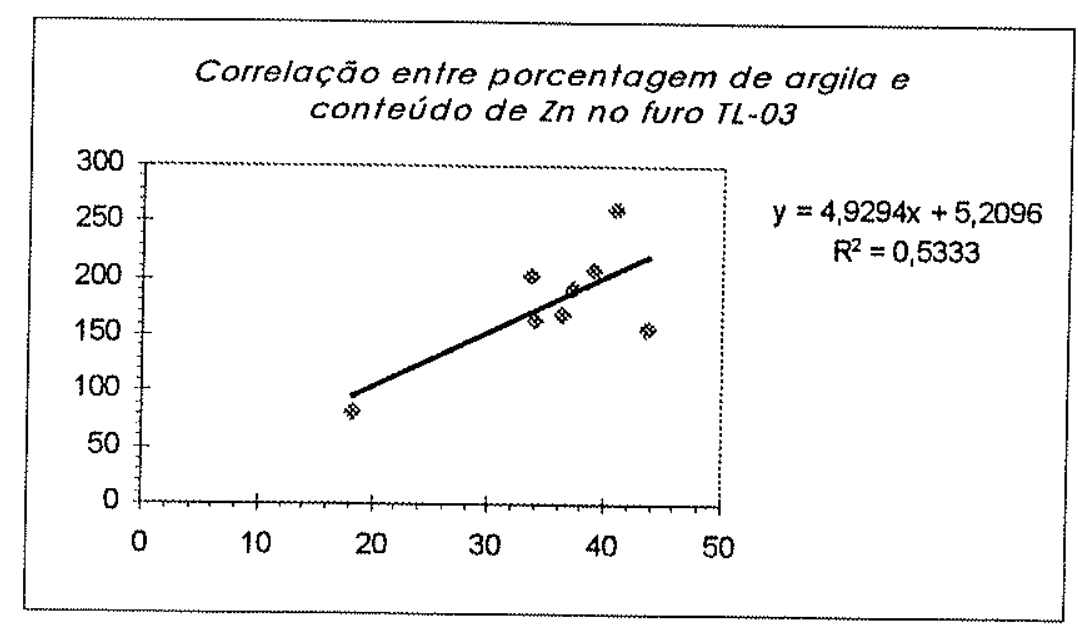

Figura 45 : Gráfico de correlação linear entre a porcentagem de argila e conteúdo de zinco nas amostras do furo TL-03.

\section{b) associacões com o conteúdo de silte}

Ao contrário da argila, o silte apresenta uma melhor correlação com o conteúdo de metais pesados ao longo de todo o perfil.

Para o Cu, foi observada uma boa correlação entre o seu conteúdo e a porcentagem de silte nos diversos níveis, nos furos TL-01 $\left(R^{2}=0,69\right), T L-02\left(R^{2}=0,71\right)$ e TL$04\left(R^{2}=0,7\right)$, situando-se os furos restantes com uma correlação abaixo de 0,40 (Figuras 46,47 e 48). 


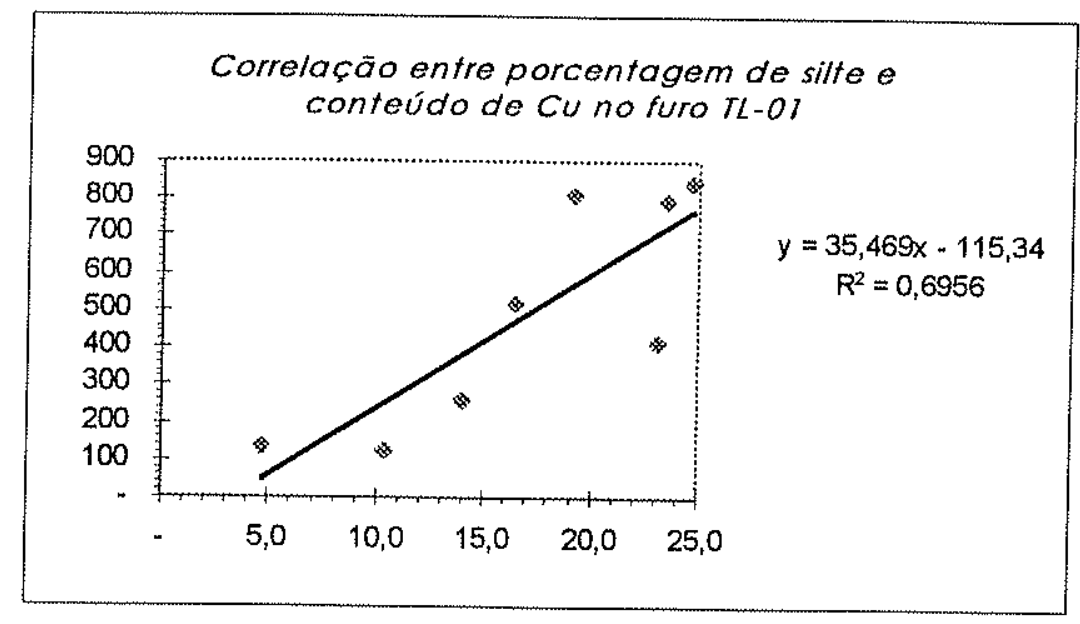

Figura 46 : Gráfico de correlação linear entre a porcentagem de silte e conteúdo de cobre nas amostras do furo TL-01.

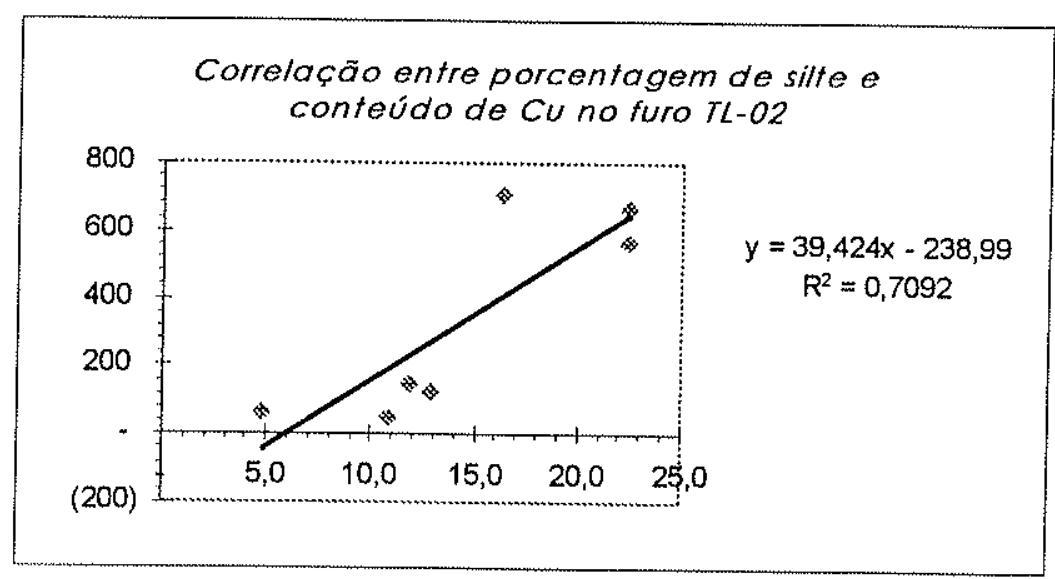

Figura 47 : Gráfico de correlação linear entre a porcentagem de silte e conteúdo de cobre nas amostras do furo TL-02.

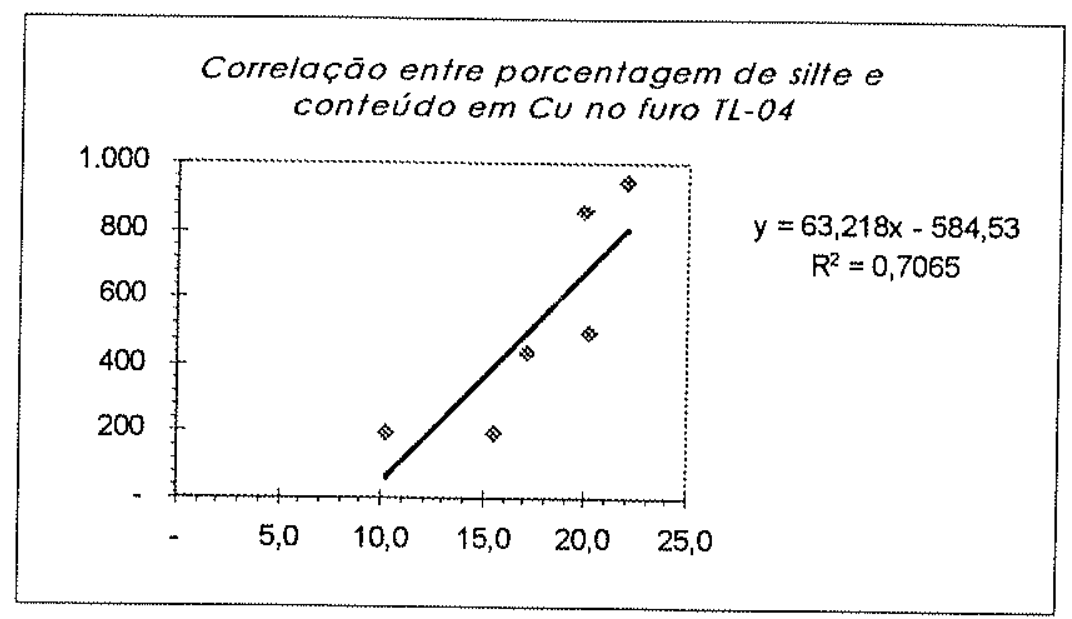

Figura 48 : Gráfico de correlação linear entre a porcentagem de silte e conteúdo de cobre nas amostras do furo TL-04. 
No caso do Zinco, o maior valor observado foi no furo $T L-02$ ( $R^{2}=0,64$ - Figura 49). Neste furo, fambém encontra-se o maior valor observado para o Mo, de $R^{2}=0,75$ (Figura 50).

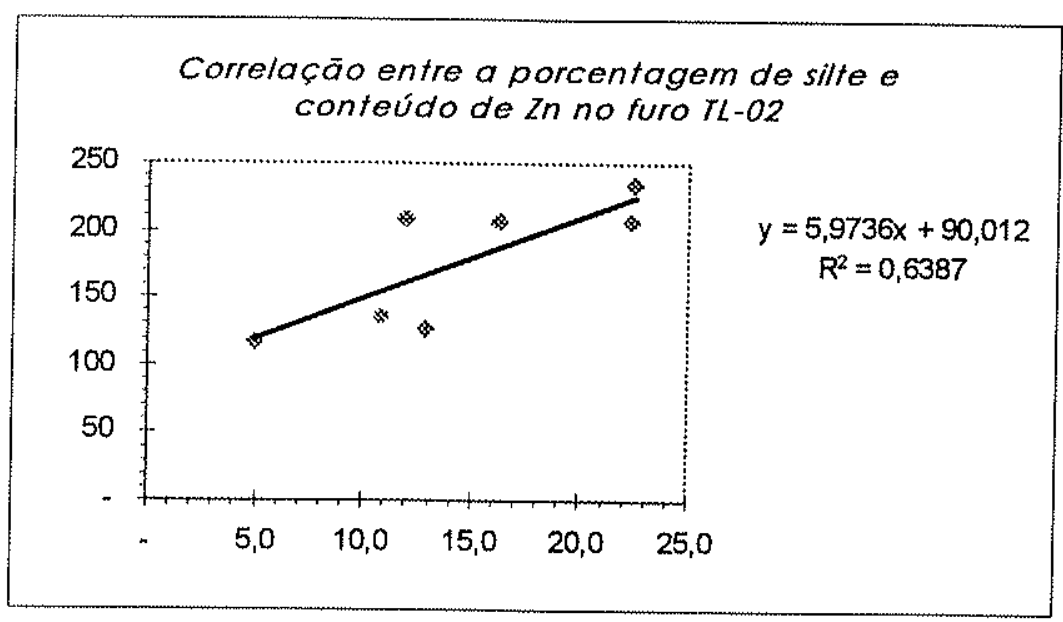

Figura 49: Gráfico de correlação linear entre a porcentagem de silte e conteúdo de zinco nas amostras do furo TL-02.

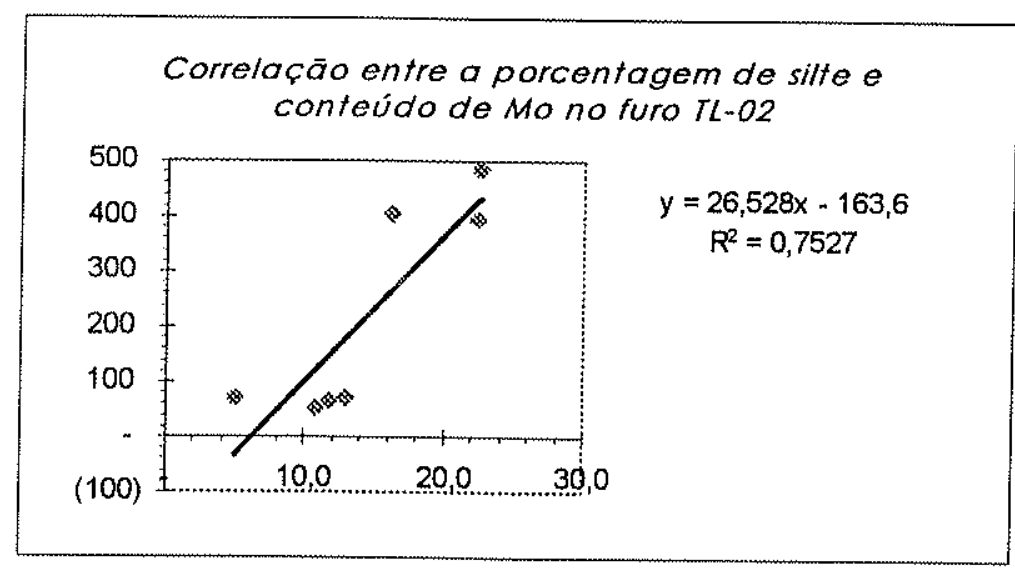

Figura 50 : Gráfico de correlação linear entre a porcentagem de silte e conteúdo de molibdênio nas amostras do furo TL-02.

\section{c) associacões com o conteúdo de areia}

Apenas o cobre apresentou uma correlação negativa com a areia, nos furos TL-01 $\left(R^{2}=0,46\right)$ e TL-04 $\left(R^{2}=0,65\right)$ (Figuras 51 e 52). Para os demais metais, não foi observada uma correlação existente entre o seu conteúdo no perfil e a porcentagem de areia no mesmo. 


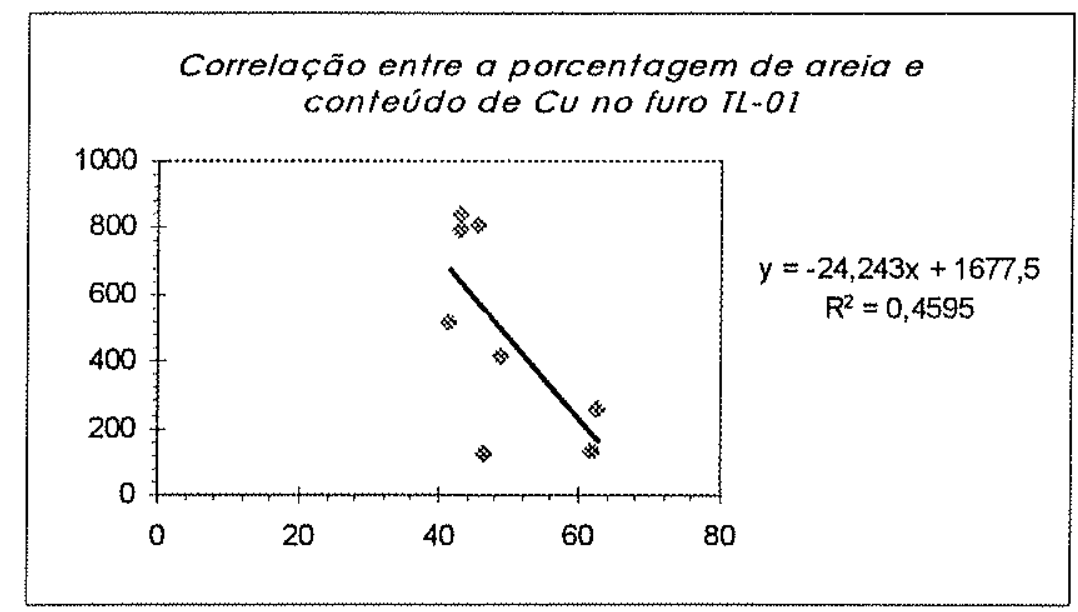

Figura 51 : Gráfico de correlação linear entre a porcentagem de areia e conteúdo de cobre nas amostras do furo TL-01.

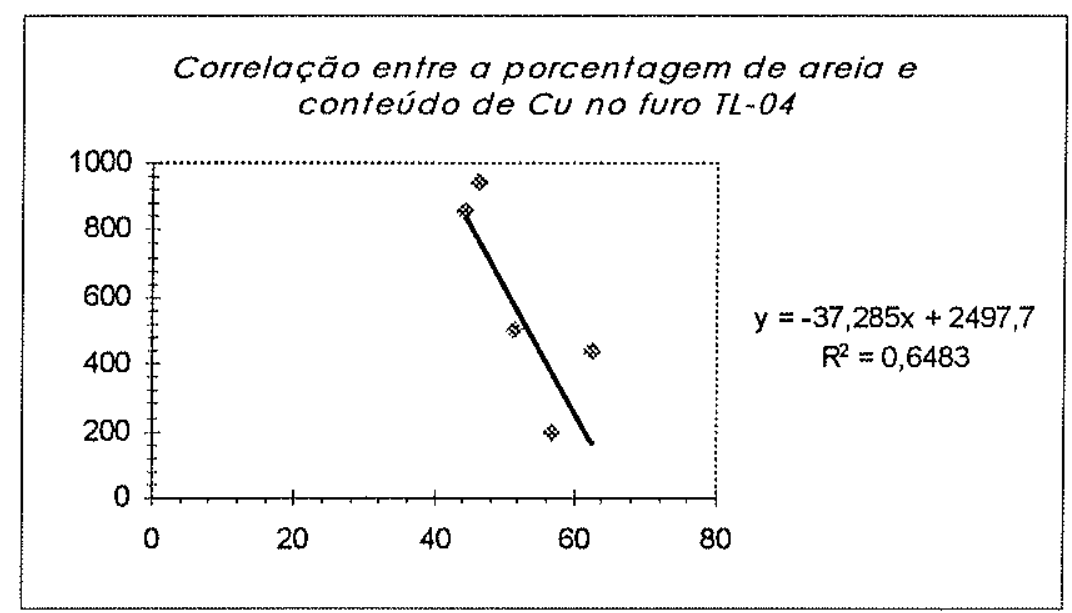

Figura 52: Gráfico de correlação linear entre a porcentagem de areia e conteúdo de cobre nas amostras do furo TL-04.

\subsection{Associações do conteúdo de MP com o teor de matéria orgânica}

No perfil de estudo, foi possivel observar um bom coeficiente de correlação linear $\left(R^{2}=0,60\right)$ entre o teor de zinco e o de matéria orgânica apenas nos furos TL-06 e TL-07, desconsiderando-se o nivel de entulho. Nos furos TL-02, TL-04 e TL-05, esta correlação ficou ao redor de $\mathrm{R}^{2}=0,50$, e para os demais furos, ao redor de 0,25.

O cobre apresenta boas correlações com o teor de matéria orgânica nos furos TL-02 $\left(R^{2}=0,8711\right)$ e TL-03 $\left(R^{2}=0,848\right)$ (Figuras 53 e 54), sendo observada também uma correlação no furo $T L-06\left(R^{2}=0,63\right)$, desconsiderando-se o nivel de entulho, sendo que esta correlação é menor nos demais. 


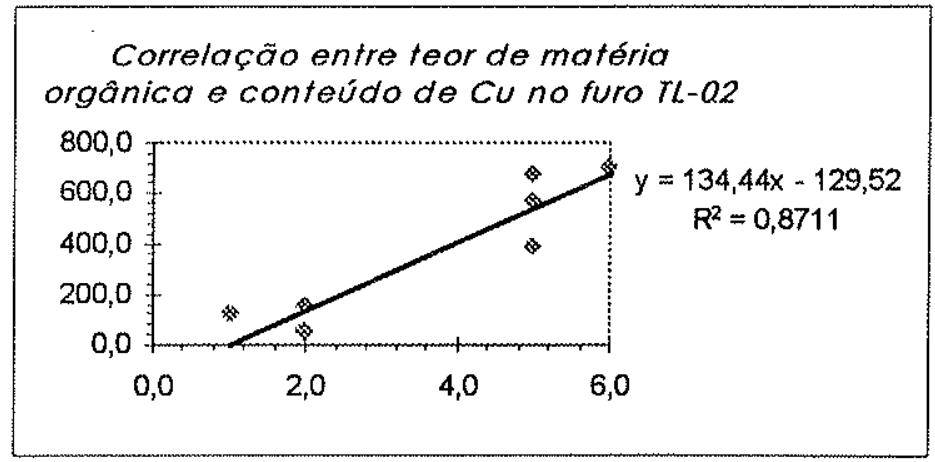

Figura 53 : Gráfico de correlação linear entre o teor de matéria orgânica e o conteúdo de cobre nas amostras do furo TL-02

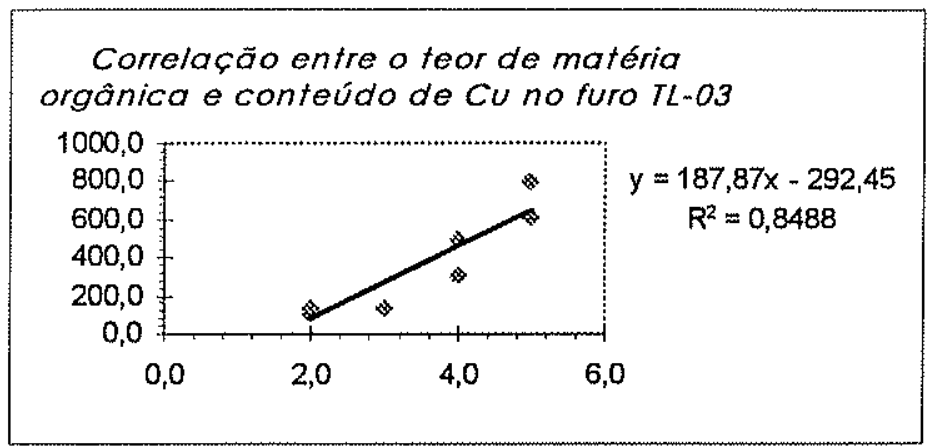

Figura 54: Gráfico de correlação linear entre o teor de matéria orgânica e o conteúdo de cobre nas amostras do furo TL-03.

O manganês foi o metal que apresentou a melhor correlação com o teor de matéria orgânica no perfil. Nos furos TL-02 e TL-03, foram observadas correlações de 0,79 e 0,91, respectivamente (Figuras 55 e 56), sendo que no furo TL-01, esta correlação caiu para $R^{2}=0,35$.

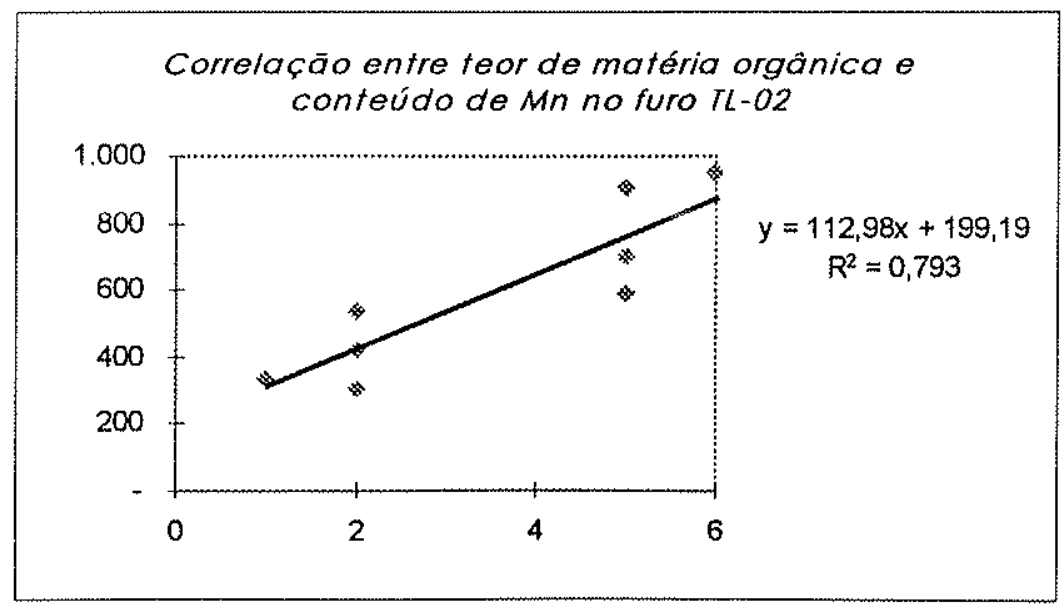

Figura 55: Gráfico de correlação linear entre o teor de matéria orgânica e o conteúdo de manganês nas amostras do furo TL-02. 


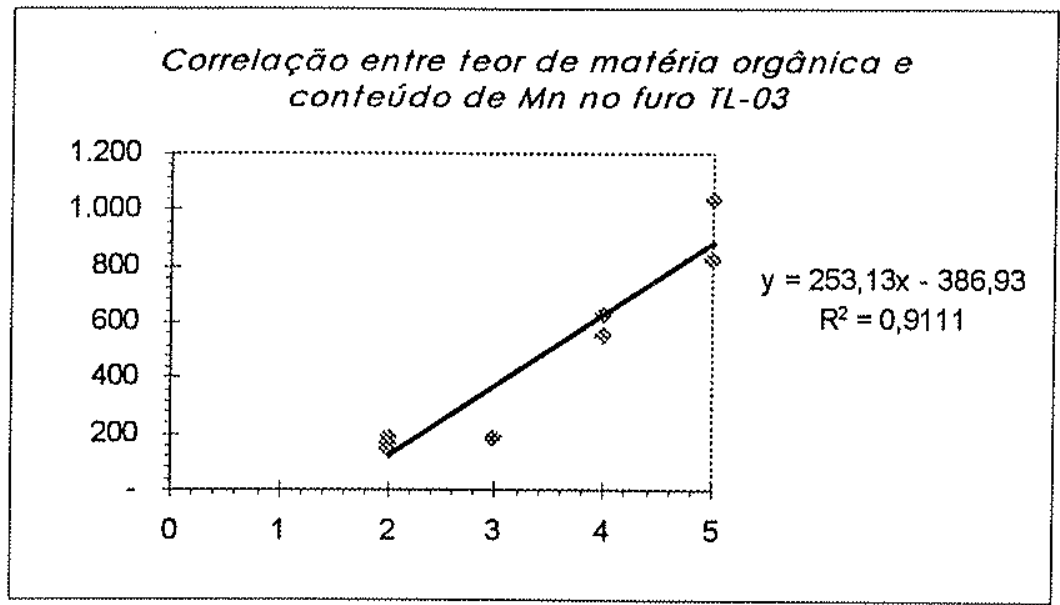

Figura 56: Gráfico de correlação entre o teor de matéria orgânica e o conteúdo de manganês nas amostras do furo TL-03.

\subsection{Correlações entre o comportamento do $\mathrm{Cu}, \mathrm{Pb}$ e $\mathrm{Zn}$ no perfil}

O cobre, chumbo e zinco apresentam um comportamento semelhante do longo do perfil, principalmente nos furos localizados dentro e a montante da lagoa (TL-04 a TL-07). Neste local, o comportamento destes metais apresenta correlaçōes da ordem de 0,90 (Figuras 57, 58 e 59).

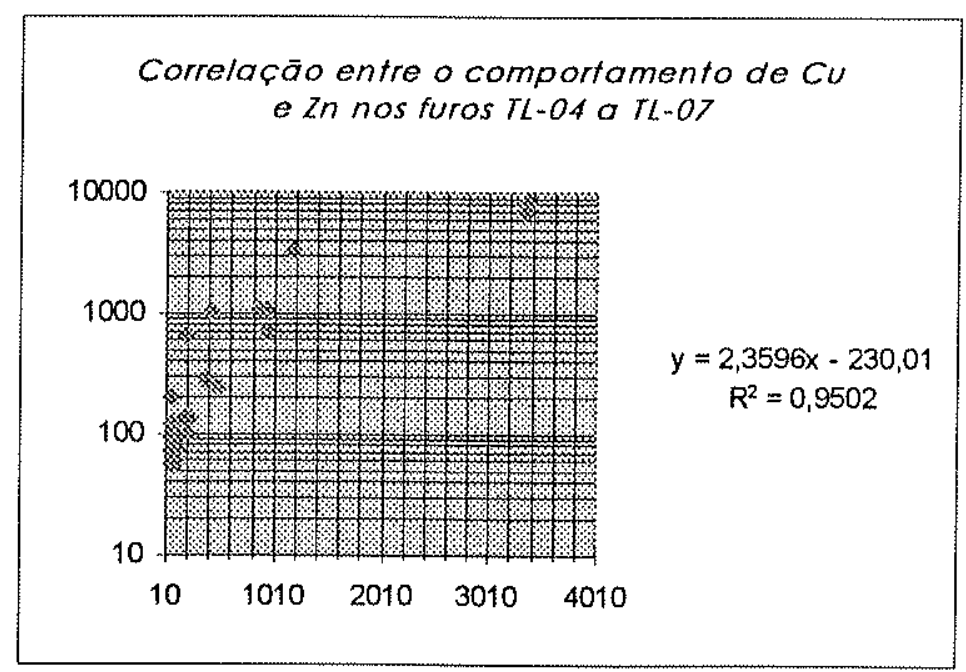

Figura 57: Gráfico de correlação linear entre o comportamento do Cu e Zn nos furos TL-04 a TL-07. 


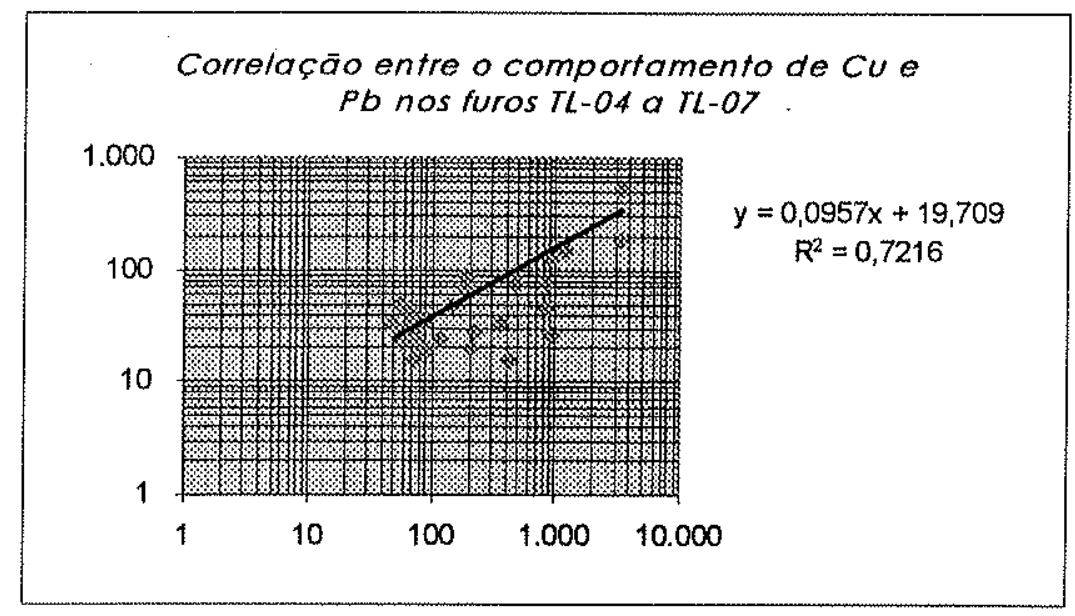

Figura 58: Gráfico de correlação linear entre o comportamento do $\mathrm{Cu}$ e $\mathrm{Pb}$ nos furos TL-04 a TL-07.

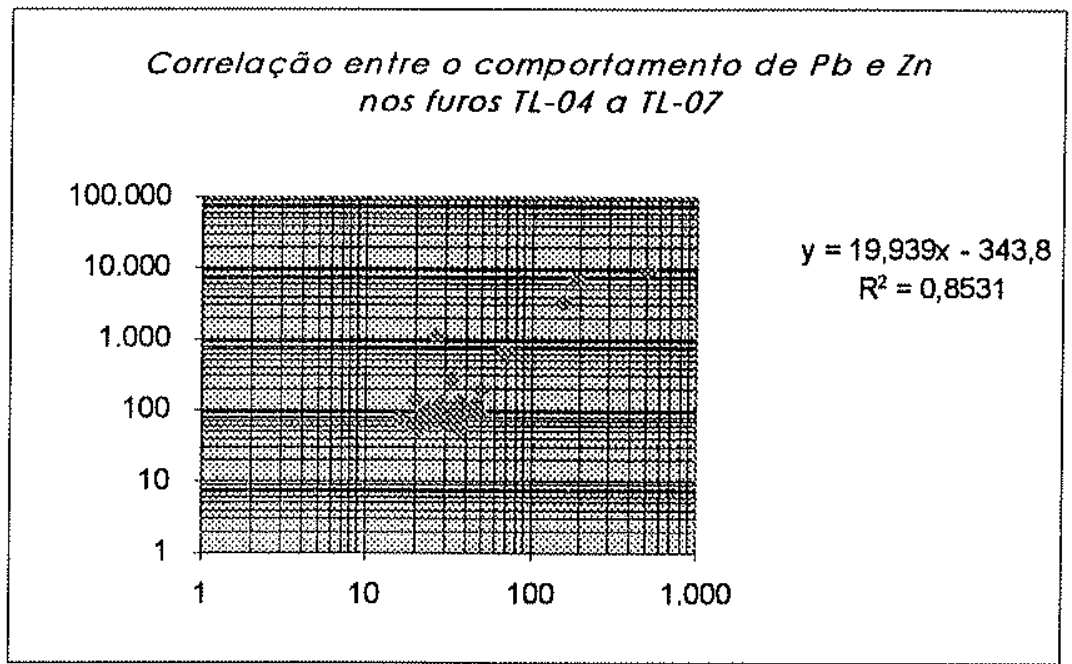

Figura 59: Gráfico de correlação linear entre o comportamento do Pb e Zn nos furos TL-04 a TL-07. 


\section{DISCUSSÃO DOS RESULTADOS}

\subsection{Comportamento dos metais pesados (MP) na seção de estudo}

Os dados apresentados nos capítulos anteriores permitem o estabelecimento de nítida correlação entre o conteúdo de metais pesados e a camada de argila cinza-escura (Unidade 2), especialmente nos furos TL-01 a TL-03, onde os diferentes perfis não sofreram intervenção antrópica. Esta correlação também pode ser observada nos furos superiores, embora tenham sofrido modificações no topo do seu perfil de solo por outras atividades (lagoa de infiltração e nível de entulho). No nível de entulho, foram encontradas as maiores concentrações para $\mathrm{Cu}, \mathrm{Pb}, \mathrm{Zn}$ e $\mathrm{Mn}$.

Nos furos TL-01 a TL-03, especialmente neste último, onde identificou-se e caracterizou-se a seção completa dos diferentes litotipos observados, nota-se um aumento dos teores de $\mathrm{Cu}, \mathrm{Zn}$ e $\mathrm{Pb}$ assim que a argila cinza-escura é atingida.

O Mn e Mo apresentam comportamento semelhante na camada de argila cinza-escura (Unidade 2), aumentando consideravelmente sua concentração quando ela é atingida, nas três situações (a jusante, dentro e montante da lagoa). O que se observa, na maioria dos perfis, é que a diminuição da sua concentração coincide não somente com a passagem para a unidade inferior, mas também com o nível do lençol freático (período de seca).

MATHEWS et al (1994), do estudarem o comportamento do $\mathrm{Cd}$ em solos com alto conteúdo de matéria orgânica, localizados abaixo de um aterro sanitário, não observaram um padrão de distribuição deste metal, sendo que seus teores variaram localmente, tanto horizontal quanto verticalmente de 0,002 a $14,8 \mathrm{mg} / \mathrm{kg}$. O Cd não apresentou um padrão de comportamento em relação aos litotipos que pudesse ser identificado ao longo dos perfis. Também não foram identificadas correlaçōes entre $\mathrm{Cd} e$ as carcterísticas granulométricas ou de teor de matéria orgânica nos diferentes perfis. Observou-se, porém, um certo padrão com relação à profundidade nos diferentes perfis, onde até a profundidade de $2,50 \mathrm{~m}$, houve uma diminuição da sua concentração; desta profundidade até $3,50 \mathrm{~m}$, houve um novo aumento da sua concentração. A partir desta profundidade, a concentração de Cd continua 
sofrendo aumento e decréscimo, até a base dos perfis. Para o perfil TL-05, a concentração deste metal aumenta com a profundidade, decaindo quando a Unidade 3 (camada de silte cinza-clara) é atingida.

Comportamento similar foi observado para o Pb nos furos TL-01 a TL-03. Nos demais furos, apresentou concentração mais alta na superficie, seja devido à lagoa de infiltração, seja devido à camada de entulho. Com o aumento da profundidade, de modo geral, a concentração de $\mathrm{Pb}$ diminuiu.

Embora alguns autores apontem para uma correlação existente entre o comportamento do $\mathrm{Cd}$ e $\mathrm{Pb}$ em ambientes sujeitos à contaminação antropogênica, este tipo de correlação não foi observado na seção de estudo.

Outras correlações, como comportamento geoquímico semelhante entre Cde Zn, são apontadas em THORTON (1996), e foram observadas apenas no perfil TL-02, onde parece ocorrer uma semelhança nos aumentos e decréscimos das concentrações destes dois metais, ocorrendo em profundidades muito semelhantes. Porém, não foram identificados valores de correlação significativos, quando os dados foram plotados em um diagrama do tipo $X Y$.

Nos furos TL-06 e TL-07 foram detectadas correlações muito altas entre o comportamento do $\mathrm{Cu}, \mathrm{Zn}$ e $\mathrm{Pb}$. Para o caso do $\mathrm{Cu}$ e $\mathrm{Zn}$, esta correlação chega à ordem de 0,95 , evidenciando não haver nestes perfis, competição entre estes dois metais, como sugerido por KUO \& BAKER (1980) e sim, comportamentos geoquímicos semelhantes.

Nestes furos, em especial, nota-se uma grande concentração de $\mathrm{Pb}, \mathrm{Zn}$ e Cu, que diminuem drasticamente logo no primeiro metro de perfil. Isto pode sugerir que há a precipitação destes metais em associação com óxidos e hidróxidos de ferro, como já foi sugerido por MCBRIDE (1994). Tal comportamento impediria que estes metais migrassem para a base do perfil.

VALADARES \& CATANI (1975) ao analisarem o conteúdo de Zn natural em solos do Estado de São Paulo, notaram haver correlação entre o conteúdo de óxidos de ferro das amostras e o seu teor de $\mathrm{Zn}$, ao redor de 0,75. VALADARES (1975), ao estudar o conteúdo de Cu natural em solos do Estado de São Paulo, também encontrou boa correlação entre o conteúdo de Cu nos mesmos e o seu teor de óxido de ferro. 
Neste estudo, não foram efetuadas análises químicas que pudessem quantificar o conteúdo de ferro nas amostras. Nas análises microscópicas de amostras da argila cinza-escura (Unidade 2), foi identificada uma matriz mais escura, provavelmente devido à presença de matéria orgânica e hidróxidos de ferro amorfos associados. Em alguns casos, este material tende a concentrar-se dando origem a nódulos.

Nas análises em MEV, tanto dos fragmentos quanto das lâminas, foi identificada uma grande presença de $\mathrm{Fe}$, geralmente disseminado na matriz, ocorrendo, por vezes, associado aos MP. No entanto, os DRX dos diferentes materiais não exibiram picos definidos para hidróxidos ou óxidos de $\mathrm{Fe}$, o que nos leva a supor que estes encontrem-se sob formas amorfas, como sugerido por PARKMAN ef al(1996).

As análises em MEV identificaram a presença de metais pesados principalmente na Unidade 2 (argila cinza-escura), sendo que, dos detectados nas análises químicas, apenas foi possivel a identificação de $\mathrm{Pb}, \mathrm{Cu}, \mathrm{Zn}$ e $\mathrm{Mn}$. O Cd e o Mo não chegaram a ser identificados nas amostras selecionadas.

Geralmente $\mathrm{Cu}, \mathrm{Pb}$ e $\mathrm{Zn}$ aparecem associados a argilas, hidróxidos de Fe, sais e compostos neoformados. Ocorrem com freqüência como pequenos fragmentos dispersos na matryz, ou ainda associados aos compostos precipitados em microfissuras presentes nesta. $O \mathrm{Mn}$ ocorre precipitado no próprio plasma que constitui a matriz.

\subsection{Conteúdo de MP X Granulometria}

Os dados obtidos nos capítulos anteriores exibiram uma tendência dos MP estarem associados às partículas finas da seção de estudo, em especial à fração silte.

Os furos localizados a jusante da lagoa, por não terem sofrido intervenções antrópicas significativas, são os que apresentam melhor correlação entre o conteúdo de metais pesados e as características intrínsecas das diferentes unidades, como granulometria e teor de matéria orgânica.

O silte foi a fração granulométrica que apresentou as melhores correlações com o conteúdo de MP, principalmente em relação ao Cu, Zn e Mo nos furos TL-01 e TL-02. Uma boa correlação entre o silte e o Cu também foi observada no furo TL-04, localizado dentro da lagoa de infiltração. Por outro lado, no furo TL-05, localizado 
dentro da lagoa, e TL-06 e TL-07, localizados a montante da mesma, não foi obtido este tipo de correlaçäo.

O Cu também apresentou um padrão de comportamento com relação à quantidade de areia no solo - principalmente nos furos TL-01 a TL-03 - obtendo uma forte correlação negativa com a mesma, tendendo a diminuir a sua concentração com a aumento da porcentagem de areia. Provavelmente, isto pode estar relacionado à porosidade do solo e à dinâmica da água nos interstícios. Provavelmente, o Cu pode estar sendo lixiviado pela água visto que na maioria das amostras analisadas por MEV, ele quase sempre estava presente na forma de sais (cloretos).

\subsection{Conteúdo de MP X Teor de matéria orgânica}

O teor de matéria orgânica é apontado por vários autores como um dos principais agentes de retenção de metais pesados no solo. GROHMANN (1972) menciona que isto se deve do fato da matéria orgânica possuir uma superfície específica muito elevada $\left(700 \mathrm{~m}^{2} / \mathrm{g}\right)$, o que faz com que a sua presença no solo influencie significativamente as propriedades físico-químicas do mesmo, aumentando a sua superfície específica e capacidade de retenção de metais. Na seção de estudo, observou-se que, com exceção dos niveis de entulho e da base da lagoa de infiltração, foi na camada de argila cinza-escura (Unidade 2) que foram obtidos os maiores teores de matéria orgânica e os maiores conteúdos de $\mathrm{Cu}, \mathrm{Mn}, \mathrm{Mo}$ e $\mathrm{Pb}$.

VALADARES \& CATANI (1975) e VALADARES (1975), ao estudarem a concentração natural de $\mathrm{Zn}$ e Cu em solos do Estado de São Paulo, não obtiveram uma boa correlação entre o conteúdo destes metais e o teor de matéria orgânica no solo, situando-se estes valores em 0,20 para o Zn e 0,17 para o CU. KUO \& BAKER (1980) e ERALDISHI \& O'CONNOR (1982), porém, identificaram em seus trabalhos uma certa afinidade do cobre com o teor de matéria orgânica do solo.

Na presente dissertação, os resultados mostram que na seção de estudo, o Cu foi o metal que apresentou melhor correlação com o teor de matéria orgânica, principalmente nos furos localizados a jusante da lagoa de infiltração. 
Também foi observada uma boa correlação entre o manganês e o teor de matéria orgânica nestes perfis. CASTRO et al (1992) já haviam obtido boas correlações entre a distribuição deste metal e o teor de matéria orgânica em solos argilosos do Estado de São Paulo.

Para os demais metais abordados neste estudo, não foram observadas correlações significativas. 


\section{CONSIDERAÇÕES FINAIS}

Os dados obtidos através das diversas análises efetuadas, bem como das observações de campo, permitem elaborar as seguintes considerações:

1. Embora não exista um registro do material previamente lançado na lagoa, a análise das tortas provenientes do beneficiamento atual, bem como a análise de amostras na base da lagoa (furos TL-04 e TL-05) e do nivel de entulho (TL-06 e TL-07) evidenciam um material com alto conteúdo de metais pesados, especialmente $\mathrm{Cu}, \mathrm{Pb}$ e $\mathrm{Zn}$;

2. O material infiltrado na lagoa atravessou as camadas situadas abaixo da mesma, sendo retido pela camada da argila cinza-escura, com alto conteúdo de matéria orgânica (Unidade 2). Análises em MEV de amostras desta unidade identificaram a presença de metais ( $\mathrm{CU}, \mathrm{Zn}, \mathrm{Mo}$ e $\mathrm{Mn}$ ) presos a argilas, associados a sais neoformados, associados à presença de Fe, e precipitados na matriz e no plasma.

3. As análises em MEV demonstraram que a precipitação dos metais não está associada à organização textural do solo. Eles se encontram em pequenos fragmentos, geralmente disseminados ao longo da matriz, não sendo encontrados precipitados em microfraturas existentes na mesma.

4. $\mathrm{Cu}, \mathrm{Pb}$ e $\mathrm{Zn}$ apresentam comportamento geoquímico semelhante nas áreas que sofreram intervenção antrópica (lagoa de infiltração e nível de entulho - TL-04 a TL-07), tendo sido obtidos valores de correlação superiores a 0,85 para estes metais.

5. O Mn e Mo apresentam comportamento geoquímico semelhante do longo do perfil, em relação aos diferentes litotipos, aumentando a sua concentração quando a Unidade 2 é atingida. Há uma tendência da diminuição de suas concentrações quando se aproxima do lençol freático (período de seca). Provavelmente, o Mn deve estar sendo retido pela matéria orgânica presente nesta Unidade, visto que foi, ao lado do Cu, o metal que obteve melhor correlação com o seu conteúdo: 0,91.

6. Existe uma correlação entre o comportamento dos metais pesados (MP) e as granulometrias finas do perfil. Ao contrário do citado na literatura, fol a fração silte, e não a argila, que apresentou as melhores correlações com o conteúdo de metais pesados; as melhores correlações obtidas para o silte foram: Cu $(0,70)$, In $(0,64)$ e $\mathrm{Mn}$ 
$(0,75)$, ao passo que, para a argila, as melhores correlações obtidas foram com o $\mathrm{Pb} e$ Zn, situando-se, em ambos os casos, ao redor de 0,55.

7. $\mathrm{Cd}$, embora não apresente nenhuma correlação com granulometria, teor de matéria orgânica, ou comportamento em relação aos diferentes litotipos ou aos outros metais analisados, apresenta um comportamento padrão em relação as primeiros metros do perfil de solo, sendo que este tipo de comportamento só não foi observado no furo TL-05.

8. Ao contrário do esperado em solos tropicais, os compostos à base de sais permaneceram no sistema, tendo sido encontrados freqüentemente precipitados ao longo de microfraturas da matriz, formando compostos bem cristalizados. Cloretos de $\mathrm{K}$ e Na são os mais abundantes, tendo sido encontrado Cu associado à estes sais.

9. A disposição de material rico em metais pesados sobre um latossolo (colúvio) possibilitou a migração dos mesmos até 2 a 3 metros de profundidade, cómo pode ser observado nas seções dos Anexos 5 e 6 . Nota-se em desordenamento no comportamento geoquímico dos metais nos perfis que estão sofrendo diretamente uma influência antrópica (TL-04 a TL-07), ao passo que, nos perfis a jusante da lagoa, tende a ocorrer um ordenamento no comportamento geoquímico dos mesmos. 


\section{REFERÊNCIAS BIBLIOGRÁFICAS}

ADRIANO, D.C. 1986. Trace Elements in the Terrestrial Environment. New York, Springer Verlag, $532 \mathrm{p}$.

ALLOWAY, B. J. 1990. Heavy Metals in Soils. London, Blackie and Son Ltd, 339p.

ALLOWAY, B. J. 1995. Heavy Metals in Soils. London, Blackie Academic \& Professional, $368 p$.

AMARANTE, A.; SÍGOLO, J.B. 1996. Concentração de metais pesados (Cu, Zn, Mn e Mo) em horizontes argilo-orgânicos de rochas sedimentares da Bacia de São Paulo. In: CONGRESSO BRASILEIRO DE GEOLOGIA, 39, Salvador. Anais...Salvador, v.2, p.157-160.

ASSUNÇÃO, J.C.B.de. 1996. Análise Mineralógica, Geoquímica e Textural de lodos gerados e dispostos pela ETE de Barveri - SP: Associaçöes com metais pesados e seus efeitos no solo. Dissertação de mestrado apresentada ao Instituto de Geociências da Universidade de São Paulo. São Paulo, IG/USP, 118 p.

AUBERT, H.; PINTA, M. 1977. Trace Elements in Soils. Oxford, Elsevier Scientific Publ. Co, $395 \mathrm{p}$.

BARRĖS, M. 1989. Rôle de la géologie dans l'elimination des déchets urbains ef industriels, quelques exemples. Mines \& Carrières, Paris, 71, p. 51-55.

BATAGLIA, O.C.; FURLANI, P.R.; VALADARES, J.M.A.S. 1976. O molibdênio em solos do estado de São Paulo. In: CONGRESSO BRASILEIRO DE CIÊNCIAS DO SOLO, 15, Campinas. Anais...Campinas, p.107-111.

BENNET, G.F. 1989. Impact of toxic Chemicals on local wastewater treatment plant and the environment. Environmental Geology and Water Sciences, 13 (3), p. 201 212.

BRADY, N.C. 1989. Natureza e Propriedade dos Solos. Rio de Janeiro, Ed. Freitas Bastos, 598 p. 
CASTELO BRANCO, M.A.; BALSA, M.E.; GUSMÃO, M.R.; VIEIRA E SILVA, J.M.; FERNANDES, M.L.; SEQUEIRA, E.M. 1996. Use of pyrite in the reclamation of degraded calcareous soils. Applied Geochemistry, vol. 11, p. 347-349.

CASTRO, O.M.; CAMARGO, O.A.; CANTARELLA, H.; VIEIRA, S.R.; DECHEN, S.C.F. 1992. Teores de Zinco, Cobre, Manganês e Ferro em dois latossolos sob plantios direto e convencional. Campinas, Bragantia, 51 (1), p. 77-84.

CATANI, R.A.; GALLO, J.R. 1951 A extração de manganês e suas formas de ocorrência em alguns solos do Estado de São Paulo. Campinas, Bragantia, 11 (7-9), p.255266.

CATANI, R.A.; KÜPPER, A. 1946. Algumas características químicas dos solos do Estado de São Paulo e sua interprełação analítica. Campinas, Bragantia, 6 (4), p. 147 163.

COMPANHIA DE PESQUISA DE RECURSOS MINERAIS - CPRM. 1990. Projeto Santa /sabel/ Mogi das Cruzes / Mauá-Relatório Final. São Paulo, CPRM, V.1.

COORDENADORIA DE ASSISTÊNCIA TÉCNICA INTEGRAL / SECRETARIA DE AGRICULTURA E ABASTECIMENTO DO ESTADO DE SÃO PAULO - CATI/SAA. 1994. Manual técnico de Manejo e Conservaçāo do Solo e Água. Campinas, CATI/SAA, Manual no 39, v.2.

COSTA, J.B. da. 1991. Caracterização e Constituição do solo. Lisboa, Fundação Calouste Gulbenkian, $527 \mathrm{p}$.

COTTER-HOWELLS, J.; CAPORN, S. 1996. remediation of contaminated land by formation of heavy metals phosphates. Applied Geochemistry, vol.11, p. 335-342.

ELRASHIDI, M.A.; O'CONNOR, G.A. 1982. Influence of solution composition on sorption of zinc by soils. Soil Science Society of America Journal, 46 (6), p. 1152-1157.

GÖSKET, J.; PRIETO, G.; PÖLMANN, H. 1996. Fixation of harmful substances in lamellan metal-metal-hydroxisalts. In: INTERNATIONAL SYMPOSIUM ON ENVIRONMENTAL GEOCHEMISTRY IN TROPICAL COUNTRIES, 2, Cartagena. CD-ROM...Cartagena

GROHMANN, F. 1972. Superfície específica do solo de unidades de mapeamento do Estado de São Paulo. II - Influência da matéria orgânica, dos óxidos de ferro livres e dos cátions trocáveis, na superfície específica total do solo. Campinas, Bragantia, 31 (14), p. 167-185. 
HAINES, R.C.; HARRIS, M.R. 1987. Main Types of Contaminants. Reclaming Contaminated Land, Blackie \& Son Ltd., p. 39-60.

INSTITUTO DE PESQUISAS TECNOLÓGICAS DO ESTADO DE SÃO PAULO -SP-IPT/SA; Secretaria de Indústria, Comércio, Ciência e Tecnologia - SICCT.1981. Mapa Geomorfológico do Estado de São Paulo. São Paulo, IPT/SICCT, 2 V.

INSTITUTO GEOGRÁFICO E GEOLÓGICO - IGG. 1974. Folha Suzano (escala 1: 50.000).

KABATA-PENDIAS, A.; PENDIAS, H. 1984. Trace Elements in Soils and Plants. Boca Raton, CRC Press Inc., $315 \mathrm{p}$.

KARCZEWSKA, A. 1996. Metal species distribution in top-and sub-soil in an area affected by copper smelter emissions. Applied Geochemistry, V.11, p. 35-42.

KARCZEWSKA, A.; CHODAK, T.; KASZUBKIEWICZ, J. 1996. The suitable of brown coal as a sorbent for heavy metals in polluted soils. Applied Geochemistry, V.11, p. 343-346.

KELLY, J.; THORNTON, I.; SIMPSON, P.R. 1996. Urban Geochemistry: a study of the influence of anthropogenic activity on the heavy metal content of soils in traditionally industrial and non-industrial areas of Britain. Applied Geochemistry, V.11, p. 363-370.

KOONER, Z.S. 1993. Comparative study of adsorption behaviour of copper, lead and zinc onto goethite in aqueous systems. Environmental Geology, 21, p. 242-250.

KUO, S.; BAKER, A.S. 1980. Sorption of copper, zinc and cadmium by acid soils. Soil Science Society of America Journal, 44 (5), p. 969-974.

LORING, D.H.; ASMUND, G. 1989. Heavy metal contamination of a Greeland Fjord System by mine wastes. Environmental Geology and Water Sciences, 14 (1), p. 6171.

MALAVOLTA, E. 1994. Fertilizantes e seu impacto ambiental: metais pesados, mitos, mistificação e fatos. São Paulo, Produquímica, $153 \mathrm{p}$.

MALINI, S. ; NAGAIA, N.; PARAMESH, L.; VENKATARAMAIAH, P. 1995. Study of the distribuition of trace elements in soils in and around mysore City, Karnataka. Environmental Geology, 26, p. 107-110. 
MANTEl, E.J.; COONROD, D.D. 1989. Heavy metal content in the stream sediments adjacent to a sanitary landfill. Environmental Geology and Water Sciences, 13 (1), p. 51-58.

MATHEWS, W.H.; BUSTIN, R.M. 1994. Trace metal geochemistry of peat under a sanitary landfill - a reconaissance. Environmental Geology, 23, p.14-22.

MCBRIDE, M.B. 1994. Environmental Geochemistry of Soils. New York, Oxford University Press, $406 \mathrm{p}$.

MELO, M.S.; CAETANO, S.L.V.; COIMBRA, A.M. 1986. Tectônica e sedimentação na área das bacias de São Paulo e Tremembé. In: CONGRESSO BRASILEIRO DE GEOLOGIA, 34, Goiânia. Anais.....Goiânia, p. 321-336.

MELO, M.S.; PONÇANO, V.L., MOOK, W.G. AZEVEDO, A.E.G.de. 1987. Datações C14 em sedimentos quaternários da Grande São Paulo. In: CONGRESSO DA ASSOCIAÇÃO BRASILEIRA DE ESTUDOS DO QUATERNÁRIO - ABEQUA, 1, Porto Alegre. Anais...Porto Alegre, p.427 -437.

NAVARRA, C.T.; FURTADO, V.V.; EICHLER, B.B.; PRADO, O.R. 1980. Distribuição da matéria orgânica nos sedimentos costeiros e nos solos hidromórficos da orla litorânea do Estado de São Paulo. Boletim do Instituto Oceanográfico - IO/USP, v. 29, p. $267-270$.

NIMER, E. 1977. Clima. In: Geografia do Brasil - Região Sudeste. Rio de Janeiro, IBGE, V.3, p. $51-89$.

OLIVEIRA, J.B. de; JACOMINE, P.K.T.; CAMARGO, M.N. 1992. Classes Gerais de Solos do Brasil: guia auxiliar para seu reconhecimento. Jaboticabal, FUNEP, 201 p.

PARKMAN, R.H.; CURTIS, C.D.; VAUGHAN, D.J. 1996. Metal fixation and mobilisation in the sediments of the Afon Goch estuary - Dulas Bay, Anglesey. Applied Geochemistry, V.11, p. 203-210.

PREFEITURA MUNICIPAL DE SUZANO - PMS. 1991. Plano Diretor do Municipio - Item III: Município de Suzano - Dados Gerais. p. 33-38.

PROHIC.E.; JURACIC, M. 1989. Heavy Metals in sediments - problems concerning determination of the antropogenic influence. Study in the Krka River estuary, 
Eastern Adriatic Coast, Yugoslavia. Environmental Geology and Water Sciences, 13 (2), p. 145-151.

RAIJ, B.V.; QUAGGIO, J.A.; CANTARELLA, H.; FERREIRA, M.E.; LOPES, A.S.; BATAGLIA, O.C. 1987. Análise Química do Solo para fins de fertilidade. Campinas, Fundação Cargill, $170 \mathrm{p}$.

RICCOMINI, C. 1989. O Rift Continental do Sudeste do Brasil. Tese de Doutoramento apresentada ao Instituto de Geociências da Universidade de São Paulo. São Paulo, IG/USP, $256 \mathrm{p}$.

RICCOMINI, C.; COUTINHO, J.M.V.; GUARANÁ, C.A.; COIMBRA, A.M.; HACHIRO, J.; ATENCIO, D.; IOMASA, W.W. 1988. Evidências de Hidrotermalismo em sedimentos da Bacia de São Paulo: Considerações Genéticas. In: Anais da Academia Brasileira de Ciências, 60, p. 105-106 (Resumos).

SíGOLO, J.B.; AMARANTE, A. 1996. Heavy Metal retention in a organic argillaceouous layer near a chemical industry in Suzano, State of Sao Paulo, Brazil. In: INTERNATIONAL SYMPOSIUM OF ENVIRONMENTAL GEOCHEMISTRY IN TROPICAL COUNTRIES, 2, Cartagena. CD-ROM...Cartagena.

SíGOLO, J.B.; AMARANTE, A. 1997. Zn, Mo, Mn and Cu concentration in an argillaceous layer near a chemical industry in SUzano, State of Sao Paulo, Brazil. CONGRESSO DE GEOQUIMICA DOS PAÍSES DE LÍNGUA PORTUGUESA, 4, Braga. Actas da 109 Semana...Braga, p. 511-514.

SíGOLO, J.B.; MELLO JR., R.F. 1994. O uso da geoquímica na caracterização da contaminação industrial do solo por metais pesados: um caso prático. CONGRESSO BRASILEIRO DE GEOLOGIA, 38, Camboriú. Anais...Camboriú, V.1, p. 63-64.

TAKIYA, H. 1991. Aplicações de métodos quantitativos espaciais a dados geológicos da Bacia de São Paulo. Dissertação de mestrado apresentada ao Instituto de Geociências da Universidade de São Paulo. São Paulo, IG/USP, 109p.

TAN, K.H. 1993. Principles of Soil Chemistry. New York, Marcel Dukker Inc, $2^{\text {nd }}$ Edition, 362p. 
THORNTON, 1. 1996. Impacts of mining on the environment: some local, regional and global issues. Applied Geochemistry, V.11, p. 355-361.

VALADARES, J.M.A.S. 1975. Cobre em solos do estado de São Paulo. 1 - Cobre Total. Campinas, Bragantia, 34, p. 125-132.

VALADARES, J.M.A.S.; CATANI, R.A. 1975. Zinco em solos do Estado de São Paulo. 1 Zinco Total. Campinas, Bragantia, 34 (5), p. 133-139.

VERDADE, F.C. 1954. Ação da água oxigenada sobre a matéria orgânica do solo. Campinas, Bragantia, 13 (24), p. $287-295$.

VERLENGIA, F.; GARGANTINI, H. 1968. Determinação de matéria orgânica em solos estudo comparativo de métodos. Campinas, Bragantia, 27 (23) , p. 257-265. 


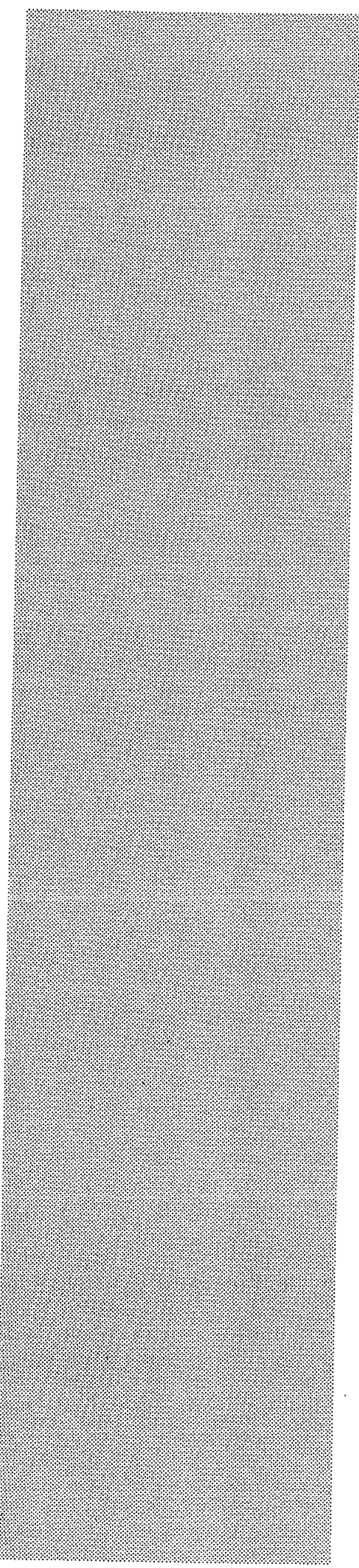

ANEXO 1 


\begin{tabular}{|c|c|c|c|c|c|c|c|}
\hline \multirow{2}{*}{ Perfil / prof (m) } & \multicolumn{7}{|c|}{ Análise Granulométrica Quantitativa } \\
\hline & $\begin{array}{l}\text { Argila } \\
\% \\
\%\end{array}$ & $\begin{array}{c}\text { Silte Fino } \\
\% \\
\%\end{array}$ & $\begin{array}{c}\text { Silte Grosso } \\
\%\end{array}$ & $\begin{array}{l}\text { Areia Fina } \\
\%\end{array}$ & $\begin{array}{c}\text { Areia Grossa } \\
\%\end{array}$ & $\begin{array}{c}\text { Umidade } \\
\%\end{array}$ & Total \\
\hline TLO1 / 0,00- 0,25 & 41,00 & 8,56 & 3,52 & 25,30 & 19,79 & 2,62 & 100,79 \\
\hline TLOI / 0,75 - 1,00 & 41,82 & 6,01 & 4,16 & 24,74 & 20,53 & 1,15 & 98,41 \\
\hline TLO1 / 1,75-2,00 & 30,60 & - & 4,29 & 35,41 & 21,00 & 1,75 & 93,05 \\
\hline TLO1 / 2,50 - 2,75 & 24,07 & 10,93 & 3,34 & 23,26 & 40,58 & 1,52 & 98,70 \\
\hline TLO1 / 3,00-3,25 & 28,05 & 18,25 & 4,64 & 25,65 & 22,83 & 2,11 & 101,53 \\
\hline TLO1 / 3,25 - 3,50 & 40,90 & 11,42 & 4,47 & 21,45 & 18,57 & 2,76 & 99,50 \\
\hline TLO1 / 3,50 - 3,75 & 31,31 & 11,52 & 6,50 & 26,76 & 14,44 & 3,50 & 94,03 \\
\hline TLO1 / 3,75 - 4,00 & 30,60 & 16,52 & 7,06 & 25,26 & 15,76 & 3,25 & 98,45 \\
\hline TLO1 / 4,00 - 4,25 & 32,53 & 17,64 & 5,61 & 22,93 & 18,20 & 2,83 & 99,44 \\
\hline TLO2 / 0,75 - 1,00 & 44,47 & 8,46 & 3,82 & 21,83 & 20,61 & 2,19 & 101,3 \\
\hline TLO2 / 1,50 - 1,75 & 37,89 & - & 4,50 & 25,08 & 23,80 & 2,78 & 94,05 \\
\hline TLO2 / 2,00 - 2,25 & 28,56 & 6,83 & 4,14 & 36,72 & 22,31 & 1,90 & 100,46 \\
\hline TLO2 / 2,50 - 2,75 & 30,19 & 8,67 & 4,23 & 31,29 & 24,92 & 2,03 & 101,38 \\
\hline TLO2 / 3,00 - 3,25 & 40,29 & 17,44 & 4,82 & 22,94 & 19,91 & 2,37 & $107,77^{*}$ \\
\hline TLO2 / 3,25 - 3,50 & 29,17 & 12,54 & 5,76 & 27,73 & 19,83 & 3,11 & 98,14 \\
\hline TLO2 / 3,50 - 3,75 & 24,07 & 13,77 & 7,29 & 32,40 & 18,23 & 3,93 & 99,69 \\
\hline TLO2 / 3,75 - 4,00 & 41,31 & 18,36 & 5,56 & 19,74 & 8,99 & 3,94 & 97,90 \\
\hline TLO2 / 4,00 - 4,25 & 38,55 & 25,29 & 4,65 & 16,94 & 8,00 & 4,21 & 97,64 \\
\hline & & & & & & & \\
\hline
\end{tabular}


ANEXO 1

ANÁLSES GRANULOMETRICAS QUANIIIATIVAS

\begin{tabular}{|c|c|c|c|c|c|c|c|}
\hline \multirow[b]{2}{*}{ Perfil / prof (m) } & \multicolumn{7}{|c|}{ Análise Granulométrica Quantifativa } \\
\hline & $\begin{array}{c}\text { Argila } \\
\%\end{array}$ & $\begin{array}{c}\text { Silte Fino } \\
\%\end{array}$ & $\begin{array}{l}\text { Silte Grosso } \\
\%\end{array}$ & $\begin{array}{l}\text { Areia Fina } \\
\%\end{array}$ & $\begin{array}{c}\text { Areia Grossa } \\
\%\end{array}$ & $\begin{array}{c}\text { Umidade } \\
\%\end{array}$ & Total \\
\hline IL03 / 0,75- 1,00 & 42,73 & 31,00 & 3,98 & 21,22 & 20,10 & 6,67 & $125,70^{*}$ \\
\hline $\mathrm{T} 203 / 1,50-1,75$ & 36,72 & 5,61 & 4.79 & 26,86 & 24,71 & 1,58 & 100,27 \\
\hline TLO3 / $2,00-2,25$ & 36,72 & 6,32 & 4,94 & 26,52 & 22,95 & 3,65 & 101,10 \\
\hline TL.03 / 2,25 - 2,50 & 40,80 & 7.44 & 5,38 & 22,92 & 22,46 & 5,58 & 104,58 \\
\hline TL03 / $2,75-3,00$ & 42,84 & 7,85 & 4,56 & 22,40 & 20,54 & 2,05 & 100,24 \\
\hline $\mathrm{TL}, 03 / 3,00-3,25$ & 34,98 & 12,34 & 5.77 & 24,83 & 19,00 & 2,63 & 99,55 \\
\hline $\mathrm{TLO3} / 3,50-3,75$ & 32,13 & 11,93 & 6,23 & 26,91 & 18,61 & 3,48 & 99,29 \\
\hline TLO3/3,75-4,00 & 32,64 & 12,44 & 6,82 & 26,99 & 17,35 & 3,23 & 99,47 \\
\hline$\lceil\mathrm{L} 03 / 4,00-4,25$ & 31,00 & 10,60 & 5,69 & 24,92 & 27,24 & 1.79 & 101,24 \\
\hline $\mathrm{rLO} / 4,75-5,00$ & 17,95 & 15,40 & 8,14 & 27,40 & 30,80 & 0,85 & 100,84 \\
\hline TLO3 / 5,00 - 5,25 & 8,77 & 24,37 & 9,48 & 28,65 & 32,58 & 0,33 & 104,18 \\
\hline$\lceil L 03 / 2,50-2,60$ & 7,34 & 20,91 & 8,74 & 28,09 & 37,24 & 0,95 & 103.27 \\
\hline & & & & & & & \\
\hline
\end{tabular}




\begin{tabular}{|c|c|c|c|c|c|c|c|}
\hline \multirow[b]{2}{*}{ Perfil / prof (m) } & \multicolumn{7}{|c|}{ Anólise Granulométrica Quantitativa } \\
\hline & $\begin{array}{c}\text { Argila } \\
\%\end{array}$ & $\begin{array}{l}\text { Silte Fino } \\
\%\end{array}$ & $\begin{array}{l}\text { Silte Grosso } \\
\%\end{array}$ & $\begin{array}{c}\text { Areia Fina } \\
\%\end{array}$ & $\begin{array}{c}\text { Areia Grossa } \\
\%\end{array}$ & $\begin{array}{c}\text { Umidade } \\
\%\end{array}$ & Tolot \\
\hline TLO4 $/ 0,25-0,50$ & 19.68 & 9,48 & 6.79 & 29,81 & 29.53 & 3,61 & 98,90 \\
\hline TLO4 / $0,75-1,00$ & 34,47 & 13,66 & 5,61 & 22,68 & 20,23 & 3,12 & 99.77 \\
\hline $\mathrm{TLO} 4 / 1,00-1,25$ & 30,49 & 15,60 & 5,65 & 24,93 & 19,52 & 1.96 & 98,15 \\
\hline $\mathrm{rLO} 4 / 1,25-1,50$ & 27.23 & 12,03 & 7,43 & 27.99 & 21,33 & 2,44 & 98,45 \\
\hline$\tau \mathrm{LO} 4 / 1,50-1,75$ & 30,00 & 6,93 & 4,16 & 28,66 & 32,66 & 1,32 & 109,73 \\
\hline rLo4 / $1,75-2,00$ & 33,66 & 9,38 & 4,29 & 28,34 & 25,23 & 1,07 & 101,97 \\
\hline $\mathrm{ILO} 4 / 2,00-2,25$ & 27,13 & 9.18 & 6,05 & 32,22 & 23,23 & 3,04 & 100,85 \\
\hline fLO5 / 0,25 - 0,50 & 19.17 & 10,40 & 6,61 & 31,49 & 28,58 & 2,84 & 99.09 \\
\hline $1 L 05 / 0,50-0,75$ & 23,33 & 7,34 & 7,44 & 31,96 & 20,34 & 6.52 & 96,93 \\
\hline TLOS / $0,75-1,00$ & 24,68 & 11,11 & 5,88 & 27,42 & 27,00 & 4,31 & 100,40 \\
\hline $7205 / 1,00-1,25$ & 38,14 & 5.71 & 4,76 & 24,78 & 23,64 & 1,58 & 98,61 \\
\hline $1205 / 1.25-1,50$ & 41,10 & 7,85 & 5.27 & 26,78 & 18,13 & 2,33 & 101,46 \\
\hline $\mathrm{TL} 05 / 1,50-1,75$ & 32,53 & 9,89 & 4,60 & 27,66 & 28,32 & 1,20 & 104,20 \\
\hline TLO5/1,75-2,00 & 37,43 & 8,87 & 5,24 & $28,6]$ & 19,27 & 1,56 & 100,98 \\
\hline $1105 / 2,0-2,25$ & 45,59 & 12,44 & 5,02 & 26,60 & 13,62 & 2,15 & 105,42 \\
\hline & & & & & & & \\
\hline
\end{tabular}


ANEXO 1

ANÁLIIES GRANULOMETRICAS QUANIITAIVAS

PARA AS AMOSTRAS NOS DIFERENTES PERFIS

Tabela 4/5

\begin{tabular}{|c|c|c|c|c|c|c|c|}
\hline \multirow{2}{*}{ Perfiliprof (m) } & \multicolumn{7}{|c|}{ Análise Granulomérica Quantitativa } \\
\hline & $\begin{array}{l}\text { Argila } \\
\%\end{array}$ & $\begin{array}{l}\text { Silte fino } \\
\%\end{array}$ & $\begin{array}{c}\text { Silie Grosso } \\
\%\end{array}$ & $\begin{array}{l}\text { Areia fina } \\
\%\end{array}$ & $\begin{array}{c}\text { Areia Grossa } \\
\%\end{array}$ & $\begin{array}{c}\text { Umidade } \\
\%\end{array}$ & Total \\
\hline TLO6 $/ 0,80-1,00$ & 6,93 & 25,90 & 5,21 & 2484 & & & \\
\hline TLO6 / $/ 1,60 / 1,80$ & 3133 & & & & & 6.57 & 95,95 \\
\hline & $31,3 i$ & 15,09 & 4,50 & 23,12 & 21,11 & 3,70 & 98,23 \\
\hline FLO6 $/ 2,20-2,40$ & 30,80 & 18,36 & 5,09 & 21,02 & 23,70 & 1,02 & 100,00 \\
\hline TLO6 / $2,40-2,60$ & 22,23 & 21,72 & 6.14 & 25,80 & 23,55 & 2,42 & 103,86 \\
\hline ILO6 / $2,60-2,80$ & 18,05 & 14,64 & 9,46 & 35,19 & 20,01 & 3,45 & 100,84 \\
\hline YLO6 / $2,80-3,00$ & 17,64 & 19,27 & 13,96 & 31,69 & 14,95 & 3,00 & 100,51 \\
\hline T206/3,0-3,20 & 30,49 & 15,50 & 8,46 & 25,54 & 17,68 & 3,88 & 101,55 \\
\hline TLOO6/3,20 - 3,40 & 33,04 & 14,68 & 6,67 & 23,27 & 18,50 & 3,59 & 99,75 \\
\hline$T L 06 / 3,40-3,0$ & 33,92 & 7,85 & 5,62 & 23,67 & 20,82 & 2,73 & 97,61 \\
\hline TLO6 $/ 3,60-3,80$ & 30,19 & 30,71 & 5,37 & 26,32 & 21,16 & 2,56 & 96,31 \\
\hline TLO6 / 4,00-4,20 & 36,00 & 8,36 & 4,56 & 26,45 & 22,61 & 0,93 & 98,91 \\
\hline $\mathrm{TLO6} / 4,40-4,60$ & 34,68 & 12,03 & 5,88 & 30,34 & 15,88 & 2,20 & 101,10 \\
\hline 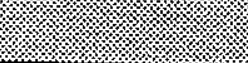 & & & & & & & \\
\hline
\end{tabular}


ANEXO 1

ANÁLISES GRANULOMETRICAS QUANTITATIVAS PARA AS AMOSTRAS NOS DIFERENTES PERFIS

Tabela 5/5

\begin{tabular}{|c|c|c|c|c|c|c|c|}
\hline \multirow[b]{2}{*}{ Perfil / prof $(m)$} & \multicolumn{7}{|c|}{ Análise Granulométrica Quantitativa } \\
\hline & $\begin{array}{c}\text { Argila } \\
\%\end{array}$ & $\begin{array}{c}\text { Silte Fino } \\
\%\end{array}$ & $\begin{array}{c}\text { Silte Grosso } \\
\%\end{array}$ & $\begin{array}{l}\text { Areia Fina } \\
\%\end{array}$ & $\begin{array}{c}\text { Areia Grossa } \\
\%\end{array}$ & $\begin{array}{c}\text { Umidade } \\
\%\end{array}$ & Total \\
\hline TLO7 / $0,20-0,40$ & 21,31 & 11.42 & 5,44 & 29,10 & 28.61 & 3,70 & 99,38 \\
\hline TLO $/ 1,00-1,20$ & 42,33 & 8,05 & 4,13 & 23,87 & 18,32 & 2,86 & 99,56 \\
\hline TLOT / 2,20-2,40 & 34,37 & 5,61 & 3,92 & 26,36 & 26,88 & 3,21 & 100,35 \\
\hline $\mathrm{TLO} / 2,80-3,00$ & 39,06 & 7,24 & 4,84 & 24,95 & 20,83 & 3,40 & 100,32 \\
\hline ILOT / 3,00-3,20 & 33,04 & 12,34 & 4,87 & 23,95 & 16,07 & 4,16 & 94,43 \\
\hline fLO7 / 3,20-3,40 & 23,25 & 22,44 & 5,46 & 24,39 & 17,90 & 3,61 & 97.05 \\
\hline TLO7 / 3,40-3,60 & 27,94 & 17,44 & 7,08 & 26,69 & 17,21 & 2.76 & 99,12 \\
\hline fL07 / 3,60-3,80 & 28,05 & 15,09 & 6.72 & 28,98 & 13,81 & 2.13 & 94,78 \\
\hline T:07/3,80-4,00 & 31,51 & 10,81 & 6,59 & 29,25 & 20,32 & 1,60 & 100,08 \\
\hline & & & & & & & \\
\hline
\end{tabular}




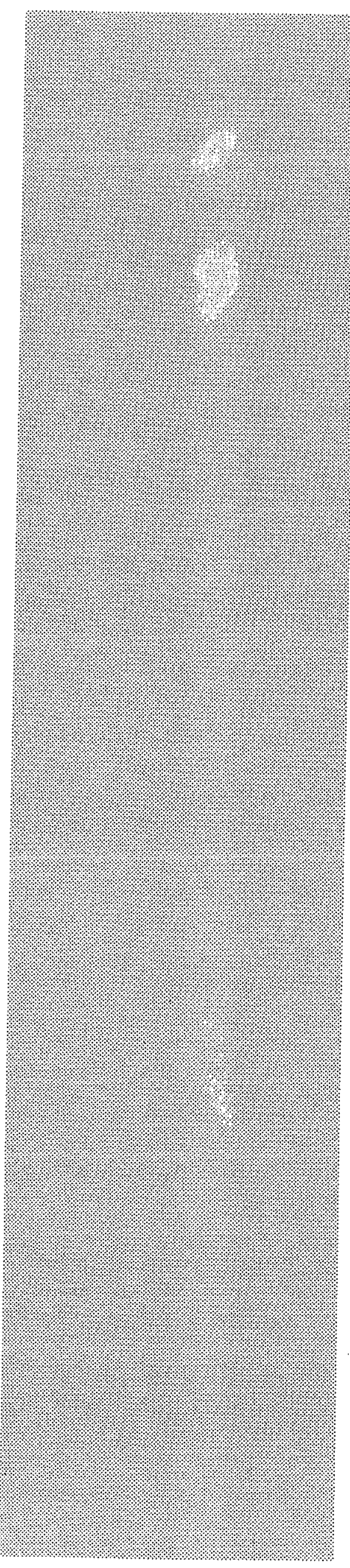

ANEXO 2 
ANEXO 2

DOSAGEM DO CONTEÚDO DE MATERIA ORGÂNICA PARA AS AMOSTRAS NOS DIFERENTES PERFIS

\begin{tabular}{|c|c|c|c|c|c|c|}
\hline W\% $\%$ \% & 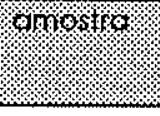 & Hing & \%orowo & 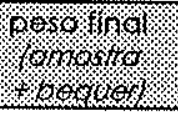 & 7.7.6.6. & 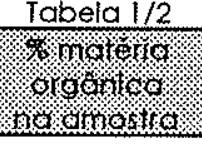 \\
\hline $\mathrm{TL} 01 / 3,25-3,50$ & $01 \mathrm{~J}$ & 59,24 & 60,24 & 60,23 & 0,01 & 01 \\
\hline TLO1/3,50-3,75 & 02J & 69.79 & 70,79 & 70,74 & 0,05 & 05 \\
\hline TLOI/3,75 4,00 & 03J & 71,33 & 72,33 & 72,26 & 0,07 & 07 \\
\hline TLOI $/ 4,00-4,25$ & $04 J$ & 46,78 & 47,78 & 47,74 & 0,04 & 04 \\
\hline $\mathrm{TL} 02 / 3,00-3,25$ & 05J & 77,71 & 78,71 & 78,66 & 0,05 & 05 \\
\hline $\mathrm{TL} 02 / 3,50 \cdot 3,75$ & $06 \mathrm{~J}$ & 67,61 & 68,61 & 68,55 & 0,06 & 06 \\
\hline TLO2/3,75-4,00 & 07\} & 61,56 & 62,56 & 62,51 & 0,05 & 05 \\
\hline $\mathrm{TLO} 2 / 4,00-4,25$ & $08 \mathrm{~J}$ & 61,93 & 62,93 & 62,88 & 0,05 & 05 \\
\hline $\mathrm{TLO} / 2,25-2,50$ & $09 \mathrm{~J}$ & 59,22 & 60,22 & 60,19 & 0,03 & 03 \\
\hline $\mathrm{TL} 03 / 2,75-3,00$ & $10 \mathrm{~s}$ & 69,77 & 70,77 & 70,73 & 0,04 & 04 \\
\hline $\mathrm{TLO} / 3,00-3,25$ & $11 \mathrm{~J}$ & 71,30 & 72,30 & 72,25 & 0,05 & 05 \\
\hline $\mathrm{TLO} 03 / 3,75 \sim 4,00$ & 121 & 46,76 & 47,76 & 47,72 & 0,04 & 04 \\
\hline $\mathrm{TL} 03 / 4,75-5,00$ & $13 \mathrm{~J}$ & 77,68 & 78,68 & 78,66 & 0,02 & 02 \\
\hline $\mathrm{TLO4/1,00-1,25}$ & 14.J & 67,58 & 68,58 & 68,54 & 0,04 & 04 \\
\hline $\mathrm{TLO} / \mathrm{A} / \mathrm{25-1,50}$ & $15 \mathrm{~J}$ & 61,54 & 62,54 & 62,50 & 0,04 & 04 \\
\hline TLO4/1,50-1,75 & $16 \mathrm{~J}$ & 61,91 & 62,91 & 62,87 & 0,04 & 04 \\
\hline ILO4/0,75-1,00 & $17\rfloor$ & 61,54 & 62,54 & 62,51 & 0,03 & 03 \\
\hline TLO4/0,50-0,60 & $18 \mathrm{~J}$ & 61,90 & 62,90 & 62,86 & 0,04 & 04 \\
\hline $\mathrm{TL} 05 / 0,75-1,00$ & $19 \mathrm{~J}$ & 59,22 & 60,22 & 60,20 & 0,02 & 02 \\
\hline TLO5/1,00-1,25 & $20 \mathrm{~J}$ & 69,77 & 70,77 & 70,76 & 0.01 & 01 \\
\hline IL05/1,25-1,50 & $21 \mathrm{~J}$ & 67,57 & 68,57 & 68,56 & 0,01 & 01 \\
\hline TLOS/1,50-1,75 & 223 & 77,67 & 78,67 & 78,66 & 0,01 & 01 \\
\hline $1106 / 0,60-0,80$ & 23J & 71,29 & 72,29 & 72,21 & 0,08 & 08 \\
\hline $\mathrm{rLO} / \mathrm{S} / 2,20-2,40$ & $24 \mathrm{~J}$ & 46,75 & 47,75 & 47,73 & 0,02 & 02 \\
\hline TLOO6/2,60-2,80 & $25 \mathrm{~J}$ & 59.23 & 60,23 & 60,21 & 0,02 & 02 \\
\hline$\Upsilon \mathrm{L} 06 / 2,80 \cdot 3,00$ & $26 \mathrm{~J}$ & 67,58 & 68,58 & 68,55 & 0,03 & 03 \\
\hline TLO6/3,20-3,40 & $27 \mathrm{~J}$ & 71,31 & 72,31 & 72,27 & 0,04 & 04 \\
\hline TLO6/3,60-3,80 & $28 \mathrm{~J}$ & 61.92 & 62,92 & 62,87 & 0.05 & 05 \\
\hline $\mathrm{TL}, 07 / 3,00-3,20$ & $29 \mathrm{~J}$ & 69,78 & 70,78 & 70,74 & 0,04 & 04 \\
\hline $\mathrm{ILO} / \mathrm{O} / 3,20 \cdot 3,40$ & $30 \mathrm{~J}$ & 61,54 & 62,54 & 62,52 & 0,02 & 02 \\
\hline $\mathrm{TL} 07 / 3,40-3,60$ & $31 \mathrm{~J}$ & 46,77 & 47,77 & 47,75 & 0,02 & 02 \\
\hline $\mathrm{rLO5} / 0,25 \cdots 0,50$ & $32 \mathrm{~J}$ & 77,68 & 78,68 & 78,62 & 0,06 & 06 \\
\hline IGUAL A 04J & 33.J & 71,33 & 72,33 & 72,29 & 0,04 & 04 \\
\hline IGUAL A 07J & $34 \mathrm{~J}$ & 61,56 & 62,56 & 62,51 & 0,05 & 05 \\
\hline IGUAL A 17J & $35 \mathrm{~J}$ & 61,92 & 62,92 & 62,84 & 0,08 & 08 \\
\hline IGUAL A 14J & $36 \mathrm{~J}$ & 59,25 & 60,25 & 60,21 & 0,04 & 04 \\
\hline IGUAL A $11 \mathrm{~J}$ & $37 \mathrm{~J}$ & 69.79 & 70,79 & 70,74 & 0,05 & 05 \\
\hline $\mathrm{TLO} / 0,75-1,00$ & $38 \mathrm{~J}$ & 46,78 & 47,78 & 47,73 & 0,05 & 05 \\
\hline TL01/1,75-2,00 & $39 \mathrm{~J}$ & 77,69 & 78,69 & 78,66 & 0,03 & 03 \\
\hline โLO1/2,50-2,75 & $40 \mathrm{~J}$ & 67,59 & 68,59 & 68,57 & 0,02 & 02 \\
\hline
\end{tabular}


ANEXO 2

DOSAGEM DO CONTEUDOO DE MATERIA ORGANICA PARA AS AMOSTRAS NOS DIFERENIES PERFIS

Tabeia $2 / 2$

\begin{tabular}{|c|c|c|c|c|c|c|}
\hline 16\% & \%10 $17 \%$ & & W6 $6 \%$ & \%ororor & 10\%1 & 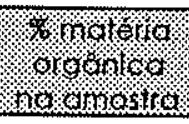 \\
\hline $\mathrm{Tt}(0) / 3,00-3,25$ & $41 \mathrm{~J}$ & 61,54 & 62,54 & 62,53 & 0,01 & 01 \\
\hline $\mathrm{TL} 02 / 0,75-1,00$ & $42 \mathrm{~J}$ & 69.77 & 70,77 & 70,75 & 0,02 & 02 \\
\hline TL02/1,50-1,75 & 43. & 71,30 & 72,30 & 72,28 & 0,02 & 02 \\
\hline $\mathrm{ILO} / 2 / 2,00-2,25$ & $44 \mathrm{~J}$ & 61,90 & 62.90 & 62,88 & 0,02 & 02 \\
\hline $\mathrm{TLO} 2 / 2,50-2,75$ & $45 \mathrm{~J}$ & 59,23 & 60,23 & 60,21 & 0,02 & 02 \\
\hline $\mathrm{TLO} / 0,75-1,00$ & $46 \mathrm{~J}$ & 67,58 & 68,58 & 68,55 & 0,03 & 03 \\
\hline $\mathrm{TLO} / 1,50-1,75$ & $47 \mathrm{~J}$ & 77,68 & 78,68 & 78,66 & 0,02 & 02 \\
\hline $\mathrm{Tt} 03 / 2,00-2,25$ & 483 & 46,77 & 47.77 & 47,75 & 0,02 & 02 \\
\hline $\mathrm{TLO} / 3,50 \cdot 3,75$ & $49 J$ & 77,69 & 78,69 & 78,64 & 0,05 & 05 \\
\hline $\mathrm{rLO} / \mathrm{H} / 0,25-0,50$ & $50 \mathrm{~J}$ & 59,24 & 60,24 & 60,21 & 0,03 & 03 \\
\hline $\mathrm{TL} 104 / 2,00-2,25$ & $51 \mathrm{~J}$ & 71,31 & 72,31 & 72,30 & 0,01 & 01 \\
\hline TL05/0,50-0,75 & 53J & 61,55 & 62,55 & 62,53 & 0,02 & 02 \\
\hline $\mathrm{TLOS} / 1,75-2,00$ & $54 \mathrm{~J}$ & 67,59 & 68,59 & 68,57 & 0,02 & 02 \\
\hline $\mathrm{TL} 05 / 2,00-2,25$ & $55 \mathrm{~J}$ & 46,76 & 47,76 & 47,754 & 0,01 & 01 \\
\hline $\mathrm{TLO} / 0,80-1,00$ & 57J & 69,78 & 70,78 & 70,68 & 0,10 & 10 \\
\hline $\mathrm{TLO6} / 1,60-1,80$ & $58 \mathrm{~J}$ & 61,91 & 62,91 & 62,87 & 0,04 & 04 \\
\hline $\mathrm{TLO} / 4,00-4,20$ & $59 \mathrm{~J}$ & 46,76 & 47,76 & 47,74 & 0,02 & 02 \\
\hline IL.06/4,40-4,60 & $60 \mathrm{~J}$ & 61.91 & 62,91 & 62,84 & 0,07 & 07 \\
\hline זL07/0,20-0,40 & $61 \mathrm{~J}$ & 71,30 & 72,30 & 72,26 & 0,04 & 04 \\
\hline$[\mathrm{LO} / 1,00-1,20$ & $62 \mathrm{~J}$ & 67,58 & 68,58 & 68,52 & 0,06 & 06 \\
\hline $\mathrm{ILO} / 2,20 \cdot 2,40$ & $63 \mathrm{~J}$ & 69,77 & 70,77 & 70,73 & 0,04 & 04 \\
\hline$\Gamma L O 7 / 2,80-3,00$ & 64J & 59,24 & 60,24 & 60,19 & 0,05 & os \\
\hline
\end{tabular}




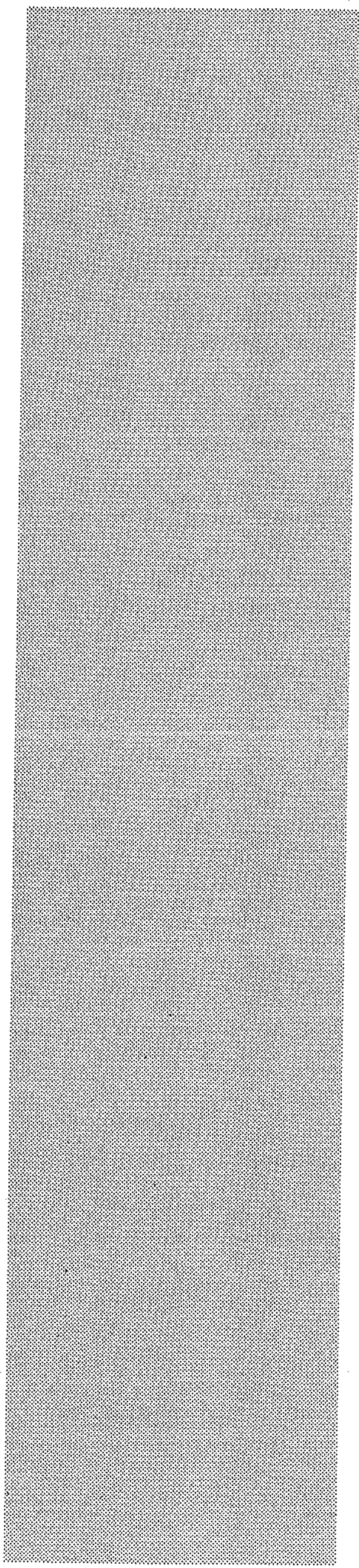

ANEXO 3 


\begin{tabular}{|c|c|c|c|c|c|c|c|c|c|c|c|c|c|c|}
\hline \multirow[t]{2}{*}{ furo/prof $(\mathrm{m})$} & \multirow{2}{*}{$\begin{array}{l}\mathrm{n}^{\circ} \mathrm{da} \\
\text { análise }\end{array}$} & \multirow{2}{*}{$\begin{array}{l}\text { peso da } \\
\text { amostra }\end{array}$} & \multicolumn{2}{|c|}{$2 n$} & \multicolumn{2}{|c|}{$\mathrm{Co}$} & \multicolumn{2}{|c|}{$\mathrm{pb}$} & \multicolumn{2}{|c|}{$\mathrm{Mn}$} & \multicolumn{2}{|c|}{$\mathrm{Mo}$} & \multicolumn{2}{|c|}{$\mathrm{C} \checkmark$} \\
\hline & & & $\mathrm{ce}$ & $\mathrm{mglkg}$ & $\mathrm{ICP}$ & $\mathrm{mg} / \mathrm{kg}$ & ICP & $\mathrm{mg} / \mathrm{kg}$ & $\mathrm{CP}$ & $\mathrm{mg} / \mathrm{kg}$ & $\mathrm{ICP}$ & $\mathrm{mg} / \mathrm{kg}$ & $1 \mathrm{CP}$ & $\mathrm{ng} / \mathrm{kg}$ \\
\hline $\mathrm{TL} 01 / 3,25-3,50$ & $01 \mathrm{~J}$ & 0,2420 & 1,129 & 233,264 & 0,060 & 1.9 & 0,457 & 12,0 & 3,334 & 827,0 & 2,079 & 429,545 & 2,503 & 517.149 \\
\hline $\mathrm{TLO1/3,50-3,75}$ & 023 & 0,2483 & 1,238 & 249,295 & 0,061 & 2,0 & 0.488 & 18,0 & 5,168 & 1249,0 & 2,101 & 423,077 & 4,021 & 809,706 \\
\hline $1101 / 3,75-4,00$ & 03J & 0,2551 & 1.176 & 230,498 & 0,061 & 2,0 & 0,509 & 21,0 & 5,697 & 1340,0 & 2,088 & 409,251 & 4,293 & 841,435 \\
\hline $\mathrm{TLOI} / 4,00-4,25$ & $04 \mathrm{~J}$ & 0,2498 & 1,156 & 231,385 & 0,054 & 0,6 & 0,455 & 11.0 & 5,312 & 1276,0 & 1,863 & 372,898 & 3,961 & 792,834 \\
\hline $\mathrm{TLO} 2 / 3,00-3,25$ & 05J & 0.2420 & 0,906 & 187,190 & 0,058 & 1.4 & 0,450 & 10,0 & 2,406 & 597,0 & 1,952 & 403,306 & 1,896 & 391,736 \\
\hline $\mathrm{TLO} 2 / 3,50-3,75$ & $06 \mathrm{~J}$ & 0,2468 & 1.020 & 206,645 & 0,059 & 1,6 & 0,526 & 26,0 & 3,934 & 956,0 & 1,997 & 404,579 & 3,479 & 704,822 \\
\hline $\mathrm{TLO} / 3,75 \sim 4,00$ & $07 \mathrm{~J}$ & 0,2514 & 1.041 & 207,041 & 0,059 & 1,6 & 0.525 & 25,0 & 3,801 & 907,0 & 1,994 & 396,579 & 3,379 & 672,037 \\
\hline $\mathrm{TL} 02 / 4,00-4,25$ & 08j & 0,2511 & 1.175 & 233,971 & 0,072 & 4,2 & 0,634 & 47.0 & 2,931 & 700,0 & 2,430 & 483,871 & 2,852 & 567,901 \\
\hline $\mathrm{TL} 03 / 2,25-2,50$ & 091 & 0,2453 & 1,283 & 261,517 & 0,053 & 0,4 & 0,454 & 11,0 & 0,782 & 191,0 & 1,721 & 350.795 & 0,668 & 136,160 \\
\hline $\mathrm{ILO} / 2,75-3,00$ & $10\rfloor$ & 0,2496 & 0,785 & 157,252 & 0,057 & 1,2 & 0,559 & 32,0 & 2,303 & 554,0 & 1,987 & 398,037 & 1.516 & 303,686 \\
\hline $\mathrm{TL} 03 / 3,00-3,25$ & 113 & 0,2492 & 0,844 & 169,342 & 0,056 & 1,0 & 0,520 & 24,0 & 3,426 & 825,0 & 1.979 & 397,071 & 3,067 & 615,369 \\
\hline$T L 03 / 3,75-4, \infty$ & $12 \mathrm{~J}$ & 0,2528 & 0,825 & 163,172 & 0,054 & 0,6 & 0,493 & 18,0 & 2,644 & 628,0 & 1,826 & 367,155 & 2,508 & 496,044 \\
\hline $\mathrm{TLO} / 4,75-5,00$ & $13 \mathrm{~J}$ & 0,2423 & 0,393 & 81,098 & 0,043 & 0,0 & 0,400 & 0,0 & 0,596 & 148,0 & 1,544 & 318,613 & 0,653 & 134,750 \\
\hline $\mathrm{TLO} / / 1,00-1,25$ & $14 \mathrm{~J}$ & 0.2496 & 3,598 & 720,753 & 0,054 & 0,6 & 1,044 & 129.0 & 1,759 & 423,0 & 1,843 & 369.191 & 4,717 & 944,912 \\
\hline $\mathrm{TL} 04 / 1,25-1,50$ & 153 & 0,2495 & 1,230 & 246,493 & 0,044 & 0,0 & 0,772 & 75,0 & 2,030 & 488,0 & 1,570 & 314,629 & 2,502 & 501,403 \\
\hline TLO4/1,50-1,75 & 163 & 0.2467 & 0,680 & 137,819 & 0,056 & 1,0 & 0,830 & 87,0 & 2,014 & 490,0 & 1.997 & 404,743 & 0,950 & 192,542 \\
\hline TLO4/0,75-1,00 & 173 & 0,2488 & 4,644 & 933,280 & 0,052 & 0,2 & 0.780 & 76,0 & 1.439 & 347,0 & 1.976 & 397,106 & 3,890 & 781,752 \\
\hline $104 / 0,50-0,60$ & $18 J$ & 0,2509 & 5,702 & 1136,309 & 0,062 & 2,2 & 0,635 & 47,0 & 1,392 & 333,0 & 2,730 & $544,047^{i}$ & 4,300 & 856,915 \\
\hline ILO5/0,75-1,00 & $19 \mathrm{~J}$ & 0,2502 & 0,672 & 134,293 & 0,054 & 0,6 & 0,546 & 29.0 & 1.468 & 352,0 & 1,855 & 370,703 & 1,154 & 230,616 \\
\hline $1105 / 1,00-1,25$ & 201 & 0,2442 & 0,700 & 143,325 & 0,055 & 0,8 & 0,498 & 20,0 & 1,997 & 491,0 & 1.923 & 393,735 & 1,043 & 213,554 \\
\hline $1105 / 1,25-1,50$ & $21 \mathrm{~J}$ & 0,2468 & 0,359 & 72,731 & 0,057 & 1,2 & 0.517 & 24,0 & 2,559 & 622,0 & 2,056 & 416,532 & 0,585 & 118,517 \\
\hline TLOS/1,50-1,75 & 223 & 0,2526 & 0,487 & 96,397 & 0,062 & 2.2 & 0,579 & 35,0 & 2,081 & 494,0 & 2,126 & 420,823 & 0,462 & 91,449 \\
\hline
\end{tabular}




\begin{tabular}{|c|c|c|c|c|c|c|c|c|c|c|c|c|c|c|}
\hline \multirow{2}{*}{ furo $/ p r o f(m)$} & \multirow{2}{*}{$\begin{array}{l}\text { ndo } \\
\text { onólise }\end{array}$} & \multirow{2}{*}{ Peso da } & \multicolumn{2}{|c|}{$2 n$} & \multicolumn{2}{|c|}{$\mathrm{C}, \mathrm{d}$} & \multicolumn{2}{|c|}{$\mathrm{P} \quad \mathrm{b}$} & \multicolumn{2}{|c|}{$\mathrm{Mr}$} & \multicolumn{2}{|c|}{$\mathrm{Mr}$} & \multicolumn{2}{|c|}{$\mathrm{c} \quad \mathrm{O}$} \\
\hline & & & $1 \mathrm{CP}$ & $\mathrm{mg} / \mathrm{kg}$ & $1 C P$ & $\mathrm{mg} / \mathrm{kg}$ & $\mathrm{CP}$ & $\mathrm{mg} / \mathrm{kg}$ & $\mathrm{CP}$ & $\mathrm{mg} / \mathrm{kg}$ & $\mathrm{CP}$ & $\mathrm{mg} / \mathrm{kg}$ & $1 \mathrm{CP}$ & $\mathrm{mg} / \mathrm{kg}$ \\
\hline TLO6/0,60-0,80 & 233 & 0.2511 & 44,229 & 8807,049 & 0,056 & 1,0 & 3,018 & 521,0 & 12,100 & 2891,0 & 1,406 & 279,968 & 16,948 & 3374,751 \\
\hline TLO6 /2,20-2,40 & $24 \mathrm{~J}$ & 0,2499 & 1,002 & 200,480 & 0,066 & 3,0 & 0,650 & 50,0 & 3,370 & 809,0 & 2.114 & 422,969 & 0,291 & 58,223 \\
\hline TLO6/2,60-2,80 & $25\rfloor$ & 0,2520 & 0,355 & 70,437 & 0.058 & 1,4 & 0,564 & 33,0 & 4,370 & 1040,0 & 1.963 & 389,484 & 0,243 & 48,214 \\
\hline$\{06 / 2,80-3,00$ & 261 & 0,2495 & 0,271 & 54,309 & 0,053 & 0,4 & 0,503 & 21,0 & 4,970 & 1195,0 & 1.786 & 357,916 & 0,441 & 88,377 \\
\hline $\mathrm{TL} 06 / 3,20-3,40$ & $27 \mathrm{~J}$ & 0,2511 & 0,382 & 76,065 & 0,060 & 1,8 & 0,540 & 28,0 & 3,316 & 1152,0 & 2,003 & 398,845 & 0,370 & 73,676 \\
\hline$T L .06 / 3,60-3,80$ & 28J & 0,2484 & 0,532 & 107,085 & 0,056 & 1.0 & 0.517 & 24,0 & 5,399 & 1304,0 & 0,855 & 172,101 & 0,371 & 74,678 \\
\hline $\mathrm{TL} 07 / 3,00-3,20$ & 291 & 0,2490 & 0,284 & 57,028 & 0,058 & 1,4 & 0,585 & 37,0 & 1,471 & 354,0 & 2,031 & 407,831 & 0,422 & 84.739 \\
\hline $\mathrm{TL} .07 / 3,20-3,40$ & $30 J$ & 0.2498 & 0,320 & 64,051 & 0,062 & 2,2 & 0,548 & 30,0 & 1,717 & 424,0 & 0,935 & 187,150 & 0,343 & 68,655 \\
\hline IGUAL A 30J & $30 \mathrm{~s} B$ & 0,2498 & 0,335 & 67,054 & 0,062 & 2,2 & 0,552 & 30,0 & 1,764 & & 2,074 & 415,132 & 0,340 & 68,054 \\
\hline $.1 \mathrm{LO} / 3,40-3,60$ & 313 & 0,2494 & 0,309 & 61,949 & 0,060 & 1,8 & 0,493 & 19,0 & 2,432 & 585,0 & 1,488 & 298,316 & 0,468 & 93,825 \\
\hline $\mathrm{TL}, 05 / 0,25-0,50$ & $32\rfloor$ & 0,2487 & 5,489 & 1103,538 & 0,051 & 0,0 & 0.535 & 27,0 & 2,364 & 570,0 & 1.925 & 387,012 & 4,646 & 934,057 \\
\hline IGUAL A 04J & 331 & 0,2401 & 1,162 & 241,983 & 0,051 & 0,0 & 0,447 & 10,0 & 5.156 & 1288,0 & 1,266 & 263,640 & 3,946 & 821,741 \\
\hline IGUAL A 07J & $34 \mathrm{~J}$ & 0,2499 & 1.159 & 231,893 & 0,062 & 2,2 & 0,560 & 32,0 & 3,980 & 956,0 & 0.954 & 190,876 & 3,917 & 783,713 \\
\hline IGUAL A $17 \mathrm{~J}$ & $35\rfloor$ & 0,2497 & 5,591 & 1119,543 & 0,059 & 1,6 & 0,621 & 44,0 & 1,305 & 314,0 & 2,479 & 496,396 & 4,300 & 861,033 \\
\hline IGUAL A $|4|$ & 36] & 0,2495 & 3,399 & 681,162 & 0,051 & 0,0 & 1,026 & 125,0 & 1,570 & 378,0 & 1,759 & 352,505 & 4,804 & 962,725 \\
\hline IGUAL A 11$\rfloor$ & 37 & 0,2523 & 0,900 & 178,359 & 0,058 & 1,4 & 0,530 & 26,0 & 3,357 & 978,0 & 0.345 & 68,371 & 3,072 & 608,799 \\
\hline $\mathrm{TLO} 01 / 0,75-1,00$ & $38 \mathrm{~J}$ & 0,2500 & 1,487 & 297,400 & 0.056 & 1,0 & 0,416 & 3,0 & 2,577 & 618,0 & 0.299 & 59,800 & 0,643 & 128,600 \\
\hline TLO1/1,75-2,00 & 391 & 0.2515 & 1,106 & 219,881 & 0.051 & 0,0 & 0,482 & 16,0 & 2,520 & 601,0 & 0,306 & 60,835 & 0,679 & 134,990 \\
\hline $\mathrm{TLO} 1 / 2,50-2,75$ & 40.1 & 0.2509 & 1,462 & 351 & 0,053 & 0,4 & 0,485 & 17.0 & 2,516 & 602,0 & 0,279 & 55,600 & 1,316 & 262,256 \\
\hline $\mathrm{TL} 01 / 3,00-3,25$ & J1 & 0,2505 & 1.030 & 205,589 & 0,064 & 2,6 & 0,545 & 29,0 & 3,316 & 794,0 & 0,389 & 77,645 & 2,093 & 417,764 \\
\hline$T L 02 / 0,75-1,00$ & 423 & 0,2461 & 0,627 & 127,387 & 0,067 & 3,3 & 0,458 & 12,0 & 1,390 & 339,0 & 0,355 & 72,125 & 0.621 & 126,168 \\
\hline$\lceil\mathrm{LO} 2 / 1,50-1,75$ & $43\rfloor$ & 0,2498 & 0,589 & 117,894 & 0,065 & 2.8 & 0,552 & 30,0 & 2,250 & 540,0 & 0,365 & 73,058 & 0,326 & 65,252 \\
\hline $\mathrm{T}(\mathrm{L} 2 / 2,00-2,25$ & 44 & 0,2480 & 0,674 & 135,887 & 0,050 & 0,0 & 0,385 & 0,0 & 1,253 & 303,044 & 0.267 & 53,831 & 0.241 & 48,589 \\
\hline$\lceil\mathrm{L} 02 / 2,50-2,75$ & $45 J ?$ & 0,2490 & 1.040 & 208,835 & 0,064 & 2,6 & 0,508 & 22,0 & 1,746 & 121,0 & 0,342 & 68,675 & 0,756 & 151,807 \\
\hline
\end{tabular}


ANEXO 3

ANÁLISES QUIMICAS PORICP-AES

PARA AS AMOSTRAS NOS DIFERENTES PERFIS

\begin{tabular}{|c|c|c|c|c|c|c|c|c|c|c|c|c|c|c|}
\hline \multirow[t]{2}{*}{ furo/prof. (m) } & \multirow{2}{*}{$\begin{array}{l}\text { no da } \\
\text { análise }\end{array}$} & \multirow{2}{*}{$\begin{array}{l}\text { peso da } \\
\text { amostra }\end{array}$} & \multicolumn{2}{|c|}{$2 \mathrm{n}$} & \multicolumn{2}{|c|}{$c d$} & \multicolumn{2}{|c|}{$\mathrm{P} \quad \mathrm{b}$} & \multicolumn{2}{|c|}{$M n$} & \multicolumn{2}{|c|}{$M \circ$} & \multicolumn{2}{|c|}{ C u } \\
\hline & & & ICP & $\mathrm{mg} / \mathrm{kg}$ & $\mathrm{ICP}$ & $\mathrm{mg} / \mathrm{kg}$ & $\mathrm{ICP}$ & $\mathrm{mg} / \mathrm{kg}$ & ICP & $\mathrm{mg} / \mathrm{kg}$ & ICP & $\mathrm{mg} / \mathrm{kg}$ & ICP & $\mathrm{mg} / \mathrm{kg}$ \\
\hline TLO3/0,75-1,00 & $46 \mathrm{~J}$ & 0,2507 & 0,895 & 178,500 & 0,068 & 3,4 & 0,465 & 13,0 & 0,867 & 207,0 & 0,394 & 78,580 & 0,409 & 81,572 \\
\hline TL03/1,50-1,75 & $47 \mathrm{~J}$ & 0,2501 & 0,956 & 191,124 & 0,065 & 2,8 & 0,549 & 30,0 & 0,776 & 186,0 & 0,343 & 68,573 & 0,577 & 115,354 \\
\hline $\mathrm{TLO} / 2,00-2,25$ & $48 \mathrm{~J}$ & 0,2482 & 1,429 & 287,873 & 0,064 & 2,6 & 0,522 & 25,0 & 0,697 & 168,0 & 0,358 & 72,119 & 0,642 & 129,331 \\
\hline TLO3/3,50-3,75 & $49 \mathrm{~J}$ & 0,2504 & 1,019 & 203,474 & 0,049 & 0,0 & 0,444 & 9,0 & 4,336 & 1039,0 & 0,262 & 52,316 & 4,018 & 802,316 \\
\hline $\mathrm{TLO4} / 0,25-0,50$ & $50 \mathrm{~J}$ & 0,2495 & 5,366 & 1075,351 & 0,051 & 0,0 & 0,478 & 16,0 & 1,100 & 265,0 & 2,554 & 511,824 & 2,183 & 437,475 \\
\hline TLO4/2,00-2,25 & $51 \mathrm{~J}$ & 0,2507 & 0,508 & 101,316 & 0,052 & 0,2 & 0,734 & 67,0 & 1,342 & 321,0 & 0,319 & 63,622 & 1,000 & 199,442 \\
\hline TLO5/0,50-0,75 & $53 \mathrm{~J}$ & 0,2500 & 1,399 & 279,800 & 0,054 & 0,6 & 0,572 & 34,0 & 1,468 & 352,0 & 0,323 & 64,600 & 1,886 & 377,200 \\
\hline $\mathrm{TL} 05 / 1,75-2,00$ & $54 \mathrm{~J}$ & 0,2453 & 0,464 & 94,578 & 0,063 & 2,4 & 0,592 & 39,0 & 2,289 & 560,0 & 0,364 & 74,195 & 0,356 & 72,564 \\
\hline TL05/2,00-2,25 & $55 \mathrm{~J}$ & 0,2503 & 0,474 & 94,686 & 0,072 & 4,2 & 0,640 & 48,0 & 0,444 & 106,0 & 0,357 & 71,314 & 0,723 & 144,427 \\
\hline TLO5/2,50-2,75 & $56 \mathrm{~J}$ & 0,2499 & 0,624 & 124,850 & 0,064 & 2,6 & 0,589 & 38,0 & 0,298 & 72,0 & 0,360 & 72,029 & 0,364 & 72,829 \\
\hline TLO6/0,80-1,00 & $57 \mathrm{~J}$ & 0,2499 & 16,294 & 3260,104 & 0,029 & 0,0 & 1,175 & 155,0 & 27,260 & 6545,0 & 0,142 & 28,411 & 5,949 & 1190,276 \\
\hline TLO6/1,60-1,80 & $58 \mathrm{~J}$ & 0,2500 & 3,292 & 658,400 & 0,052 & 0,2 & 0,745 & 69,0 & 3,250 & 780,0 & 0,247 & 49,400 & 0,984 & 196,800 \\
\hline TLO6/4,00-4,20 & $59 \mathrm{~J}$ & 0,2500 & 0,604 & 120,800 & 0,070 & 3,8 & 0,631 & 46,0 & 3,983 & 956,0 & 0,386 & 77,200 & 0,308 & 61,600 \\
\hline TLO6/4,40-4,60 & $60 \mathrm{~J}$ & 0,2497 & 0,490 & 98,118 & 0,058 & 1,4 & 0,535 & 27,0 & 3,025 & 727,0 & 0,341 & 68,282 & 0,283 & 56,668 \\
\hline TLOT/0,20-0,40 & $61 \mathrm{~J}$ & 0,2495 & 35,800 & 7174,349 & 0,054 & 0,6 & 1,355 & 191,0 & 22,810 & 6237,0 & 0,257 & 51,503 & 16,661 & 3338,878 \\
\hline TLO7/1,00-1,20 & $62 \mathrm{~J}$ & 0,2501 & 0,472 & 94,362 & 0,065 & 2,8 & 0,511 & 22,0 & 0,975 & 234,0 & 0,350 & 69,972 & 0,294 & 58,776 \\
\hline $\mathrm{TL} 07 / 2,20-2,40$ & 63J & 0,2491 & 0,385 & 77,278 & 0,057 & 1,2 & 0,481 & 16,0 & 0,910 & 219,0 & 0,323 & 64,833 & 0,353 & 70,855 \\
\hline TLO7/2,80-3,00 & $64 \mathrm{~J}$ & 0,2507 & 0,393 & 78,381 & 0,060 & 1,8 & 0,544 & 29,0 & 1,453 & 348,0 & 0,308 & 61,428 & 0,289 & 57,639 \\
\hline IGUAL A 3J & 03JB & 0,2494 & 1,147 & 229,952 & 0,060 & 1,8 & 0,501 & 20,0 & 5,850 & 1407,0 & 2,023 & 405,573 & 4,164 & 834,804 \\
\hline IGUAL A 25J & $25 \mathrm{JB}$ & 0,2481 & 0,370 & 74,567 & 0,055 & 0,8 & 0,551 & 30,0 & 4,325 & 1046,0 & 1,869 & 376,663 & 0,242 & 48,771 \\
\hline
\end{tabular}

Tabela $3 / 3$ 



$$
1 \equiv 1,1
$$




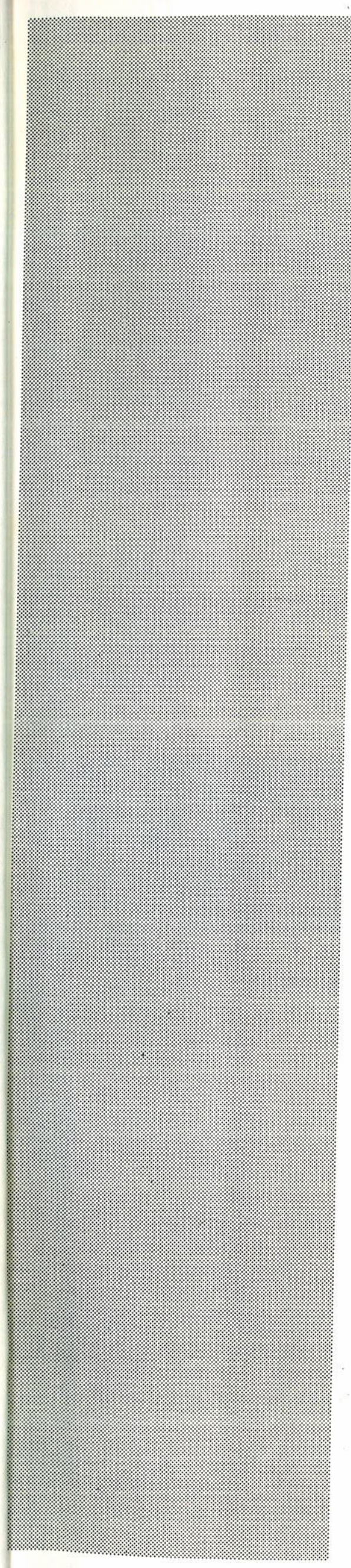

ANEXO 5 
[5: Unidade 1 (coluvio)

Unidade 2 (argila cinza-escuro - B.S.Paulo)

Unidade 3 (silte cinza-claro - B.S.Paulo)

$\therefore$ alterita / embasamento

प] material remobilizado / aterro

nivel de entulho

$\mathrm{Mn}-$

$\mathrm{Zn}-$

$\mathrm{Pb}-$

$=$

$\mathrm{Cu}$

\& nivel d'aguo

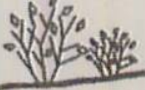

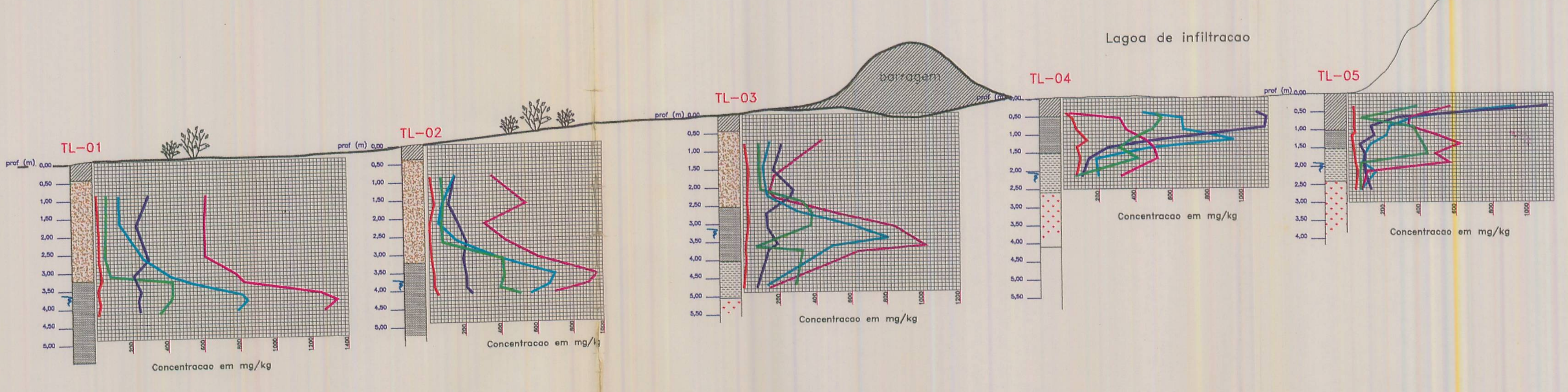

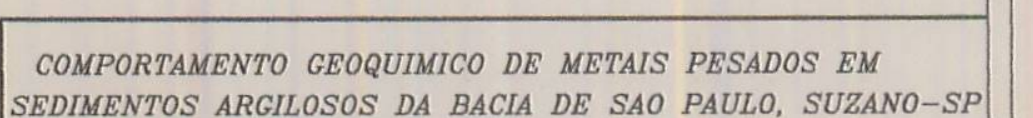


Unidade 2 (argila cinza-escura - B.S.Paulo)

Unidade 3 (silte cinza-claro - B.S.Paulo)

$\therefore$ alterita / embasamento

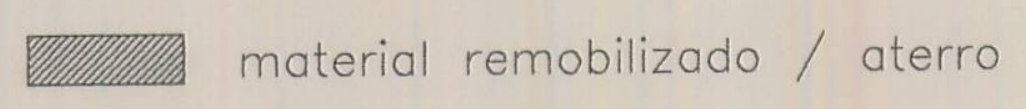

nivel de entulho

F nivel d'agua
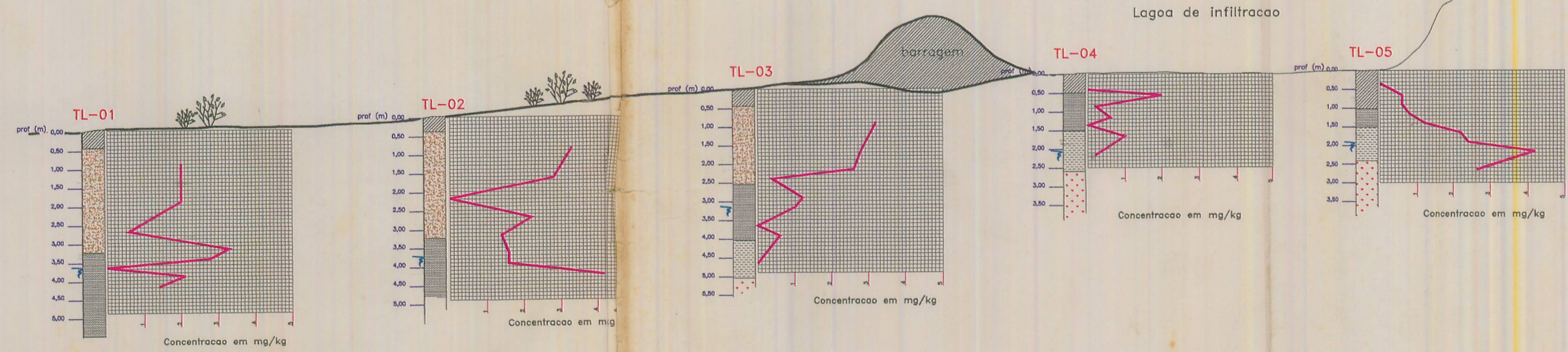

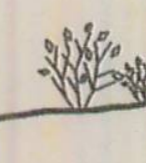

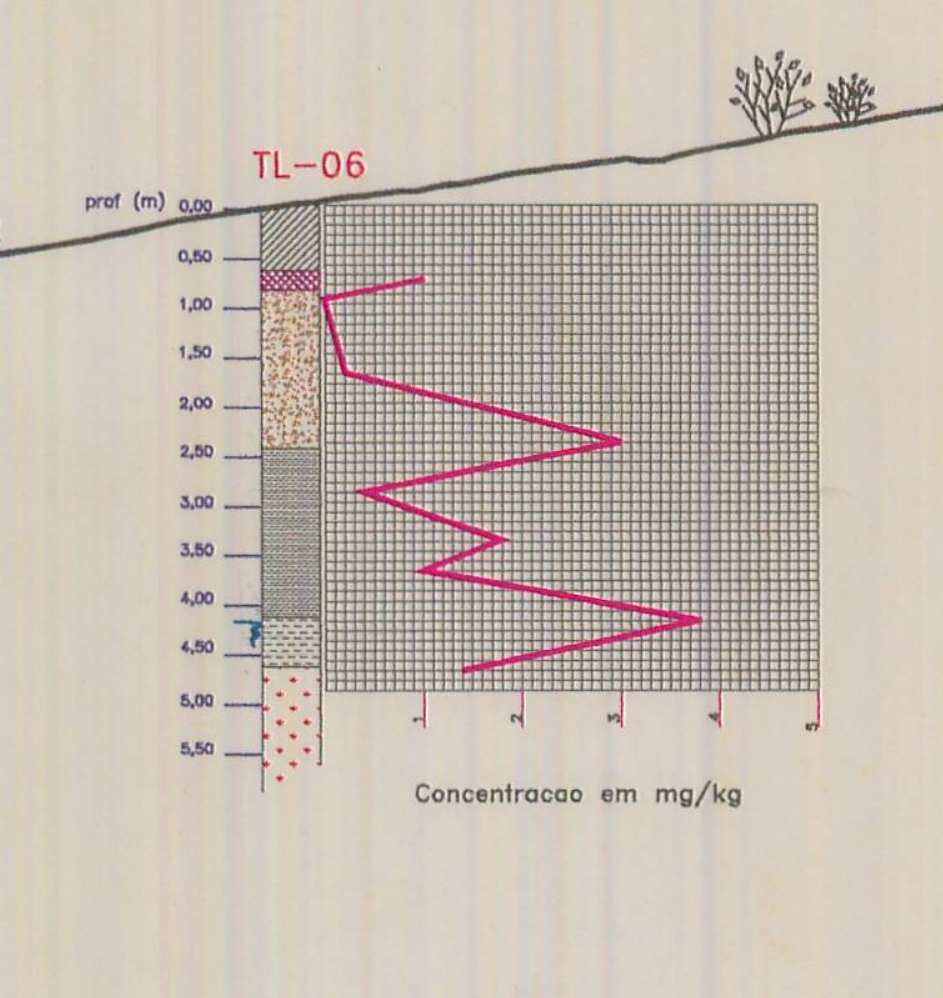

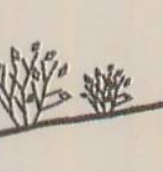

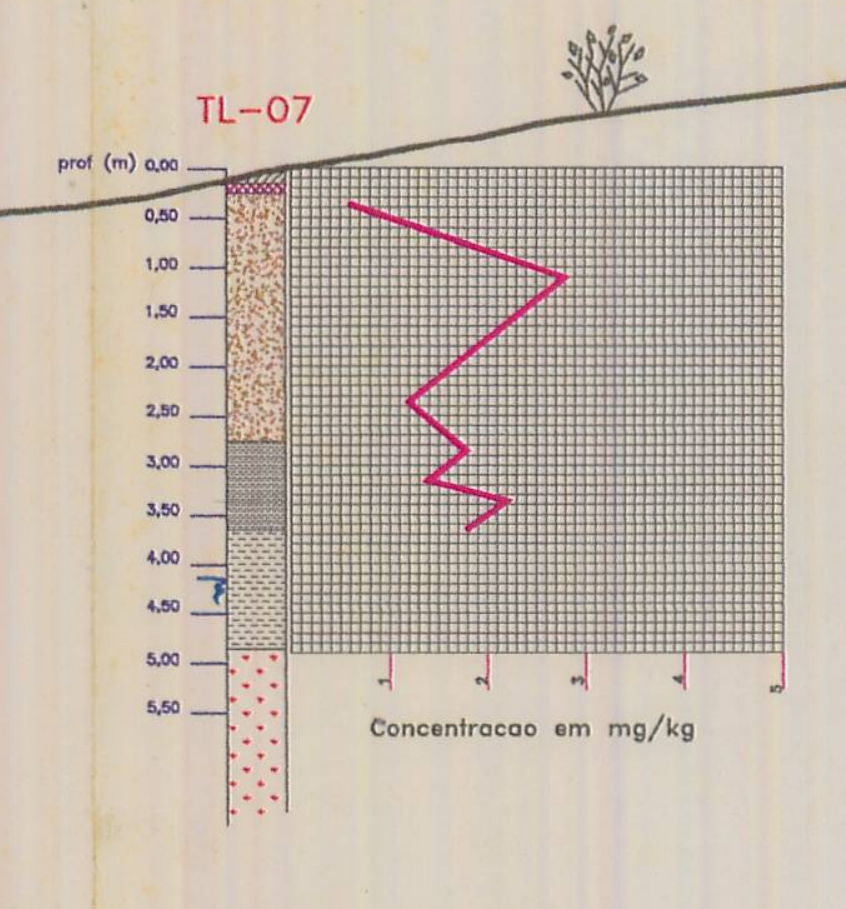

